
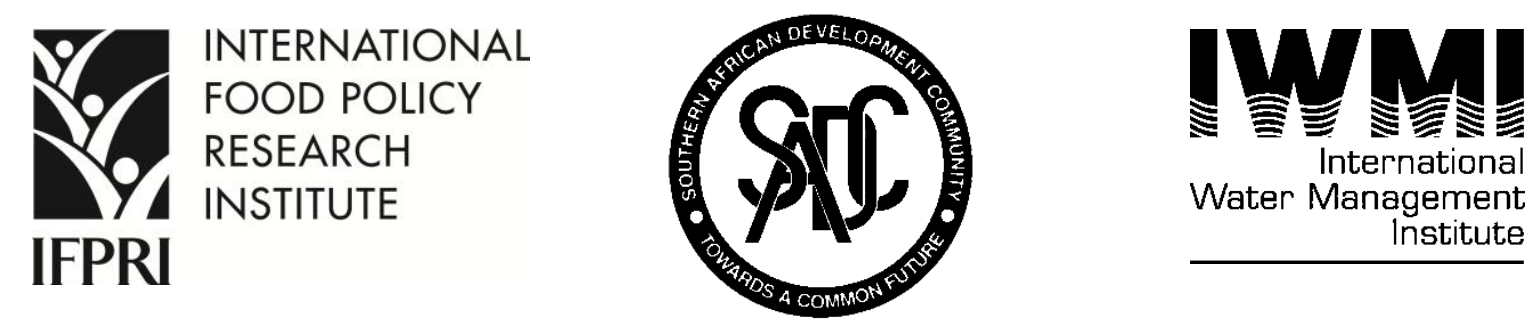

IFPRI Discussion Paper 01318

January 2014

\title{
Exploring Strategic Priorities for Regional Agricultural Research and Development Investments in Southern Africa
}

\author{
Michael Johnson \\ Samuel Benin \\ Liangzhi You \\ Xinshen Diao \\ Pius Chilonda \\ Adam Kennedy
}

Development Strategy and Governance Division 


\section{INTERNATIONAL FOOD POLICY RESEARCH INSTITUTE}

The International Food Policy Research Institute (IFPRI), established in 1975, provides evidence-based policy solutions to sustainably end hunger and malnutrition and reduce poverty. The Institute conducts research, communicates results, optimizes partnerships, and builds capacity to ensure sustainable food production, promote healthy food systems, improve markets and trade, transform agriculture, build resilience, and strengthen institutions and governance. Gender is considered in all of the Institute's work. IFPRI collaborates with partners around the world, including development implementers, public institutions, the private sector, and farmers' organizations, to ensure that local, national, regional, and global food policies are based on evidence. IFPRI is a member of the CGIAR Consortium.

\section{AUTHORS}

Michael Johnson (m.johnson@cgiar.org) is a research fellow in the Development Strategy and Governance Division of the International Food Policy Research Institute (IFPRI), Washington, DC.

Samuel Benin (s.benin@cgiar.org) is a research fellow in the Development Strategy and Governance Division of IFPRI, Washington, DC.

Liangzhi You (1.you@cgiar.org) is a senior research fellow in the Environment and Production Technology Division of IFPRI, Washington, DC.

Xinshen Diao (x.diao@cgiar.org) is a deputy division director in the Development Strategy and Governance Division of IFPRI, Washington, DC.

Pius Chilonda (p.chilonda@cgiar.org) is the head of the Southern Africa Office of the International Water Management Institute, Pretoria, South Africa.

Adam Kennedy (a.kennedy@cgiar.org) is a program manager in the Development Strategy and Governance Division of IFPRI, Washington, DC.

\footnotetext{
Notices

1. IFPRI Discussion Papers contain preliminary material and research results and are circulated in order to stimulate discussion and critical comment. They have not been subject to a formal external review via IFPRI's Publications Review Committee. Any opinions expressed are those of the author(s) and do not necessarily reflect the policies or opinions of IFPRI.

2. The boundaries and names shown and the designations used on the map(s) herein do not imply official endorsement or acceptance by the International Food Policy Research Institute (IFPRI) or its partners and contributors.

Copyright 2014 International Food Policy Research Institute. All rights reserved. Sections of this material may be reproduced for personal and not-for-profit use without the express written permission of but with acknowledgment to IFPRI. To reproduce the material contained herein for profit or commercial use requires express written permission. To obtain permission, contact the Communications Division at ifpri-copyright@cgiar.org.
} 


\section{Contents}

Abstract vii

Foreword viii

Preface $\quad$ ix

Acknowledgments $\quad$ X

Abbreviations and Acronyms xi

1. Introduction 1

2. Review of Agricultural Performance and Growth Opportunities 5

3. Spatial Analysis of Agricultural Development Potential 13

4. Assessing the Potential for Agricultural Research and Development Spillovers 26

5. Exploring the Economywide Impact of Research and Development Investments 35

6. Summary Rankings and Policy Implications 55

$\begin{array}{ll}\text { 7. Conclusion } & 61\end{array}$

Appendix A: Supplementary Tables for Section 4

Appendix B: Supplementary Tables for Section 5 80

Appendix C: Supplementary Table for Section 6

Appendix D: The Spatial Analysis Model and Determination of Development Domains 95

Appendix E: Estimating ex Ante Technology Spillovers 100

Appendix F: Description of the Economywide Multimarket Model for SADC 104

Appendix G: Evolution of Regional Research and Development Cooperation and

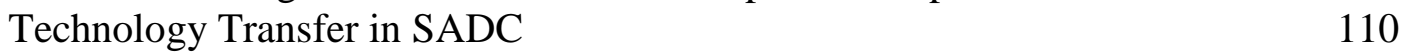

$\begin{array}{ll}\text { References } & 122\end{array}$ 


\section{Tables}

2.1 Economic performance, importance of agriculture, and welfare $\quad 6$

3.1 Percent distribution of total area by agroecological zone and by SADC member state 16

3.2 Distribution of population by agroecological zone, by country (thousands) and by total share (\%) 17

3.3 Agricultural suitability and population density 21

3.4 Areas of varying weighted travel time to markets in SADC countries (\% of total area) 22

3.5 Selected examples of potential yield gains from improved crop technologies in the SADC region 24

4.1 Similarity in maize production environment in SADC 28

4.2 Similarity in cattle production environment in SADC 28

4.3 Summary of similarity in crop production environment in SADC 29

4.4 Summary of similarity in livestock production environment in SADC 30

4.5 Estimated probability of success for adaptive research and development 30

4.6 Yield differences in maize production across countries 31

4.7 Final spillover coefficient matrix for maize $\quad 32$

4.8 Summary of average spill-out effects in crop/livestock production in SADC 33

4.9 Summary of average spill-in effects in crop/livestock production in SADC 33

5.1 Definitions of agricultural subsectors 36

5.2 Agricultural subsector annual growth rates in the base run (2009-2015) 39

5.3 Subsectors' contribution to agricultural growth in the base run (2009-2015) 40

5.4 Commodities with greatest spillover potential in SADC 51

5.5 Beneficiaries of spillovers (spill-in) by country and commodity 53

5.6 Sources of spillovers (spill-out) by country and commodity 54

6.1 Ranking by contribution to agricultural growth, as share of total agricultural GDP growth 56

6.2 Ranking of spillover beneficiaries across commodities (left to right in each row) 57

6.3 Example of suggested rankings based on growth and spillovers, all SADC 58

6.4 Example of suggested rankings based on growth and spillovers, low-income countries 58

A.1 Symmetrical matrix of similarity in production environment for beans 63

A.2 Symmetrical matrix of similarity in production environment for cassava 63

A.3 Symmetrical matrix of similarity in production environment for cotton 64

A.4 Symmetrical matrix of similarity in production environment for groundnuts 64

A.5 Symmetrical matrix of similarity in production environment for millet 64

A.6 Symmetrical matrix of similarity in production environment for potatoes 65

A.7 Symmetrical matrix of similarity in production environment for rice 65

A.8 Symmetrical matrix of similarity in production environment for sorghum 65

A.9 Symmetrical matrix of similarity in production environment for sugarcane 66

A.10 Symmetrical matrix of similarity in production environment for wheat 66

A.11 Symmetrical matrix of similarity in production environment for pigs 66

A.12 Symmetrical matrix of similarity in production environment for sheep and goats 67

A.13 Symmetrical matrix of similarity in production environment for poultry 67

A.14 Asymmetrical matrix of yield gaps for beans $\quad 67$

$\begin{array}{ll}\text { A.15 Asymmetrical matrix of yield gaps for cassava } & 68\end{array}$

$\begin{array}{ll}\text { A.16 Asymmetrical matrix of yield gaps for cotton } & 68\end{array}$

$\begin{array}{ll}\text { A.17 Asymmetrical matrix of yield gaps for groundnuts } & 68\end{array}$ 
A.18 Asymmetrical matrix of yield gaps for millet $\quad 69$

A.19 Asymmetrical matrix of yield gaps for potatoes and sweet potatoes 69

A.20 Asymmetrical matrix of yield gaps for rice $\quad 69$

A.21 Asymmetrical matrix of yield gaps for sorghum $\quad 70$

A.22 Asymmetrical matrix of yield gaps for sugarcane $\quad 70$

$\begin{array}{ll}\text { A.23 Asymmetrical matrix of yield gaps for wheat } & 70\end{array}$

$\begin{array}{ll}\text { A.24 Asymmetrical matrix of yield gaps for cattle } & 70\end{array}$

A.25 Asymmetrical matrix of yield gaps for pigs $\quad 71$

A.26 Asymmetrical matrix of yield gaps for sheep and goats $\quad 71$

A.27 Asymmetrical matrix of yield gaps for poultry 71

A.28 Final spillover coefficient matrix for maize $\quad 73$

A.29 Final spillover coefficient matrix for beans $\quad 73$

A.30 Final spillover coefficient matrix for cassava $\quad 73$

A.31 Final spillover coefficient matrix for cotton $\quad 74$

A.32 Final spillover coefficient matrix for groundnuts $\quad 74$

A.33 Final spillover coefficient matrix for millet $\quad 75$

A.34 Final spillover coefficient matrix for potatoes and sweet potatoes 75

A.35 Final spillover coefficient matrix for rice $\quad 76$

A.36 Final spillover coefficient matrix for sorghum $\quad 76$

A.37 Final spillover coefficient matrix for sugarcane $\quad 77$

A.38 Final spillover coefficient matrix for wheat $\quad 77$

$\begin{array}{ll}\text { A.39 Final spillover coefficient matrix for cattle } & 78\end{array}$

$\begin{array}{ll}\text { A.40 Final spillover coefficient matrix for pigs } & 78\end{array}$

A.41 Final spillover coefficient matrix for sheep and goats $\quad 79$

A.42 Final spillover coefficient matrix for poultry $\quad 79$

B.1 Initial yield level for selected crops, 2007 (metric tons/hectare) 81

B.2 Yield level for selected crops in the base run, 2015 (metric tons/hectare) 81

B.3 Yield level for selected crops in growth scenario, 2015 (metric tons/hectare) 82

B.4 Annual yield growth rates to 2015 to achieve target yields, regional averages 83

B.5 Value of production gains from the base over 2009-2015 (six years) in real terms, US\$thousands 84

B.6 Regional shares of the value of production gains from the base over 2009-2015 (six years) in real terms, \%

B.7 Annual growth rate in the aggregate by economic indicator, 2009-2015 (\%) 85

B.8 Annual growth rate by agricultural subsector, 2009-2015 (\%) 85

B.9 Agricultural commodity-level annual growth and contribution to overall agricultural growth, 2009-2015 (\%), total SADC without South Africa $\quad 86$

B.10 Net imports, total SADC (without South Africa) 87

B.11 Price changes by 2015, total SADC (without South Africa) 88

C.1 Summary and implications for agricultural research and development strategies in SADC $\quad 89$

D.1 Relative shares in total area of agricultural development zones 97

E.2 Summary of yield gaps in crop production in SADC 102

E.1 Number of full-time equivalent researchers by commodity in $2008 \quad 103$

G.1 List of regional programs/projects/networks coordinated by SACCAR 112

G.2 Review of economic rates of return on research and development investments 114 


\section{Figures}

1.1 Integrated analytical framework 3

2.1 Evidence of high correlation of national income status, poverty, and hunger 5

2.2 Share of global agricultural exports and cereal imports, 1961-2009 8

2.3 Cereal yields by major developing region, 1961-2009 8

2.4 Trends in total factor productivity in SADC region 10

2.5 Comparison of total factor productivity growth decomposition in SADC low-income countries and $\begin{array}{ll}\text { other regions } & 10\end{array}$

3.1 Length of growing period 14

3.2 Agroecological zones $\quad 15$

3.3 Dominant farming systems in the SADC region $\quad 18$

3.4 Population density and degree of market access 20

3.5 Degree of market access: Example of Malawi $\quad 22$

3.6 Current yield gaps for selected crops in the SADC region 23

5.1 Base-run annual growth rates (2009-2015) 38

5.2 Subsectors' contribution to total agricultural growth in the base run (2009-2015) 40

5.3 Regional total net imports in the base run, excluding South Africa 41

5.4 Closing current yields gaps under growth scenario, regional averages 42

5.5 Regional agricultural subsectors' growth, SADC excluding South Africa (2009-2015) 43

5.6 Growth in area and yield at the agricultural subsector level (2009-2015) 44

5.7 Average annual growth in economic indicators, 2009-2015 (SADC excluding South Africa) 45

5.8 Agricultural annual growth rates by country and region, 2009-2015 46

5.9 Subsectors' contribution to additional agricultural growth by country (difference between annual

growth rates under the two scenarios)

5.10 Subsectors' contribution to additional agricultural growth by country (difference between annual growth rate under the two scenarios)

5.11 Share of grain, livestock, and edible oils imports in total consumption 49

5.12 Price effects of growth scenarios $\quad 50$

5.13 Subsectors with greatest potential gains from research and development spillovers in SADC (comparing between low- and middle-income countries) 52

6.1 Suggested top 10 final rankings grouped by nutritional value, low-income countries only $\quad 59$

D.1 Agricultural development zones 97

D.2 Overview of spatial production allocation model (SPAM) 99 


\begin{abstract}
An in-depth quantitative analysis is undertaken in this paper to assist the Southern African Development Community (SADC) Secretariat, member countries, and development partners in setting future regional investment priorities for agricultural research and development in the SADC region. A primary goal of this work was to identify a range of agricultural research priorities for achieving sector productivity and overall economic growth in southern Africa, at both the country and regional levels. This is accomplished by adopting an integrated modeling framework that combines a disaggregated spatial analytical model with an economywide multimarket model developed specifically for the region. The spatial disaggregation uses information on current yield gaps to project growth and technology spillovers across countries among different agricultural activities that share similar conditions and thus potential for adoption and diffusion in the region. The economywide multimarket model is used to simulate ex ante the economic effects of closing these yield gaps through a country's own investments in research and development $(R \& D)$ and from potential $R \& D$ spill-ins from neighboring countries. Results indicate a high potential of spillovers and technology adaptability across countries due to similar agroecological and climatic conditions and the countries' own capacities for adaptive R\&D. The greatest agriculture-led growth opportunities reside in staple crops and in roots and tubers, especially among the low-income countries. Together, these sectors have the potential to contribute up to 40 percent of future possible growth. There are differences (areas of comparative advantage) at the country level that offer opportunities for specialization. For example, grains are the dominant subsector for Zimbabwe; in Botswana, opportunities will depend on more growth in its livestock sector; and for Namibia promoting fish growth may be more important. The root crops sector is as important as that of grains in Angola, Democratic Republic of the Congo, and Malawi, but even more important in Mozambique. The study finds evidence of high spillover potential, especially for maize, rice, cattle, cassava, sorghum, and beans. Low-income countries gain the most from spill-in of R\&D in the grains and roots subsectors; yield growth in these subsectors explains about 20 percent of these countries' gains in the total value of production, compared with only 2.2 percent among middle-income countries. Our results emphasize not only the importance of expanding regional cooperation in $R \& D$ and technology diffusion in southern Africa, but the importance of strengthening regional agricultural markets and linkages with nonagricultural sectors.
\end{abstract}

Keywords: agricultural growth, multimarket model, spatial analysis, technology spillovers, staple crops, southern Africa, priority setting, agricultural research, yield gap 


\section{FOREWORD}

The importance of agriculture to social and economic growth, poverty reduction, and food and nutrition security remains central to the Southern African Development Community (SADC) region's overall developmental agenda. The central role of agriculture is further heightened considering that the region is characterized by more than 61percent of its 277 million people living in rural areas mainly as small-scale farmers whose livelihoods depend on it. With an average annual agricultural growth rate of 2.6 percent against a population growth rate of 2.5 percent, it is imperative that agricultural growth and development in the region be accelerated.

Research shows that the returns in agricultural growth and poverty reduction are substantially higher in response to investment in agricultural research and development (R\&D) and related sub-sectors, such as road infrastructure and education. In a 2006 study by the World Bank and the United States International Trade Commission on agricultural research and development investment opportunities in Africa south of the Sahara, it was concluded that while most economies in Africa south of the Sahara gain more from R\&D investment in crops than in livestock, the overall effect of increased investment in both crops and livestock results in significant overall economic growth. This demonstrates the importance of Agricultural R\&D, hence SADC's determination to improve the region's agricultural R\&D agenda and its implementation.

At the continental level, Pillar 4 of the Comprehensive African Agricultural Development Programme (CAADP) focuses on research, technology generation, dissemination and adoption. At the regional level, SADC Council approved a 15-year SADC Multi-country Agricultural Productivity Programme (MAPP) to implement Pillar 4. Based on consultative processes and qualitative analysis, a range of priority thematic areas were formulated to promote agricultural research and development in the SADC region. Using these results, this study went further and more objectively through evidence-based analyses, identified, detailed and quantified strategic priorities for regional agricultural R\&D investment in SADC. These strategic priorities were derived by identifying areas that will generate the most overall growth and potential $R \& D$ spillover benefits - a term for the way that the majority of countries, especially low-income countries can potentially benefit from research conducted elsewhere in the region.

With regards to implementation mechanisms, through the MAPP, SADC has successfully established and launched the Centre for Coordination of Agricultural Research and Development for Southern Africa (CCARDESA) to coordinate all R\&D programs in the region guided substantially by the strategic priorities outlined in this study. Through CCARDESA, the SADC region joins the ranks of similar other regional institutions including the Association for Strengthening Agricultural Research in Eastern and Central Africa (ASARECA) in Eastern and Central Africa and the West and Central African Council for Agricultural Research and Development (CORAF) in West Africa in contributing towards the continental attainment of CAADP Pillar 4.

SADC recognizes the great contributions by and would like to thank all the key stakeholders particularly the International Food Policy Research Institute (IFPRI) and the Regional Strategic Analysis and Knowledge Support Systems for Southern Africa (ReSAKSS) for successfully undertaking this enormous task. This study, however, could not have been achieved without the financial support from the United States Agency for International Development (USAID). SADC acknowledges and greatly appreciates this continued financial support. Last but not least, SADC acknowledges the stewardship by the Food, Agriculture and Natural Resources experts at the Secretariat in these processes and its continued hard work and tirelessness to achieve and implement planned programs and activities towards the attainment of the SADC Common Agenda which promotes sustainable and equitable economic growth and socioeconomic development.

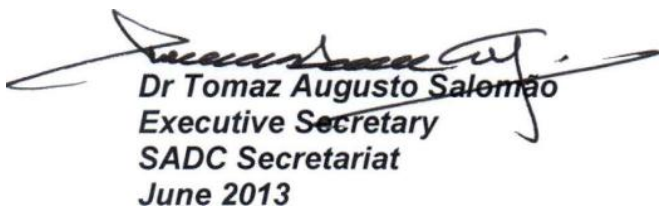




\section{PREFACE}

The Secretariat of the Southern African Development Community (SADC) commissioned the International Food Policy Research Institute (IFPRI) to undertake an in-depth quantitative analysis to assess future investment priority options for agricultural research and development (R\&D) in the SADC region. The study was commissioned through the Regional Strategic Analysis and Knowledge Support System for Southern Africa, which is facilitated by IFPRI and the International Water Management Institute in support of implementation of the Comprehensive Africa Agricultural Development Programme of the African Union and the Regional Indicative Strategic Development Plan of SADC.

The results in this study are based on information from expert surveys undertaken in SADC Member States (with the exception of Mauritius and Madagascar), using IFPRI's analytical methods and approaches, including reviews and feedback during workshops conducted to validate the approach and preliminary results with stakeholders. The study combines both economic and spatial modeling tools in order to explore future alternative investment priorities for agricultural $\mathrm{R} \& \mathrm{D}$ in order to achieve sectorwide and overall economic growth and poverty reduction in the SADC region. The study findings are intended to complement other, similar work undertaken by IFPRI in the past for the Association for Strengthening Agricultural Research in East and Central Africa and the West and Central African Council for Agricultural Research and Development. In the process, it is hoped it will enrich the ongoing policy dialogue about alternative agricultural development priorities needed to promote regional growth and poverty reduction in the SADC region and Africa south of the Sahara more generally. 


\section{ACKNOWLEDGMENTS}

The authors wish to thank the Food, Agriculture and Natural Resources (FANR) Directorate of the Southern African Development Community (SADC) for recognizing the need to undertake this important study by providing financial and human resource support for its timely completion. In particular, the authors wish to thank the leadership of Margaret Nyirenda (director of SADC-FANR) and Keoagile Molapong (senior program manager for research and development, SADC-FANR). We are grateful for the comments and feedback shared by Patrick Tawonezvi (Multi-country Agricultural Productivity Programme [MAPP] coordinator, SADC-FANR) and Alfred Mapiki (MAPP consultant, SADC-FANR) during a series of workshops for presenting preliminary results and for their review of a first draft of this paper.

The conclusion of this study could not have been possible without the information on agricultural research and development shared by national collaborators from SADC member countries, including Adriane Andre (Angola), Howard Sigwele (Botswana), Baelo Jose (Democratic Republic of the Congo), Mamolemo Pomela (Lesotho), Alexander Phiri (Malawi), Carlos Zandamela (Mozambique), Sikunawa Negumbo (Namibia), Mermedah Moustache (Seychelles), Francois Lategan (South Africa), John Pali (Swaziland), Ninatubu Lema (Tanzania), Medson Chisi (Zambia), and Edward Nengomasha (Zimbabwe). Finally, the research support provided by Adam Kennedy and Renato Folledo at IFPRI and Fred Kalibwani at the International Water Management Institute were commendable. 


\section{ABBREVIATIONS AND ACRONYMS}

ADZ

AgGDP

AEZ

ASARECA

AVRDC

CAADP

CARDESA

CCARDESA

CIAT

CIESIN

CIP

CIMMYT

COMESA

CORAF/WECARD

COSTECH

CPI

DRC

ECOWAS

EMM

ESAMI

FANR

FAO

FOFIFA

GAEZ

GDP

GIS

GRUMP

GTZ

ICART

ICRAF

ICRISAT

IIASA

IITA

ILRI

INERA

INTSORMIL CRSP

IRRI

ISNAR agricultural development zone

agricultural value-added or agricultural gross domestic product

agroecological zone

Association for Strengthening Agricultural Research in Eastern and Central

Africa

World Vegetable Center

Comprehensive Africa Agriculture Development Programme

Centre for Agricultural Research and Development for Southern Africa

Centre for Coordination of Agricultural Research and Development for Southern

Africa

International Center for Tropical Agriculture

Columbia University Center for International Earth Science Information Network

International Potato Center

International Maize and Wheat Improvement Center

Common Market of East and Southern Africa

West and Central African Council for Agricultural Research and Development

Commission for Science and Technology

consumer price index

Democratic Republic of Congo (or Congo, D. R.)

Economic Community of West African States

economywide multimarket model

Eastern and Southern African Management Institute

Food, Agriculture and Natural Resources

Food and Agriculture Organization of the United Nations

National Center for Applied Research on Rural Development (Madagascar)

Global Agro-Ecological Zones

gross domestic product

geographic information systems

Global Rural-Urban Mapping Project

German Agency for Technical Cooperation

Implementation and Coordination of Agricultural Research and Training

World Agroforestry Centre

International Crops Research Institute for the Semi-arid Tropics

International Institute for Applied Systems Analysis

International Institute of Tropical Agriculture

International Livestock Research Institute

Institut National pour l'Etude et la Recherche Agronomiques (DRC)

International Sorghum and Millet Collaborative Research Support Program

International Rice Research Institute

International Service for National Agricultural Research 
LGP

MDGs

NARS

NEPAD

PFP

$\mathrm{R} \& \mathrm{D}$

R\&D ACAL

ReSAKSS

RISDP

ROR

SABRN

SACCAR

SADC

SADC MAPP

SADCC

SAFRINET

SARRNET

SPAM

SSA

TFP

UF

USAID

WARDA

ZRTC length of growing period

Millennium Development Goals

national agricultural research system(s)

New Partnership for Africa's Development

partial factor productivity

research and development

R\&D Advisory Committee on Agriculture and Livestock

Regional Strategic Analysis and Knowledge Support System

Regional Indicative Strategic Development Plan of SADC

rate of return

Southern Africa Bean Research Network

Southern Africa Center for Cooperation in Agricultural Research and Training Southern African Development Community

SADC Multi-country Agricultural Productivity Programme

Southern African Development Coordination Conference

Biosystematics Network for Southern Africa

Southern African Root and Tuber Crops Research Network

spatial production allocation model

Africa south of the Sahara

total factor productivity

University of Florida

United States Agency for International Development

West Africa Rice Development Association

Zonal Research and Technical Committee 


\section{INTRODUCTION}

To achieve the first Millennium Development Goal of halving poverty and hunger by 2015, the Southern African Development Community (SADC), through the Comprehensive Africa Agricultural Development Programme (CAADP) and the SADC Regional Indicative Strategic Development Plan (RISDP), has set targets of achieving 6 percent agricultural gross domestic product growth per year and attaining average cereal yield levels of 2 metric tons (mt)/hectare (ha). ${ }^{1}$ Agricultural research and development (R\&D) has been identified as one of the key areas that can help achieve these targets (FANR Directorate 2008).

Whether agricultural R\&D has such potential, and how much growth would be realized, is the question this study addresses. Answering this question may be a challenging task considering the diversity of agricultural economies in the region. The SADC region is composed of 15 member states: Angola, Botswana, Democratic Republic of the Congo, Lesotho, Madagascar, Malawi, Mauritius, Mozambique, Namibia, Seychelles, South Africa, Swaziland, United Republic of Tanzania, Zambia, and Zimbabwe. Among them, many have small economies and face limited capacities and resources for R\&D. For these countries, a shared regional strategy for R\&D rather than going it alone at the country level can help trigger economies of scale and potentially generate huge benefits. Unfortunately, little is known about which regional priorities to target since priorities are typically formulated at the country level, and even if they are considered at the regional level, they are rarely assessed in any economically rigorous fashion.

The principal purpose of this study, therefore, is to fill this important gap by assessing ex ante the critical investments and policy alternatives needed to rapidly raise and sustain agricultural growth in the SADC region. To do so, the study undertakes an economic analysis to empirically estimate the potential flow of future benefits from a regional R\&D strategy, broken out by specific commodity area. The goal is to help the SADC Secretariat and the Member States understand how they might position their priorities for agricultural R\&D, especially in order to meet the RISDP and CAADP goals. To this end, the study systematically analyzes and identifies certain economic and other quantifiable criteria that can serve as a strategic entry point for ranking future R\&D priorities at the SADC level.

The study accomplishes these goals by identifying commodity areas that will generate the most overall growth and potential $R \& D$ spillover benefits - a term for the way that a majority of countries, especially low-income countries, can potentially benefit from research conducted elsewhere in the region. More specifically, the study asks these questions:

1. What investment and policy options, in which commodity areas, offer the best potential for accelerating agricultural-sector growth and increasing national incomes in order to achieve the RISDP and CAADP goals?

2. Among the key commodity areas, which ones have greater potential for adaptation and direct transfer across countries?

3. Finally, what constraints and other issues might affect productivity growth in the SADC countries?

Other important criteria, such as poverty reduction effects, intraregional trade expansion, and gender implications, are beyond the scope of this study. Ultimately, finding answers to these questions will help enrich the ongoing policy dialogue for shaping a future agricultural R\&D strategy in the SADC region. The analysis builds and expands on the work the International Food Policy Research Institute (IFPRI) has undertaken in other regions in Africa, notably, in the Common Market of East and Southern Africa (COMESA) region for the Association for Strengthening Agricultural Research in Eastern and Central Africa (ASARECA), and in the Economic Community of West African States (ECOWAS) region for the West and Central African Council for Agricultural Research and Development (CORAF/WECARD). ${ }^{2}$

\footnotetext{
${ }^{1}$ Metric tons are used throughout the text.

${ }^{2}$ See Omamo et al. (2006), and Johnson et al. (2008), respectively.
} 
The study adopted three methodological approaches. First, it undertook a review of the literature to take stock of the existing knowledge on agricultural $R \& D$ and past efforts at setting regional $R \& D$ priorities in the SADC region. This involved reviewing both the general academic literature and official SADC documents (Appendix G). Second, national collaborators conducted country-level expert opinion surveys to draw on local knowledge about key aspects of agricultural R\&D and farming systems that are unique to each Member State. Finally, we developed an integrated analytical framework to link spatial and economic analytical tools for answering the questions above. The national collaborators also helped to review and validate preliminary results of the analysis in addition to providing some secondary data.

Figure 1.1 presents the integrated analytical framework, which involves three different but integrated methods of analysis, applied in the following order:

1. First, we used a spatial analysis model (A) to analyze diversity in the distribution of underlying biophysical and socioeconomic factors in order to define unique agricultural development domains (as a function of agricultural potential or suitability and degree of market access) and then to estimate actual and maximum potential yield levels (or yield gaps) associated with each domain in order to determine the feasibility of or potential for raising yields in the future.

2. Next we constructed an $R \& D$ spillover matrix (B) of the similarities of agricultural production environments and differences in yield performance across countries for different commodities, drawing on the spatial information from (A). We then used other institutional and resource capacity information on national $R \& D$ systems to estimate the likelihood for successful adoption and diffusion of $R \& D$ for the different agricultural commodities.

3. Then we applied an economywide framework of analysis $(\mathrm{C})$ to assess the overall implications of future yield growth scenarios, including effects on overall economic growth, prices, incomes, consumption, and trade. Based on the spillover analysis in (B), we also undertook a decomposition of the economic benefits derived from a country's own R\&D and from R\&D in neighboring countries.

4. Finally, using the results of the analysis in (B) and (C), we used criteria based on the degree to which productivity growth of a commodity contributes to overall sector growth and to spillover benefits to provide a final ranking of R\&D investments in different commodities using a simple scoring tool. The tool allows for other criteria to be added in finalizing any future rankings. 
Figure 1.1 Integrated analytical framework

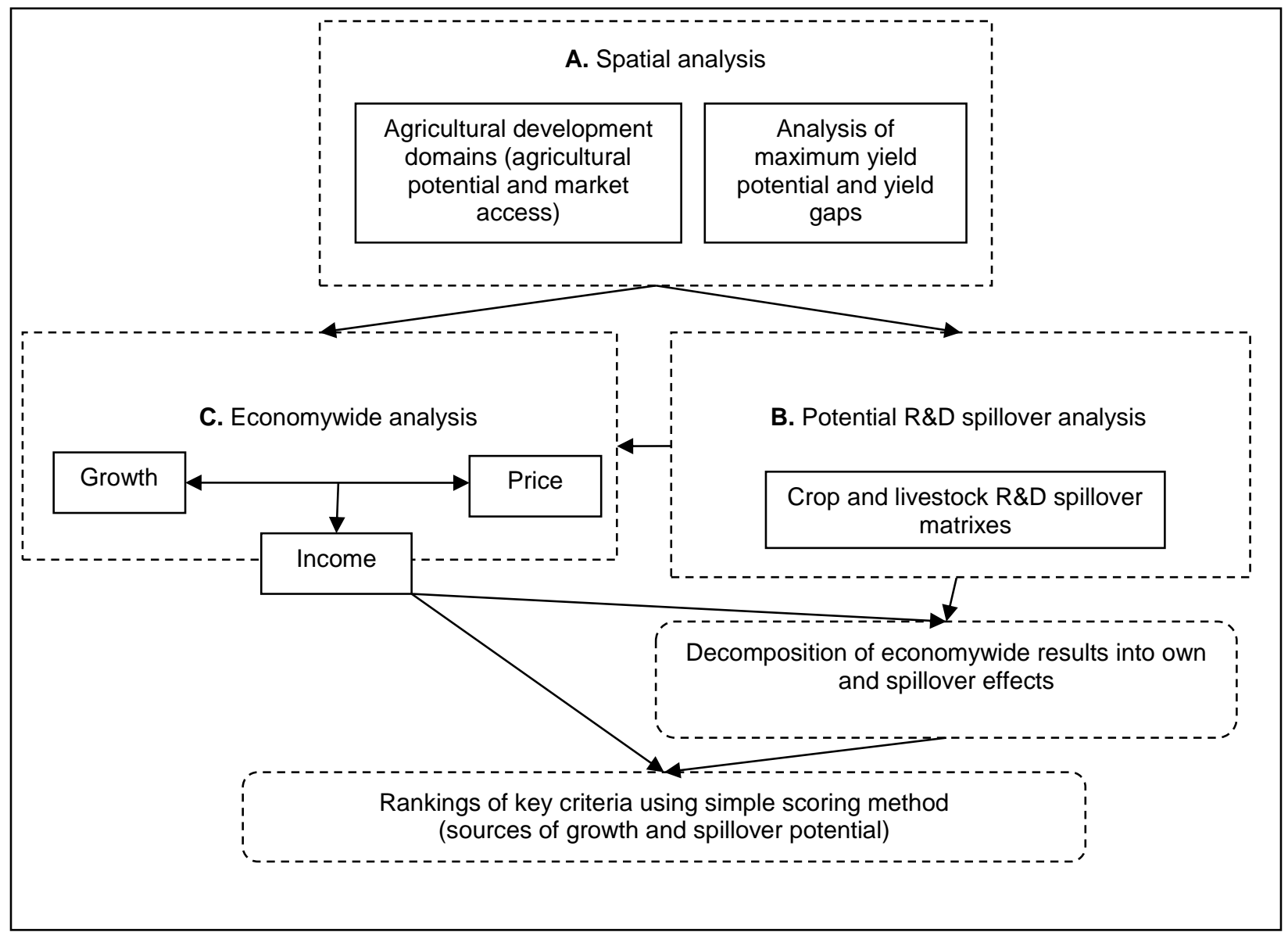

Source: Authors.

Note: $\quad R \& D=$ research and development.

The three analytical components-(A), (B), and (C)—are integrated through yield gap estimates derived from the spatial analysis to provide an indicative measure of the potential for, and thus feasibility of, future yield growth. Integration also occurs through the construction of the R\&D spillover potential matrixes, derived from the spatial analysis and linked to the economywide model for estimating overall economic benefits from spillovers and decomposing them into own and other countries' sources of R\&D. As a result, the approach has a number of advantages: it explicitly recognizes the spatial patterns of production and socioeconomic conditions across different countries in the SADC region; it adds a strong regional R\&D spillover dimension; it allows for a more dynamic and forward-looking approach; and finally, it ensures a sufficiently broad economic perspective in considering the effects of alternative R\&D interventions on growth and welfare outcomes (for example, incomes, consumption, and production).

A key challenge faced in undertaking the analysis was obtaining sufficiently rich information on $\mathrm{R} \& \mathrm{D}$ and farming systems, especially at a more disaggregated level (that is, for different commodities under various subsectors: crops, livestock, and forests and fisheries). Although information from experts through the individual country surveys helped to fill these gaps, the information collected varied so widely in terms of quality and completeness that it eventually proved difficult to apply all the information in the different analytical components. Fortunately, data from other secondary sources (including the FAOSTAT and Agricultural Science and Technology Indicators databases) was sufficient to provide quantifiable rankings at the country and regional levels. 
The rest of the paper is organized as follows. Section 2 provides a very brief overview of agricultural performance and dynamics in the SADC region. Section 3 introduces the spatial analysis approach to describing the socioeconomic and biophysical underpinnings of agriculture in the SADC region. This includes identifying unique agricultural development domains as defined by agricultural potential and markets. Across these environments we estimate yield gaps to provide indicative measures of the potential for yield growth using the extensive database of the Food and Agriculture Organization (FAO) and IFPRI's Spatial Production Allocation Model (SPAM). Section 4 then explores the degree to which R\&D and technology spillover potential exists in the SADC region. Here we construct spillover matrixes for different commodities based on both similarities and differences in agricultural suitability, yield performance, and R\&D capacities. Section 5 introduces the economywide multimarket model (EMM) developed for the SADC region. Yield growth scenarios are applied using information on the RISDP targets and validated, in terms of feasibility, with the yield gap information from the spatial analysis. Finally, Section 6 concludes by offering a ranking of future priorities based on the results of analysis, together with a range of recommendations and policy implications. 


\section{REVIEW OF AGRICULTURAL PERFORMANCE AND GROWTH OPPORTUNITIES ${ }^{3}$}

Between 2007 and 2009, SADC generated US\$275 billion in annual average gross domestic product (GDP), about 53 percent of the total for Africa south of the Sahara (SSA) (calculated from World Development Indicators 2010). South Africa alone accounts for about two-thirds of the SADC total and, together with five other middle-income countries (Angola, Botswana, Mauritius, Namibia, Seychelles, and Swaziland), accounts for 82 percent of the region's total value of economic activity. Compared with the rest of SSA, the region has a mix of both middle- and low-income countries. Among the middleincome countries, poverty and hunger are less prevalent in aggregate, while the opposite is true among low-income countries (Figure 2.1). Per capita incomes are highest among the island economies of Mauritius and Seychelles, followed by those of Botswana and South Africa-above US $\$ 3,000$ per person. In sharp contrast, lower-income countries generate about a tenth of this, ranging between US\$94 and US $\$ 500$ per person. Consequently, poverty rates are also much higher for the latter group, ranging between 43 and 89 percent, compared with 1 to 63 percent among middle-income countries.

Figure 2.1 Evidence of high correlation of national income status, poverty, and hunger

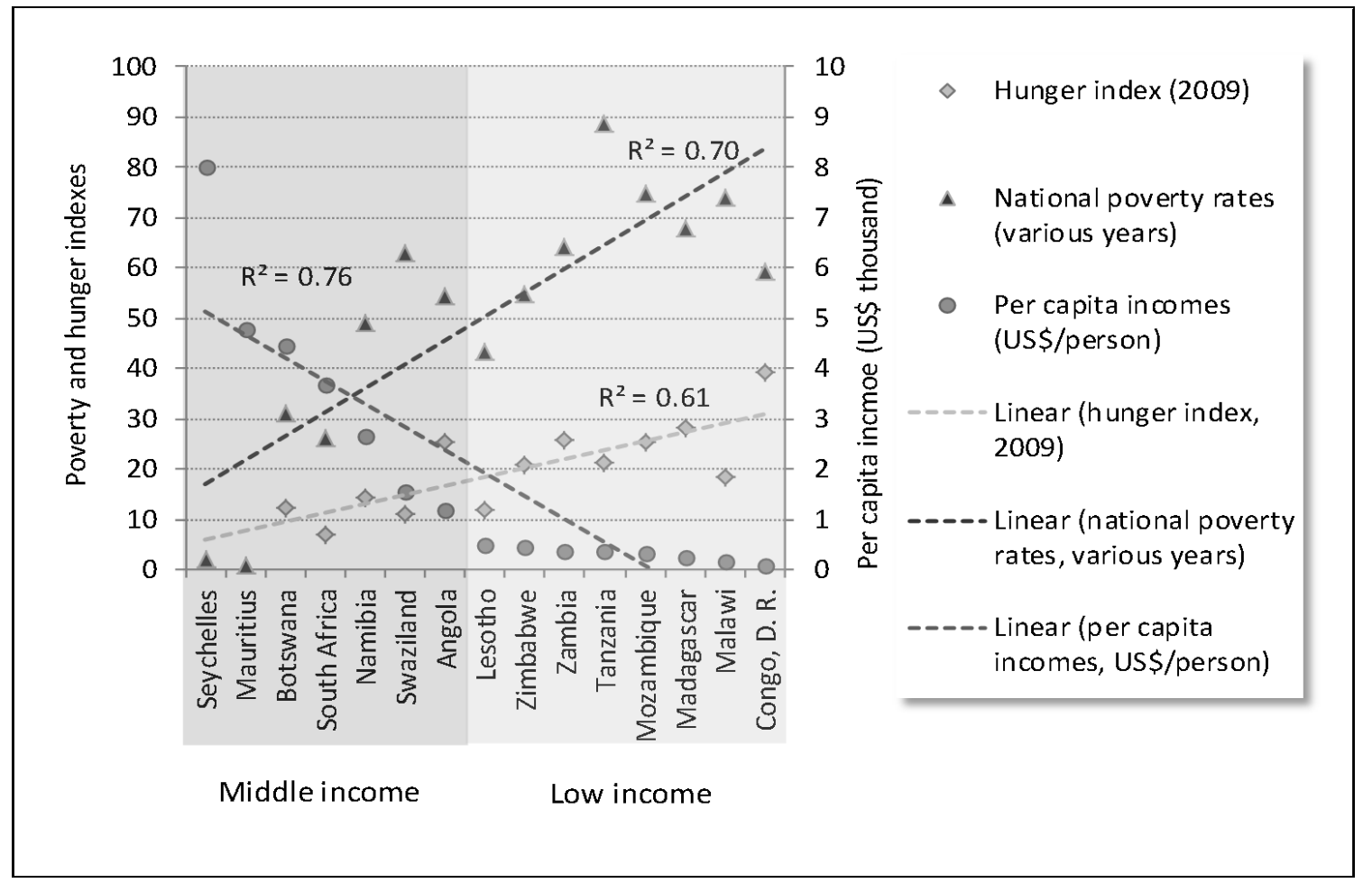

Sources: Per capita income is from World Development Indicators 2010. Poverty rates are from ReSAKSS) database, based on most recent survey year (for Zimbabwe, this is a straight-line estimate from a 1996 survey).

Note: IFPRI's Hunger Index is a composite index of three indicators (proportion of undernourished population, prevalence of underweight in children under five, and under-five mortality rate).

The picture can be misleading, however, considering the highly uneven distribution of incomes among a majority of the middle-income countries (as expressed by their higher Gini coefficients; Table 2.1). In remote rural areas of these countries, poverty and hunger are as prevalent as they are in lowerincome countries, where a majority of the population still relies on agriculture for subsistence.

\footnotetext{
${ }^{3}$ This section was authored by Michael Johnson and Pius Chilonda.
} 
Table 2.1 Economic performance, importance of agriculture, and welfare

Middle-income countries

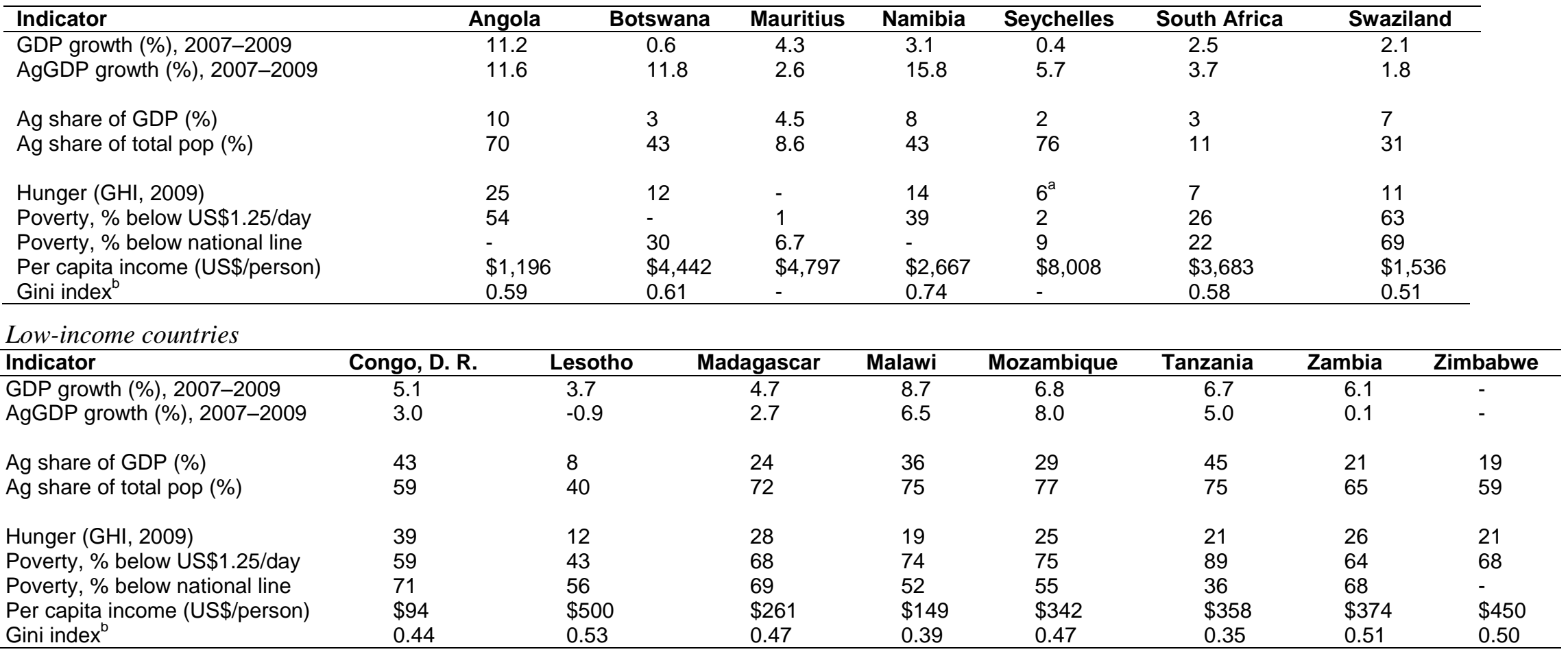

Source: World Development Indicators 2010.

Notes: GDP $=$ gross domestic product. AgGDP $=$ agricultural value-added or agricultural gross domestic product. GHI $=$ Global Hunger Index. ${ }^{a}$ Measures only the percentage of underweight under-five children (source: Government of Seychelles (2010). ${ }^{\mathrm{b}}$ A measure of the inequality of income distribution. A value of 0 expresses total equality while a value of 1 expresses maximum inequality. 


\section{Overview of Agricultural Sector and Importance of Food Staples}

Differences between low- and middle-income-status countries are reflected not only by per capita income and the prevalence of poverty and hunger, but also in the relative importance of the agricultural sector in the overall economy. Measured as a percentage share of total GDP, the sector contributes between 2 and 10 percent among middle-income countries, while this figure ranges between 19 and 43 percent among the low-income countries, with the exception of Lesotho (Table 2.1). Additionally, the sector in lowincome countries is characterized by the production of food staples (both crops and livestock) on millions of smallholder plots or common rangelands, with cereals and root crops occupying almost 66 percent of cropland and another 30 percent devoted to traditional export crops, such as tobacco, tea, coffee, spices, sugar, and cotton. Other crops typically grown include oilseeds, pulses, and fruits and vegetables. On the other hand, large-scale and high-input commercial agriculture is prominent among a majority of the middle-income countries, especially South Africa. In fact, the bulk of cereals, livestock products, and fruits and vegetables in SADC are produced in South Africa and the other middle-income countries of Botswana, Namibia, and Swaziland. Altogether, these countries produce about 65 percent of the cereals, 80 percent of the beef and poultry meat, and 80 percent of the fruits and vegetables in SADC.

Given the sheer size of the agricultural sector among a majority of low-income countries in SADC, and considering that millions rely on it as a source of employment and food security, it has the potential to serve as a key driver of overall economic growth and of poverty and hunger reduction. Studies have shown that if investments help integrate the majority, smallholder population into the broader economy in these countries, agricultural growth can be particularly effective at generating overall income growth that is pro-poor (Christiaensen, Demery, and Kuhl 2006; World Bank 2007). This means for most low-income countries, focusing attention on improving the productivity and commercialization of smallholder production systems, especially those that produce food staples, which millions of smallholders typically cultivate, can go a long way in stimulating both growth and poverty reduction (Diao, Headey, and Johnson 2008).

There are several good reasons for focusing on food staples. Aside from the scale effect - through which millions of small farmers would benefit directly from increased land and labor productivity, food consumption, and incomes - the growth in staples production would further benefit the poor through its effect on food prices. The poor spend most of their income on food, and lower food prices allow them to consume more without increasing spending. Finally, growth in staples production has also been shown to have strong multiplier effects on other sectors through production-consumption linkages, which stimulate additional growth in nonstaple agricultural as well as nonagricultural sectors, such as manufacturing, construction, and various services (Delgado, Hopkins, and Kelly 1998). Diao et al. (2007) illustrated this important role of staple crops and livestock sectors in stimulating overall economic growth and poverty reduction, drawing on a number of case studies in Africa.

Unfortunately, the production of food staples in SADC has not performed at levels that will make meaningful contributions to overall growth and poverty reduction in the region. Although the region allocates more than 50 percent of agricultural land to cereal production, it has failed to keep up with population growth such that imports have been gradually increasing over time (Figure 2.2). Hardest hit have been the poorer countries, where the gap between demand and production has hovered around 20 percent. Explaining much of this gap is the serious lag in cereal yields compared with those of other major developing regions of the world (Figure 2.3). 
Figure 2.2 Share of global agricultural exports and cereal imports, 1961-2009

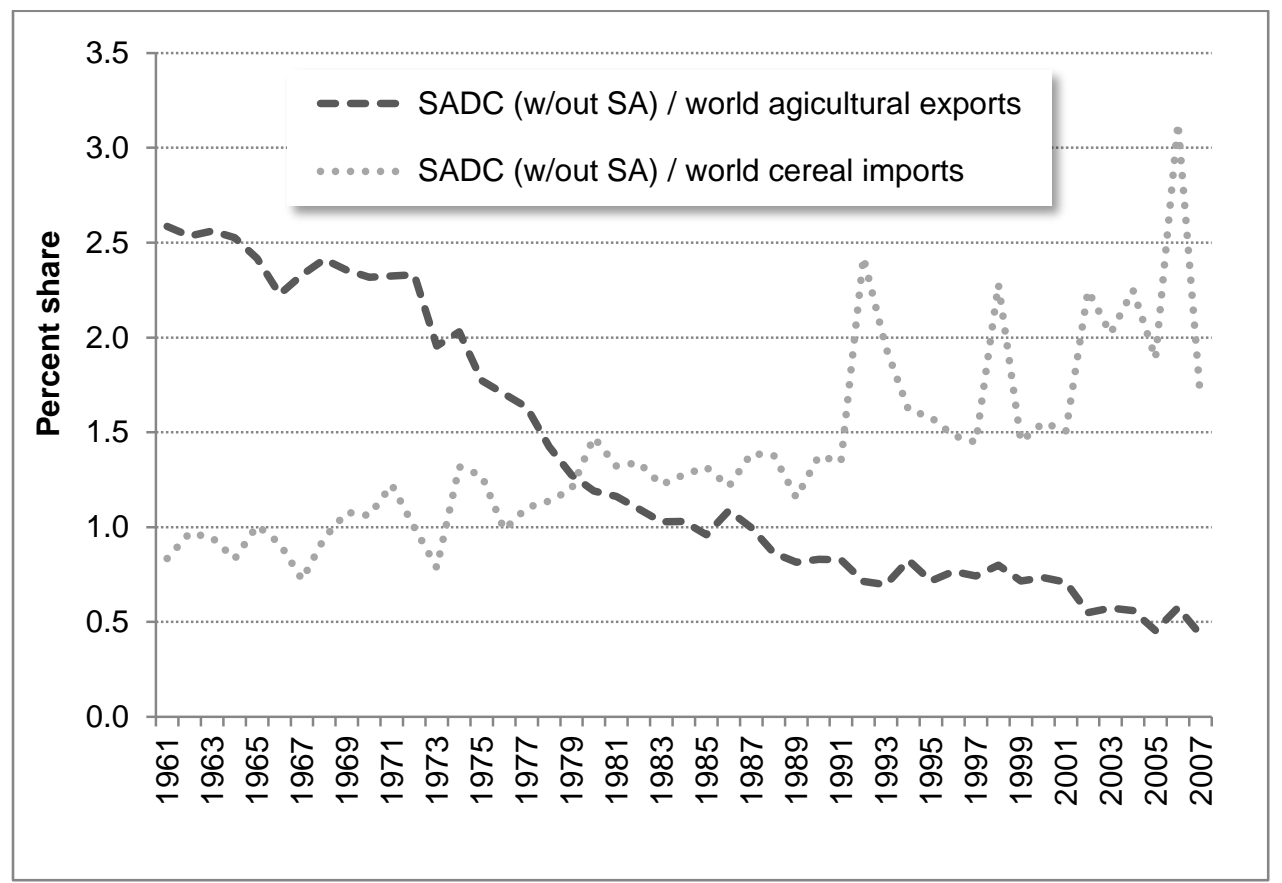

Source: FAO (2010).

Notes: $\mathrm{SADC}=$ Southern Africa Development Community. $\mathrm{SA}=$ South Africa.

Figure 2.3 Cereal yields by major developing region, 1961-2009

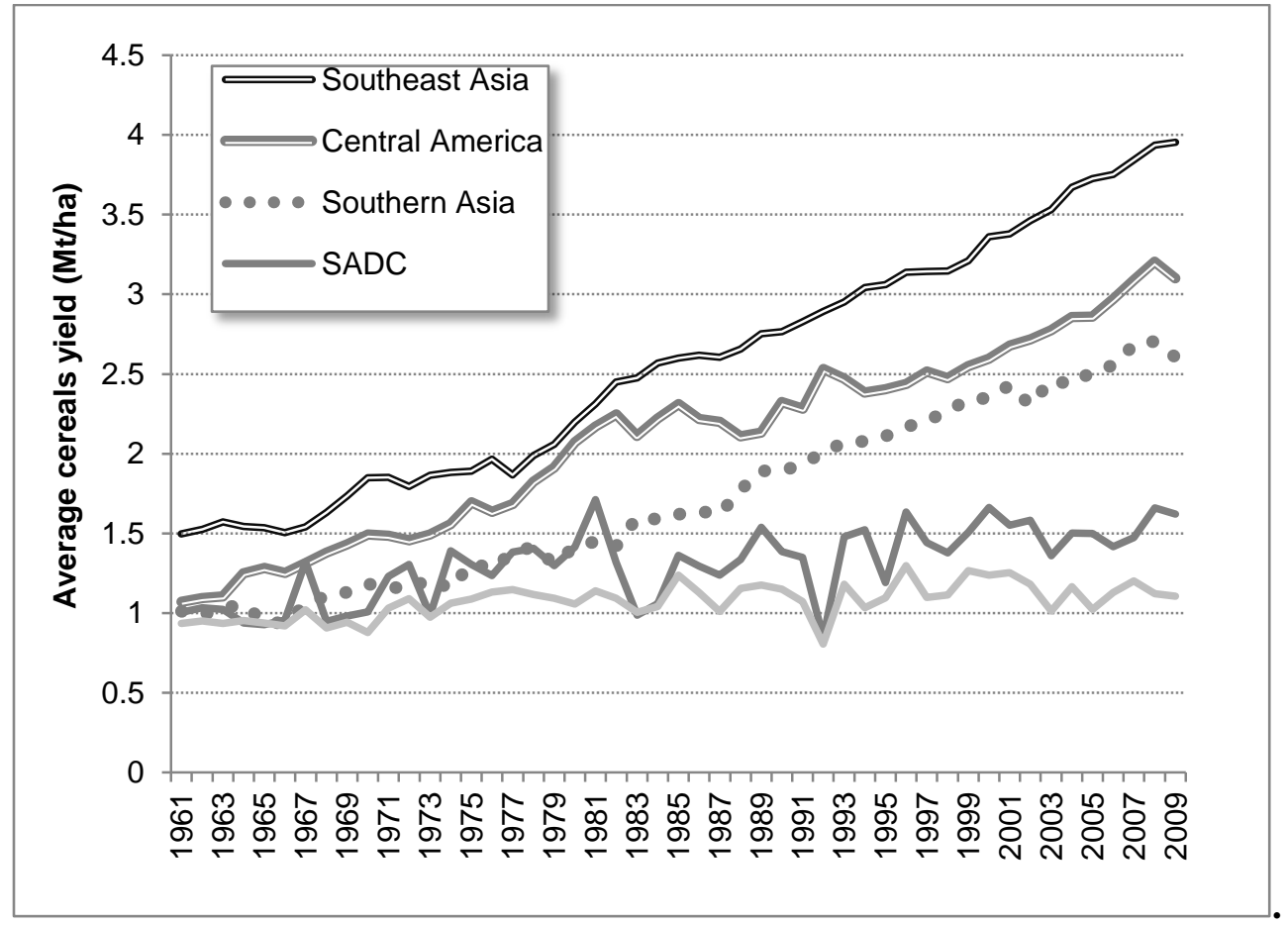

Source: FAO (2010).

Notes: $\mathrm{Mt} / \mathrm{ha}=$ metric ton per hectare. 
A few countries, such as Malawi and Zambia, have experienced bumper harvests in recent years, following good rains and the introduction of farm subsidies, particularly for fertilizers and improved seeds. However, the extent to which this boom will be sustainable in the long run remains to be seen. Threats of food insecurity still loom on the horizon when the next droughts arrive or when governments can no longer sustain farm subsidies. Pressure from increasing populations will only exacerbate these challenges, and while input subsidies can help produce significant output growth under favorable conditions (for example, adequate access to water), long-run allocative efficiency problems can also arise. For example, when government support policies for maize and other cereals were removed abruptly as part of the structural adjustment programs in the late 1980s, cassava production in low-income southern African countries increased as households shifted away from maize. More recently, and unlike the cereals subsector, productivity growth of cassava has been quite positive, with an annual average growth rate of about 2.3 percent per year between 2000 and 2009 (calculated from FAO 2010). Together with a rapid expansion in production area (as much as 50 percent), cassava output has more than doubled in the last 20 years, contributing to the food security situation of millions of poorer rural households. During the surge in cassava production, output grew by more than 20 percent per year (for some years) in Malawi and Zambia, for example (Haggblade and Hazell 2010).

Aside from food crops, livestock production is also quite important in the region. On average, the sector has performed better than the grain sector. Compared with the average for 1977-81, the region's total meat production has increased by 1.92 percent per year over the past 20 years. However, demand has grown more rapidly, at 2.57 percent per year in the same period. Consequently, the region shifted from a meat surplus position in the early 1980s (when net exports accounted for more than 6 percent of total production) to a deficit in the current decade. Among the low-income group, about 14 percent of the milk consumed and 6 percent of the poultry meat consumed are imported annually (Nin Pratt and Diao 2006).

\section{Productivity Trends and Future Growth Opportunities}

As pointed out previously, the production of food staples in SADC has not performed at levels that will make meaningful contributions to overall growth and poverty reduction, or keep up with population growth. A good example is the slow growth in cereal productivity (or yields), as illustrated in Figure 2.3. This lack of performance is especially evident among the low-income group of countries, where yields have been a fraction of those in neighboring middle-income countries. If agriculture is going to grow in these countries, therefore, productivity will need to increase significantly over time.

Productivity is defined as the ratio of outputs to inputs, in which larger values are associated with better performance. In economics, two index ratios are used to measure productivity: total factor productivity (TFP), which involves all inputs used in the production process, and partial factor productivity (PFP), which measures the ratio of output to one particular input. While the TFP measure provides a good aggregate picture, PFPs are more intuitive and can provide valuable information in the analysis of overall TFP.

Drawing heavily on some recent work by Nin Pratt and Yu (2008), we review trends in these key measurements to determine overall productivity performance in the SADC region, highlighting any crosscountry differences. Estimates of agricultural TFP growth across individual countries in southern Africa show an average growth rate of only 0.4 percent per year between 1961 and 2006, resulting in a total gain of 17 percent over 42 years. As shown in Figure 2.4, most of this growth has occurred in the last 20 years, accelerating in the 1990s decade. Faster growth occurred between 1987 and 2006 for some countries, including Tanzania, Mozambique, South Africa, and Angola, where agriculture grew at an average annual rate of about 3.6 percent. In contrast, productivity growth was virtually zero for Malawi, Zambia, Zimbabwe, and Swaziland during this same period. 
Figure 2.4 Trends in total factor productivity in SADC region

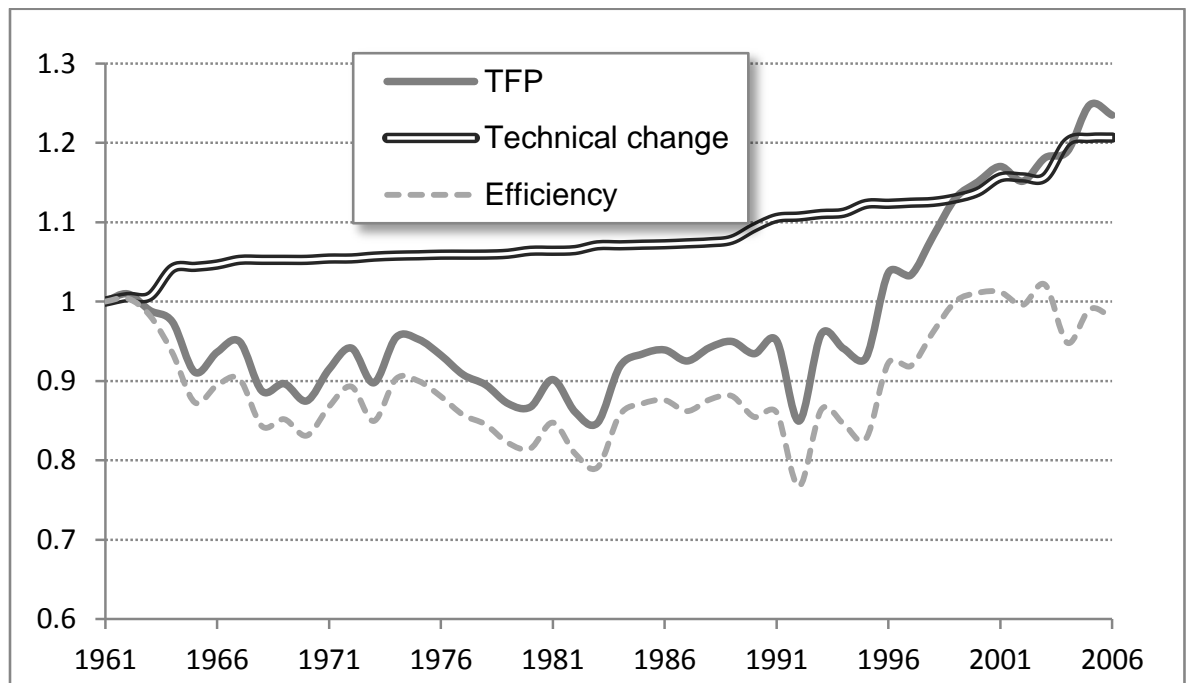

Source: Authors' calculations updated from Nin Pratt and Yu (2009).

Notes: $\quad \mathrm{SADC}=$ Southern Africa Development Community. TFP $=$ total factor productivity. The most recent period for which complete data were available is 2006 .

To explain the source of change in overall TFP over time, it helps to decompose it into its two components, technical efficiency and technical change. Results of this decomposition reveal efficiency gains as a key source of TFP growth in the 1990s, especially among lower-income countries. Production efficiencies reflect improvements in the allocation and use of existing factor resources and technologies in the production process. These appear to have reached a ceiling in the period 2000-2006. This experience is in sharp contrast to that of other developing regions (for example, China, India, the Middle East, and Latin America), where technical change, rather than efficiency, has played a more prominent role (Figure 2.5 ) in growth.

Figure 2.5 Comparison of total factor productivity growth decomposition in SADC low-income countries and other regions

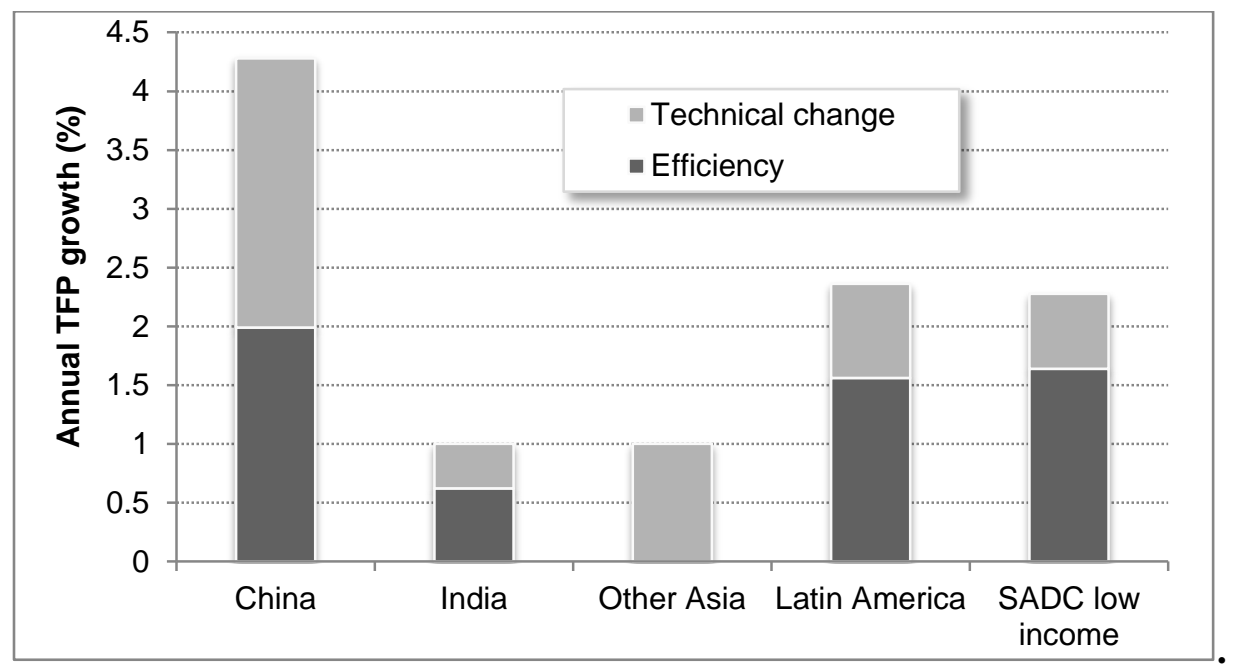

Source: Authors' calculations updated from Nin Pratt and Yu (2009).

Notes: The period covered is 1994-2006, with 2006 being the most recent year for which data are available. TFP $=$ total factor productivity. $\mathrm{SADC}=$ Southern Africa Development Community. 
It is possible to distinguish, at a minimum, a number of factors that may offer plausible explanations for the changes in efficiency observed in Figure 2.4. According to the analysis by Nin Pratt and $\mathrm{Yu}$ (2009), these include (1) the recovery of some of the economies from periods of political conflict; (2) policy reforms that started in the mid-1980s following the implementation of the structural adjustment programs, and later, with the end of the apartheid regime in South Africa; and (3) past R\&D investments that helped produce higher returns under a better economic environment for agricultural growth.

Aside from the decomposition of TFP growth, PFP measures of labor and land productivity are also frequently used to explain the underlying sources of change in overall sector productivity. Changes in these PFP measures are driven by changes in the labor-to-land ratio, which is in turn affected by two things: (1) the increase in rural population and therefore the number of agricultural workers, and (2) the incorporation of arable land to crop production. If the ratio is increasing due to increases in rural population and thus the number of agricultural workers, rural living standards will decline as output per worker falls - assuming yields do not change much or grow at a pace slower than the growth in population. Attributing a change in the labor-to-land ratio to an increase in the rural labor force also implies that increasing labor productivity, for example, is necessary to increase the incomes of agricultural workers. However, increasing land productivity, as in yields, can also have the same effect if the increase is faster than the increase in the number of workers per ha (Block 1995). In other words, because output per ha grows faster than the number of workers per ha, output per worker (and therefore income per worker) rises.

Table 2.2 presents a summary of PFP levels and growth rates among SADC member states between 1961 and 2006 for which information was available. ${ }^{4}$ Evidently, land productivity levels in SADC rose significantly beginning in the 1990s after changing little in the first two decades of independence. Angola and Zambia experienced the greatest growth rates, above 3 percent per year after 1991. At the regional level, land productivity grew by a mere 1 percent per year. Considering growth in labor productivity together with TFP growth, South Africa was the best-performing country from the early 1990s to 2006, showing, on average, high TFP growth together with increased labor and land productivity. Taken together, this information tells us that aside from South Africa and other middleincome countries, most low-income countries in SADC experienced gains in land productivity (or yields) that are associated with greater intensity in use of labor rather than with simply employing more capital in the form of such investments as chemical input and machinery. In other words, increases in output per ha occurred as the number of workers per ha increased more rapidly due to population growth.

These results emphasize not only the varied performance of the agricultural sector across countries as explained by their underlying patterns of productivity growth, and therefore their comparative advantages, but also the potential for narrowing any wide gaps. This potential exists especially for food staples such as maize, which can generate overall income growth and poverty reduction among the low-income countries, as discussed in the previous section. Increases in maize productivity can significantly improve the competitiveness of low-income countries to tap regional markets for maize as a food staple and for agroprocessing industries. If these increases occur, the import substitution of maize, livestock, and other commodities would potentially rise, thus providing these countries with more growth opportunities in agriculture. These opportunities in turn will strengthen the ability of SADC to transform itself into a food-secure region.

The uniqueness of the southern Africa region in having a number of middle- and low-income countries in proximity to each other offers the region opportunities to foster such growth opportunities by taking advantage of complementarities between countries. South Africa is already the region's engine of growth, with 38 percent of its total population and more than 70 percent of its GDP. South Africa could influence growth in other countries through international trade, spillover effects, foreign direct investment, financial linkages, and overall business and consumer confidence. A growing South African economy can benefit low-income countries in the region through increased demand for their agricultural

\footnotetext{
${ }^{4}$ Lesotho, Mauritius, and Seychelles were not included in the study by Nin Pratt and Yu (2009) from which the productivity estimates were drawn.
} 
exports (Nin Pratt and Diao 2006). Unfortunately, as we have shown, few among the poorer countries in the region are poised to respond to any such increase in demand. Such readiness will depend heavily on the abilities of member states to increase productivity and tap domestic and regional market growth opportunities, including new burgeoning global markets in China and India, for example.

Table 2.2 Land and labor productivity levels and growth rates for the period 1961-2006

\begin{tabular}{|c|c|c|c|c|c|c|c|c|c|c|}
\hline \multirow[b]{3}{*}{ Country } & \multicolumn{5}{|c|}{ Land productivity } & \multicolumn{5}{|c|}{ Labor productivity } \\
\hline & \multicolumn{3}{|c|}{$\begin{array}{l}\text { Levels } \\
\text { (I\$/ha) }\end{array}$} & \multicolumn{2}{|c|}{$\begin{array}{c}\text { Annual growth } \\
(\%)\end{array}$} & \multicolumn{3}{|c|}{$\begin{array}{c}\text { Levels } \\
\text { (I\$/person) }\end{array}$} & \multicolumn{2}{|c|}{$\begin{array}{c}\text { Annual growth } \\
\text { (\%) }\end{array}$} \\
\hline & $\begin{array}{c}1961- \\
1970 \\
\end{array}$ & $\begin{array}{l}1971- \\
1980\end{array}$ & $\begin{array}{l}1991- \\
2006\end{array}$ & $\begin{array}{c}1965- \\
1975 \\
\end{array}$ & $\begin{array}{l}1975- \\
2006\end{array}$ & $\begin{array}{c}1961- \\
1970 \\
\end{array}$ & $\begin{array}{l}1971- \\
1980\end{array}$ & $\begin{array}{l}1991- \\
2006 \\
\end{array}$ & $\begin{array}{l}1965- \\
1975\end{array}$ & $\begin{array}{l}1975- \\
2006\end{array}$ \\
\hline Angola & 200 & 209 & 291 & 0.46 & 3.35 & 270 & 290 & 245 & 0.72 & -1.68 \\
\hline Botswana & 347 & 360 & 424 & 0.36 & 1.64 & 529 & 541 & 489 & 0.22 & -1.00 \\
\hline Congo, D. R. & 320 & 310 & 376 & -0.31 & 1.96 & 292 & 287 & 229 & -0.16 & -2.23 \\
\hline Lesotho & - & - & - & - & - & - & - & - & & - \\
\hline Madagascar & 532 & 538 & 571 & 0.10 & 0.59 & 433 & 441 & 354 & 0.19 & -2.19 \\
\hline Malawi & 419 & 465 & 537 & $1.06 \mathrm{k}$ & 1.46 & 245 & 272 & 275 & 1.06 & 0.11 \\
\hline Mauritius & - & - & - & - & - & - & - & - & - & - \\
\hline Mozambique & 279 & 303 & 268 & 0.83 & -1.20 & 173 & 184 & 153 & 0.62 & -1.77 \\
\hline Namibia & 421 & 477 & 393 & 1.26 & -1.92 & 1,162 & $\begin{array}{l}\text { 1,3 Celis } \\
21\end{array}$ & 1,026 & 1.29 & -2.49 \\
\hline Seychelles & - & - & - & - & - & - & - & - & - & - \\
\hline South Africa & 432 & 446 & 518 & 0.32 & 1.50 & 2,674 & 2,680 & 4,747 & 0.02 & 5.88 \\
\hline Swaziland & 809 & 769 & 934 & -0.51 & 1.96 & 1,271 & 1,285 & 1,511 & 0.11 & 1.63 \\
\hline Tanzania & 595 & 630 & 680 & 0.57 & 0.76 & 265 & 271 & 236 & 0.23 & -1.36 \\
\hline Zambia & 81 & 87 & 121 & 0.77 & 3.29 & 226 & 251 & 213 & 1.08 & -1.62 \\
\hline Zimbabwe & 399 & 426 & 425 & 0.65 & -0.04 & 471 & 524 & 398 & 1.07 & -2.73 \\
\hline Region & 403 & 418 & 461 & 0.38 & 0.99 & 667 & 695 & 823 & 0.41 & 1.70 \\
\hline
\end{tabular}

Source: Authors' calculations updated from Nin Pratt and Yu (2009).

Notes: I\$ = international dollars. The most recent year for which complete data were available is 2006 . The study by Nin Pratt and Yu (2009) excluded Lesotho, Mauritius, and Seychelles.

\section{Summary Conclusion}

The region of southern Africa is unique to the African continent because it comprises both low- and middle-income countries in close proximity to each other. Already an engine of growth, South Africa accounts for 38 percent of the region's total population and more than 70 percent of its GDP. Economic growth among the middle-income countries in the region can create opportunities for agricultural growth among the neighboring low-income countries - especially if the latter can exploit this potential through agricultural productivity growth and stronger market linkages.

In the meantime, the evidence of low productivity levels (by both total and partial measures) relative to what has been achieved under more ideal conditions and farming practices elsewhere in the world emphasizes the enormous potential for future growth. Additionally, since much of the productivity growth among poorer countries in the last two decades can be explained by efficiency gains, inducing technical change through $R \& D$ can be expected to result in much higher productivity growth rates. The extent of this potential, however, will depend on how well suitable technologies can be identified and targeted across a landscape characterized by varying patterns of agroecology and climate, population densities, and access to markets and services. We turn to this issue in the next section. 


\section{SPATIAL ANALYSIS OF AGRICULTURAL DEVELOPMENT POTENTIAL ${ }^{5}$}

The SADC region is characterized by a wide variation of underlying biophysical and socioeconomic conditions, which present challenges to policymakers in formulating well-targeted agricultural interventions. These conditions nonetheless also present an opportunity at the regional level since many countries share similar characteristics among these conditions. A detailed geographic information systems (GIS) analysis across the entire region can help delineate those geographic areas that are likely to be similar. Even more important, measuring the spatial dimension of an area's agricultural production potential (as derived from the underlying biophysical nature of the land and its suitability for agriculture) as well as its population density and market potential (as derived from the degree of access to major urban markets) can help determine the potential for agricultural productivity and commercialization. When these factors are aggregated at the regional level, the future growth potential can be assessed in a way that is cognizant of the underlying agroecological and socioeconomic constraints within and across member states in the SADC region.

To more explicitly explore the potential for agricultural productivity growth in the SADC region, we adopt the concept of development domains as described by Wood and Chamberlin (2003). The development domain concept focuses attention on identifying unique geographic areas that share similar endowments in biophysical and socioeconomic factors, which in turn help define the set of viable options for improved agricultural production and commercialization, such as low-input food crop production versus high-input commercial production systems. From a policy perspective, therefore, each domain would represent an area requiring similar interventions and development solutions. Drawing on past studies on the development domain concept, we use three principal characteristics that have been shown to matter the most: agricultural potential, population density, and market access (Pender et al. 2004; Benin, Ehui, and Pender 2003; Wood and Chamberlin 2003; Omamo et al. 2006).

\section{Defining Underlying Biophysical Constraints and Farming Systems}

The underlying agroecology (soils, topography) and climate (annual rainfall, temperatures) within and across countries in SADC affects the agronomic potential for crop production and the optimal types of farming systems, given that much of agriculture in the region is still rainfed and relies heavily on local soil fertility conditions. The length of growing period (LGP) is particularly useful for measuring how localized rainfall patterns influence crop production cycles and, thus, an area's agricultural potential (Voortman, Sonneveld, and Keyzer, 2003). The LGP measures the number of months per year in which rainfall exceeds evapotranspiration (that is, the sum of evaporation and plant transpiration), leaving sufficient excess water to support the growth of crops and pasture. Figure 3.1 shows the distribution of LGP across the SADC region.

\footnotetext{
${ }^{5}$ This section was authored by Liang You and Michael Johnson.
} 


\section{Figure 3.1 Length of growing period}
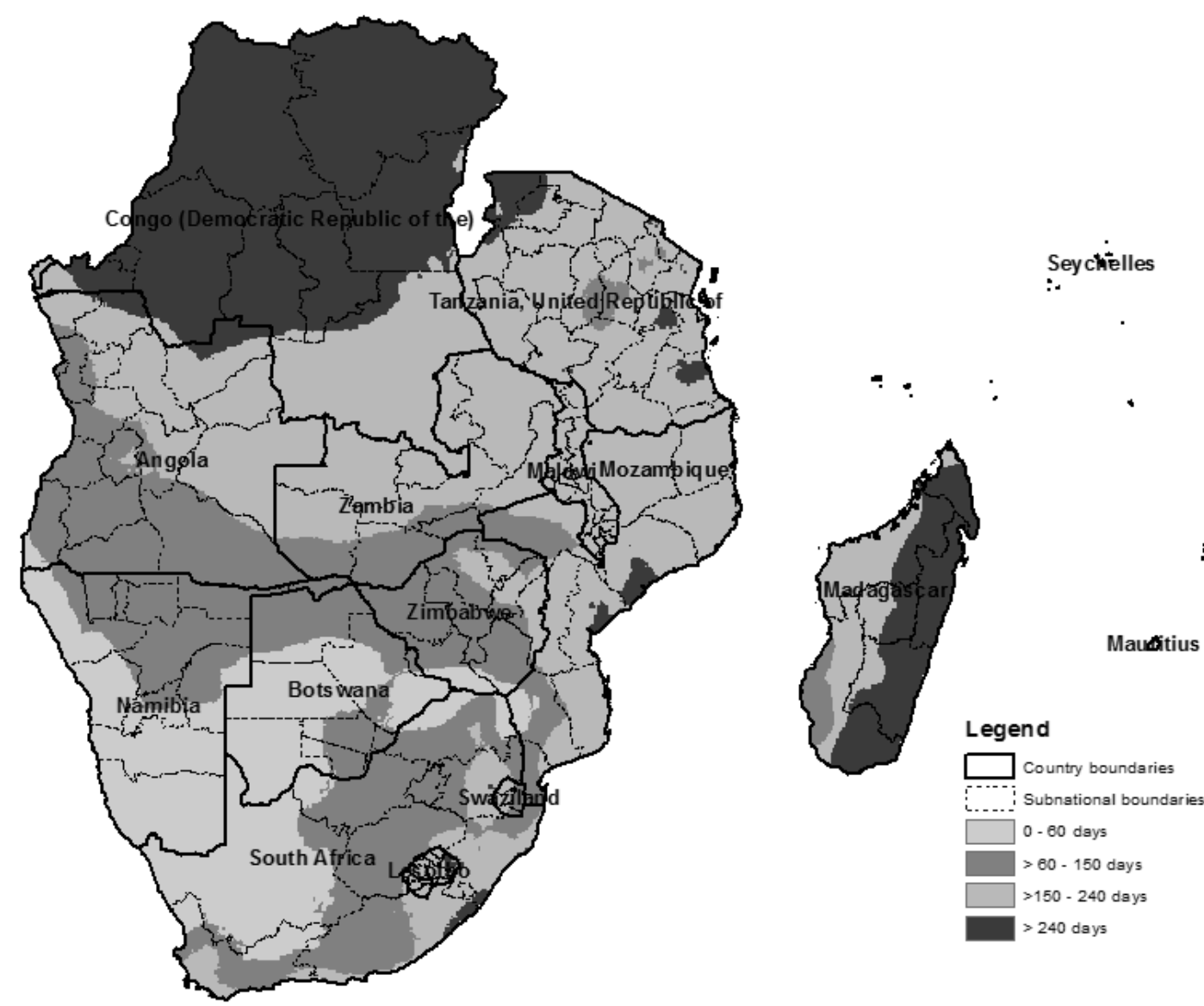

Source: Spatial analysis results.

There are at least four distinct bands of LGP in SADC: humid, greater than 240 days (to the north and mostly in the Democratic Republic of the Congo [DRC] and Madagascar); semihumid, 150 to 240 days (mostly in the central north regions, including much of Zambia, Malawi, Tanzania, and Mozambique); semiarid, 60 to 150 days (mostly in the central south regions, including large parts of Angola, South Africa, and Zimbabwe); and arid, less than 60 days (mostly in the desert areas of Botswana, Namibia, and South Africa).

In addition to rainfall, local soil conditions and temperature also affect an area's agricultural potential. Overlaying LGP with soil conditions, topography, and temperatures results in distinctive agroecological zones (AEZs) for the SADC region (Figure 3.2). Among the defined AEZs, the tropicwarm/semiarid and tropic - warm/subhumid zones dominate with respect to both the share of total area (42 percent, Table 3.1) and total population (40 percent, Table 3.2). These are zones that span multiple countries. 
Figure 3.2 Agroecological zones

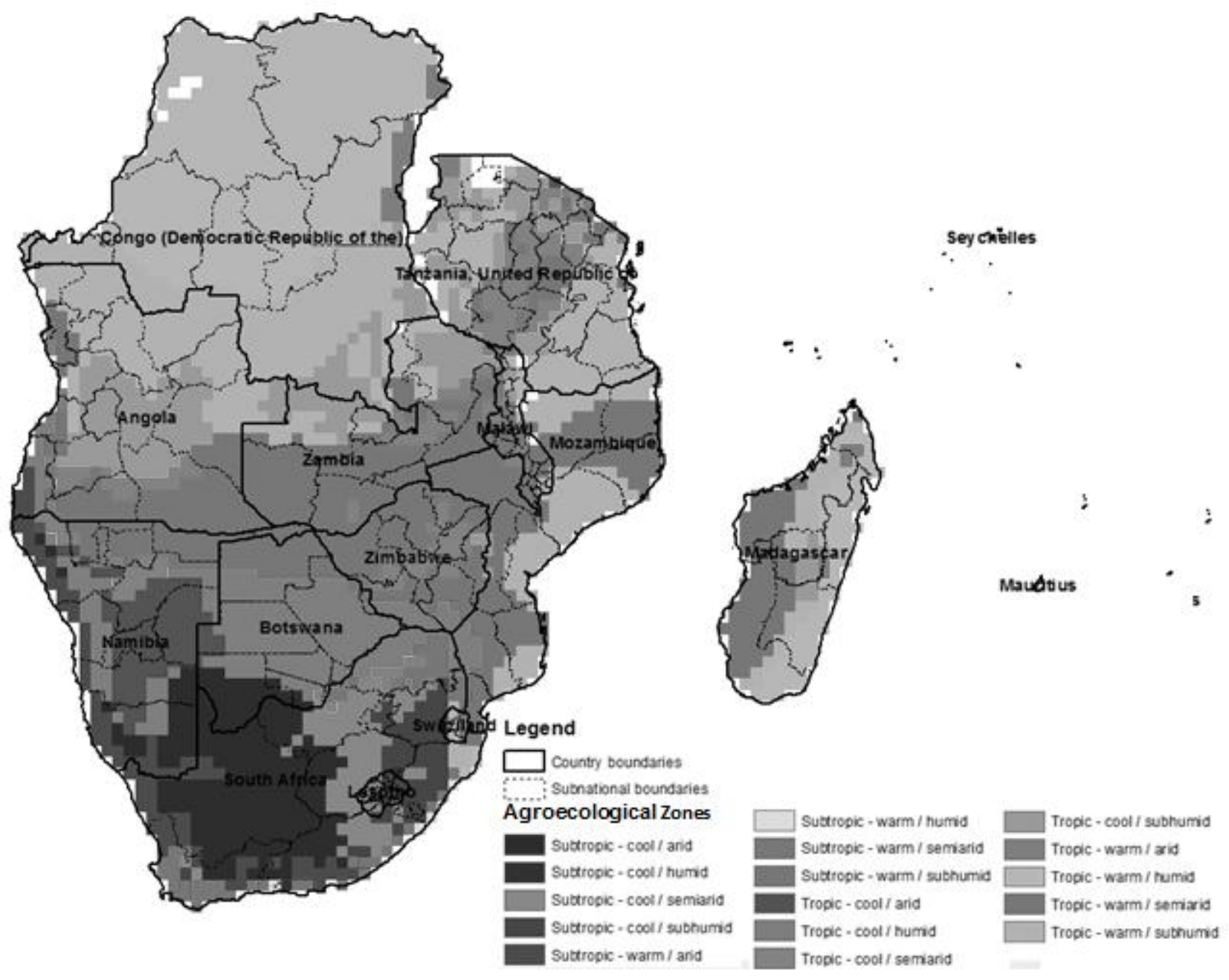

Source: Spatial analysis results.

Note: The Zambia map was taken from the country survey report. 
Table 3.1 Percent distribution of total area by agroecological zone and by SADC member state

\begin{tabular}{|c|c|c|c|c|c|c|c|c|c|c|c|c|c|c|c|c|}
\hline Agroecological zone & $\begin{array}{l}\frac{\pi}{0} \\
\frac{0}{2}\end{array}$ & 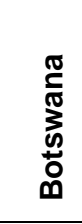 & 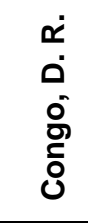 & 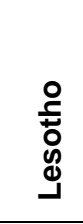 & 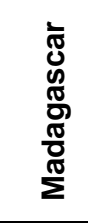 & $\frac{\sqrt[3]{3}}{\frac{\pi}{\pi}}$ & 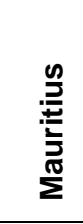 & $\begin{array}{l}\frac{0}{J} \\
\text { 홍 } \\
\text { 을 } \\
\frac{\mathbb{N}}{N} \\
\stackrel{N}{\Sigma}\end{array}$ & $\frac{\frac{\pi}{0}}{\frac{0}{\bar{N}}}$ & 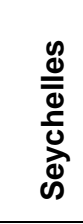 & 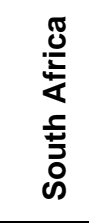 & 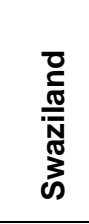 & 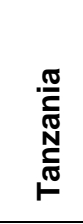 & $\begin{array}{l}\frac{\pi}{0} \\
\frac{0}{\mathbb{C}} \\
\text { N }\end{array}$ & $\begin{array}{l}0 \\
\frac{0}{3} \\
\frac{0}{\pi} \\
\frac{O}{E} \\
\stackrel{N}{N}\end{array}$ & $\begin{array}{l}\bar{\pi} \\
\text { 믐 }\end{array}$ \\
\hline Subtropic-warm/arid & 1.6 & - & - & - & - & - & - & - & 14.7 & - & 9.8 & - & - & - & - & 2.8 \\
\hline Subtropic_-warm/semiarid & - & - & - & - & - & - & - & 0.1 & - & - & 4.1 & - & - & - & 0.8 & 0.6 \\
\hline Subtropic-warm/subhumid & - & - & - & - & - & - & - & - & - & - & 3.1 & - & - & - & - & 0.4 \\
\hline Subtropic_-warm/humid & - & - & - & - & - & - & - & - & - & - & 0.6 & - & - & - & - & 0.1 \\
\hline Subtropic-cool/arid & - & 14.1 & - & - & - & - & - & - & 11.8 & - & 39.3 & - & - & - & - & 7.3 \\
\hline Subtropic-cool/semiarid & - & 0.2 & - & 39.9 & - & - & - & - & - & - & 17.9 & - & - & - & - & 2.6 \\
\hline Subtropic-cool/subhumid & - & - & - & 58.0 & - & - & - & - & - & - & 12.2 & 23.2 & - & - & - & 1.9 \\
\hline Subtropic-cool/humid & - & - & - & 2.1 & - & - & - & - & - & - & 0.4 & - & - & - & - & 0.1 \\
\hline Tropic-warm/arid & 4.2 & 64.4 & - & - & - & - & - & 3.4 & 19.5 & - & 4.9 & - & 0.3 & - & 11.1 & 7.6 \\
\hline Tropic-warm/semiarid & 24.2 & 17.5 & 0.3 & - & 39.7 & 59.0 & - & 58.7 & 17.1 & - & 4.5 & 29.0 & 11.7 & 56.9 & 65.5 & 22.2 \\
\hline Tropic-warm/subhumid & 37.8 & - & 23.2 & - & 18.3 & 18.9 & - & 36.5 & - & - & 1.1 & 47.8 & 45.3 & 14.8 & - & 19.6 \\
\hline Tropic-warm/humid & 0.1 & - & 69.1 & - & 33.5 & - & - & - & - & - & 0.5 & - & 0.7 & - & - & 17.8 \\
\hline Tropic-cool/arid & - & 3.3 & - & - & - & - & - & - & 30.5 & - & - & - & 0.3 & - & - & 2.8 \\
\hline Tropic-cool/semiarid & 4.9 & 0.5 & 0.3 & - & - & 15.0 & - & 0.6 & 6.3 & - & 1.6 & - & 17.3 & 9.3 & 21.0 & 4.8 \\
\hline Tropic-cool/subhumid & 27.2 & - & 4.7 & - & 5.9 & 7.1 & - & 0.6 & - & - & - & - & 22.8 & 19.0 & 1.7 & 8.5 \\
\hline Tropic-cool/humid & - & - & 2.4 & - & 2.7 & - & - & - & - & - & - & - & 1.6 & - & - & 0.8 \\
\hline \multicolumn{17}{|l|}{ Share of total SADC area } \\
\hline Total & 100 & 100 & 100 & 100 & 100 & 100 & - & 100 & 100 & - & 100 & 100 & 100 & 100 & 100 & 100 \\
\hline
\end{tabular}

Source: Spatial analysis results.

Note: $\quad \mathrm{SADC}=$ Southern Africa Development Community. 
Table 3.2 Distribution of population by agroecological zone, by country (thousands) and by total share (\%)

\begin{tabular}{|c|c|c|c|c|c|c|c|c|c|c|c|c|c|c|c|}
\hline Agroecological zone & $\frac{\pi}{\frac{\pi}{0}}$ & 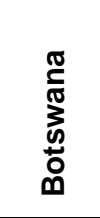 & $\begin{array}{l}\dot{0} \\
\dot{0} \\
0 \\
\dot{0} \\
0 \\
0\end{array}$ & 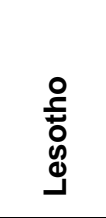 & $\begin{array}{l}\frac{1}{\pi} \\
\mathbb{O} \\
\mathbb{8} \\
\frac{\pi}{0} \\
\frac{\pi}{\pi} \\
\Sigma\end{array}$ & $\frac{\bar{N}}{\frac{\Sigma}{\pi}}$ & 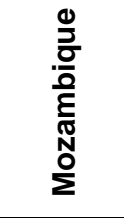 & $\begin{array}{l}\frac{\pi}{0} \\
\frac{\pi}{\bar{N}} \\
\frac{\pi}{Z}\end{array}$ & 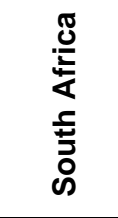 & 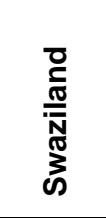 & 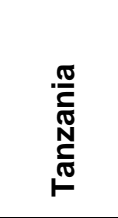 & $\begin{array}{l}\frac{\pi}{0} \\
\frac{0}{E} \\
\text { N }\end{array}$ & 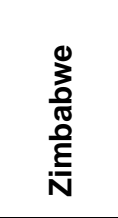 & 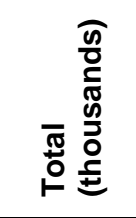 & 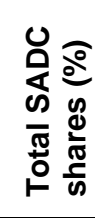 \\
\hline Subtropic-warm/arid & 24 & - & - & - & - & - & - & 14 & 1,969 & - & - & - & - & 2,008 & 1 \\
\hline Subtropic-warm/semiarid & - & - & - & - & - & - & 9 & - & 1,488 & - & - & - & 72 & 1,569 & 1 \\
\hline Subtropic-warm/subhumid & - & - & - & - & - & - & - & - & 6,477 & - & - & - & - & 6,477 & 3 \\
\hline Subtropic-warm/humid & - & - & - & - & - & - & - & - & 758 & - & - & - & - & 758 & 0 \\
\hline Subtropic-cool/arid & - & 88 & - & - & - & - & - & 13 & 2,466 & - & - & - & - & 2,567 & 1 \\
\hline Subtropic-cool/semiarid & - & 47 & - & 1,489 & - & - & - & - & 13,635 & - & - & - & - & 15,171 & 6 \\
\hline Subtropic-cool/subhumid & - & - & - & 892 & - & - & - & - & 16,245 & 377 & - & - & - & 17,515 & 7 \\
\hline Subtropic-cool/humid & - & - & - & 20 & - & - & - & - & 445 & - & - & - & - & 465 & 0 \\
\hline Tropic-warm/arid & 1,865 & 1,391 & - & - & - & - & 78 & 67 & 1,492 & - & 38 & - & 513 & 5,445 & 2 \\
\hline Tropic-warm/semiarid & 856 & 190 & 39 & - & 2,858 & 10,192 & 11,614 & 1,201 & 4,564 & 256 & 5,368 & 7,403 & 7,849 & 52,391 & 22 \\
\hline Tropic_-warm/subhumid & 4,045 & - & 10,561 & - & 2,989 & 2,027 & 8,333 & - & 948 & 721 & 14,095 & 1,140 & - & 44,860 & 18 \\
\hline Tropic-warm/humid & 6 & - & 32,455 & - & 6,410 & - & - & - & 1,235 & - & 110 & - & - & 40,216 & 17 \\
\hline Tropic-cool/arid & - & 5 & - & - & - & - & - & 463 & - & - & 19 & - & - & 487 & 0 \\
\hline Tropic_-cool/semiarid & 895 & 135 & 38 & - & - & 1,336 & 438 & 84 & 899 & - & 5,312 & 881 & 6,788 & 16,806 & 7 \\
\hline Tropic-cool/subhumid & 4,492 & - & 3,347 & - & 5,389 & 290 & 153 & - & - & - & 8,505 & 2,851 & 263 & 25,291 & 10 \\
\hline Tropic-cool/humid & - & - & 7,838 & - & 493 & - & - & - & - & - & 2,177 & - & - & 10,507 & 4 \\
\hline Total (thousands) & 12,184 & 1,857 & 54,278 & 2,401 & 18,140 & 13,846 & 20,625 & 1,842 & 52,618 & 1,355 & 35,625 & 12,275 & 15,486 & 242,532 & 100 \\
\hline Total SADC share (\%) & 5 & 1 & 22 & 1 & 7 & 6 & 9 & 1 & 22 & 1 & 15 & 5 & 6 & 100 & \\
\hline
\end{tabular}

Source: Spatial analysis results.

Note: $\quad \mathrm{SADC}=$ Southern Africa Development Community. 
As Figure 3.2 illustrates, there are also some AEZs that are dominated by only a few countries. For example, the DRC is mostly covered by the tropic — warm/humid and tropic - warm/subhumid zones, which together represent about 35 percent of the total area and total population in SADC. South Africa, Lesotho, and Swaziland take up much of the subtropic - cool zones, accounting for 15 percent of total area and 19 percent of total population in SADC.

LGP and AEZs ultimately influence the types of cropping and livestock systems that evolved in the region over time. Drawing on the work done by Dixon and Gibbon (2001), who mapped out dominant farming systems in the region based on LGP and AEZs, we illustrate this influence in Figure 3.3. The map shows 14 distinctive farming systems in the SADC region. In the semihumid and humid zones that dominate the northern part of the region, particularly DRC, and in Madagascar, forest-based farming systems are prevalent. These typically translate into mixed cereal-tree crop farming systems.

\section{Figure 3.3 Dominant farming systems in the SADC region}

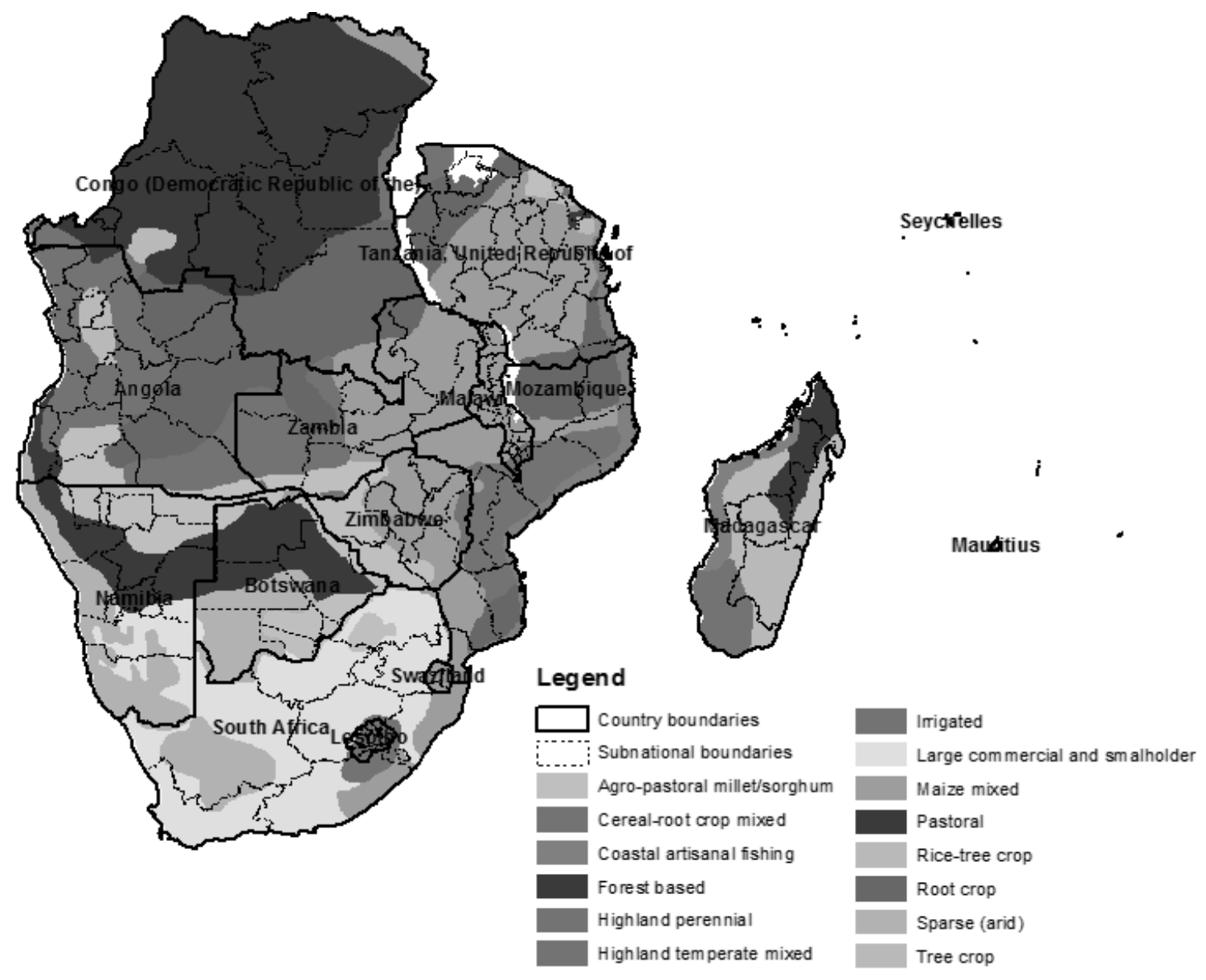

Source: Spatial analysis results based on Dixon and Gibbon (2001).

Note: $\quad \mathrm{SADC}=$ Southern Africa Development Community.

In the semihumid areas, including large areas of northern Angola, Zambia, and Mozambique, cassava and other root crops dominate the landscape. Mixed farming systems, including crop-livestock and cereal-root crop systems, are also very common within these semihumid areas. Farming systems in the humid and semihumid areas face considerable challenges, including soil erosion, weeds, pests, and diseases. While the risk of crop failure due to drought seems moderate in these areas, there are limited technological advances that would allow for increased production of the crops that dominate in these 
systems. In addition to these biotic constraints, high heat and humidity easily cause rot during transportation without proper storage or postharvest processing technologies. Increasing agricultural production without concurrent infrastructure development can thus lead to severe inefficiencies.

In the semiarid and dry subhumid zones of northern South Africa and southern Namibia, the dominant agriculture is mixed cereal-livestock systems. Within these systems - in which are found both smallholdings and large commercial farms - maize predominates in the north and east, while sorghum and millet are most important in the west. An estimated 11 million head of cattle, as well as large numbers of small ruminants, are found in these zones. The level of crop-livestock integration is relatively limited (Dixon and Gibbon 2001). Smallholders within these areas are particularly vulnerable to rainfall patterns, since soils tend to be poor and drought is frequent. Dependence on off-farm employment is very high in these areas.

In much of the region rainfall is limited; where it is sufficient to sustain arable agriculture, farming systems are dominated by traditional coarse grains and cereals, crop-livestock systems, and cereal-root crop systems. Grains like millet and cowpeas are important crops because they can thrive on soils of relatively low fertility. The crops grown are mainly annual, and systems are determined by rainfall distribution (generally one or two wet seasons per year), the water-holding capacity of the soil, and the topographic position of the area.

The semiarid zones in southern Africa are particularly vulnerable to greater climatic variability, including frequent droughts and periodic flooding. The droughts here result in crop failure, declining terms of trade among livestock and cereal producers (cereal prices rise while livestock prices decline), and widespread hunger, which leads to famine at the extreme. The availability of cultivable land in the more arid zone has been severely restricted by land degradation, increasing desertification, and limited water availability. Declining soil fertility, together with widespread deforestation and overgrazing, has reduced arable land to precarious levels in some areas. Global climate change is likely to be the most damaging to those farming systems in arid and semiarid zones. These semiarid and arid regions are also vulnerable to an increased likelihood of conflict between farmers as availability of land becomes more limited.

This representation of these farming systems is very aggregated and mostly based on large areas characterized by similar agroecological and climatic factors. Aside from the large commercial farming areas in South Africa and some export crop plantations (such as those for tobacco, sugar, and cotton) in other countries, most are traditional smallholder production systems. Yet we know there are significant commercial farming activities, such as for ranching, horticulture, other cash crops, and even food staples, that agglomerate near large urban markets and along major transportation corridors in the region. Therefore we expect the extent of intensification or commercialization to be quite high in some of these areas, stressing the importance of considering socioeconomic factors in assessing agricultural growth potential.

\section{Incorporating Socioeconomic Considerations}

Agricultural potential represents only an area's absolute advantage for agricultural production.

Socioeconomic factors such as degree of access to markets and population densities translate this absolute advantage into comparative advantage. Population density, through its effect on local land-to-labor ratios, influences the comparative advantage of labor-intensive production. Boserup's (1965) theory of induced innovation put the land-to-labor ratio as the core parameter in determining the evolution of farming systems in terms of land management and production technologies. Simply stated, holding other factors constant, farmers in areas of high population density are more likely to adopt intensive farming systems than those in areas of low density. At the same time, high land-to-labor ratios in areas with poor access to markets and low agricultural potential endowments may encourage labor-intensive but low-external-input agriculture production strategies. All three factors together affect the profitability of different commodities, production technologies and priorities, and land management practices (Pender et al. 2004). 
The intersection of different levels of the biophysical measure (agricultural potential) with different levels of the socioeconomic measure (population density and market access) defines distinctive development domains. Different domains have different influences on the profitability of different types of agricultural economic activities: choice of crops and livestock products, production technologies and priorities, and land management practices - for example, mixed versus specialized, degree of intensification, and modern input use. While the domains can be mapped out with GIS tools, the main problem with such characterization is the identification of thresholds distinguishing between fundamentally different levels of a given factor (say, high versus low market access). These have potentially different meanings for different crops or livestock systems, for example. Another problem is the extreme variation in both biophysical and socioeconomic conditions across space, which can result in maps that are difficult to read. In this study, therefore, we avoid explicitly mapping out domains that include all three factors - agricultural potential, population density, and market access. Instead, we present each of the factors separately, or combine two at a time, for discussion.

Figure 3.4 presents the spatial distribution of population density and degree of market access. A glance at both maps makes it quite evident there is some positive correlation between the two, with areas of high population density also being in or very close to urban centers. Only a few areas with high population densities are far from urban centers, evident in countries such as Madagascar, Mozambique, and DRC. Often, high population densities are found in areas with high agricultural potential as well as better access to markets. However, the reverse is not true, as is evident in Table 3.3, which compares the agricultural suitability of areas with their population densities. Almost half (at least 45 percent) of the total SADC area falls into the more suitable areas for agriculture. Of this area, almost 60 percent is characterized by low population densities. Only 7 percent is in highly dense areas-such as a number of areas in Malawi and northern Tanzania. These are areas that are more likely to practice intensive farming systems, given such severe land constraints. But also critical to this decision is the degree of market access, which affects the profitability for intensification.

Figure 3.4 Population density and degree of market access

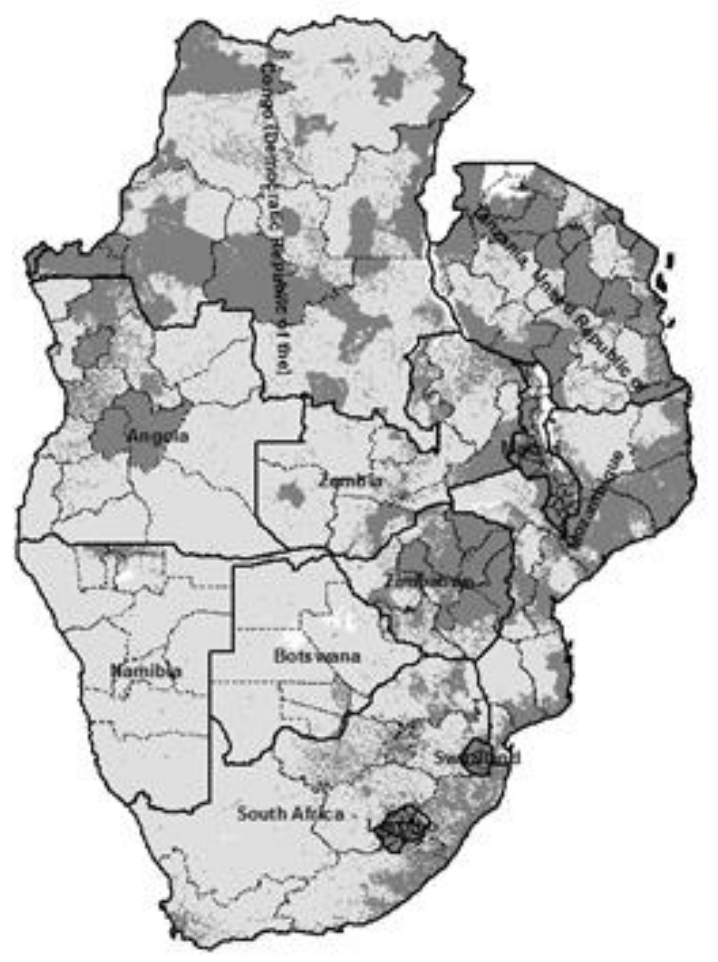

\section{Population density}

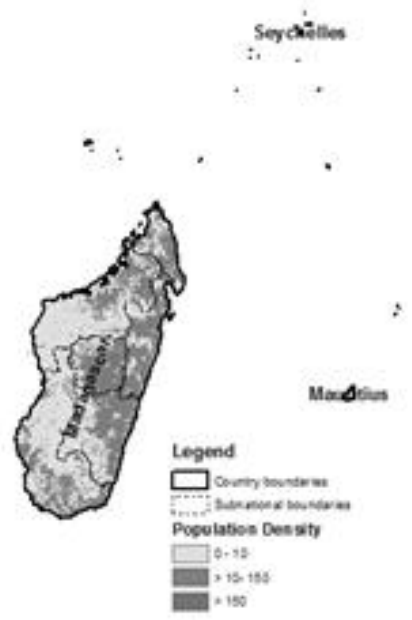


Figure 3.4 Continued

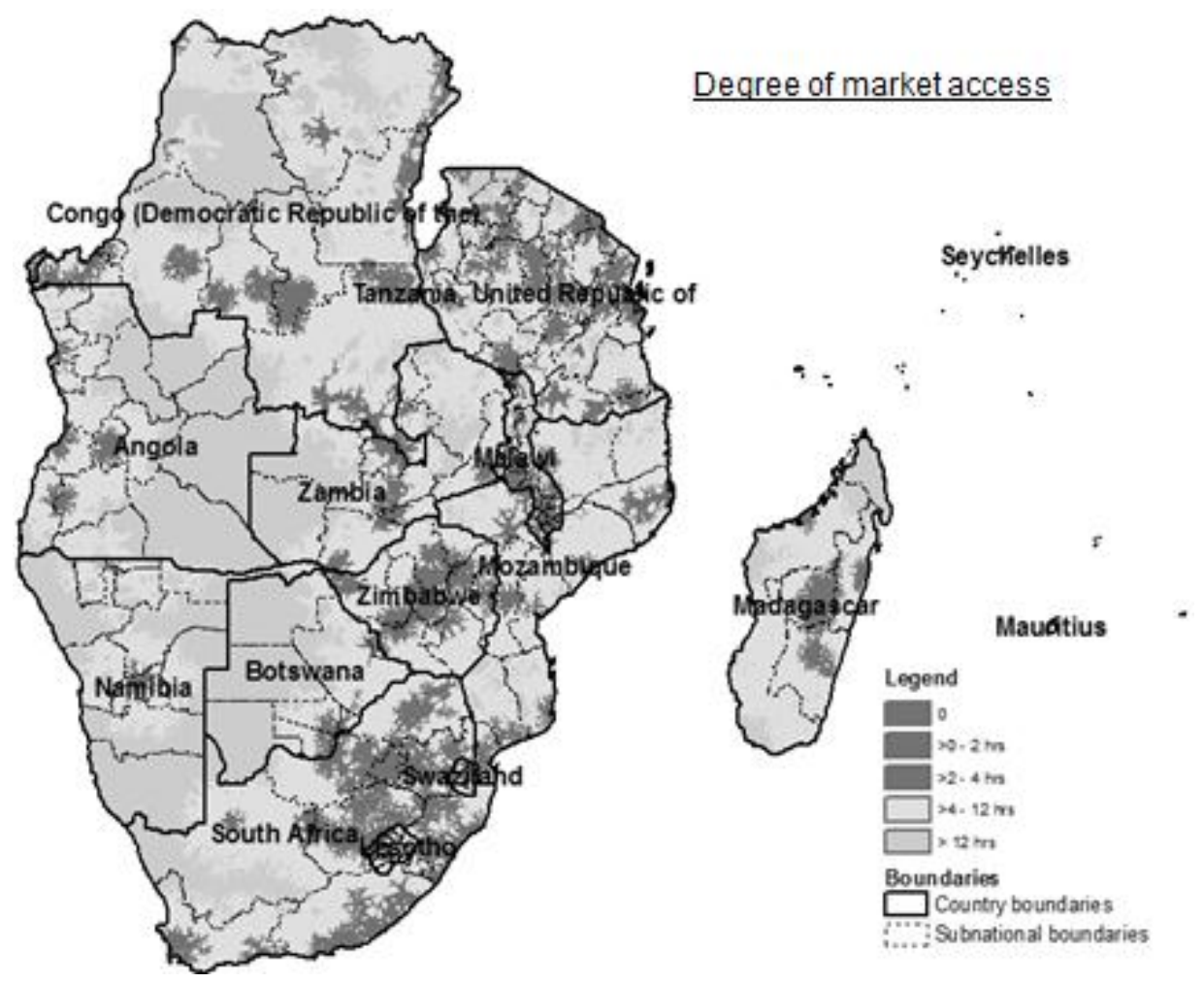

Source: Spatial analysis results.

Table 3.3 Agricultural suitability and population density

\begin{tabular}{|c|c|c|c|c|c|}
\hline \multicolumn{6}{|c|}{ Population density (persons per square kilometer) } \\
\hline Suitability & Urban & $>150(\mathrm{H})$ & $>10-150(\mathrm{M})$ & $\leq 10(\mathrm{~L})$ & Total \\
\hline & \multicolumn{5}{|c|}{ (Square kilometer) } \\
\hline Very suitable $(\mathrm{H})$ & 12,018 & 254,855 & $1,233,998$ & $2,161,284$ & $3,662,156$ \\
\hline Suitable (M) & 17,126 & 264,768 & $1,355,341$ & $2,433,393$ & $4,070,628$ \\
\hline Not suitable (L) & 1,826 & 19,033 & 42,559 & 360,569 & 423,986 \\
\hline \multirow[t]{2}{*}{ Total } & 30,969 & 538,657 & $2,631,897$ & $4,955,247$ & $8,156,770$ \\
\hline & \multicolumn{5}{|c|}{ (\%) } \\
\hline Very suitable $(\mathrm{H})$ & 0.33 & 6.96 & 33.70 & 59.02 & 44.9 \\
\hline Suitable (M) & 0.42 & 6.50 & 33.30 & 59.78 & 49.9 \\
\hline Not suitable (L) & 0.43 & 4.49 & 10.04 & 85.04 & 5.2 \\
\hline Total & 0.38 & 6.60 & 32.27 & 60.75 & 100 \\
\hline
\end{tabular}

Source: Spatial analysis results.

Notes: $\mathrm{H}=$ high, $\mathrm{M}=$ medium, $\mathrm{L}=$ low.

The degree-of-market-access factor uses market locations (size and potential to be affected by urbanization, globalization, and regional integration) and access (affected both by physical barriers such as distance and institutional barriers) to identify market potential for agricultural products. Here the focus is on agglomeration effects (or development of market clusters) surrounding higher-density areas or near major urban centers. A close-up example for Malawi is shown in Figure 3.5. Here we expect the kinds of commodities grown in proximity to more sophisticated market clusters (for example, near major cities) to be higher-value commodities, such as horticulture, poultry, and export crops, in addition to popular staples. Such areas will also often have stronger links with regional and international markets. 
Figure 3.5 Degree of market access: Example of Malawi

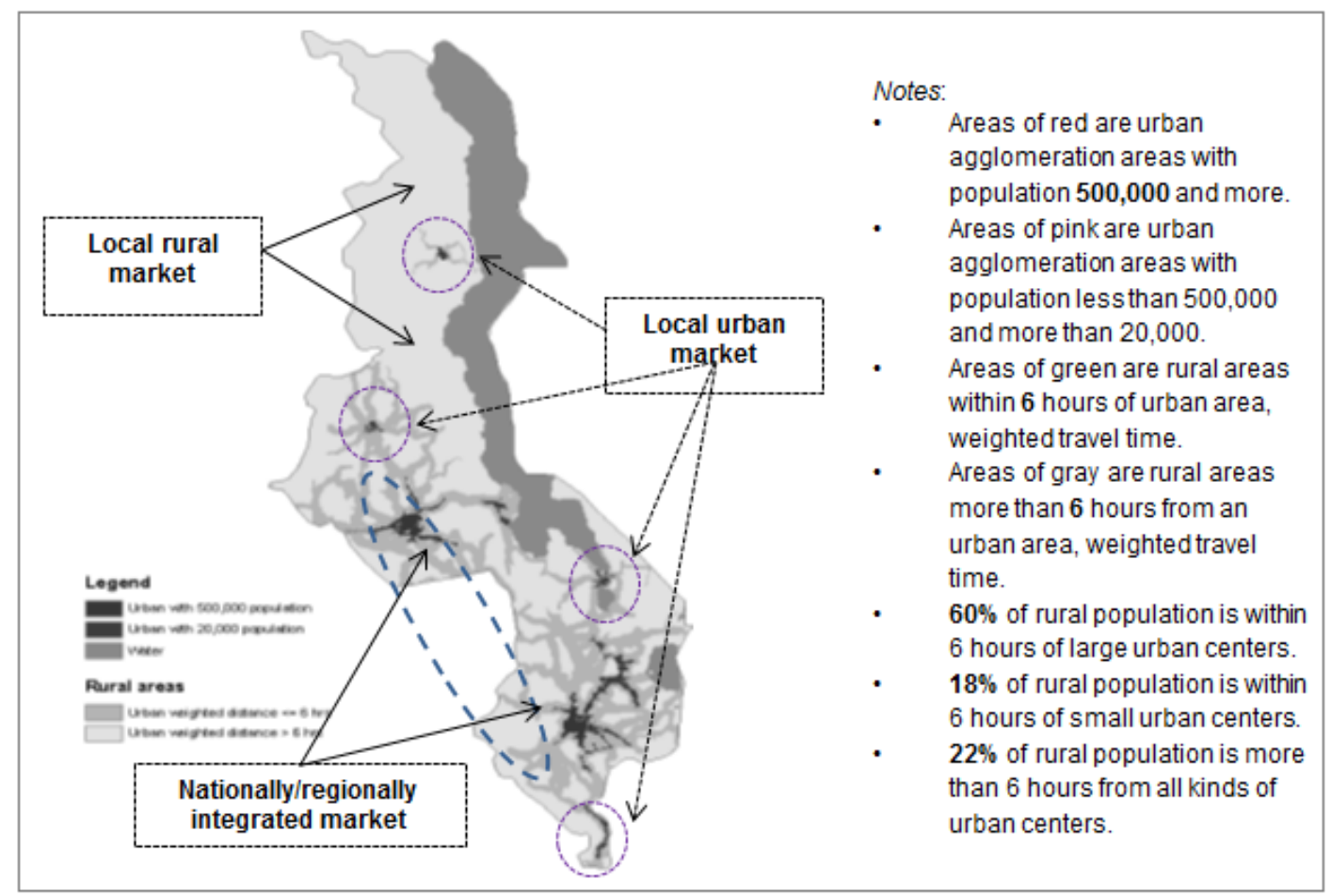

Source: Spatial analysis results.

Table 3.4 provides summary statistics of the degree of market access in the SADC region and across member countries based on these criteria (excluding Mauritius and Seychelles, for which there were no data available at the time of the analysis). On average, 4 percent of the total area in SADC is in areas that have 0 to 2 hours' travel time to a market, which are really urban and peri-urban areas (the orange and red areas in the top panel of Figure 3.4). Large portions (about 85 percent) of the region take more than 4 hours' travel time. Where there is good infrastructure, large areas are covered in less than 4 hours (for example, Zimbabwe, South Africa, Swaziland, Lesotho, and Malawi).

Table 3.4 Areas of varying weighted travel time to markets in SADC countries (\% of total area)

\begin{tabular}{|c|c|c|c|c|c|c|}
\hline Country & $<2$ hours & 2-4 hours & 4-8 hours & 8-12 hours & $>12$ hours & Total \\
\hline Angola & $1 \%$ & $4 \%$ & $16 \%$ & $18 \%$ & $60 \%$ & $13 \%$ \\
\hline Botswana & $1 \%$ & $4 \%$ & $16 \%$ & $14 \%$ & $65 \%$ & $6 \%$ \\
\hline Congo, D. R. & $3 \%$ & $10 \%$ & $28 \%$ & $28 \%$ & $31 \%$ & $24 \%$ \\
\hline Lesotho & $14 \%$ & $16 \%$ & $23 \%$ & $28 \%$ & $19 \%$ & $0 \%$ \\
\hline Madagascar & $4 \%$ & $10 \%$ & $30 \%$ & $35 \%$ & $21 \%$ & $6 \%$ \\
\hline Malawi & $18 \%$ & $33 \%$ & $28 \%$ & $6 \%$ & $14 \%$ & $1 \%$ \\
\hline Mozambique & $3 \%$ & $11 \%$ & $42 \%$ & $33 \%$ & $11 \%$ & $8 \%$ \\
\hline Namibia & $0 \%$ & $2 \%$ & $11 \%$ & $24 \%$ & $63 \%$ & $8 \%$ \\
\hline South Africa & $9 \%$ & $21 \%$ & $37 \%$ & $19 \%$ & $14 \%$ & $12 \%$ \\
\hline Swaziland & $18 \%$ & $46 \%$ & $36 \%$ & $0 \%$ & $0 \%$ & $0 \%$ \\
\hline Tanzania & $8 \%$ & $23 \%$ & $39 \%$ & $17 \%$ & $13 \%$ & $10 \%$ \\
\hline Zambia & $3 \%$ & $6 \%$ & $24 \%$ & $24 \%$ & $42 \%$ & $8 \%$ \\
\hline Zimbabwe & $11 \%$ & $24 \%$ & $46 \%$ & $17 \%$ & $2 \%$ & $4 \%$ \\
\hline Total & $4 \%$ & $11 \%$ & $28 \%$ & $23 \%$ & $33 \%$ & $100 \%$ \\
\hline
\end{tabular}

Source: Spatial analysis results.

Notes: Mauritius and Seychelles were excluded due to lack of data at the time of the analysis. SADC $=$ Southern Africa Development Community. 


\section{Assessing Yield Growth Potential}

Finally, a key component of the spatial analysis is to determine the extent to which there is potential for yield growth in the SADC region. To accomplish this, we use the SPAM, which is so far developed only for the crops subsector. The model attempts to make plausible allocations of land for crop production by dividing large reporting units such as a country or state into smaller spatial units organized as cells of a regularly spaced grid, or pixels. SPAM generates highly disaggregated, crop-specific production data by a triangulation of any and all relevant background and partial information that affects the performance of agricultural crop production systems. Such disaggregated results allow us to do analysis on diverse geographic scales at the level of agricultural potential zones and market potential zones. Details of the methods used to define both agricultural development zones and market access zones are discussed briefly in Appendix D. Here we focus on the results.

From the SPAM analysis, potential achievable yields are estimated for selected crops on which sufficient data were available based on the underlying agricultural potential characteristics (biophysical factors). These were then aggregated to the national and regional levels to compare with current actual yields and provide yield gap estimates at this high level of aggregation. In essence, such yield gap estimates are much lower than a yield potential under ideal conditions only, such as in areas with high agricultural potential and high input use. Here, yield potential is influenced by each country's own relative share of high versus low agricultural potential areas as calculated from production estimates at very small units of analysis (at pixel level), which are determined by the underlying agronomic and socioeconomic environment at each location before aggregating to national levels.

Average yield gaps at the regional level - the difference between current actual and potential yields - are presented Figure 3.6. The results show that there are sufficiently large yield gaps in the region, between 30 and 100 percent. This is not the same as a yield gap showing the difference between actual yield and a maximum achievable yield derived from on-farm trials (as often found in the literature), but an average across both high- and low-agricultural-potential areas in the region. The average yield gaps shown here, therefore, may seem quite low compared with some estimates in the literature (Table 3.5). Adaptive research and development (R\&D) and complementary investments, including extension and improving access to input and output markets, could easily help close these gaps by widening diffusion of the technologies. With new $R \& D$, average yields could rise even further in decades to come.

\section{Figure 3.6 Current yield gaps for selected crops in the SADC region}

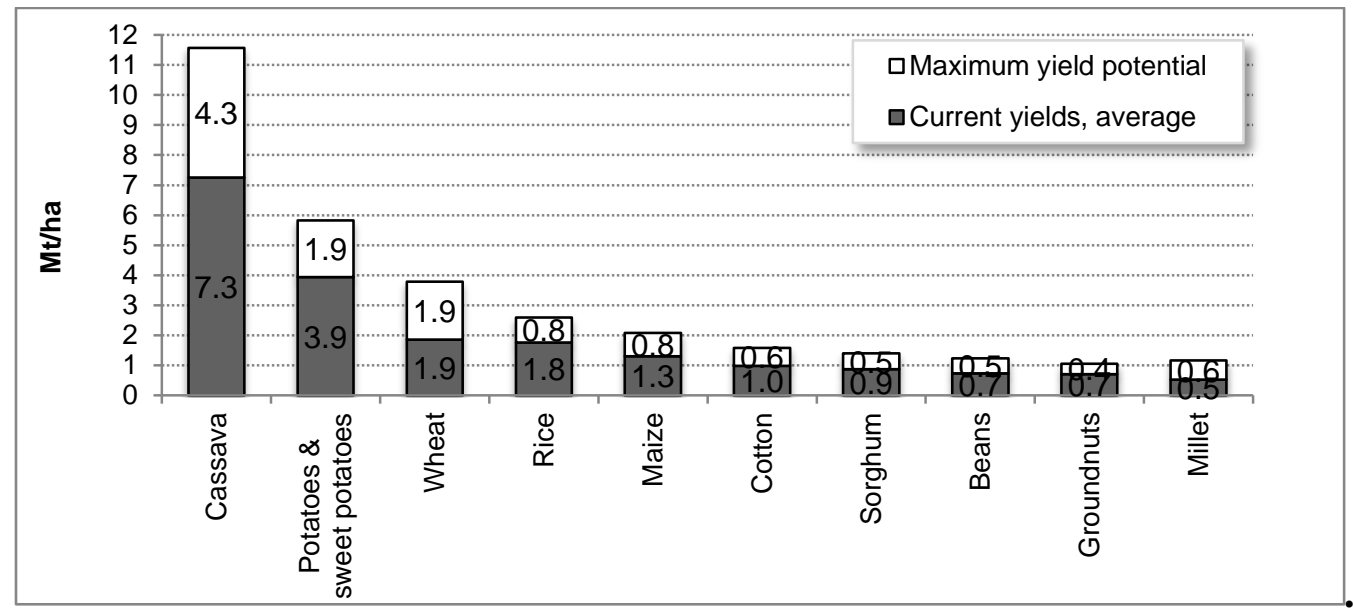

Sources: Potential yields were calculated using data from Fischer and others (2002). Current yields were calculated using spatial analysis results and FAO (2010).

Notes: $\quad \mathrm{SADC}=$ Southern Africa Development Community. Mt $/ \mathrm{ha}=$ metric tons per hectare. Yields represent simple averages of national mean yields among all member states based on FAO data. Potential yields are averaged across the agroecological zones and farming systems among all SADC member states. Therefore, they do not represent the maximum achievable yields. 
Table 3.5 Selected examples of potential yield gains from improved crop technologies in the SADC region

\begin{tabular}{|c|c|c|c|c|c|c|}
\hline Crop & $\begin{array}{l}\text { Without } \\
\text { technology } \\
\text { (kg/ha) }\end{array}$ & $\begin{array}{l}\text { With } \\
\text { technology } \\
\text { (kg/ha) }\end{array}$ & $\begin{array}{l}\text { Yield gain (ratio of } \\
\text { with/without) }\end{array}$ & Type of technology & Country & Source \\
\hline \multicolumn{7}{|l|}{ Maize } \\
\hline & 1.34 & 3.1 & 2.33 & Hybrid + 92-40-0 NPK & Malawi & Benson 1997 \\
\hline & 1.34 & 2.2 & 1.68 & Hybrid + 35-0-0 NPK & Malawi & Benson 1997 \\
\hline & 1.34 & 2.8 & 2.10 & Hybrid + 35-10-0 NPK & Malawi & Benson 1997 \\
\hline & 1.34 & 3.1 & 2.33 & Hybrid + 69-21-0 NPK & Malawi & Benson 1997 \\
\hline & 1.34 & 3.2 & 2.37 & Hybrid + 92-21-0 NPK & Malawi & Benson 1997 \\
\hline & .879 & 1.0 & 1.22 & Local seed + fertilizer & Zambia & Celis et al. 1991 \\
\hline & .879 & 2.4 & 2.80 & Hybrid seed + fertilizer & Zambia & Celis et al. 1991 \\
\hline & 2.0 & 2.5 & 1.25 & Fertilizer & Tanzania & Nkonya, Schroeder, and Norman 1997 \\
\hline & 2.0 & 2.8 & 1.40 & Hybrid seed & Tanzania & Nkonya, Schroeder, and Norman 1997 \\
\hline & 2.0 & 3.9 & 1.95 & Hybrid seed + fertilizer & Tanzania & Nkonya, Schroeder, and Norman 1997 \\
\hline \multicolumn{7}{|c|}{ Sorghum } \\
\hline & 1.5 & 2.5 & 1.67 & Fertilizer & Zambia & Stringfellow 1997 \\
\hline & 1.5 & 2.16 & 1.44 & Hybrid seed & Zimbabwe & \\
\hline & 1.2 & 1.6 & 1.33 & Hybrid seed & Zimbabwe & Anandajayasekeram et al. 1995 \\
\hline & 1.9 & 3.0 & 1.58 & Hybrid seed & Zimbabwe & \\
\hline \multicolumn{7}{|c|}{ Groundnuts } \\
\hline \multirow[t]{8}{*}{$\underline{\text { Cotton }}$} & .825 & 2.3 & 2.79 & Fertilizer & Zimbabwe & Keyser 2002 \\
\hline & .750 & 1.4 & 1.87 & Fertilizer & Mozambique & Geurts 1997 \\
\hline & 1.1 & 1.7 & 1.55 & Fertilizer & Mozambique & Geurts 1997 \\
\hline & 1.2 & 1.7 & 1.36 & Fertilizer & Mozambique & Geurts 1997 \\
\hline & 1.4 & 2.4 & 1.71 & Fertilizer & Mozambique & Geurts 1997 \\
\hline & 1.4 & 3.2 & 2.24 & Fertilizer & Mozambique & Geurts 1997 \\
\hline & 1.5 & 2.2 & 1.50 & Fertilizer & Mozambique & Geurts 1997 \\
\hline & 1.2 & 1.9 & 1.58 & Fertilizer & Zimbabwe & Keyser 2002 \\
\hline \multicolumn{7}{|c|}{ Soybeans } \\
\hline \multirow{3}{*}{ Tobacc } & 1.0 & 2.1 & 2.10 & Fertilizer & Zimbabwe & Keyser 2002 \\
\hline & & & & & & \\
\hline & .800 & 1.5 & 1.88 & Fertilizer & Zimbabwe & Keyser 2002 \\
\hline
\end{tabular}

Source: Adapted from Yanggen et al (1998) and compiled by authors.

Notes: $\quad \mathrm{SADC}=$ Southern Africa Development Community. NPK = nitrogen, phosphorus, potassium; $\mathrm{kg} / \mathrm{ha}=$ kilogram per hectare.. 


\section{Summary Conclusion}

While the economic analysis in this study provides quantifiable criteria for increased public investment priorities in the agriculture sector, the complementary role of the spatial analysis is to provide a more visually intuitive basis for where such cross-cutting investments may be most appropriately targeted, that is, in different agricultural development domains. Some agricultural development domains may cross national boundaries while others will manifest as distinct areas within individual countries. The key recognition is that each unique domain is defined in the same way across the region-offering ample opportunity for targeting appropriate $\mathrm{R} \& \mathrm{D}$ strategies and other development interventions with potential benefits across national boundaries sharing similar development domains. At the same time, development domains that dominate in a few countries offer opportunities for these countries to enjoy a greater comparative advantage in specialized commodities for trade in the region.

Overall, and across the different domains, a yield gap analysis shows sufficient potential for future yield growth across countries in the SADC region - showing that, on average, most commodities are still producing below their production possibilities frontier. The potential to realize this growth exists, considering that 45 percent of the region's rural population lives in areas of high agricultural potential, and among these, 40 percent are in areas of medium to high population density. These are areas most conducive to policy interventions, since resource bases tend to be more intact and productivity often responds strongly to the enhanced market opportunities and input availability brought about by improvements in market access. They are also found in several countries and spanning national borders, pointing to a high potential for shared $R \& D$ and technology priorities.

However, because there is sufficient variation across distinctive domains, and within and across countries, shared R\&D will require targeted interventions. How this variation affects the potential for R\&D spillovers, overall changes in sector growth, and improved welfare outcomes (food security and poverty reduction) at the national and regional level becomes especially relevant in narrowing the set of commodities most suitable for targeting regional R\&D investments. We turn to this question in the next two sections. 


\section{ASSESSING THE POTENTIAL FOR AGRICULTURAL RESEARCH AND DEVELOPMENT SPILLOVERS ${ }^{6}$}

Using information generated from the spatial analysis in the previous section, we assess the spillover potential of commodity-specific technologies among selected crops and livestock for which sufficient data were available. ${ }^{7}$ The underlying assumption is that agricultural R\&D outputs and technologies are likely to be suitable and adaptable across countries where there are sufficient similarities in agroecology, farming systems, and other socioeconomic factors (for example, population density and access to input markets), as well as sufficient capacities for adaptive research and extension that enhance the likelihood of adoption. We construct a spillover matrix based on some of these key indicators, which will then be used to project ex ante economic impacts derived from spillovers using the economic multimarket model in the next section. We begin by providing a rationale for incorporating the potential for R\&D spillovers in our overall analysis.

\section{Importance of Research Spillovers}

The challenge of raising productivity, especially among food staple crops, in the SADC region is substantial due to increased frequency of droughts in the region, poor access to markets, and a general neglect of public funding for agricultural $R \& D$, especially during the past decade. In fact, spending for agricultural R\&D in Africa south of the Sahara as a whole slowed significantly throughout the 1990s compared with the 1980s (Beintema and Stads 2006). With drastically reduced funding for R\&D, local research infrastructure and capacity have eroded over time, contributing to higher marginal costs for undertaking even the most basic of research. There is therefore a need to find more cost-effective and sustainable ways to rebuild national agricultural R\&D systems among SADC countries.

A regional approach that takes advantage of similar biophysical and socioeconomic environments across national boundaries is one way to reduce what would otherwise be expensive and inefficient country-level R\&D programs. For example, national agricultural research systems (NARS) can pool scarce resources, collaborate more frequently, and share knowledge and information on technology solutions and applications for the common good. The principal challenge is identifying research priorities that offer the highest economic returns from a regional perspective. Applying economic tools that consider the presence of potential research spillovers; weighing likely costs and benefits that flow between countries for different commodities, technologies, or both; and capturing any complementarities that exist across national R\&D systems can all help to meet this challenge.

The presence of research spillovers across geographic areas (for example, countries) is well documented in the literature (Griliches 1991; Alston, Norton, and Pardey 1995). Simply ignoring their presence underestimates the economic benefits from R\&D by failing to capture unintended benefits in neighboring countries. Armed with knowledge on cross-country spillovers, basic R\&D that has wider applicability_across more than one country — will be more efficient (or cost-effective) as a multicountry regional program than as a number of country projects that potentially duplicate efforts. Information on potential spillovers can also help guide decisions on the optimal size, type, and location of the research.

\footnotetext{
${ }^{6}$ This section was authored by Sam Benin and Michael Johnson.

${ }^{7}$ Crops included are beans, cassava, cotton, groundnuts, maize, millet, potatoes (including sweet potatoes), rice, sorghum, sugarcane, and wheat. Livestock are cattle, pigs, sheep and goats, and poultry. Together these account for a significant share of the total value of agricultural production in SADC (about 62 percent, or, including by-products such as eggs, milk, and skins, about 70 percent). Another 27 percent is made up of fisheries and fruits and vegetables.
} 
The difficulty with incorporating information on research spillovers is that they are poorly understood in practice and are difficult to quantify reliably (in ex post) due to onerous data requirements (Alston 2002, Pardey et al. 2007). Alternatively, assessing spillover potential (in ex ante) is more feasible because it demands fewer data. Drawing on theory, potential spillovers can be estimated based on a range of underlying biophysical and socioeconomic factors that are known to affect the likely suitability and adoption of research-induced technologies between regions and countries (for example, see Oram, Davis, and Ryan 1987). Given limited information to estimate the extent of past spillovers, we adopt the ex-ante approach in this study by estimating potential research spillovers.

\section{Estimating Potential Research Spillovers}

We define research spillover potential in this study as the likely diffusion of a technology developed in one locality to be adapted in another location for which it was not initially intended. Because agricultural production is especially dependent on biophysical factors (that is, suitability of particular crops or production practices), the degree of agroecological similarity plays a fundamental role in the degree to which spillovers can occur. Basically, countries that have similar agroecological characteristics or production patterns are likely to have higher potential for spillovers among them. On the other hand, spillovers will be limited among countries that are dissimilar in agroecological characteristics or production patterns. Such countries may be referred to as being technologically distant. Since evidence suggests that research undertaken in one country or region is rarely directly usable in other countries or regions without further adaptive research effort in the importing country or region, success of adaptive research across countries is also an important determinant of technological distance, as is the availability of technologies across countries or their transfer from one country to the other.

We use a measure that combines these three different dimensions to construct spillover matrixes for the 14 different crops and livestock presented earlier. In other words, each unique matrix constructed for each crop or livestock commodity reflects the overlay of all three dimensions: the suitability of the agricultural production environment, the likelihood of success for adaptive R\&D and adoption, and the direction of flow or transfer of technologies.

Following Jaffe's $(1986,1989)$ approach and the method popularized by Pardey et al. (2007), we measure the similarity of agricultural production environments by defining the share of cultivated land in each agricultural development zone (ADZ) in a country. By definition, the shares tell us the degree of correlation in the agricultural production environments across countries. A very low relationship simply indicates a very low degree of similarity and therefore lower potential for spillover effects between the two countries. The relationship is naturally symmetrical, implying that spillover from one country to another is the same in the reverse direction. Details of the model and equations are provided in Appendix E.

The data for this analysis come from the spatial analysis on shares of cultivated land under different crops in each of 12 different ADZs in the SADC region. Table 4.1 shows an example for maize, which indicates that Malawi and Namibia are the least similar (a spillover coefficient of 0.03) while Botswana and Namibia are the most similar (at 0.46). Similarly, Table 4.2 provides an alternative example for livestock (in this case, cattle), showing the DRC and Namibia as the least similar (at 0.00), and Botswana and Zambia as the most similar (at 0.46). 
Table 4.1 Similarity in maize production environment in SADC

\begin{tabular}{|c|c|c|c|c|c|c|c|c|c|c|c|c|c|}
\hline Country & ANG & BOT & DRC & LES & MAD & MAL & MOZ & NAM & SAF & SWZ & TNZ & ZAM & ZIM \\
\hline ANG & 1.00 & 0.33 & 0.18 & 0.08 & 0.27 & 0.04 & 0.22 & 0.37 & 0.32 & 0.05 & 0.21 & 0.22 & 0.11 \\
\hline BOT & 0.33 & 1.00 & 0.25 & 0.18 & 0.37 & 0.06 & 0.23 & 0.46 & 0.19 & 0.14 & 0.22 & 0.18 & 0.25 \\
\hline DRC & 0.18 & 0.25 & 1.00 & 0.19 & 0.22 & 0.09 & 0.20 & 0.09 & 0.12 & 0.21 & 0.21 & 0.17 & 0.22 \\
\hline LES & 0.08 & 0.18 & 0.19 & 1.00 & 0.20 & 0.16 & 0.14 & 0.05 & 0.06 & 0.22 & 0.19 & 0.11 & 0.21 \\
\hline MAD & 0.27 & 0.37 & 0.22 & 0.20 & 1.00 & 0.08 & 0.18 & 0.14 & 0.12 & 0.17 & 0.19 & 0.16 & 0.17 \\
\hline MAL & 0.04 & 0.06 & 0.09 & 0.16 & 0.08 & 1.00 & 0.12 & 0.03 & 0.07 & 0.22 & 0.21 & 0.12 & 0.09 \\
\hline MOZ & 0.22 & 0.23 & 0.20 & 0.14 & 0.18 & 0.12 & 1.00 & 0.11 & 0.17 & 0.19 & 0.23 & 0.23 & 0.16 \\
\hline NAM & 0.37 & 0.46 & 0.09 & 0.05 & 0.14 & 0.03 & 0.11 & 1.00 & 0.30 & 0.06 & 0.23 & 0.23 & 0.16 \\
\hline SAF & 0.32 & 0.19 & 0.12 & 0.06 & 0.12 & 0.07 & 0.17 & 0.30 & 1.00 & 0.09 & 0.22 & 0.24 & 0.08 \\
\hline SWZ & 0.05 & 0.14 & 0.21 & 0.22 & 0.17 & 0.22 & 0.19 & 0.06 & 0.09 & 1.00 & 0.25 & 0.20 & 0.25 \\
\hline TNZ & 0.21 & 0.22 & 0.21 & 0.19 & 0.19 & 0.21 & 0.23 & 0.23 & 0.22 & 0.25 & 1.00 & 0.17 & 0.13 \\
\hline ZAM & 0.22 & 0.18 & 0.17 & 0.11 & 0.16 & 0.12 & 0.23 & 0.23 & 0.24 & 0.20 & 0.17 & 1.00 & 0.13 \\
\hline ZIM & 0.11 & 0.25 & 0.22 & 0.21 & 0.17 & 0.09 & 0.16 & 0.16 & 0.08 & 0.25 & 0.13 & 0.13 & 1.00 \\
\hline
\end{tabular}

Source: Spillover matrix analysis.

Notes: $\quad \mathrm{SADC}=$ Southern Africa Development Community. $\mathrm{ANG}=$ Angola, $\mathrm{BOT}=$ Botswana, $\mathrm{DRC}=$ Democratic Republic of the Congo, $\mathrm{LES}=$ Lesotho, $\mathrm{MAD}=$ Madagascar, $\mathrm{MAL}=$ Malawi, MOZ $=$ Mozambique, $\mathrm{NAM}=\mathrm{Namibia}, \mathrm{SAF}=$ South Africa, $\mathrm{SWZ}=$ Swaziland, TNZ = Tanzania, ZAM = Zambia, and ZIM = Zimbabwe.

Table 4.2 Similarity in cattle production environment in SADC

\begin{tabular}{|c|c|c|c|c|c|c|c|c|c|c|c|c|c|}
\hline Country & ANG & BOT & DRC & LES & MAD & MAL & MOZ & NAM & SAF & SWZ & TNZ & ZAM & ZIM \\
\hline ANG & 1.00 & 0.31 & 0.09 & 0.00 & 0.23 & 0.34 & 0.31 & 0.32 & 0.07 & 0.15 & 0.26 & 0.33 & 0.33 \\
\hline BOT & 0.31 & 1.00 & 0.00 & 0.03 & 0.50 & 0.80 & 0.82 & 0.78 & 0.21 & 0.36 & 0.27 & 0.86 & 0.83 \\
\hline DRC & 0.09 & 0.00 & 1.00 & 0.00 & 0.45 & 0.15 & 0.18 & 0.00 & 0.04 & 0.42 & 0.44 & 0.03 & 0.01 \\
\hline LES & 0.00 & 0.03 & 0.00 & 1.00 & 0.00 & 0.00 & 0.00 & 0.01 & 0.47 & 0.14 & 0.00 & 0.00 & 0.00 \\
\hline MAD & 0.23 & 0.50 & 0.45 & 0.00 & 1.00 & 0.31 & 0.34 & 0.22 & 0.07 & 0.38 & 0.30 & 0.26 & 0.23 \\
\hline MAL & 0.34 & 0.80 & 0.15 & 0.00 & 0.31 & 1.00 & 0.39 & 0.39 & 0.08 & 0.24 & 0.24 & 0.39 & 0.39 \\
\hline MOZ & 0.31 & 0.82 & 0.18 & 0.00 & 0.34 & 0.39 & 1.00 & 0.45 & 0.11 & 0.35 & 0.27 & 0.50 & 0.48 \\
\hline NAM & 0.32 & 0.78 & 0.00 & 0.01 & 0.22 & 0.39 & 0.45 & 1.00 & 0.11 & 0.20 & 0.23 & 0.49 & 0.52 \\
\hline SAF & 0.07 & 0.21 & 0.04 & 0.47 & 0.07 & 0.08 & 0.11 & 0.11 & 1.00 & 0.10 & 0.03 & 0.06 & 0.06 \\
\hline SWZ & 0.15 & 0.36 & 0.42 & 0.14 & 0.38 & 0.24 & 0.35 & 0.20 & 0.10 & 1.00 & 0.22 & 0.17 & 0.15 \\
\hline TNZ & 0.26 & 0.27 & 0.44 & 0.00 & 0.30 & 0.24 & 0.27 & 0.23 & 0.03 & 0.22 & 1.00 & 0.11 & 0.12 \\
\hline ZAM & 0.33 & 0.86 & 0.03 & 0.00 & 0.26 & 0.39 & 0.50 & 0.49 & 0.06 & 0.17 & 0.11 & 1.00 & 0.68 \\
\hline ZIM & 0.33 & 0.83 & 0.01 & 0.00 & 0.23 & 0.39 & 0.48 & 0.52 & 0.06 & 0.15 & 0.12 & 0.68 & 1.00 \\
\hline
\end{tabular}

Source: Spillover matrix analysis.

Notes: $\quad \mathrm{SADC}=$ Southern Africa Development Community. $\mathrm{ANG}=$ Angola, $\mathrm{BOT}=\mathrm{Botswana}, \mathrm{DRC}=$ Democratic Republic of the Congo, $\mathrm{LES}=$ Lesotho, $\mathrm{MAD}=$ Madagascar, $\mathrm{MAL}=$ Malawi, MOZ $=$ Mozambique, NAM $=$ Namibia, $\mathrm{SAF}=$ South Africa, SWZ = Swaziland, TNZ = Tanzania, ZAM = Zambia, and ZIM = Zimbabwe.

Tables A.1 to A.13 in Appendix A provide 13 other such matrixes, 1 each for the other 10 crops considered (beans, cassava, cotton, groundnuts, millet, potatoes and sweet potatoes, rice, sorghum, sugarcane, and wheat) and 3 for the other livestock (pigs, sheep and goats, and poultry). Tables 4.3 and 4.4 provide a summary of these matrixes with the least and most similar countries for each of the crops and livestock, respectively, reflecting the potential for technology transfer and spillovers based on this dimension alone. The results show that the extent of similarity between countries is different for different agricultural commodities. For example, Lesotho turns out to be dissimilar from any other countries in the region for crop production, except for Zimbabwe. For livestock, the DRC and Lesotho are dissimilar from most countries.

The second measure we use is the probability of success of adaptive research in each country. As indicated earlier, research undertaken in one country is rarely directly usable in other countries without further adaptive research effort in the importing country. To measure the probability of success of adaptive research in each country, we use rates of return (RORs) on agricultural R\&D among the countries based on the recent study by Alene and Coulibaly (2009), who estimated such RORs. The estimates are based on a host of factors, including national R\&D capacity, that reflect past efficiency 
ratios of expenditures in agricultural $R \& D$ relative to actual agricultural productivity gains. Thus, a high ROR reflects high potential to adapt research outputs from other countries, and vice versa. This dimension of the spillover index reflects the pull or demand-side effect in the technology generationconsumption continuum.

As Table 4.5 shows, the countries for which data were available included 10 from the SADC region, with RORs ranging from 5 percent in Lesotho to 62 percent in Tanzania. Unfortunately, we did not have complete information on these indicators for all the relevant commodities in all SADC countries. Therefore, we use the aggregate ROR in the analysis for all commodities with the exception of maize, for which more data were available. For livestock, the aggregate RORs are adjusted with weighted averages of each country's relative share in SADC of full-time equivalent scientists in livestock research (Table 4.5).

Table 4.3 Summary of similarity in crop production environment in SADC

\begin{tabular}{|c|c|c|}
\hline Crop & Least similar country pairs & Most similar country pairs \\
\hline Beans & $\begin{array}{l}\text { DRC-Namibia (0.07), Angola-Botswana (0.08), } \\
\text { Botswana-DRC (0.08), Madagascar-Malawi } \\
(0.08) \text {, Malawi-Namibia }(0.08)\end{array}$ & $\begin{array}{l}\text { Botswana-Namibia (0.52), Botswana- } \\
\text { Madagascar }(0.40)\end{array}$ \\
\hline Cassava & $\begin{array}{l}\text { Lesotho-all other countries }(0.0 \text {, since no } \\
\text { production there), Angola-Namibia }(0.02) \text {, } \\
\text { Malawi-Namibia }(0.01) \text {, Namibia-Swaziland } \\
(0.0) \text {, South Africa-Swaziland }(0.0)\end{array}$ & $\begin{array}{l}\text { Swaziland-Zimbabwe (0.83), Namibia-Zambia } \\
(0.70)\end{array}$ \\
\hline Cotton & $\begin{array}{l}\text { Lesotho-all other countries }(0.0 \text {, since no } \\
\text { production there), Botswana-Tanzania (0.03), } \\
\text { Madagascar-Malawi }(0.04) \text {, Malawi-Namibia } \\
(0.01) \text {, Namibia-Swaziland }(0.02)\end{array}$ & $\begin{array}{l}\text { Tanzania-Swaziland (0.78), Botswana- } \\
\text { Madagascar }(0.51)\end{array}$ \\
\hline Groundnuts & $\begin{array}{l}\text { Lesotho-all other countries }(0.0 \text {, since no } \\
\text { production there), Malawi-Botswana }(0.07) \text {, } \\
\text { Malawi-Madagascar }(0.07) \text {, Malawi-Namibia } \\
(0.07)\end{array}$ & $\begin{array}{l}\text { Botswana-Namibia (0.49), Botswana-South } \\
\text { Africa }(0.33)\end{array}$ \\
\hline Maize & $\begin{array}{l}\text { Malawi-Namibia }(0.03) \text {, Angola-Malawi }(0.04) \text {, } \\
\text { Angola-Swaziland }(0.05) \text {, Lesotho-Namibia } \\
(0.05)\end{array}$ & $\begin{array}{l}\text { Botswana-Namibia (0.46), Botswana- } \\
\text { Madagascar (0.37), Angola-Namibia (0.37) }\end{array}$ \\
\hline Millet & $\begin{array}{l}\text { Madagascar-all other countries }(0.0, \text { since no } \\
\text { production there), Angola-Swaziland }(0.02) \text {, } \\
\text { Botswana-Swaziland }(0.03)\end{array}$ & $\begin{array}{l}\text { Lesotho-Zimbabwe (0.96), Tanzania-Swaziland } \\
(0.68) \text {, Lesotho-Namibia }(0.64)\end{array}$ \\
\hline $\begin{array}{l}\text { Potatoes } \\
\text { and sweet } \\
\text { potatoes }\end{array}$ & Malawi-Namibia (0.0), Namibia-Swaziland (0.0) & $\begin{array}{l}\text { Namibia-South Africa (0.79), Botswana- } \\
\text { Swaziland (0.53), Botswana-Madagascar (0.52) }\end{array}$ \\
\hline Rice & $\begin{array}{l}\text { Namibia-Botswana/Lesotho/Malawi/Swaziland } \\
(0.0)\end{array}$ & $\begin{array}{l}\text { Lesotho-Zimbabwe (0.88), Namibia-Zambia } \\
\text { (0.65), Lesotho-Madagascar }(.59)\end{array}$ \\
\hline Sorghum & $\begin{array}{l}\text { Malawi-Namibia (0.06), Malawi-Zambia }(0.07) \text {, } \\
\text { Botswana-Malawi }(0.07) \text {, Lesotho-Zambia }(0.07)\end{array}$ & $\begin{array}{l}\text { Botswana-Namibia (0.42), Botswana- } \\
\text { Madagascar (0.35), Botswana-Zimbabwe }(0.35)\end{array}$ \\
\hline Sugarcane & $\begin{array}{l}\text { Lesotho-Botswana/Malawi/Namibia }(0.0) \text {, } \\
\text { Namibia-Swaziland }(0.0)\end{array}$ & $\begin{array}{l}\text { Lesotho-Zimbabwe }(0.97) \text {, Botswana-Namibia } \\
(0.89) \text {, Lesotho-Swaziland }(0.84)\end{array}$ \\
\hline Wheat & $\begin{array}{l}\text { Angola-Swaziland (0.04), Malawi-Namibia } \\
(0.05) \text {, DRC-Namibia }(0.06) \text {, Namibia-Swaziland } \\
(0.06)\end{array}$ & $\begin{array}{l}\text { Angola-Namibia }(0.51) \text {, Botswana-Madagascar } \\
(0.44) \text {, Angola-South Africa }(0.41) \text {, Namibia- } \\
\text { South Africa }(0.40)\end{array}$ \\
\hline
\end{tabular}

Source: Spillover matrix analysis.

Notes: $\quad \mathrm{SADC}=$ Southern Africa Development Community. DRC $=$ Democratic Republic of the Congo. The figures in parentheses are the estimated $\omega_{i j}$ (Appendix E). 
Table 4.4 Summary of similarity in livestock production environment in SADC

\begin{tabular}{|c|c|c|}
\hline Crop & Least similar country pairs & Most similar country pairs \\
\hline Cattle & $\begin{array}{l}\text { DRC-Angola/Botswana/Namibia/South Africa/ } \\
\text { Zambia/Zimbabwe (0.00-0.09), Lesotho-- } \\
\text { Angola/Botswana/DRC/Madagascar/Malawi/ } \\
\text { Mozambique/Namibia/Tanzania/Zambia/Zimbabwe (0.00-0.03), } \\
\text { South Africa-Angola/ } \\
\text { DRC/Madagascar/Malawi/Swaziland/Tanzania/ } \\
\text { Zambia/Zimbabwe }(0.03-0.10)\end{array}$ & $\begin{array}{l}\text { Botswana-Madagascar/Malawi/ } \\
\text { Mozambique/Namibia/Zambia/Zimbabwe } \\
(0.50-0.86) \text {, South Africa-Lesotho }(0.47) \text {, } \\
\text { Zambia-Zimbabwe (0.68), Zimbabwe- } \\
\text { Namibia (0.52) }\end{array}$ \\
\hline Pigs & $\begin{array}{l}\text { Lesotho-Angola/Botswana/DRC/Madagascar/ } \\
\text { Malawi/Mozambique/Namibia/Tanzania/Zambia/Zimbabwe } \\
\text { (0.00-0.08), DRC-Angola/Botswana/ Namibia/South } \\
\text { Africa/Zambia/Zimbabwe (0.00-0.07), South Africa- } \\
\text { Angola/Madagascar/ Malawi/Mozambique/Swaziland/Tanzania/ } \\
\text { Zambia/Zimbabwe (0.00-0.06) }\end{array}$ & $\begin{array}{l}\text { Botswana-Malawi/Mozambique/Namibia/ } \\
\text { Zambia/Zimbabwe }(0.54-0.65), \text { DRC- } \\
\text { Madagascar/Swaziland/Tanzania }(0.47- \\
0.73) \text {, South Africa-Lesotho }(0.50), \\
\text { Namibia-Zambia/Zimbabwe }(0.73-0.74) \text {, } \\
\text { Zambia-Zimbabwe }(0.52)\end{array}$ \\
\hline $\begin{array}{l}\text { Sheep } \\
\text { and } \\
\text { goats }\end{array}$ & $\begin{array}{l}\text { Lesotho-Angola/Botswana/DRC/Madagascar/ } \\
\text { Malawi/Mozambique/Namibia/Tanzania/Zambia/Zimbabwe } \\
\text { (0.00-0.05), DRC-Botswana/Namibia/South } \\
\text { Africa/Zambia/Zimbabwe (0.00-0.08), South Africa- } \\
\text { Angola/Botswana/ Madagascar/Malawi/Mozambique/Swaziland/ } \\
\text { Tanzania/Zambia/Zimbabwe (0.00-0.09), Angola- } \\
\text { Madagascar/Swaziland (0.08-0.10), Madagascar-Namibia } \\
\text { (0.07) }\end{array}$ & $\begin{array}{l}\text { Botswana-Malawi/Mozambique/ } \\
\text { Zambia/Zimbabwe }(0.66-0.72), \\
\text { Zimbabwe-Mozambique/Zambia (0.54- } \\
\text { 0.60), DRC-Madagascar }(0.59) \\
\text { Mozambique-Zambia }(0.59)\end{array}$ \\
\hline Poultry & $\begin{array}{l}\text { Lesotho-Angola/Botswana/DRC/Madagascar/ } \\
\text { Malawi/Mozambique/Namibia/Tanzania/ Zambia/Zimbabwe } \\
\text { (0.00-0.03), DRC-Botswana/Namibia/South Africa/Zimbabwe } \\
\text { (0.00-0.02), South Africa-Angola/Madagascar/ } \\
\text { Malawi/Mozambique/Tanzania/Zambia/Zimbabwe (0.00-0.09), } \\
\text { Swaziland-Angola/ Botswana/Malawi/Namibia/Zambia/ } \\
\text { Zimbabwe }(0.01-0.10), \text { Tanzania-Zimbabwe }(0.10) .\end{array}$ & $\begin{array}{l}\text { Botswana-Malawi/Mozambique/Namibia/ } \\
\text { Zambia/Zimbabwe (0.67-0.78), DRC- } \\
\text { Madagascar/Mozambique/Tanzania } \\
(0.50-0.80) \text {, Zimbabwe-Namibia/Zambia } \\
(0.50-0.54), \text { Zambia-Namibia }(0.50) .\end{array}$ \\
\hline
\end{tabular}

Source: Spillover analysis.

Notes: $\quad \mathrm{SADC}=$ Southern Africa Development Community. $\mathrm{DRC}=$ Democratic Republic of the Congo. The figures in parentheses are the estimated $\omega_{i j}$ (Appendix E).

Table 4.5 Estimated probability of success for adaptive research and development

\begin{tabular}{|c|c|c|c|c|c|}
\hline \multirow[b]{2}{*}{ Country } & \multicolumn{3}{|c|}{ Past evidence (average for 1980-2003) } & \multicolumn{2}{|c|}{ Estimated probability of success } \\
\hline & $\begin{array}{c}\text { ROR } \\
(\%)\end{array}$ & $\begin{array}{c}\text { Expenditure } \\
\text { (PPP\$/ha) }\end{array}$ & $\begin{array}{c}\text { Productivity } \\
\text { (US\$/ha) }\end{array}$ & $\begin{array}{c}\text { Crops } \\
\text { (\%) }\end{array}$ & $\begin{array}{l}\text { Livestock }^{\mathbf{b}} \\
(\%)\end{array}$ \\
\hline Angola & - & - & - & $0.38^{\mathrm{a}}$ & 0.32 \\
\hline Botswana & 0.14 & 0.55 & 5 & 0.14 & 0.39 \\
\hline Congo, D. R. & - & - & - & $0.39^{a}$ & 0.11 \\
\hline Lesotho & 0.05 & 4.47 & 51 & 0.05 & 0.12 \\
\hline Madagascar & 0.51 & 0.54 & 31 & 0.51 & 0.24 \\
\hline Malawi & 0.32 & 4.76 & 99 & 0.32 & 0.09 \\
\hline Mozambique & 0.54 & 0.29 & 16 & 0.54 & 0.11 \\
\hline Namibia & - & - & - & $0.25^{\mathrm{a}}$ & 0.11 \\
\hline South Africa & 0.28 & 4.00 & 35 & 0.28 & 0.75 \\
\hline Swaziland & 0.33 & 4.00 & 100 & 0.33 & 0.26 \\
\hline Tanzania & 0.62 & 0.44 & 72 & 0.62 & 0.75 \\
\hline Zambia & 0.27 & 0.60 & 14 & 0.27 & 0.28 \\
\hline Zimbabwe & 0.59 & 1.47 & 38 & 0.59 & 0.37 \\
\hline
\end{tabular}

Sources: Alene and Coulibaly (2009) unless otherwise noted. ${ }^{\text {a }}$ Authors' best estimates based on own calculations. ${ }^{\mathrm{b}}$ Authors' best estimates based on own calculations using data on full-time equivalent livestock researchers and weighted by a regional average and an aggregate rate of returns.

Notes: $\quad$ ROR $=$ rate of return. $\mathrm{PPP}=$ purchasing power parity; ha $=$ hectare. 
The third and final dimension of the spillover index captures the push or supply-side effect in the technology generation-consumption continuum, the probability for and direction of transfer of technologies. We measure this as a ratio of the difference in yields (or yield gap) between countries. As an example, Table 4.6 gives the yield differences for maize, which show wider margins between Botswana and Malawi or South Africa, for example. For all other crops and livestock, these can be found in Appendix A, Tables A.14 to A.27. The assumption here is that productivity-enhancing technologies, practices, and knowledge will naturally flow from higher- to lower-productivity areas, at least in net terms. Typically, countries reporting lower yields on average exhibit higher yield gaps as analyzed in Section 3 (that is, between the actual and the maximum potential in their production environment). Therefore, it is reasonable to assume these are countries that can benefit the most from adapting technologies from neighboring countries that have been able to close this gap. Here too, the results show that the extent of yield differences between countries varies by agricultural commodity. South Africa tends to dominate in several of the crops, while Angola, Botswana, and Mozambique tend to lagmeaning that, other things being equal, Angola, Botswana, and Mozambique stand to benefit the most from adapting technologies from other countries, particularly South Africa.

Table 4.6 Yield differences in maize production across countries

\begin{tabular}{l|lllllllllllll}
\hline Country & ANG & BOT & DRC & LES & MAD & MAL & MOZ & NAM & SAF & SWZ & TNZ & ZAM & ZIM \\
\hline ANG & 1.00 & 0.31 & 1.24 & 1.38 & 2.35 & 3.16 & 1.62 & 2.14 & 4.52 & 2.55 & 1.42 & 2.53 & 1.89 \\
BOT & 3.27 & 1.00 & 4.04 & 4.51 & 7.67 & 10.3 & 5.31 & 7.00 & 14.78 & 8.33 & 4.65 & 8.26 & 6.17 \\
DRC & 0.81 & 0.25 & 1.00 & 1.12 & 1.90 & 2.56 & 1.31 & 1.73 & 3.66 & 2.06 & 1.15 & 2.04 & 1.53 \\
LES & 0.72 & 0.22 & 0.90 & 1.00 & 1.70 & 2.29 & 1.18 & 1.55 & 3.28 & 1.85 & 1.03 & 1.83 & 1.37 \\
MAD & 0.43 & 0.13 & 0.53 & 0.59 & 1.00 & 1.35 & 0.69 & 0.91 & 1.93 & 1.09 & 0.61 & 1.08 & 0.80 \\
MAL & 0.32 & 0.10 & 0.39 & 0.44 & 0.74 & 1.00 & 0.51 & 0.68 & 1.43 & 0.81 & 0.45 & 0.80 & 0.60 \\
MOZ & 0.62 & 0.19 & 0.76 & 0.85 & 1.44 & 1.94 & 1.00 & 1.32 & 2.78 & 1.57 & 0.88 & 1.56 & 1.16 \\
NAM & 0.47 & 0.14 & 0.58 & 0.64 & 1.10 & 1.48 & 0.76 & 1.00 & 2.11 & 1.19 & 0.66 & 1.18 & 0.88 \\
SAF & 0.22 & 0.07 & 0.27 & 0.31 & 0.52 & 0.70 & 0.36 & 0.47 & 1.00 & 0.56 & 0.31 & 0.56 & 0.42 \\
SWZ & 0.39 & 0.12 & 0.49 & 0.54 & 0.92 & 1.24 & 0.64 & 0.84 & 1.77 & 1.00 & 0.56 & 0.99 & 0.74 \\
TNZ & 0.70 & 0.22 & 0.87 & 0.97 & 1.65 & 2.22 & 1.14 & 1.51 & 3.18 & 1.79 & 1.00 & 1.78 & 1.33 \\
ZAM & 0.40 & 0.12 & 0.49 & 0.55 & 0.93 & 1.25 & 0.64 & 0.85 & 1.79 & 1.01 & 0.56 & 1.00 & 0.75 \\
ZIM & 0.53 & 0.16 & 0.66 & 0.73 & 1.24 & 1.67 & 0.86 & 1.13 & 2.40 & 1.35 & 0.75 & 1.34 & 1.00 \\
\hline
\end{tabular}

Source: Spillover matrix analysis.

Notes: $\quad$ ANG $=$ Angola, $\mathrm{BOT}=$ Botswana, $\mathrm{DRC}=$ Democratic Republic of the Congo, LES $=$ Lesotho, MAD $=$ Madagascar, MAL = Malawi, MOZ = Mozambique, NAM = Namibia, SAF $=$ South Africa, $S W Z=$ Swaziland, TNZ = Tanzania, ZAM = Zambia, and ZIM = Zimbabwe . Gaps reported here are not the same as the yield gaps introduced in Section 3; these measure differences of average yields across countries.

\section{Resulting Spillover Matrixes}

In combining all three dimensions of the index - agricultural suitability, likelihood of successful adaptive research, and probability of technology transfer and adoption-we construct the final spillover matrixes in the SADC region for the different commodities. Each element of the matrix measures the effect of agricultural productivity growth in one country due to the R\&D and technology outputs originating from another country, relative to the country's own R\&D effect. A critical assumption that has to be made here relates to the direction of net spillover flow. For a comparative analysis of the final results, we use 1.25 as a cutoff point in order to avoid unreasonable outliers, and we set to zero any ratios that are less than the cutoff point. For example, using 1.25 as the cutoff point means we assume net flows from one country to another in one direction only when the yield gap between the countries is 25 percent or more. Table 4.7 shows a resulting spillover matrix for maize. Final spillover matrixes for all other crops and livestock are provided in Appendix A, Tables A.28 to A.42. 
Table 4.7 Final spillover coefficient matrix for maize

\begin{tabular}{l|llllllllllllll}
\hline Country & ANG & BOT & DRC & LES & MAD & MAL & MOZ & NAM & SAF & SWZ & TNZ & ZAM & ZIM & $\begin{array}{c}\text { Average spill- } \\
\text { in effect }\end{array}$ \\
\hline ANG & 1.00 & 0.00 & 0.00 & 0.04 & 0.23 & 0.04 & 0.13 & 0.30 & 0.54 & 0.05 & 0.11 & 0.21 & 0.08 & $\mathbf{0 . 2 5}$ \\
BOT & 0.15 & 1.00 & 0.14 & 0.12 & 0.40 & 0.09 & 0.17 & 0.45 & 0.39 & 0.16 & 0.14 & 0.21 & 0.21 & $\mathbf{0 . 2 5}$ \\
DRC & 0.00 & 0.00 & 1.00 & 0.00 & 0.16 & 0.09 & 0.10 & 0.06 & 0.18 & 0.17 & 0.00 & 0.14 & 0.13 & $\mathbf{0 . 1 0}$ \\
LES & 0.00 & 0.00 & 0.00 & 1.00 & 0.02 & 0.02 & 0.00 & 0.00 & 0.01 & 0.02 & 0.00 & 0.01 & 0.01 & $\mathbf{0 . 0 1}$ \\
MAD & 0.00 & 0.00 & 0.00 & 0.00 & 1.00 & 0.05 & 0.00 & 0.00 & 0.12 & 0.00 & 0.00 & 0.00 & 0.00 & $\mathbf{0 . 0 4}$ \\
MAL & 0.00 & 0.00 & 0.00 & 0.00 & 0.00 & 1.00 & 0.00 & 0.00 & 0.03 & 0.00 & 0.00 & 0.00 & 0.00 & $\mathbf{0 . 0 1}$ \\
MOZ & 0.00 & 0.00 & 0.00 & 0.00 & 0.14 & 0.13 & 1.00 & 0.08 & 0.26 & 0.16 & 0.00 & 0.20 & 0.00 & $\mathbf{0 . 1 2}$ \\
NAM & 0.00 & 0.00 & 0.00 & 0.00 & 0.00 & 0.01 & 0.00 & 1.00 & 0.16 & 0.00 & 0.00 & 0.00 & 0.00 & $\mathbf{0 . 0 5}$ \\
SAF & 0.00 & 0.00 & 0.00 & 0.00 & 0.00 & 0.00 & 0.00 & 0.00 & 1.00 & 0.00 & 0.00 & 0.00 & 0.00 & $\mathbf{0 . 0 0}$ \\
SWZ & 0.00 & 0.00 & 0.00 & 0.00 & 0.00 & 0.00 & 0.00 & 0.00 & 0.05 & 1.00 & 0.00 & 0.00 & 0.00 & $\mathbf{0 . 0 2}$ \\
TNZ & 0.00 & 0.00 & 0.00 & 0.00 & 0.19 & 0.29 & 0.00 & 0.21 & 0.43 & 0.28 & 1.00 & 0.19 & 0.11 & $\mathbf{0 . 2 0}$ \\
ZAM & 0.00 & 0.00 & 0.00 & 0.00 & 0.00 & 0.04 & 0.00 & 0.00 & 0.12 & 0.00 & 0.00 & 1.00 & 0.00 & $\mathbf{0 . 0 4}$ \\
ZIM & 0.00 & 0.00 & 0.00 & 0.00 & 0.00 & 0.09 & 0.00 & 0.00 & 0.11 & 0.20 & 0.00 & 0.10 & 1.00 & $\mathbf{0 . 0 5}$ \\
\hline Average spill- & $\mathbf{0 . 0 0}$ & $\mathbf{0 . 0 0}$ & $\mathbf{0 . 0 0}$ & $\mathbf{0 . 0 0}$ & $\mathbf{0 . 0 7}$ & $\mathbf{0 . 0 8}$ & $\mathbf{0 . 0 2}$ & $\mathbf{0 . 0 6}$ & $\mathbf{0 . 1 6}$ & $\mathbf{0 . 1 0}$ & $\mathbf{0 . 0 1}$ & $\mathbf{0 . 0 9}$ & $\mathbf{0 . 0 3}$ & \\
out effect & & & & & & & & & & & & & &
\end{tabular}

Source: Spillover matrix analysis.

Notes: $\quad$ ANG $=$ Angola, BOT $=$ Botswana, DRC $=$ Democratic Republic of the Congo, LES $=$ Lesotho, MAD = Madagascar, MAL $=$ Malawi, MOZ = Mozambique, NAM = Namibia, $\mathrm{SAF}=$ South Africa, $\mathrm{SWZ}=$ Swaziland, $\mathrm{TNZ}=$ Tanzania, $\mathrm{ZAM}=$ Zambia, and ZIM = Zimbabwe.

The final results in the constructed matrix in Table 4.7 suggests that the potential spillover (spillout) effect for maize can be as high as 54 percent in the case of Angola when the technology originates from South Africa, relative to the effect associated with Angola's own R\&D. The weighted totals in the columns reflect the average spillover effect on maize yield in the rest of the SADC region due to adoption of technologies originating from country $j$. The estimates suggest that maize research outputs originating from South Africa have the largest effect (average of 0.16) on yield in other countries in the region. The weighted row totals, on the other hand, reflect the average spill-in effect on maize yield in each country due to adoption of maize technologies originating from other countries in the SADC region. The estimates suggest that Angola and Botswana benefit the most from technologies originating from the rest of SADC (average spill-in effect of 0.25), compared with the effect of their own technologies and research outputs.

Tables 4.8 and 4.9 present a summary of the results for the average spill-outs and spill-ins for each of the crop and livestock subsectors. The results show that different countries are associated with different spillovers and, as expected, different countries benefit differently from the spillovers depending on the commodity in question. Regarding spill-outs, Table 4.8 shows that South Africa is a critical source of research outputs with the greatest potential impacts in the region for the majority of the crops considered here, except root crops, millet, and rice. Other countries, too, are important in the production of these and other crops, including Lesotho and. Madagascar for beans; Tanzania for cassava; Botswana and Zambia for cotton; Swaziland, Malawi, and Zambia for maize; DRC, Tanzania, and Zambia for millet; Malawi, Swaziland, and Tanzania for sugarcane; Namibia, Angola, Zimbabwe, and Madagascar for wheat; and Botswana and Namibia for cattle. Regarding countries benefiting the most, Table 4.9 shows that, relative to the country's gains from its own research outputs, Angola stands to benefit the most from spill-ins in the production of beans, groundnuts, maize, millet, and rice; Botswana for maize and sorghum; DRC for cotton and rice; Mozambique for groundnuts, rice, sorghum, and sugarcane; Swaziland for cotton and potatoes/sweet potatoes; and Zimbabwe for cassava, millet, and sorghum. For livestock, Tanzania potentially benefits for cattle and pigs, Botswana for poultry, and Lesotho for sheep and goats. 
Table 4.8 Summary of average spill-out effects in crop/livestock production in SADC

\begin{tabular}{|c|c|c|c|c|c|c|c|c|c|c|c|c|c|}
\hline Commodity & ANG & BOT & DRC & LES & MAD & MAL & MOZ & NAM & SAF & SWZ & TNZ & ZAM & ZIM \\
\hline Beans & 0 & 42 & 0 & 75 & 77 & 21 & 0 & 74 & 100 & 34 & 46 & 0 & 46 \\
\hline Cassava & 13 & 0 & 9 & 0 & 11 & 5 & 4 & 0 & 0 & 0 & 100 & 2 & 0 \\
\hline Cotton & 31 & 87 & 0 & 0 & 21 & 5 & 5 & 62 & 100 & 0 & 5 & 86 & 8 \\
\hline Groundnuts & 0 & 82 & 32 & 0 & 79 & 28 & 0 & 0 & 100 & 41 & 0 & 0 & 22 \\
\hline Maize & 0 & 0 & 0 & 1 & 46 & 50 & 12 & 38 & 100 & 63 & 4 & 55 & 21 \\
\hline Millet & 40 & 0 & 100 & 0 & 0 & 43 & 34 & 0 & 67 & 0 & 84 & 78 & 0 \\
\hline $\begin{array}{l}\text { Potatoes/ sweet } \\
\text { potatoes }\end{array}$ & 5 & 0 & 23 & 1 & 100 & 2 & 2 & 0 & 34 & 0 & 2 & 1 & 2 \\
\hline Rice & 0 & 0 & 0 & 0 & 26 & 12 & 7 & 0 & 30 & 100 & 31 & 23 & 28 \\
\hline Sorghum & 0 & 0 & 7 & 16 & 1 & 10 & 5 & 0 & 100 & 1 & 22 & 5 & 1 \\
\hline Sugarcane & 29 & 0 & 28 & 0 & 21 & 69 & 0 & 0 & 100 & 63 & 57 & 46 & 17 \\
\hline Wheat & 89 & 0 & 0 & 0 & 78 & 53 & 0 & 97 & 100 & 0 & 0 & 0 & 79 \\
\hline Cattle & 69 & 93 & 100 & 0 & 0 & 87 & 58 & 98 & 21 & 96 & 0 & 32 & 61 \\
\hline Pigs & 45 & 24 & 0 & 0 & 100 & 25 & 69 & 51 & 16 & 21 & 0 & 0 & 26 \\
\hline Sheep/goats & 100 & 1 & 0 & 0 & 0 & 4 & 0 & 89 & 14 & 98 & 0 & 1 & 0 \\
\hline Poultry & 3 & 0 & 0 & 0 & 100 & 5 & 10 & 4 & 12 & 10 & 15 & 4 & 33 \\
\hline
\end{tabular}

Source: Spillover matrix analysis.

Notes: $\quad \mathrm{SADC}=$ Southern Africa Development Community. $\mathrm{ANG}=$ Angola, $\mathrm{BOT}=$ Botswana, $\mathrm{DRC}=$ Democratic Republic of the Congo, $\mathrm{LES}=$ Lesotho, MAD = Madagascar, MAL = Malawi, MOZ = Mozambique, NAM = Namibia, $\mathrm{SAF}=\mathrm{South}$ Africa, $\mathrm{SWZ}=$ Swaziland, TNZ $=$ Tanzania, ZAM $=$ Zambia, and ZIM $=$ Zimbabwe. Indexed 1-100, where index $=\delta_{-} j$ $* 100 / \max \left(\delta_{-j}\right)$.

Table 4.9 Summary of average spill-in effects in crop/livestock production in SADC

\begin{tabular}{|c|c|c|c|c|c|c|c|c|c|c|c|c|c|}
\hline Commodity & ANG & BOT & DRC & LES & MAD & MAL & MOZ & NAM & SAF & SWZ & TNZ & ZAM & ZIM \\
\hline Beans & 100 & 10 & 36 & 1 & 0 & 16 & 64 & 0 & 0 & 16 & 26 & 24 & 17 \\
\hline Cassava & 0 & 0 & 0 & 0 & 0 & 0 & 47 & 0 & 0 & 0 & 0 & 27 & 100 \\
\hline Cotton & 22 & 0 & 82 & 0 & 58 & 11 & 63 & 0 & 0 & 100 & 25 & 16 & 28 \\
\hline Groundnuts & 95 & 12 & 31 & 0 & 0 & 16 & 100 & 55 & 0 & 16 & 88 & 43 & 30 \\
\hline Maize & 100 & 100 & 41 & 3 & 17 & 4 & 46 & 21 & 0 & 7 & 78 & 16 & 21 \\
\hline Millet & 74 & 55 & 12 & 0 & 0 & 0 & 39 & 68 & 10 & 0 & 0 & 0 & 100 \\
\hline $\begin{array}{l}\text { Potatoes/ } \\
\text { sweet potatoes }\end{array}$ & 9 & 0 & 4 & 4 & 0 & 2 & 22 & 0 & 0 & 100 & 54 & 3 & 50 \\
\hline Rice & 74 & 0 & 71 & 0 & 1 & 16 & 100 & 0 & 1 & 0 & 8 & 23 & 2 \\
\hline Sorghum & 0 & 70 & 49 & 3 & 79 & 16 & 100 & 90 & 0 & 38 & 45 & 49 & 96 \\
\hline Sugarcane & 33 & 0 & 26 & 0 & 53 & 0 & 100 & 0 & 0 & 0 & 0 & 15 & 18 \\
\hline Wheat & 50 & 26 & 35 & 4 & 7 & 17 & 71 & 3 & 0 & 24 & 100 & 0 & 0 \\
\hline Cattle & 22 & 35 & 5 & 40 & 42 & 0 & 22 & 0 & 0 & 0 & 100 & 29 & 0 \\
\hline Pigs & 3 & 41 & 12 & 43 & 0 & 5 & 3 & 4 & 0 & 26 & 100 & 32 & 7 \\
\hline Sheep/goats & 0 & 66 & 15 & 100 & 25 & 4 & 12 & 0 & 0 & 0 & 67 & 9 & 12 \\
\hline Poultry & 15 & 100 & 35 & 51 & 2 & 8 & 9 & 4 & 0 & 28 & 29 & 5 & 6 \\
\hline
\end{tabular}

Source: Spillover matrix analysis.

Notes: $\quad \mathrm{SADC}=$ Southern Africa Development Community. $\mathrm{ANG}=$ Angola, BOT $=$ Botswana, DRC $=$ Democratic Republic of the Congo, $\mathrm{LES}=$ Lesotho, MAD $=$ Madagascar, MAL $=$ Malawi, MOZ $=$ Mozambique, NAM $=$ Namibia, $\mathrm{SAF}=\mathrm{South}$ Africa, $\mathrm{SWZ}=$ Swaziland, TNZ $=$ Tanzania, ZAM $=$ Zambia, and ZIM = Zimbabwe. Indexed 1-100, where index $=\delta_{i_{-}}$ $* 100 / \max \left(\delta_{i_{-}}\right)$.

It is important to note that the analysis so far considers only the three dimensions presented earlier, and the distribution of spill-outs and spill-ins is examined from the countries' perspectives. For example, size of the country and potential changes in land allocation, prices, trade, and other factors, which are important for assessing the distribution of spill-outs and spill-ins from the regional perspective, are not considered. These issues are taken up in the multimarket scenarios, where the spillover matrixes are combined with the other factors to assess the distribution of spill-outs and spill-ins across the different countries and crops, from both country and regional perspectives. 


\section{Summary and Conclusion}

Given similar biophysical and socioeconomic environments among neighboring countries in the SADC region, it is natural to expect that significant $R \& D$ and technology spillovers occur over time. Good examples of commodities affected in the past have included maize varieties, sorghum and millet, cassava, and others. In order to quantify spillover potential for our economic analysis of future R\&D investments, we have used the several important dimensions of similarities in the agricultural production environment, probability of successful adaptive research, and current yield gaps. The estimates suggest significant potential for spillovers, especially for maize, cassava, rice, beans, groundnuts, cotton, and millet. Countries that seem to stand to gain the most from spill-ins are Angola, Mozambique, DRC, Tanzania, and Zimbabwe.

The evidence of spillover potential suggests the need to promote greater R\&D collaboration and technology transfers, especially among countries that already share similar development domains and therefore stand to benefit from pooling resources. Although beyond the scope of this study, a key challenge will be putting in place the right incentives in case the benefits from such collaboration are likely to flow in one direction. 


\section{EXPLORING THE ECONOMYWIDE IMPACT OF RESEARCH AND DEVELOPMENT INVESTMENTS ${ }^{8}$}

Having examined the wide variation of the agricultural and economic landscape in the SADC region, the potential for yield growth among key crops and livestock commodities given this diversity, and the associated potential for cross-border R\&D spillovers, we now explore how changes in yields over time will affect the broader economic and welfare goals of the SADC region using an economywide simulation model. Our rationale for using an economywide approach is to explicitly recognize the growth linkages between agriculture and other sectors - such as through incomes and demand (population growth and urbanization, size of market, location and integration of market, and market accessibility). Essentially, it will be helpful to link agricultural performance with the rest of the economy.

The key questions the analysis is intended to inform include these:

- How can different agricultural sectors contribute to accelerating growth for the SADC region as a whole?

- How do growth outcomes vary across countries and subnational regions?

- Which commodity subsectors will contribute the most to future sectorwide and overall economic growth?

- Which ones offer the greatest flow of benefits from potential spillovers?

- Which ones are promising with respect to improving the welfare of smallholder farmers and the majority poor in rural areas?

- Are there potential demand or product market constraints?

The analysis incorporates the information and results derived from both the spillover and spatial analyses in previous sections, as described in the overall integrated analytical framework (Figure 1.1 in Section 1).

\section{Background Description of the Economywide Multimarket Model}

The EMM developed for this study assesses the differential growth contribution of individual agricultural subsectors to overall economic growth under different yield growth scenarios. Details of the model have been provided in Appendix F. ${ }^{9}$ The scenarios capture the outcomes from expanded R\&D and complementary investments, which improve yields either directly (for example, from adoption of modern varieties) or through expanded use of yield-enhancing inputs (for example, fertilizer) or through efficiency gains from better agronomic practices.

In the EMM model, agricultural production, consumption, and trade are defined at the national level for individual crops, livestock, and processed commodities. There are 47 commodities in all, out of which 28 are crop-based, including annual crops, oilseeds, and tree crops. Eighteen of the crops can be considered staple food crops, including cereals (6), roots and tubers (5), oilseeds and pulses (6), and plantains (1). Another 10 crops are considered high-value crops (for example, vegetables, fruits, and sugar) or export crops (such as cotton and nuts). The model also includes 11 livestock commodities, grouped into these categories: live animals such as cattle, sheep and goats, pigs, and chickens; and processed products, such as beef, pork, milk, eggs, and skin. Fishery products are included as 2 aggregated groups: freshwater fish and seawater fish. Due to data limitations, the model does not include forestry as an agricultural subsector. Last, we include 6 processed edible oils. Table 5.1 presents a summary of the subsector definitions and commodities used in this study. Two nonagricultural sectors are

\footnotetext{
${ }^{8}$ This section was authored by Xinshen Diao, Michael Johnson, and Sam Benin.

${ }^{9}$ The SADC model's main structure and parameters were adapted and improved from an earlier application at the level of Africa south of the Sahara by Diao et al. (2008). The basic properties and equations of the original EMM models developed and applied at IFPRI are published in the study by Diao et al. (2007).
} 
included in the model in order to preserve an economywide perspective of cross-sector growth linkages. The first nonagricultural sector represents tradable industry and services, while the second represents a nontraded industry (for example, construction) and domestic services.

Table 5.1 Definitions of agricultural subsectors

\begin{tabular}{lcl}
\hline Subsector & $\begin{array}{c}\text { Number of } \\
\text { commodities }\end{array}$ & \multicolumn{1}{c}{ Names of commodities } \\
\hline Grains or cereals & 6 & maize, rice, millet, sorghum, wheat, other cereals \\
Roots (\& tubers) & 5 & cassava, potatoes, sweet potatoes, cocoyam, other root crops \\
Other food & 7 & groundnuts, soybeans, oil palm, sesame seed, other oil nuts, pulses, plantains \\
High value & 10 & cotton, sugar, coffee, cocoa, tea, tobacco, vegetables, other fruits, spices, nuts \\
Livestock (excluding meats) & 8 & cattle, chickens, sheep \& goats, pigs, other livestock, milk, eggs, skins \\
Fisheries & 2 & seawater fish, freshwater fish \\
Meat & 3 & beef, pork, other meat \\
Edible oils & 6 & cottonseed oil, groundnut oil, soybean oil, sesame oil, palm oil, other edible oil \\
\hline
\end{tabular}

Source: Economywide multimarket model (see Table B.9 in Appendix B for a full listing).

There are 13 countries in the model. The island economies of Mauritius and Seychelles were not included due to data limitations. However, their exclusion does not affect our results much, given the agricultural R\&D focus of the study and the size of their economies. Agriculture in both countries contributes very little to overall GDP growth (about 4 percent). While South Africa is included in the model, we do not simulate any future growth scenario there since the primary focus of the study is on the developing countries in the region or those with significant rural-based smallholder populations.

For each country, we aggregate demand and household income separately into rural and urban sectors. This is because growth rates of rural and urban populations differ in the process of urbanization. Moreover, consumption structure and behavior also differ between the two household types. From this aggregation, future demand growth for each agricultural product is determined by the differences in demand structure as well as different population growth projections between the two sectors. Including the demand side is critical in order to account for both future potential market opportunities and demand constraints for each of the individual agricultural products, especially as incomes grow. Therefore the model explicitly allows demand to change over time as incomes change due to growth in both agriculture and nonagriculture. Because we also consider nontraded agricultural and nonagricultural products in the model, prices for some products are endogenously determined by the relationship between supply and demand in each country's domestic market. These endogenously determined prices also affect household incomes as well as household consumption choices for different agricultural commodities.

Trade is captured in the model between individual countries and the rest of world. However, the model cannot explicitly capture either intraregional or bilateral trade flows because such an analysis would require a more sophisticated computable general equilibrium model. Because the model imposes a perfect substitution assumption between imported and domestically produced goods for the same commodity, it can only capture net trade. In this regard, we can at least estimate each country's net trade position, that is, whether it becomes a net importer or net exporter of a particular product (such as maize). For example, net trade of zero in a particular commodity simply implies the country is self-sufficient because there are no imports or exports in the country. However, it does not imply that the commodity is a nontraded product in the region.

The model is simulated over a period of eight years, between 2008 and 2015. Over this time frame, the balance between supply and demand for any commodity changes over time. If supply grows more slowly than the growth in demand for a particular commodity in a country - for example, maize in Mozambique - then the domestic maize price in Mozambique increases overtime. While Mozambique may not need to import maize in the first few years, it may eventually have to if domestic the maize price reaches a high enough level, that is, import parity price. Such a price level would imply that maize 
imports become equally competitive with domestic maize and therefore just as profitable. With growing domestic demand over time driving up prices, so long as the growth in domestic supply cannot keep up with demand, maize imports will eventually have to come into Mozambique to meet this demand. The same is true for exports. For example, Malawi may be self-sufficient at the beginning (in the model this would be in 2007 and 2008, when no significant imports or exports took place), but if the supply of maize grows more rapidly than the demand over time, domestic maize prices will fall until they reach a level that makes Malawian maize competitive in world markets. At this point, Malawi will start exporting maize, sometime during the simulated time period (2008-2015).

Having described the EMM model, we now turn to the scenarios simulated in the model. Because the primary objective of analyzing future growth scenarios among the key agricultural products is to determine their potential contribution to future overall growth and welfare (incomes, poverty reduction, and food security) in the SADC region, we focus attention on some key food staples, livestock, fishery products, and high-value products, using the following criteria:

- The scale and scope of the commodity's importance in the region-as a share of total agricultural value-added and the extent to which it is grown and consumed across countries in the region.

- Its future demand growth potential, given rural growth and urbanization trends in terms of future demand growth.

- Its future supply growth potential, given both past evidence of yield growth and existing yield gaps under current technologies from the SPAM analysis in Section 3. Final target growth rates are set at levels that closely correspond to those set by SADC (in the RISDP) as goals to achieve by 2015.

- The share of smallholder production or participation in the production of the agricultural commodity.

\section{Model Scenarios}

Based on the criteria in the previous section, we introduce two growth scenarios among the selected commodities: (1) a base-run or business-as-usual scenario and (2) an accelerated growth or businessunusual scenario. To measure potential benefit flows from $R \& D$ spillovers, results from the analysis are decomposed into those resulting from each member state's own investments and those derived from potential technology spill-ins (based on the spillover analysis in Section 4).

\section{The Base-Run or Business-as-Usual Scenario}

The EMM model is first used to simulate a base run in which growth in all countries follows their recent growth trends until 2015. This is considered as the conditions under which nothing changes much in terms of R\&D and other investments. They continue to be business as usual. Growth rates for crop yield and land expansion, for livestock production, and for the nonagricultural sector are first exogenously chosen, while the actual growth in either yield increase or total production of a product is an outcome of supply response to the changes in prices, including own prices and prices for other commodities. For example, based on the recent growth rate, the maize yield growth rate is first chosen to be 1.74 percent annually between 2008 and 2015 for Zambia, while the actual average yield growth rate, as the model result, is 1.49 percent due to the supply response to the declined maize price in the country. On the demand side, while rural and urban population growth rates are exogenous, income growth for each country's rural and urban households is an endogenous process and is determined by growth on the supply side. 
We first report the base-run growth result for the overall economy and aggregated agricultural sector in Figure 5.1. Both GDP and agricultural GDP are aggregated from the model results at the sector and commodity levels. Consistent with the countries' recent growth patterns, there are six SADC countries with annual GDP growth rates of 5.1-7.6 percent in the next six years in the model. For the other five countries (including South Africa), the annual GDP growth is 4.1-4.9 percent in the same period. Only in Swaziland and Zimbabwe is the GDP growth rate low (2.4 and 0.6 percent, respectively). In contrast to relatively impressive GDP growth in most SADC countries, agricultural growth is slower than the overall economic growth in most countries. There are only three countries, Malawi, Madagascar, and Zambia, in which the agricultural growth rate is more than 4 percent, and there is no country that reaches the 6 percent agricultural growth target set by CAADP along the current growth trend.

Figure 5.1 Base-run annual growth rates (2009-2015)

\begin{tabular}{lccc}
\hline & GDP & AgGDP & GDP per capita \\
\hline Angola & \multicolumn{3}{c}{ (Average annual \% growth) } \\
Botswana & 7.63 & 2.90 & 4.61 \\
Congo, D. R. & 5.40 & 1.88 & 3.94 \\
Lesotho & 4.37 & 1.43 & 1.44 \\
Madagascar & 4.88 & 2.14 & 3.75 \\
Malawi & 4.77 & 4.71 & 1.90 \\
Mozambique & 4.43 & 4.85 & 1.51 \\
Namibia & 7.68 & 4.53 & 4.99 \\
South Africa & 5.11 & 0.37 & 3.09 \\
Swaziland & 4.13 & 1.50 & 2.69 \\
Tanzania & 2.35 & 1.67 & 1.28 \\
Zambia & 5.34 & 3.10 & 2.55 \\
Zimbabwe & 7.23 & 4.79 & 4.75 \\
& 0.57 & 0.56 & 0.48
\end{tabular}

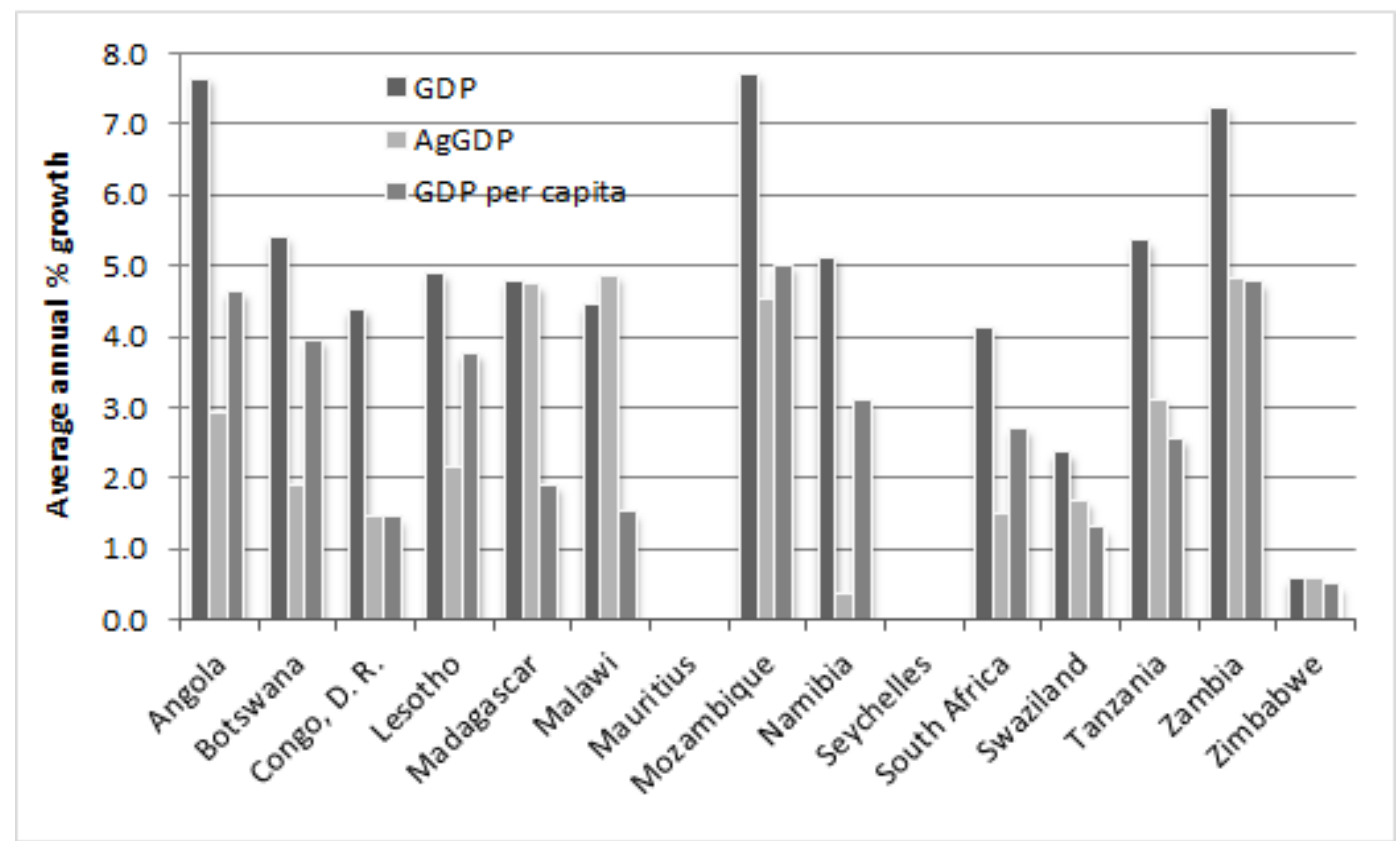

Source: Economywide multimarket model results.

Note: $\quad$ GDP = gross domestic product. AgGDP = agricultural value-added or agricultural gross domestic product. 
Table 5.2 further breaks down the agricultural sector into six subsectors and reports the base run's annual growth rate for each subsector at the country level. Grain subsectors include maize, rice, wheat, sorghum, millet, and other cereals. For most countries, the growth rate seems to be relatively higher in the grain sector than in the other sectors. There are eight countries with an annual growth rate in this subsector higher than 4 percent, and in five of these countries (Angola, Madagascar, Malawi, Mozambique, and Zambia), the growth rate is higher than 6 percent. While the grain sector's growth rate is high, it is not necessarily the most important sector contributing to overall agricultural growth. While in five SADC countries grains account for one-third to 50 percent of agricultural GDP, in the other six countries grains account for less than 20 percent of agricultural GDP.

Table 5.2 Agricultural subsector annual growth rates in the base run (2009-2015)

\begin{tabular}{llllllll|l}
\hline Country & Grains & Roots & $\begin{array}{l}\text { Other } \\
\text { food }\end{array}$ & $\begin{array}{l}\text { High-value } \\
\text { crops }\end{array}$ & Livestock & Fisheries & $\begin{array}{l}\text { Agricultural } \\
\text { GDP }\end{array}$ \\
\hline Angola & & & & (Average annual \% growth) & & \\
Botswana & 6.10 & 3.88 & 6.24 & 1.95 & 0.29 & 1.09 & 2.90 \\
Congo, D. R. & 4.87 & - & 1.09 & 0.01 & 1.79 & 0.01 & 1.88 \\
Lesotho & 1.85 & 1.60 & 1.12 & 1.79 & 0.43 & 0.89 & 1.43 \\
Madagascar & 2.37 & 1.75 & -0.04 & -0.05 & 2.42 & 2.85 & 2.14 \\
Malawi & 7.05 & 2.87 & 5.40 & 2.97 & 3.27 & 2.99 & 4.71 \\
Mozambique & 6.88 & 3.70 & 2.94 & 2.77 & 5.57 & 7.44 & 4.85 \\
Namibia & 6.17 & 3.51 & 4.35 & 5.92 & 3.34 & 4.97 & 4.53 \\
South Africa & 4.30 & - & 1.55 & 0.08 & 0.73 & 0.01 & 0.37 \\
Swaziland & -0.28 & 2.25 & 3.96 & 1.63 & 2.65 & 0.01 & 1.50 \\
Tanzania & 0.01 & 0.30 & 0.16 & 2.71 & 0.88 & 0.01 & 1.67 \\
Zambia & 5.64 & 1.78 & 1.79 & 3.39 & 2.11 & 1.08 & 3.10 \\
Zimbabwe & 7.00 & 3.23 & 4.13 & 5.10 & 3.15 & 0.99 & 4.79 \\
SADC & 0.19 & 0.28 & -0.05 & 0.25 & 2.15 & 0.25 & 0.56 \\
Low Income & 3.31 & 2.65 & 2.24 & 2.58 & 4.64 & 1.01 & 2.51 \\
Middle Income & 0.01 & 2.65 & 1.98 & 3.35 & 3.29 & 2.04 & 3.25 \\
\hline
\end{tabular}

Source: Economywide multimarket model results.

Notes: GDP $=$ gross domestic product. $\mathrm{SADC}=$ Southern Africa Development Community.

To understand the role of each agricultural subsector in overall agricultural growth across the countries, Figure 5.2 and Table 5.3 present the subsector contribution to each country's agricultural growth in the base run. Such growth decomposition is determined by the individual subsector's size in the economy and its recent growth trends. In six SADC countries, Lesotho, Madagascar, Malawi, Namibia, Tanzania, and Zambia, grains are the most important agricultural subsector and explain more than 50 percent of agricultural growth, while in Angola, DRC, and Mozambique, root crops contribute the most to overall agricultural growth. Not surprisingly, livestock is the most important contributor to agricultural growth in Botswana and Namibia, while the high-value crops (primarily sugar) explain more than 80 percent of agricultural growth in Swaziland. When we classify countries into low- and middle-income groups, grains contribute the most to agricultural growth among low-income countries while livestock matters more in the latter group. Different agricultural production patterns indicate diversified interests in prioritizing agricultural investment across SADC countries. 
Figure 5.2 Subsectors' contribution to total agricultural growth in the base run (2009-2015)

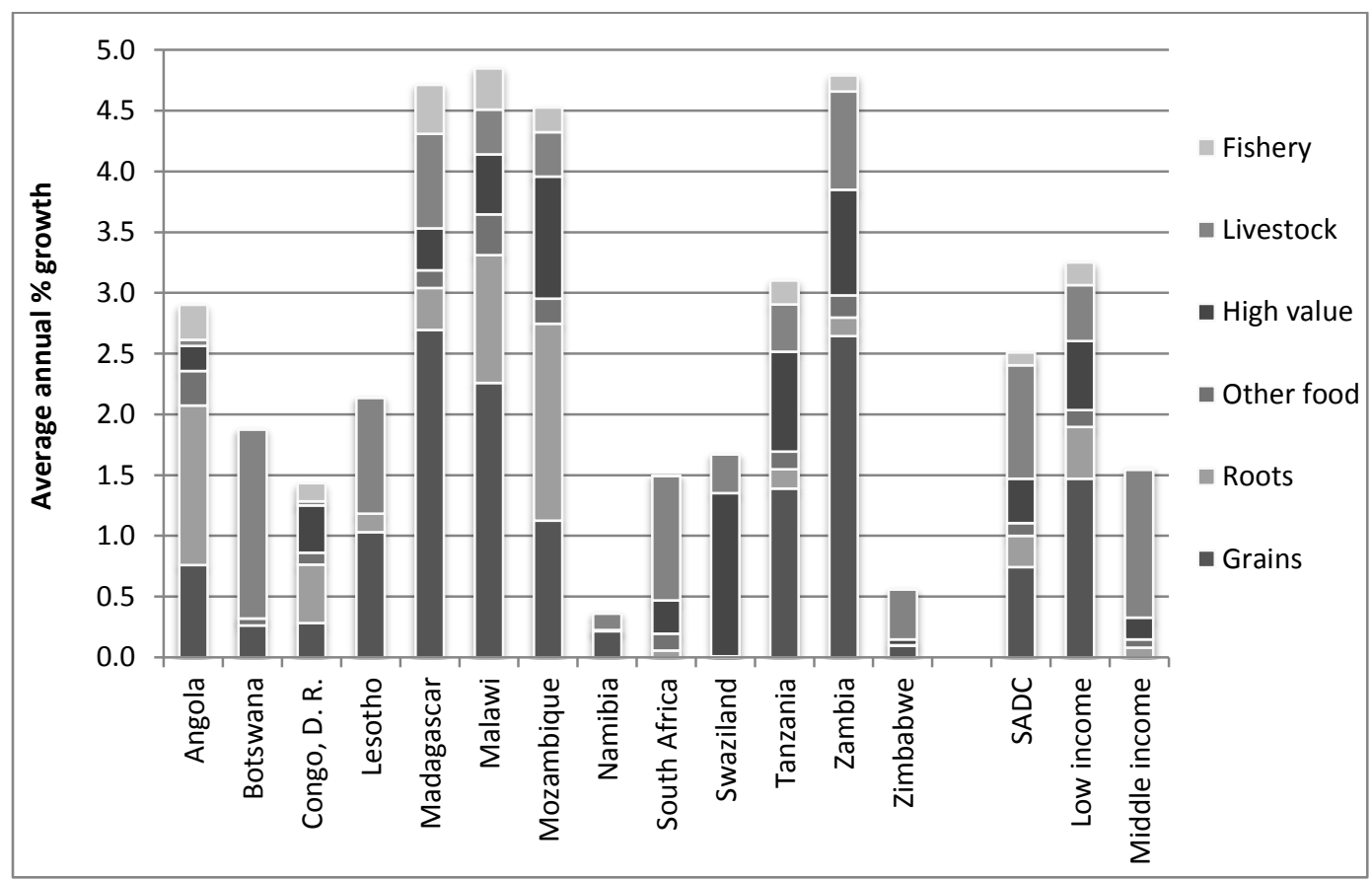

Source: Economywide multimarket model results.

Notes: See Table 5.1 for subsector definitions. The subsector growth rates here sum to total agricultural growth rates, with their shares calculated and presented in Table 5.2. SADC $=$ Southern Africa Development Community.

Table 5.3 Subsectors' contribution to agricultural growth in the base run (2009-2015)

\begin{tabular}{|c|c|c|c|c|c|c|c|}
\hline Country & Grains & Roots & $\begin{array}{l}\text { Other } \\
\text { food }\end{array}$ & $\begin{array}{l}\text { High-value } \\
\text { crops }\end{array}$ & Livestock & Fisheries & $\begin{array}{l}\text { Agricultural } \\
\text { GDP }\end{array}$ \\
\hline & \multicolumn{6}{|c|}{ (\% share contribution to total agricultural GDP growth) } & $\begin{array}{l}\text { (Average annual } \\
\text { growth rate, \%) }\end{array}$ \\
\hline Angola & 26.2 & 45.3 & 9.8 & 7.1 & 1.8 & 9.8 & 2.90 \\
\hline Botswana & 14.0 & 0.0 & 3.1 & 0.0 & 83.0 & 0.0 & 1.88 \\
\hline Congo, D. R. & 19.7 & 33.6 & 6.9 & 27.1 & 2.3 & 10.4 & 1.43 \\
\hline Lesotho & 48.2 & 7.1 & 0.0 & 0.0 & 44.7 & 0.1 & 2.14 \\
\hline Madagascar & 57.2 & 7.3 & 3.1 & 7.3 & 16.5 & 8.6 & 4.71 \\
\hline Malawi & 46.6 & 21.7 & 6.8 & 10.2 & 7.6 & 7.0 & 4.85 \\
\hline Mozambique & 24.9 & 35.8 & 4.5 & 22.2 & 8.1 & 4.5 & 4.53 \\
\hline Namibia & 59.0 & 0.0 & 1.6 & 0.7 & 36.5 & 2.3 & 0.37 \\
\hline South Africa & 0.0 & 3.8 & 9.2 & 18.4 & 68.6 & 0.1 & 1.50 \\
\hline Swaziland & 0.1 & 0.1 & 0.3 & 80.5 & 19.0 & 0.0 & 1.67 \\
\hline Tanzania & 44.8 & 5.2 & 4.7 & 26.4 & 12.5 & 6.4 & 3.10 \\
\hline Zambia & 55.2 & 3.2 & 3.8 & 18.2 & 16.9 & 2.7 & 4.79 \\
\hline Zimbabwe & 17.5 & 0.6 & 0.0 & 8.1 & 73.4 & 0.4 & 0.56 \\
\hline SADC & 29.7 & 10.2 & 4.2 & 14.5 & 37.2 & 4.2 & 2.51 \\
\hline Low income & 45.3 & 13.1 & 4.3 & 17.4 & 14.1 & 5.8 & 3.25 \\
\hline Middle income & 0.1 & 5.2 & 4.3 & 11.5 & 77.9 & 1.1 & 1.56 \\
\hline
\end{tabular}

Source: Economywide multimarket model results.

Notes: GDP = gross domestic product. $\mathrm{SADC}=$ Southern Africa Development Community. See Table 5.1 for subsector definitions. 
An agricultural growth that is slower than the overall economic growth indicates that nonagricultural growth is happening much faster than growth in agriculture. In this way, demand for some agricultural goods can grow more rapidly than the supply of these products, if demand for them has high income elasticity. This indeed happens for some agricultural products, a situation that either causes imports to increase or causes exports to fall. Figure 5.3 displays regional net imports excluding South Africa in the base run for 2009 and 2015. It shows that net imports of livestock and meat will more than double, increasing by 197 percent (from US\$767 million to US\$2.3 billion) in the next six years, and the region as a whole will see net imports almost double for agricultural products in total. While the growth rate of net grain imports is modest, in absolute terms, net grain imports will still be equivalent to almost twice the net livestock imports.

Figure 5.3 Regional total net imports in the base run, excluding South Africa

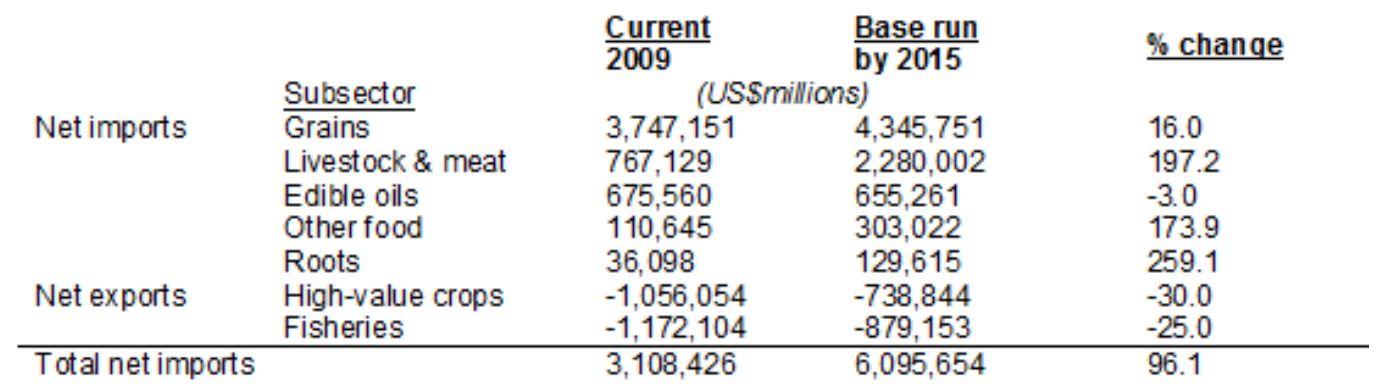

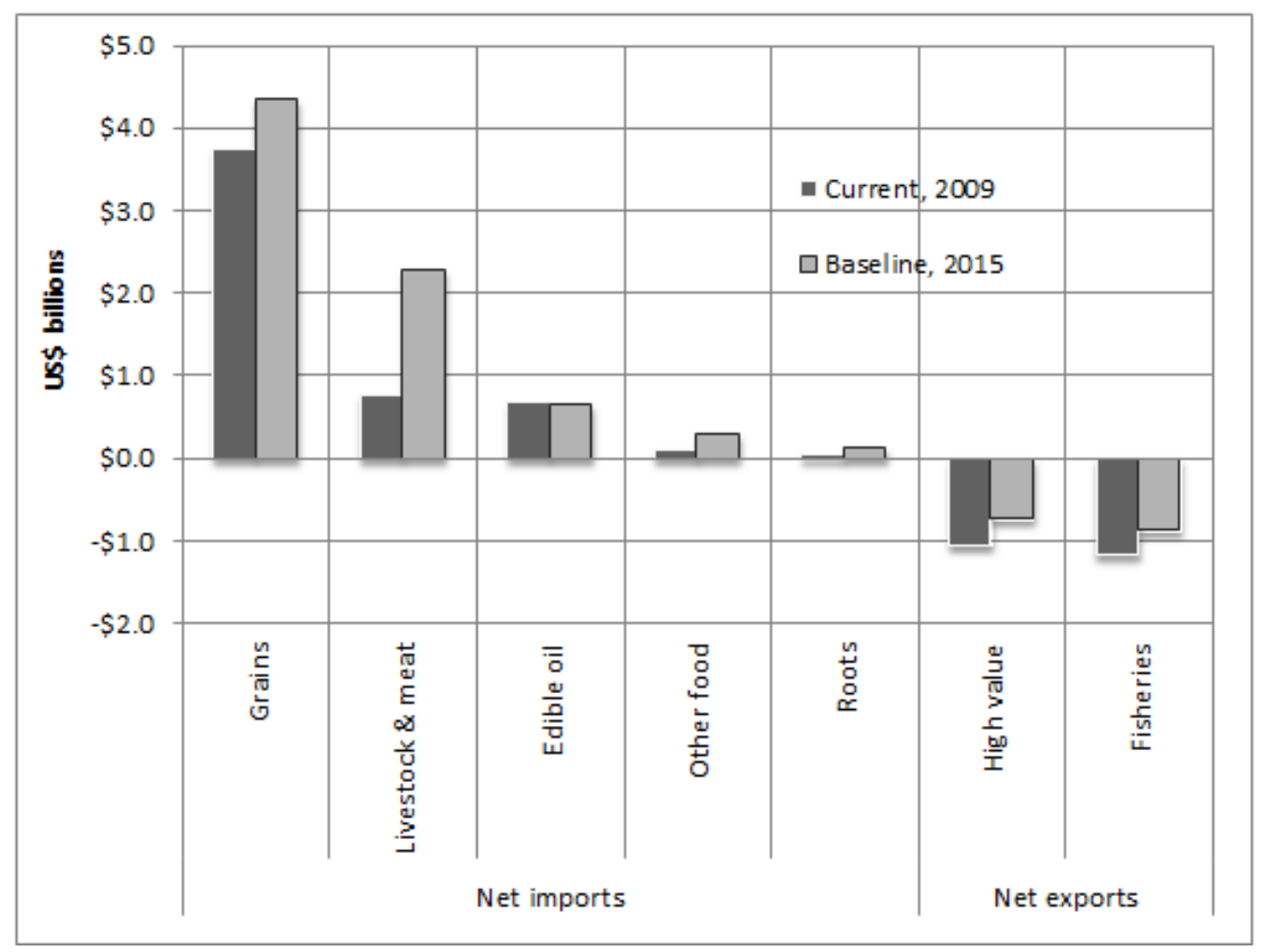

Source: Economywide multimarket model results.

Note: See Table 5.1 for subsector definitions. 


\section{Accelerated Growth or Business-Unusual Scenario}

In the second scenario, we consider accelerating growth, assuming increased investments in R\&D and other complementary investments that enhance value-added productivity growth among the commodity subsectors and individual agricultural products. Specifically, we increase productivity growth exogenously to evaluate the economywide impact of such growth coming from individual agricultural crops and livestock products.

The targeted yield levels and future growth estimates of livestock are drawn from a broad literature search and past trends, and calculated to be close to the targets set by the RISDP. Tables B.1B.3 in Appendix B provide three levels of yield for each individual crop by country: the initial level in 2007, the level in 2015 in the base run, and the level in 2015 in the accelerated growth run.

Comparisons with the yield gaps assessed in Section 3 (Figure 3.6) show that yields under the accelerated growth scenario by 2015 remain below the potential yields under current technologies and knowledge base (Figure 5.4). This implies that the increase in yields proposed for achieving RISDP targeted goals are quite feasible even under current technologies, but with expanded adaptive research and extension to increase diffusion. The exception is rice, which reaches its potential yield by 2015. Recall that the potential yield is calculated from evidence of farm trials mixed with best practices and sufficient access to modern inputs, all based on the best information available and compiled by Fischer et al. (2002). Therefore, a mixture of both new and adaptive R\&D, investments in improved extension and services, infrastructure investments to ensure adequate access to water resources and markets, and lowered transportation and transactions costs to produce favorable input and output prices at the farmgate are different kinds of targeted investments that may be required at different locations to achieve maximum yields at the national level.

Figure 5.4 Closing current yields gaps under growth scenario, regional averages

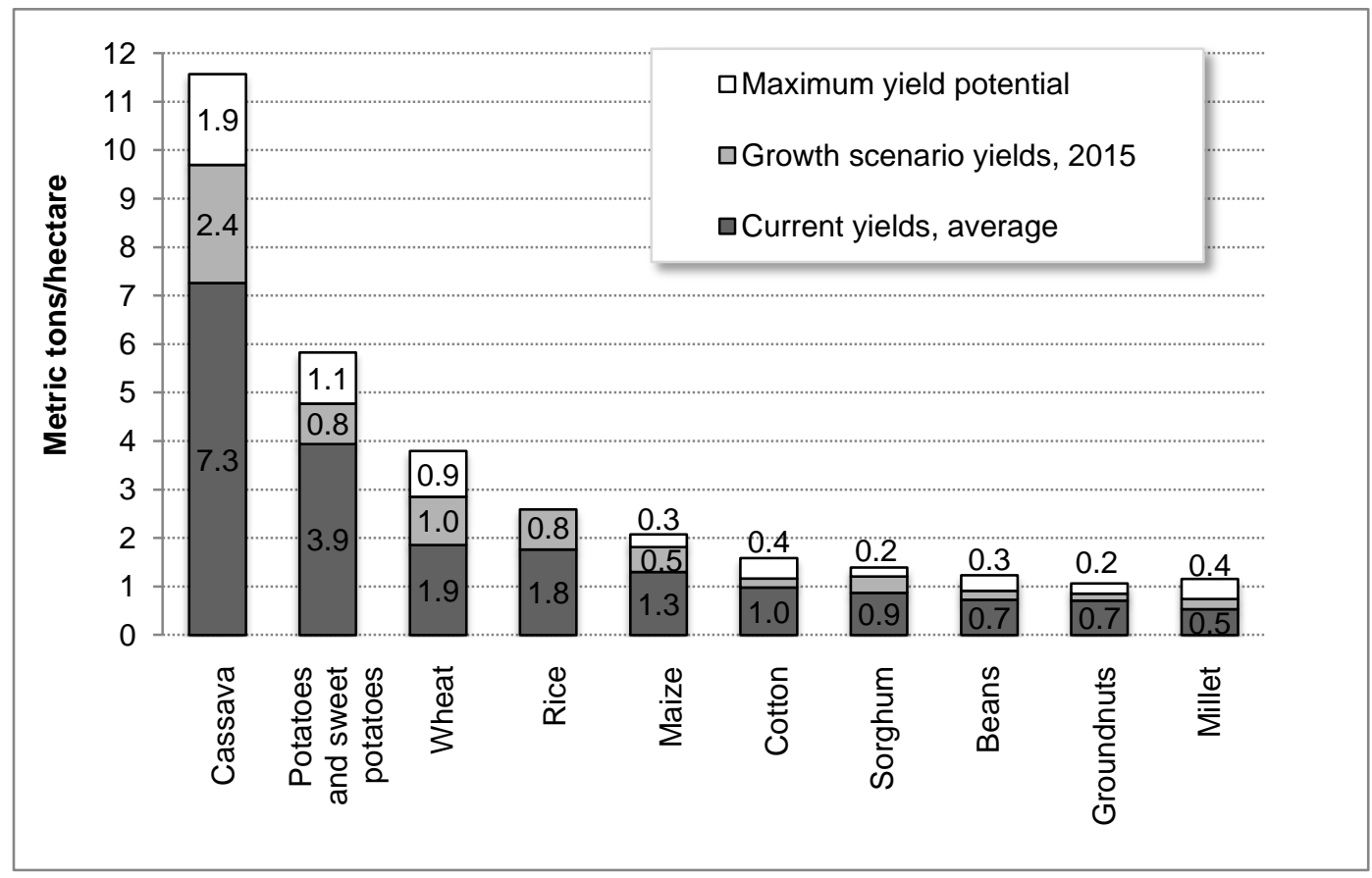

Sources: Potential yields were calculated using data from Fischer and others (2002). Current yields were calculated using spatial analysis results and FAO (2010). Both were originally presented in Figure 3.6 of Section 3. Here growth scenario yields used in the economywide multimarket model are also presented.

Notes: The potential yields are averaged across the agroecological zones and farming systems (both high- and low-potential areas) among all SADC member states; therefore, they do not represent the maximum achievable yields. 
To have a big picture of the growth that will result from such yield increases, we first present subsector-level output growth for the region as a whole. As shown in Figure 5.5, to meet the targeted yield requires the grain subsector to grow at more than 9 percent per year over the next six years, while its base-run growth rate is 5.4 percent. For most other subsectors, the growth rates need to more than double. Obviously, it will be a huge challenge to realize such growth, although feasible.

Figure 5.5 Regional agricultural subsectors' growth, SADC excluding South Africa (2009-2015)

\begin{tabular}{llc}
\hline & Base run & Targeted \\
\hline Subsector & (Annual \% growth, $2009-15$ ) \\
Grains & 5.3 & 9.5 \\
Roots & 2.7 & 6.2 \\
Other food & 2.1 & 5.7 \\
High value & 3.4 & 5.8 \\
Livestock & 2.4 & 6.7 \\
Fisheries & 1.1 & 2.8
\end{tabular}

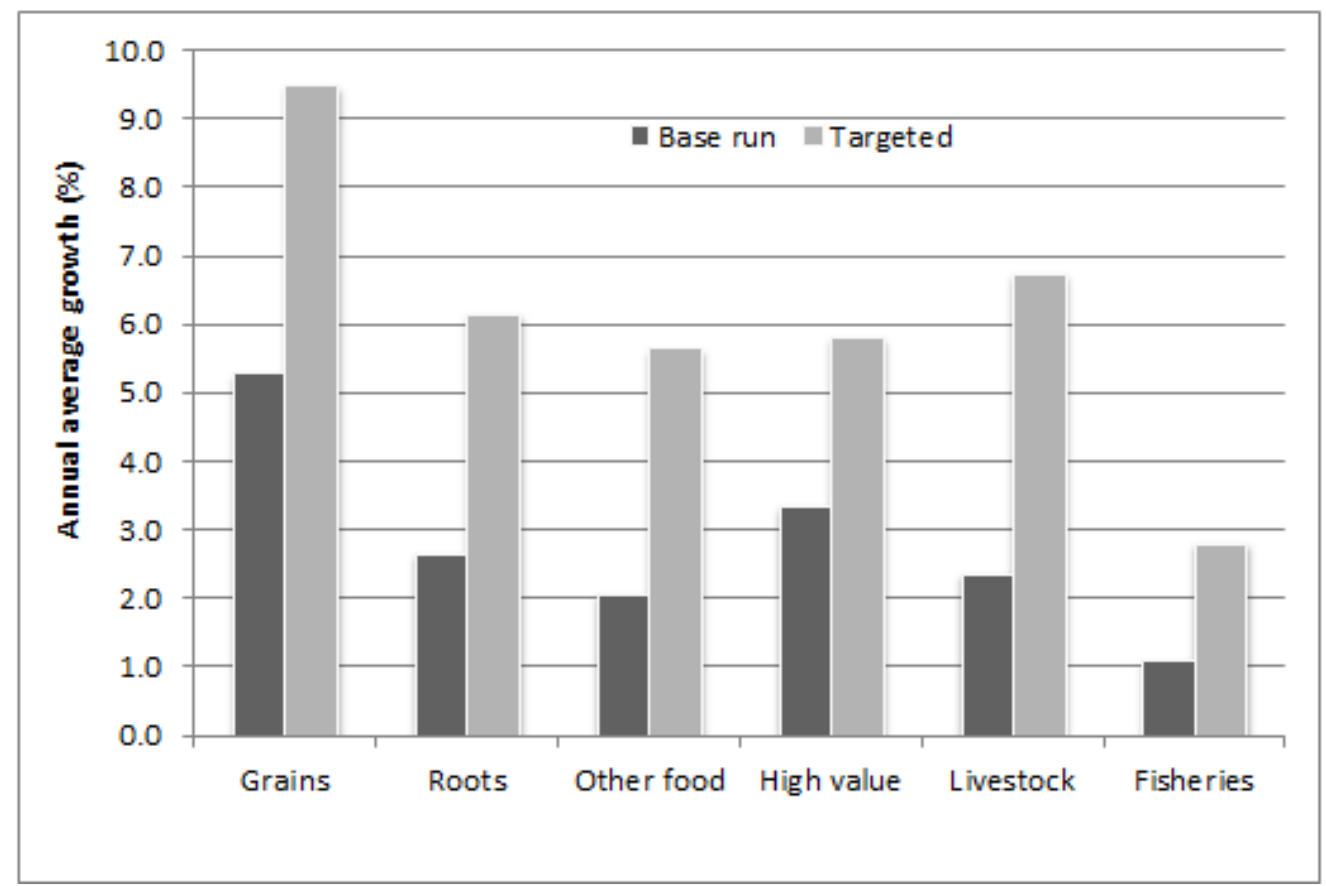

Source: Economywide multimarket model results.

Note: See Table 5.1 for subsector definitions.

Additional output growth is driven by assumed yield increases in the growth scenario. However, land allocation starts to change since growth also affects the relative prices in the crop sectors. As shown in Figure 5.6, because of rapid increases in yield, land allocated to grain production is less than that in the base run, because the grain land growth rate is lower in the growth scenario than in the base run. Land released from grain production goes to growing other crops, and most will go to high-value crops and other food crops. Such movement is primarily led by market opportunities in either exports or domestic markets, which is captured as changes in relative prices among different crop products. 
Figure 5.6 Growth in area and yield at the agricultural subsector level (2009-2015)

\begin{tabular}{|c|c|c|c|c|c|c|c|}
\hline & \multicolumn{2}{|c|}{ Area growth } & \multicolumn{2}{|c|}{ Yield growth } & \multicolumn{3}{|c|}{ Level of yield } \\
\hline & Base run & Targeted & Base run & Targeted & Current & Targeted & Change \\
\hline Subsector & \multicolumn{2}{|c|}{ (Annual \% growth) } & \multicolumn{2}{|c|}{ (Annual \% growth) } & \multicolumn{2}{|c|}{ Mt/ha } & $(\%)$ \\
\hline Grains & 4.0 & 3.2 & 1.3 & 6.1 & 1.2 & 1.7 & 42.5 \\
\hline Roots & 1.3 & 1.4 & 1.3 & 4.7 & 6.3 & 8.3 & 32.0 \\
\hline Other food & 1.3 & 1.6 & 0.8 & 4.0 & - & - & - \\
\hline High value & 1.6 & 2.1 & 1.8 & 3.6 & - & - & - \\
\hline
\end{tabular}

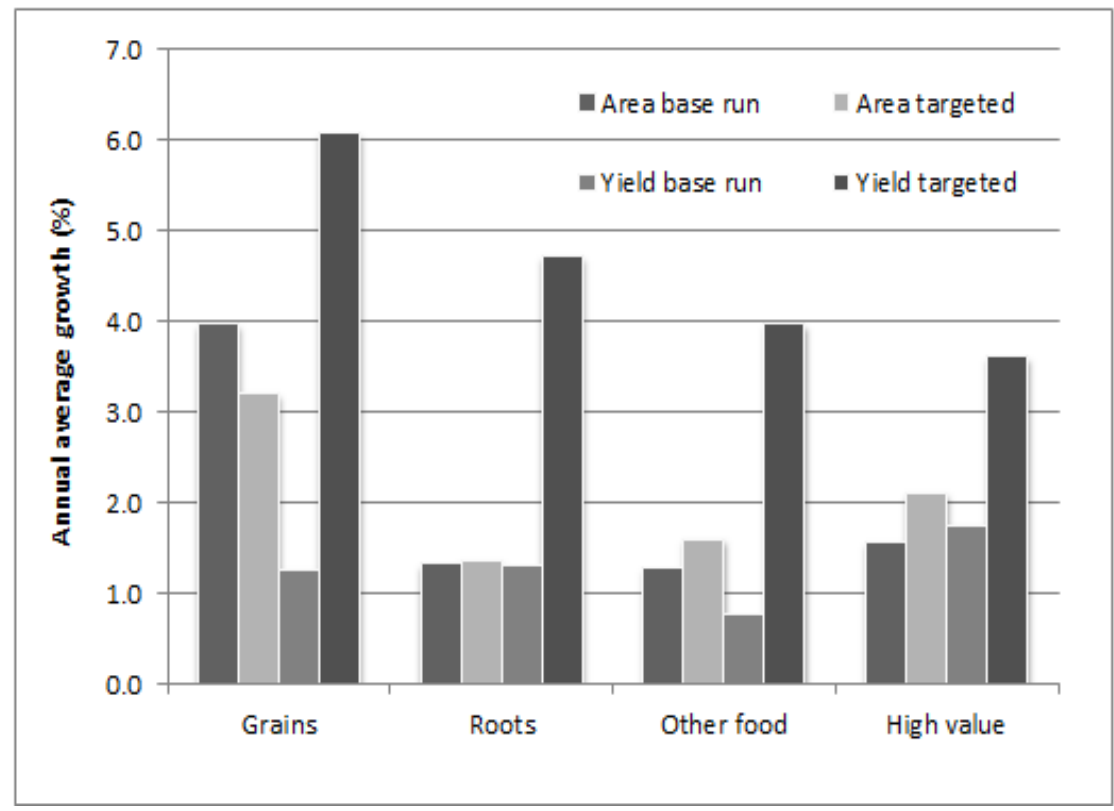

Source: Economywide multimarket model results.

Note: See Table 5.1 for subsector definitions.

\section{Model Results: Overall Growth Effects}

Assuming growth can be achieved at the crop and livestock subsector levels, we focus on the more aggregated effect on the economy of such growth, starting with the overall regional effect of accelerated agricultural growth. Figure 5.7 presents the average annual growth rates for the regional GDP, agricultural GDP, rural and urban per capita income, and agricultural consumer price index (CPI) under the two scenarios. Productivity-led agricultural growth allows the region to double its overall agricultural annual growth rate from 3.0 percent in the base run to 6.2 percent in the growth run. Additional agricultural growth results in higher total GDP growth, and the annual growth rate rises from 5.0 percent in the base run to 5.8 percent in the growth run. Both rural and urban households benefit from such growth. While the rural households benefit more in terms of the difference in growth rate between the two runs, the growth rate is still higher for urban households than for rural households. In the base run, the agricultural CPI increases because food demand grows more rapidly than agricultural supply. With accelerated growth in the agricultural sector, this trend is reversed. Instead of rising by 1.45 percent per year, the agricultural CPI falls slightly every year. 
Figure 5.7 Average annual growth in economic indicators, 2009-2015 (SADC excluding South Africa)

\begin{tabular}{|c|c|c|}
\hline & Base run & Targeted \\
\hline Economicindicator & \multicolumn{2}{|c|}{ (Annual growth, \%) } \\
\hline Gross domestic product (GDP) & 5.00 & 5.80 \\
\hline Agricultural GDP (AgGDP) & 3.08 & 6.18 \\
\hline Urban per capita income ( $\mathrm{PCl})$ & 3.52 & 4.00 \\
\hline RuralPCl & 0.43 & 1.17 \\
\hline $\mathrm{Ag}$ consumer price index (CPI) & 1.57 & -0.24 \\
\hline
\end{tabular}

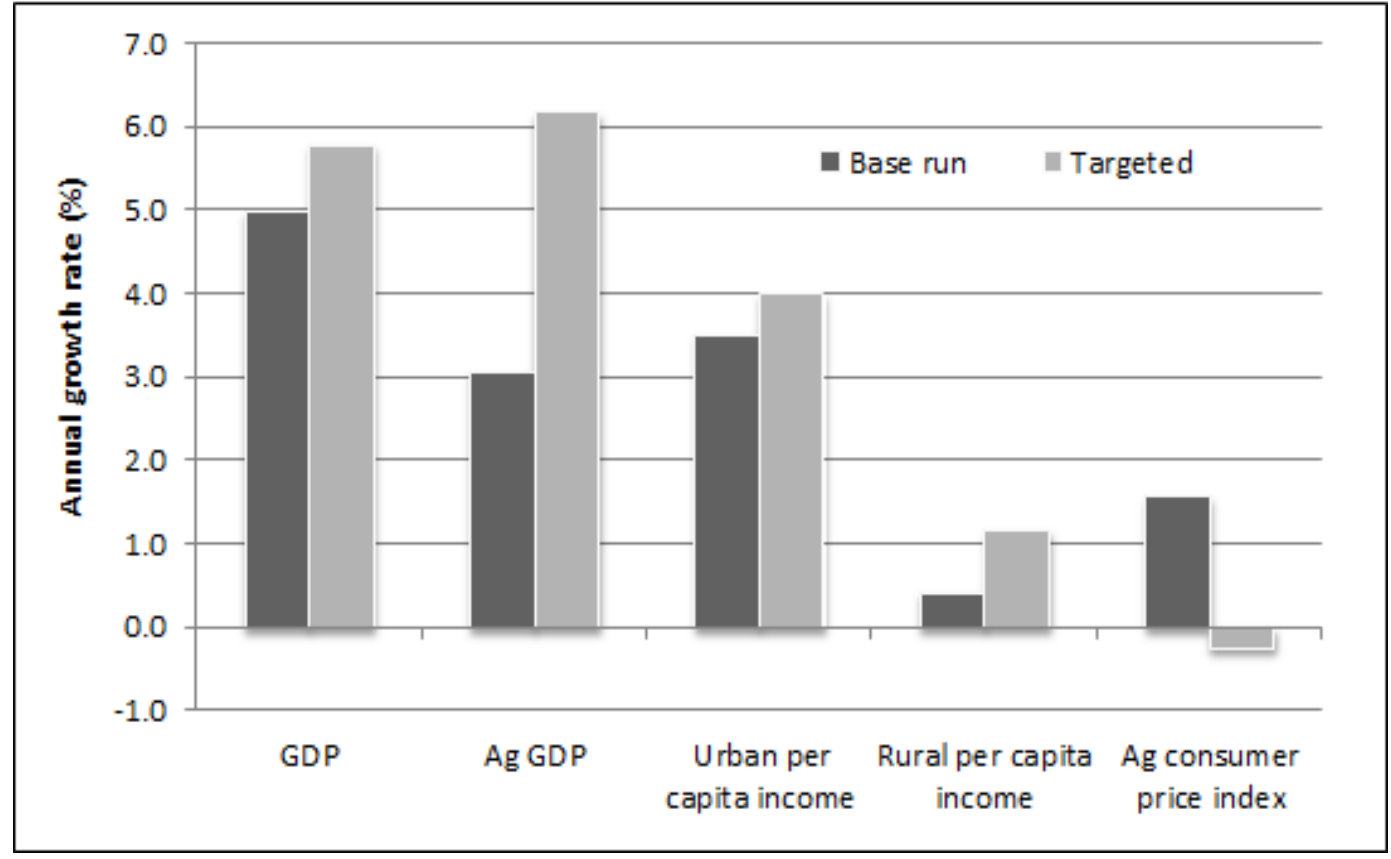

Source: Economywide multimarket model results.

Note: $\quad \mathrm{SADC}=$ Southern Africa Development Community.

We report country-level agricultural growth in Figure 5.8. As shown in this figure, growth in the crop and livestock subsectors leads the overall agricultural growth rate to increase significantly. For 10 of 13 SADC countries, the overall annual agricultural growth reaches more than or close to 6 percent, a target set in the CAADP framework. Excluding South Africa, only DRC and Namibia cannot reach the 6 percent growth target, either because of extremely low initial growth (DRC) or lack of agricultural potential (Namibia). 
Figure 5.8 Agricultural annual growth rates by country and region, 2009-2015

\begin{tabular}{|c|c|c|c|c|c|}
\hline & & Targeted & & Base run & Targeted \\
\hline Country & \multicolumn{2}{|c|}{ (Ave. annual \% growth) } & Region & \multicolumn{2}{|c|}{ (Ave. annual \% growth) } \\
\hline Angola & 2.90 & 7.01 & SADC & 2.51 & $5.3 \overline{7}$ \\
\hline Botswana & 1.88 & 6.13 & Lowincome & 3.25 & 6.88 \\
\hline Congo, D. R. & 1.43 & 5.42 & Middle income & 1.56 & 3.36 \\
\hline Lesotho & 2.14 & 6.26 & & & \\
\hline Madagascar & 4.71 & 7.32 & & & \\
\hline Malawi & 4.85 & 7.93 & & & \\
\hline Mozambique & 4.53 & 8.84 & & & \\
\hline Namibia & 0.37 & 3.11 & & & \\
\hline South Africa & 1.50 & 2.86 & & & \\
\hline Swaziland & 1.67 & 5.84 & & & \\
\hline Tanzania & 3.10 & 6.29 & & & \\
\hline Zambia & 4.79 & 7.64 & & & \\
\hline Zimbabwe & 0.56 & 5.80 & & & \\
\hline
\end{tabular}

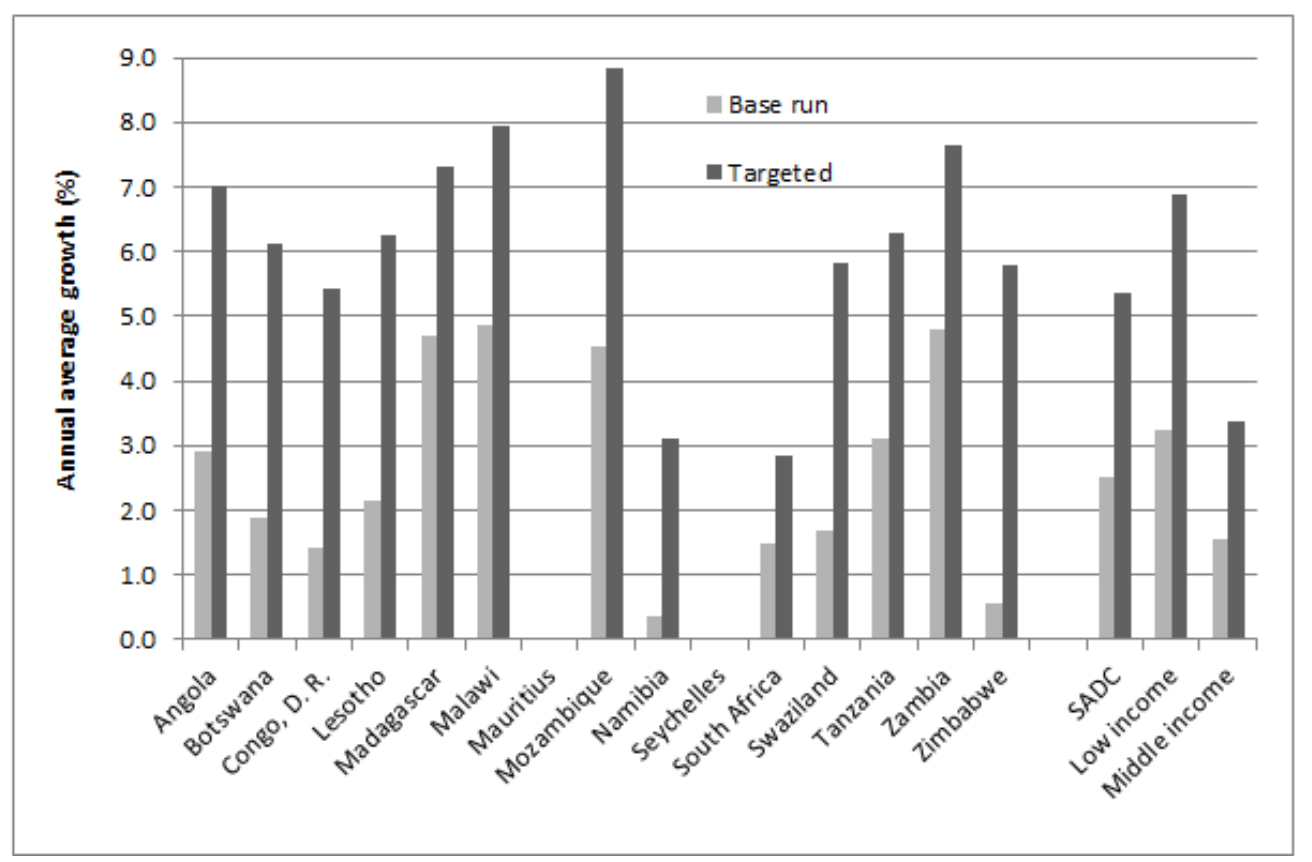

Source: Economywide multimarket model results.

Note: $\quad \mathrm{SADC}=$ Southern Africa Development Community.

Each major subsector's contribution to additional agricultural growth is displayed in Figures 5.9 and 5.10. Additional growth (Figure 5.10) is the difference in the annual growth rate between the two scenarios (Figure 5.9). As Figure 5.10 shows, only Zimbabwe will have additional growth of more than 5 percent per year if its current agricultural potential can be realized. For another five countries, additional growth is more than 4 percent per year. For some of the countries, different subsectors contribute to the additional growth. Grains are the dominant subsector for Zimbabwe to achieve more than 5 percent additional growth, while for most other countries, grains will not play a dominant role in achieving more growth. Rapid agricultural growth in Botswana will depend on its livestock sector, while for Namibia promoting fish growth may be more important. The root crops sector is just as important as grains in Angola, DRC, and Malawi, while it leads in Mozambique. Altogether, and at the regional level, almost 40 percent of the growth will be driven by the grains and roots subsectors, especially among the low-income countries (Figure 5.9). Livestock and fisheries matter more in the middle-income countries. 
Figure 5.9 Subsectors' contribution to additional agricultural growth by country (difference between annual growth rates under the two scenarios)

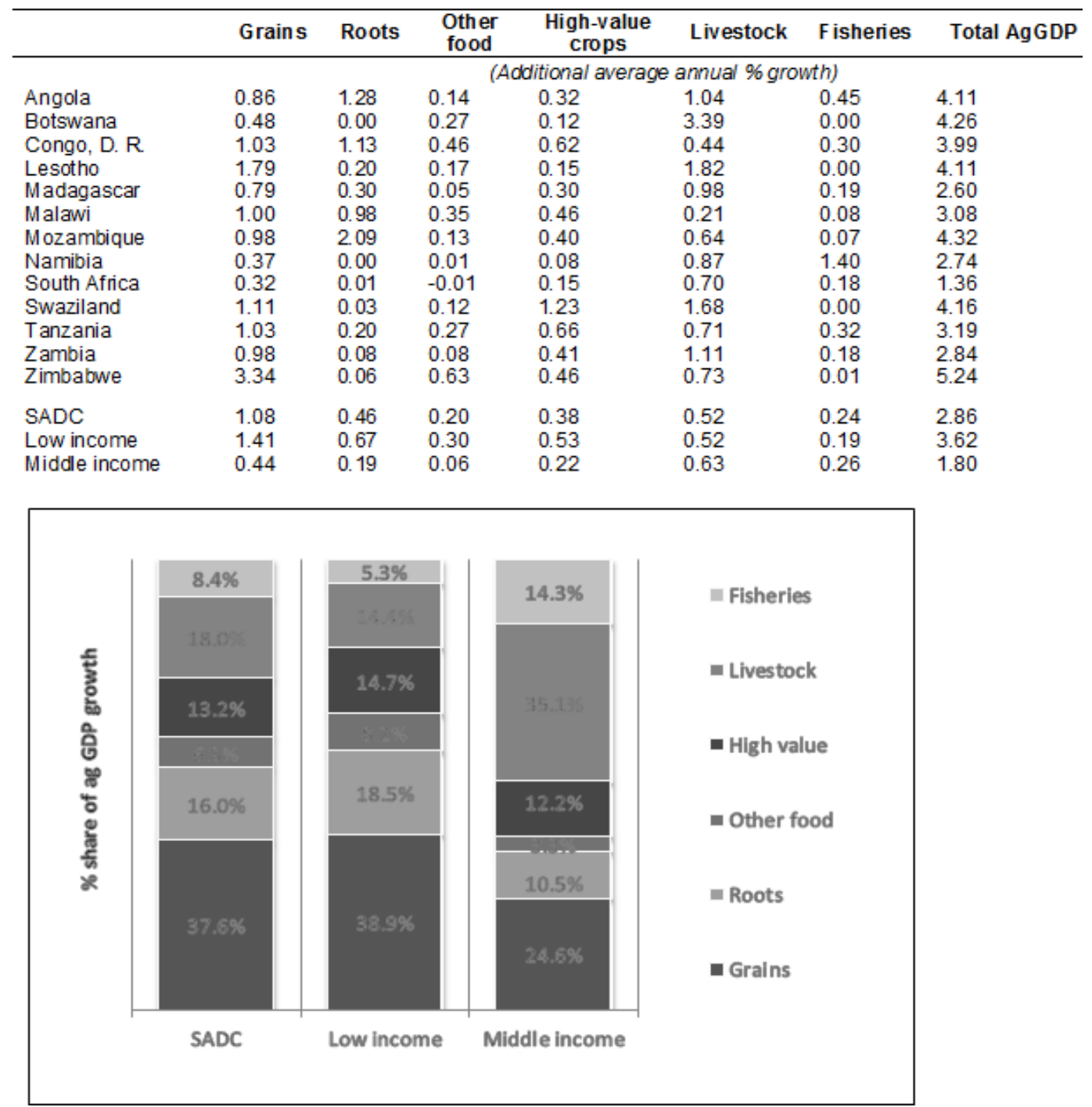

Source: Economywide multimarket model results.

Note: $\quad \mathrm{SADC}=$ Southern Africa Development Community. 
Figure 5.10 Subsectors' contribution to additional agricultural growth by country (difference between annual growth rate under the two scenarios)

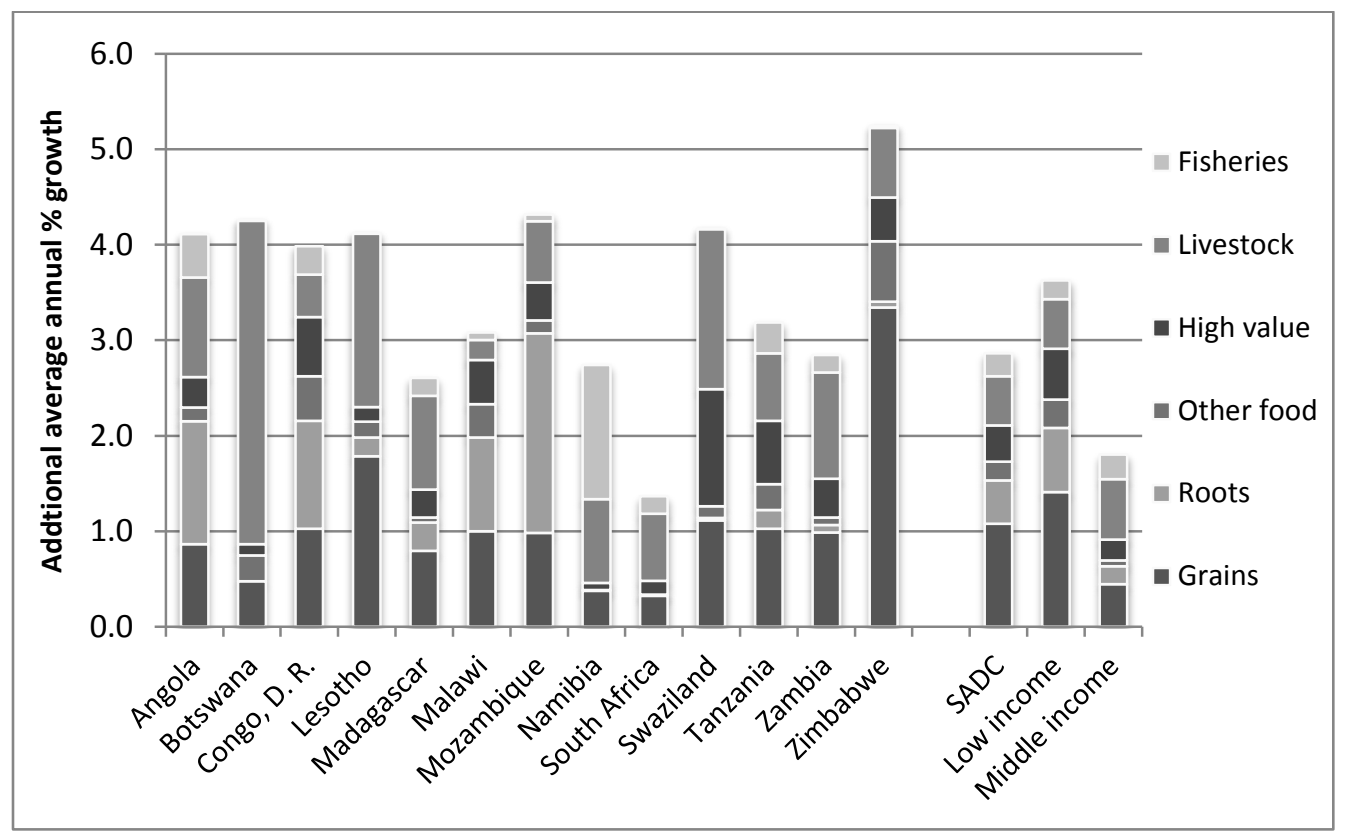

Source: Economywide multimarket model simulation result (data from Figure 5.8).

Note: $\quad \mathrm{SADC}=$ Southern Africa Development Community.

The feasibility of growth is determined not only by the technology but also by market opportunities. For the region as a whole and excluding South Africa, three major grain crops, maize, rice, and wheat, are dependent on imports to meet increased domestic demand. In the initial year of the model, only two countries, Malawi and South Africa, are maize net exporters, while eight countries are maize net importers. Almost all countries are rice and wheat importers, and imports account for 32 and 85 percent, respectively, of total consumption in the region during the initial year. The same is true for the livestock sector, for which only Botswana and Namibia are net exporters. Imports occur in almost all the other countries, while imported livestock products vary across countries. For the region as a whole and excluding South Africa, livestock imports account for 19 percent of total consumption in the initial year. This food import dependency situation will not change much if the region continues to follow its current growth pattern. Moreover, due to faster nonagricultural than agricultural growth and due to ongoing urbanization, livestock imports will grow more rapidly than the domestic supply, which will cause the livestock import-to-consumption ratio to increase to 28 percent by 2015 in the base run.

Speeding up growth in the grain subsector will help the region to reduce dependency on imported maize and rice, and the region will become almost self-sufficient in maize, while the import-toconsumption ratio will barely change in the cases of wheat and livestock products (Figure 5.11). While few countries in the region produce wheat, wheat demand increases rapidly in the urbanization process. The situation differs in the case of livestock products, especially meat. Almost all countries produce some livestock, meat, and poultry products, but these are often unable to compete with imported ones. Moreover, livestock demand has high income elasticity; with income growth, growth in such demand is often more rapid than growth in other food products. These two factors indicate that even though the livestock growth rate increases to 6.8 percent per year in the next six years for the region as a whole, which is more than double its current growth trend, about 22 percent of livestock meat demand in the region will still need to be met by imports (Figure 5.11). If no additional growth takes place, nevertheless, this would easily rise to almost 30 percent (under the baseline scenario). 
Figure 5.11 Share of grain, livestock, and edible oils imports in total consumption

\begin{tabular}{llll}
\hline & Current & \multicolumn{1}{c}{ Base run } & Targeted \\
\hline & 2009 & 2015 & 2015 \\
Maize & 10.9 & 6.8 & 2.9 \\
Rice & 32.3 & 31.0 & 21.7 \\
Wheat & 85.2 & 88.1 & 81.7 \\
Sorghum \& millet & 11.3 & 11.0 & 5.6 \\
Meat $^{3}$ & 20.3 & 29.5 & 22.2 \\
Edible oils $^{\mathrm{a}}$ & 81.4 & 74.1 & 79.6
\end{tabular}

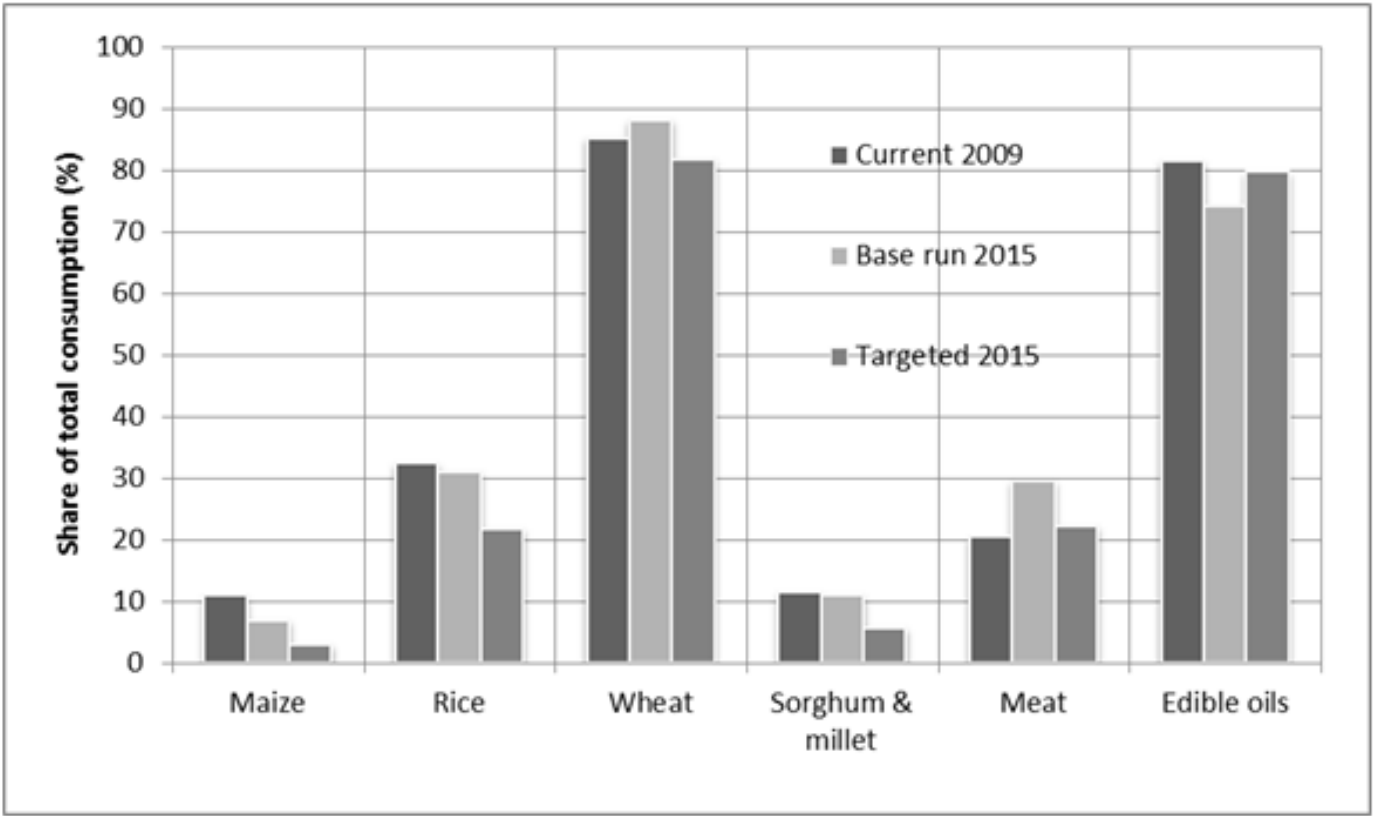

Source: Economywide multimarket model results.

Notes: See Table 5.1 for subsector definitions. ${ }^{a}$ Meat includes beef, pork and other meat. Edible oils includes cottonseed oil, groundnut oil, soybean oil, sesame oil, palm oil, and other edible oils.

The above analysis also indicates that there is enough room for the region to have high growth in many agricultural products. To understand this better, we also pay attention to the possible price effects of rapid growth. Figure 5.12 presents changes in prices for selected products, averaged from those faced by each country's consumers and producers in the domestic markets. As expected, rapid growth in agricultural products with low income elasticity can cause their prices to fall, as is the case for millet and sweet potatoes. However, prices fall modestly for most crops and barely change for most livestock products. For example, the maize price falls by 2 percent annually for the region as a whole, and the potato price even continues to increase. This result seems to indicate that for the region as a whole, there exist market opportunities for most agricultural products, particularly for those with relatively high income elasticity. 
Figure 5.12 Price effects of growth scenarios

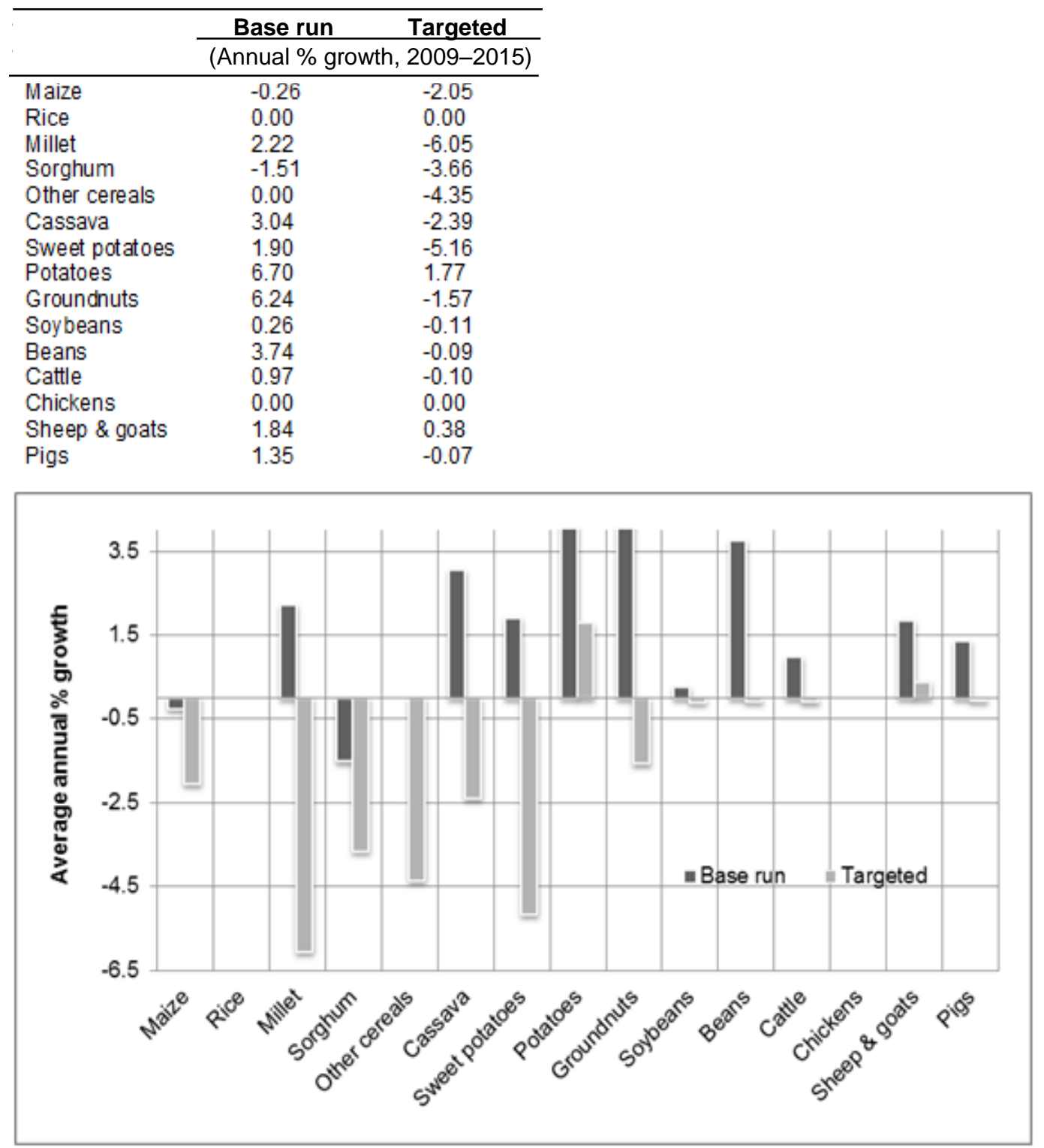

Source: Economywide multimarket model results.

\section{Model Results: Consideration of Technology Spillovers}

In this scenario, we use the results from the previous growth scenario to decompose the contribution to growth between own yield effects and those stemming from spill-ins. As shown in the previous sections, achieving the SADC agricultural growth targets will require large increases in yields on average by 2015 . The ability to capture technology spill-ins can make the costs dramatically lower than if member states relied solely on their own R\&D. Taking the case of maize production, for example, achieving the SADC yield target of 2.0 tons/ha by 2015 will require many countries to raise their annual average yield by more than 30 percent (Appendix B, Tables B.1-B.3), which will be daunting for several of those countries, but feasible considering that they will still be below their current maximum potential (Figure 5.4). 
Looking at the total incremental gains in value of production over the simulation period, Table 5.4 shows the range of commodities that stand to gain the most from spillovers. At the SADC level, these are maize, rice, cattle, cassava, sorghum, and beans (more than US\$100 million in cumulative value terms, between 2009 and 2015). With the exception of cassava, the share of spillovers in the total gains from growth is also higher across these commodities, ranging between 16.3 and 33.2 percent. Overall, the low-income countries are bound to gain greater spillovers from improved technologies in the grains and roots subsectors, about 20 percent of total gains (that is, including own effects), compared with only 2.2 percent among middle-income countries (Figure 5.13). Among member states of the low-income group, Angola, DRC, Mozambique, Tanzania, and Zimbabwe stand to potentially benefit the most, accounting for a substantial share of the total gain across all selected commodities (including livestock), about 86 percent, and ranging in value from US\$240 million to US\$776 million over six years, 2009-2015 (Table 5.5). For maize, Angola, Mozambique, Tanzania, and Zimbabwe capture up to 90 percent of the total spillover gains in the SADC region. For rice, it is Madagascar, Mozambique, and Tanzania, and for cassava, it is primarily Tanzania.

Table 5.4 Commodities with greatest spillover potential in SADC

\begin{tabular}{|c|c|c|c|c|c|c|c|c|c|}
\hline \multirow[t]{2}{*}{ Commodity } & \multicolumn{3}{|c|}{ Own effect } & \multicolumn{3}{|c|}{ Spillover effect } & \multicolumn{3}{|c|}{$\begin{array}{c}\text { Share of spillover to total } \\
\text { (total = own effect }+ \text { spillover) }\end{array}$} \\
\hline & $\begin{array}{c}\text { Low } \\
\text { income }\end{array}$ & $\begin{array}{l}\text { Middle } \\
\text { income }\end{array}$ & $\begin{array}{c}\text { SADC } \\
\text { total }\end{array}$ & $\begin{array}{c}\text { Low } \\
\text { income }\end{array}$ & $\begin{array}{l}\text { Middle } \\
\text { income }\end{array}$ & $\begin{array}{c}\text { SADC } \\
\text { total }\end{array}$ & $\begin{array}{c}\text { Low } \\
\text { income }\end{array}$ & $\begin{array}{l}\text { Middle } \\
\text { income }\end{array}$ & $\begin{array}{c}\text { SADC } \\
\text { total }\end{array}$ \\
\hline & \multicolumn{6}{|c|}{ US\$millions (cumulated over six years, 2009-2015) } & \multicolumn{3}{|c|}{$\%$} \\
\hline Beans & 837 & 40 & 877 & 183 & 2 & 184 & 17.9 & 3.8 & 17.4 \\
\hline Cassava & 3,263 & 0 & 3,263 & 264 & 0 & 264 & 7.5 & 0.0 & 7.5 \\
\hline Cotton & 211 & 23 & 234 & 39 & 1 & 40 & 15.6 & 3.1 & 14.6 \\
\hline Groundnuts & 401 & 6 & 407 & 82 & 1 & 82 & 17.0 & 7.9 & 16.8 \\
\hline Maize & 3,792 & 1,078 & 4,870 & 1,199 & 27 & 1,226 & 24.0 & 2.5 & 20.1 \\
\hline $\begin{array}{l}\text { Millet } \\
\text { Potatoes/ }\end{array}$ & 115 & 19 & 135 & 23 & 3 & 26 & 16.6 & 14.5 & 16.3 \\
\hline $\begin{array}{l}\text { sweet } \\
\text { potatoes }\end{array}$ & 745 & 42 & 787 & 79 & 0 & 79 & 9.5 & 0.9 & 9.1 \\
\hline Rice & 1,721 & 1 & 1,722 & 426 & 0 & 426 & 19.9 & 4.7 & 19.9 \\
\hline Sorghum & 331 & 52 & 383 & 184 & 6 & 190 & 35.8 & 9.9 & 33.2 \\
\hline Sugarcane & 90 & 94 & 185 & 11 & 0 & 11 & 10.7 & 0.0 & 5.5 \\
\hline Wheat & 1,723 & 549 & 2,272 & 70 & 2 & 71 & 3.9 & 0.3 & 3.0 \\
\hline Cattle & 1,002 & 506 & 1,508 & 290 & 4 & 294 & 22.5 & 0.7 & 16.3 \\
\hline Pigs & 536 & 150 & 686 & 34 & 1 & 35 & 5.9 & 0.5 & 4.8 \\
\hline $\begin{array}{l}\text { Sheep and } \\
\text { goats }\end{array}$ & 358 & 439 & 797 & 43 & 3 & 46 & 10.6 & 0.7 & 5.4 \\
\hline Poultry & 659 & 987 & 1,646 & 59 & 19 & 78 & 8.2 & 1.9 & 4.5 \\
\hline Total & 15,782 & 3,987 & 19,770 & 2,985 & 67 & 3,053 & 15.9 & 1.7 & 13.4 \\
\hline
\end{tabular}

Source: Economywide multimarket model and spillover matrix results.

Notes: $\quad \mathrm{SADC}=$ Southern Africa Development Community. Gains are measured as the total benefits accruing over six years (2009-2015) from the difference between the growth and baseline scenarios. 
Figure 5.13 Subsectors with greatest potential gains from research and development spillovers in SADC (comparing between low- and middle-income countries)

a) Low-income countries

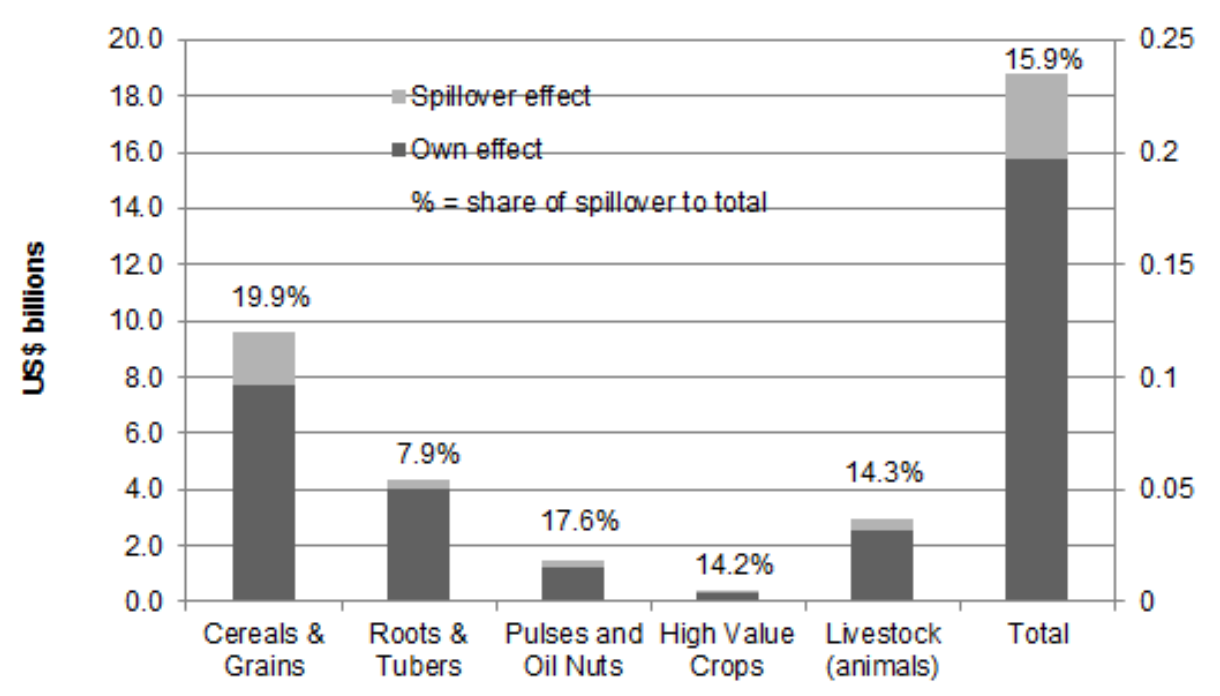

b) Middle-income countries

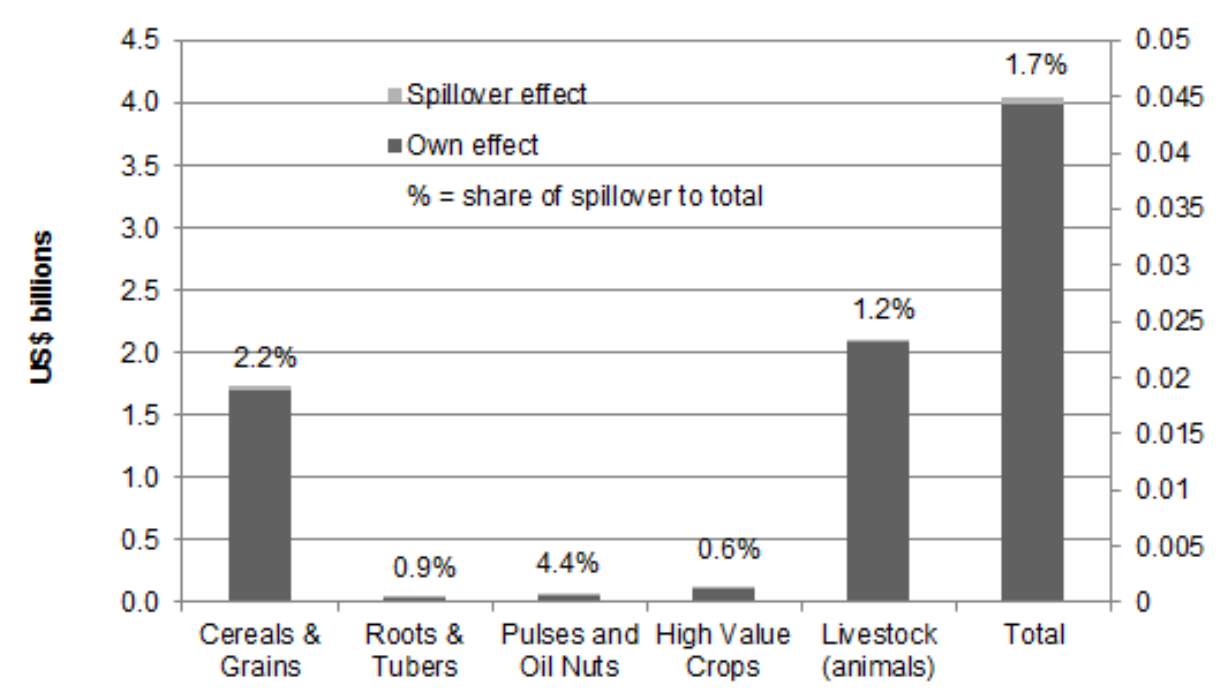

Source: Economywide multimarket model and spillover matrix results.

Notes: Gains are measured as the total benefits accruing over six years (2009-2015) from the difference between the growth and baseline scenarios. SADC $=$ Southern Africa Development Community.

There are important differences underlying these results, however. Angola and DRC stand to gain primarily from their large yield differences from the high-performing countries and moderate adaptive research capacity. The gains in the case of Tanzania and Zimbabwe, on the other hand, are more from their relatively high research capacity. Regarding spill-outs (as sources of technology), South Africa, Swaziland, Zambia, Malawi, and Madagascar generate about 82 percent of the spillovers (Table 5.6). Maize technologies are the primary source from these countries. For cassava, Tanzania dominates as a source country, while bean technologies are primary sourced from South Africa, Lesotho, and Namibia. 


\begin{tabular}{|c|c|c|c|c|c|c|c|c|c|c|c|c|c|c|c|c|c|}
\hline Country & 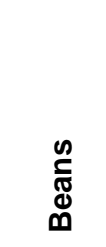 & $\begin{array}{l}\underset{\mathbb{S}}{\mathbb{S}} \\
\underset{\mathbb{J}}{\mathscr{J}}\end{array}$ & 응 & 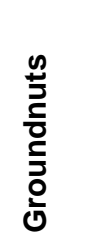 & $\frac{\mathbb{N}}{\stackrel{N}{\pi}}$ & $\frac{\bar{\Xi}}{\bar{\Sigma}}$ & 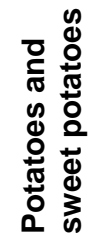 & $\frac{\Phi}{\tilde{\alpha}}$ & $\begin{array}{l}\text { E } \\
\text { 등 } \\
\text { ㅎํㅇ }\end{array}$ & 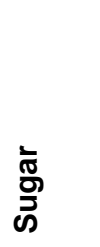 & $\frac{\pi}{\mathbb{\pi}}$ & 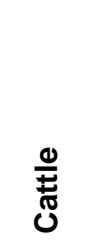 & $\frac{n}{20}$ & 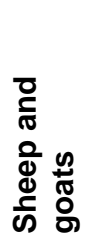 & $\frac{\geqq}{\frac{Z}{3}}$ & $\begin{array}{l}\bar{\pi} \\
\stackrel{0}{0}\end{array}$ & 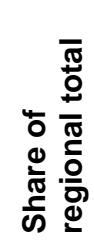 \\
\hline & \multicolumn{16}{|c|}{ Cumulative total, 2009-2015 (US\$ millions) } & (\%) \\
\hline Angola & 24.3 & - & 0.2 & - & 293.3 & 4.1 & 13.9 & 2.1 & - & 0.5 & 1.6 & 26.6 & 0.5 & - & 3.2 & 370.2 & 12.1 \\
\hline Botswana & 1.3 & - & - & 0.1 & 6.3 & 0.0 & - & - & 4.3 & - & 0.1 & 3.5 & 0.3 & 3.0 & 16.9 & 35.8 & 1.2 \\
\hline Congo, D. R. & 29.3 & - & 2.1 & 23.7 & 100.1 & 0.4 & 3.9 & 52.8 & 0.2 & 0.1 & 2.3 & 2.6 & 9.4 & 4.8 & 8.7 & 240.5 & 7.9 \\
\hline Lesotho & 0.1 & - & - & - & 0.3 & - & 0.2 & - & 0.3 & - & 1.4 & 2.0 & 1.9 & 2.2 & 0.4 & 8.9 & 0.3 \\
\hline Madagascar & - & - & 1.8 & - & 17.6 & - & - & 122.2 & 0.1 & 2.1 & 1.2 & 47.4 & - & 2.6 & 0.5 & 195.4 & 6.4 \\
\hline Malawi & 22.7 & - & 1.2 & 9.6 & 16.7 & - & 22.0 & 21.0 & 7.4 & - & 1.1 & - & 1.8 & 1.2 & 1.2 & 105.9 & 3.5 \\
\hline Mauritius & - & - & - & - & - & - & - & - & - & - & - & - & - & - & - & - & - \\
\hline Mozambique & 18.2 & 253.8 & 8.3 & 5.4 & 167.5 & 1.9 & 15.9 & 109.7 & 63.0 & 6.7 & 1.3 & 14.3 & 0.4 & 3.8 & 7.7 & 677.9 & 22.2 \\
\hline Namibia & - & - & - & 0.0 & 17.0 & 3.2 & - & - & 1.4 & - & 1.5 & - & 0.0 & - & 0.3 & 23.5 & 0.8 \\
\hline Seychelles & - & - & - & - & - & - & - & - & - & - & - & - & - & - & - & - & - \\
\hline South Africa & - & - & - & - & - & 0.0 & - & 0.0 & - & - & - & - & - & - & - & 0.1 & 0.0 \\
\hline Swaziland & 0.2 & - & 0.7 & 0.4 & 3.9 & - & 0.4 & - & 0.0 & - & 0.1 & - & 0.5 & - & 1.5 & 7.8 & 0.3 \\
\hline Tanzania & 59.1 & - & 7.2 & 13.6 & 207.3 & - & 12.3 & 117.0 & 55.2 & - & 60.8 & 175.6 & 11.5 & 23.9 & 33.0 & 776.4 & 25.4 \\
\hline Zambia & 0.9 & 1.7 & 2.4 & 1.8 & 4.7 & - & 0.1 & 1.5 & 3.0 & 1.2 & - & 21.8 & 4.0 & 1.1 & 1.3 & 45.6 & 1.5 \\
\hline Zimbabwe & 28.2 & 8.5 & 15.9 & 27.8 & 391.9 & 16.6 & 10.3 & 0.2 & 55.3 & 0.2 & - & - & 4.1 & 2.9 & 2.9 & 564.7 & 18.5 \\
\hline $\begin{array}{l}\text { Low } \\
\text { income }\end{array}$ & 182.8 & 264.0 & 39.1 & 81.9 & 1,199.3 & 23.0 & 78.6 & 426.4 & 184.4 & 10.8 & 69.7 & 293.9 & 33.8 & 45.5 & 72.1 & $2,985.5$ & 97.8 \\
\hline $\begin{array}{l}\text { Middle } \\
\text { income }\end{array}$ & 1.6 & - & 0.7 & 0.5 & 27.1 & 3.3 & 0.4 & 0.0 & 5.7 & - & 1.6 & - & 0.7 & - & 5.5 & 67.2 & 2.2 \\
\hline SADC & 184.4 & 264.0 & 39.9 & 82.4 & $1,226.4$ & 26.3 & 79.0 & 426.4 & 190.1 & 10.8 & 71.3 & 293.9 & 34.5 & 45.5 & 77.7 & $3,052.7$ & 100.0 \\
\hline
\end{tabular}

Source: Economywide multimarket model and spillover matrix results.

Notes: $\quad$ SADC $=$ Southern Africa Development Community. Total benefits accruing over six years (2009-2015) from the difference between the growth and baseline scenarios. 


\begin{tabular}{|c|c|c|c|c|c|c|c|c|c|c|c|c|c|c|c|c|c|}
\hline Country & 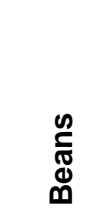 & 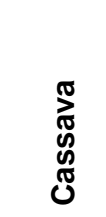 & c & 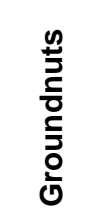 & $\frac{\mathbb{N}}{\mathbb{N}}$ & $\stackrel{\text { 㐫 }}{\underline{\Sigma}}$ & 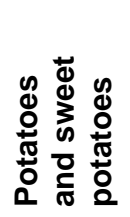 & $\frac{\Phi}{\mathbb{x}}$ & $\begin{array}{l}\text { E } \\
\text { ㄹ } \\
\text { o } \\
\text { க் }\end{array}$ & 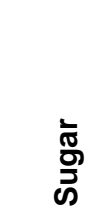 & $\frac{\mathbb{\pi}}{\stackrel{\mathbb{8}}{5}}$ & 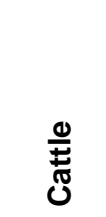 & $\frac{0}{20}$ & 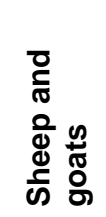 & $\frac{\geqq}{\frac{2}{3}}$ & 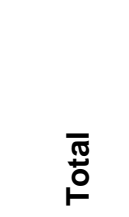 & 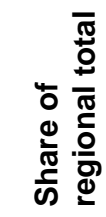 \\
\hline & \multicolumn{16}{|c|}{ Cumulative total, 2009-2015 (US\$millions) } & (\%) \\
\hline Angola & - & 9.1 & 2.1 & - & 0.6 & 2.3 & 6.7 & - & - & 1.0 & 12.9 & 26.3 & 4.2 & 12.9 & 0.7 & 78.8 & 2.6 \\
\hline Botswana & 8.0 & - & 9.0 & 22.8 & - & - & - & - & - & - & - & 39.6 & 2.3 & 0.1 & 0.0 & 81.8 & 2.7 \\
\hline Congo, D. R. & 1.8 & 5.5 & - & 4.4 & 0.6 & 6.3 & 8.2 & - & 12.4 & 0.9 & - & 35.5 & - & - & - & 75.8 & 2.5 \\
\hline Lesotho & 35.0 & - & - & - & 7.1 & - & 0.1 & - & 20.1 & - & - & - & - & - & - & 62.4 & 2.0 \\
\hline Madagascar & 29.1 & 5.6 & 1.7 & 20.6 & 122.2 & - & 47.7 & 38.8 & 0.7 & 0.7 & 11.1 & - & 9.5 & - & 27.7 & 315.4 & 10.3 \\
\hline Malawi & 3.7 & 3.8 & 0.2 & 4.5 & 149.1 & 2.9 & 2.3 & 17.2 & 11.2 & 2.0 & 7.5 & 35.4 & 2.3 & 1.1 & 1.1 & 244.1 & 8.0 \\
\hline Mauritius & - & - & - & - & - & - & - & - & - & - & - & - & - & - & - & - & - \\
\hline Mozambique & 2.9 & 4.3 & 0.3 & - & 39.7 & 2.3 & 0.2 & 8.5 & 9.0 & - & - & 20.8 & 5.5 & - & 2.1 & 95.5 & 3.1 \\
\hline Namibia & 32.1 & - & 6.5 & 0.0 & 107.0 & 0.0 & - & - & - & - & 14.2 & 42.9 & 4.4 & 13.7 & 7.7 & 228.4 & 7.5 \\
\hline Seychelles & - & - & - & - & - & - & - & - & - & - & - & - & - & - & - & - & - \\
\hline South Africa & 35.7 & - & 10.4 & 21.9 & 317.9 & 3.2 & 13.3 & 46.7 & 105.1 & 1.8 & 14.4 & 9.1 & 2.1 & 1.7 & 6.9 & 590.4 & 19.3 \\
\hline Swaziland & 7.6 & - & - & 5.6 & 227.5 & - & - & 191.8 & 0.5 & 1.3 & - & 41.1 & 2.0 & 15.7 & 2.7 & 495.8 & 16.2 \\
\hline Tanzania & 10.9 & 233.4 & 0.4 & - & 18.6 & 5.2 & 0.2 & 45.3 & 22.7 & 1.4 & - & - & - & - & 2.9 & 341.0 & 11.2 \\
\hline Zambia & 3.0 & 2.4 & 8.8 & - & 184.5 & 4.0 & 0.1 & 32.4 & 7.9 & 1.0 & - & 13.0 & - & 0.4 & 7.8 & 265.4 & 8.7 \\
\hline Zimbabwe & 14.6 & - & 0.5 & 2.7 & 51.6 & - & 0.2 & 45.7 & 0.5 & 0.6 & 11.3 & 30.3 & 2.2 & 0.0 & 18.1 & 178.1 & 5.8 \\
\hline \multirow{2}{*}{$\begin{array}{l}\text { Low income } \\
\text { Middle } \\
\text { income }\end{array}$} & 101.0 & 264.0 & 14.0 & 32.2 & 574.0 & 23.1 & 65.7 & 187.9 & 84.5 & 7.6 & 42.7 & 161.2 & 23.7 & 14.3 & 60.3 & $1,656.4$ & 54.3 \\
\hline & 83.3 & - & 25.9 & 50.3 & 652.4 & 3.2 & 13.3 & 238.5 & 105.6 & 3.2 & 28.6 & 132.7 & 10.8 & 31.2 & 17.3 & 1,396.3 & 45.7 \\
\hline SADC & 184.4 & 264.0 & 39.9 & 82.4 & $1,226.4$ & 26.3 & 79.0 & 426.4 & 190.1 & 10.8 & 71.3 & 293.9 & 34.5 & 45.5 & 77.7 & $3,052.7$ & 100.0 \\
\hline
\end{tabular}

Source: Economywide multimarket model and spillover matrix results.

Notes: $\quad$ SADC $=$ Southern Africa Development Community. Total benefits accruing over six years (2009-2015) from the difference between the growth and baseline scenarios. 


\section{SUMMARY RANKINGS AND POLICY IMPLICATIONS ${ }^{10}$}

The primary objective of this study has been to inform the SADC Secretariat and member states on how they might position their priorities for a regional agricultural R\&D strategy, especially in order to meet the goals of RISDP and CAADP. A number of key questions were posed in the beginning and would also serve as important criteria for ranking proposed $R \& D$ priorities:

- What investment and policy options, and in which key commodity areas, offer the best potential for accelerating agricultural-sector growth and national incomes in order to reduce poverty and food insecurity in the SADC region?

- Among the key commodity areas, which ones would be most suitable for a regional R\&D program to focus on, based on their potential for adaptation and direct transfer (or spillover) across countries?

- And finally, what kinds of constraints and other complementary or cross-cutting issues are important to consider in the context of enhancing productivity growth in the SADC countries?

Drawing on the final results of analysis in Section 5, we summarize the results to suggest some initial rankings based on the first two criteria by country, by commodity, and at the regional level (including both the SADC-wide and low-income groupings). Table 6.1 first ranks the contribution to agricultural growth. Based on this criterion alone, maize, rice, cassava, and cattle and dairy dominate. Maize is a leading sector in at least five countries, while cassava comes in first in three countries. With regard to rankings based on spillover potential, Table 6.2 also shows maize taking the lead, especially in terms of the number of countries that benefit most from maize technology spill-ins (up to six member states).

In combining both criteria, we can further suggest some final rankings. This is done by using a simple scoring method that weighs the importance of each criterion across all of SADC and for the lowincome group. Since the weights are subjective, and other criteria will undoubtedly matter, this is meant to serve only as an example of how such a tool can be applied in producing final rankings based on other criteria and weighting that may be important to stakeholders. Here we have chosen to weight them all equally. Tables 6.3 and 6.4 present the results of these rankings.

According to these final rankings under both criteria, focusing on maize, rice, and cassava provides the highest returns (Table 6.3). These are followed closely by cattle and dairy, fruits and vegetables, and fisheries. Other commodities that rank from the 7th to 10th position include beans, sorghum, wheat, and potatoes and sweet potatoes. Wheat drops out and is replaced by poultry when the ranking is restricted to the low-income group of countries (Table 6.4).

${ }^{10}$ This section was authored by Michael Johnson and Pius Chilonda. 
Table 6.1 Ranking by contribution to agricultural growth, as share of total agricultural GDP growth

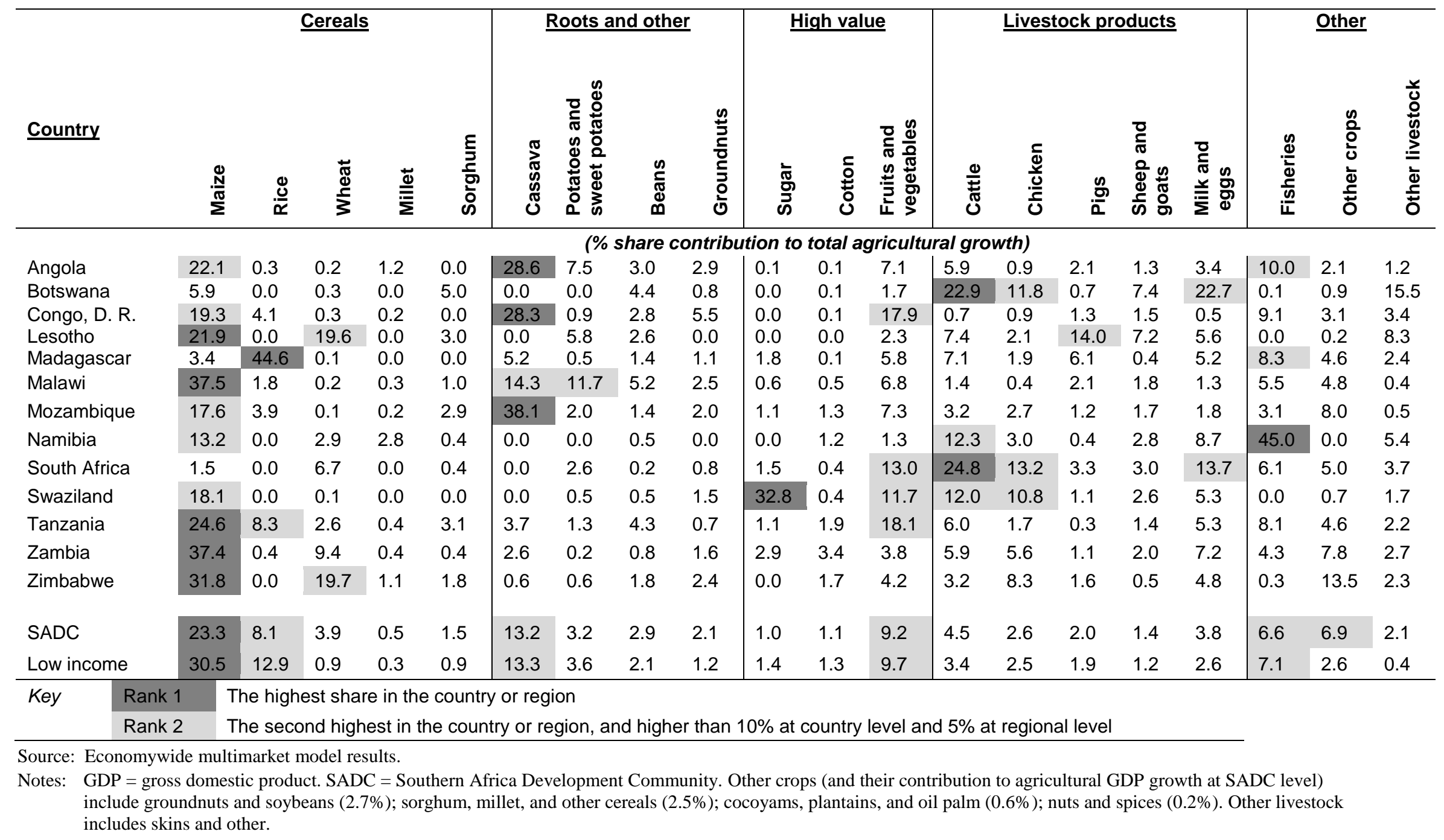


Table 6.2 Ranking of spillover beneficiaries across commodities (left to right in each row)

\begin{tabular}{|c|c|c|c|c|c|c|c|c|c|c|c|c|c|c|c|}
\hline \multirow[t]{2}{*}{ Country } & $\frac{\mathbb{N}}{\mathbb{N}}$ & $\frac{d}{0}$ & 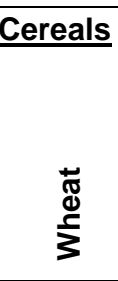 & $\stackrel{\varpi}{\stackrel{\Xi}{\Sigma}}$ & 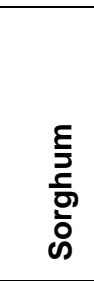 & 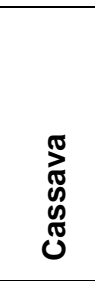 & 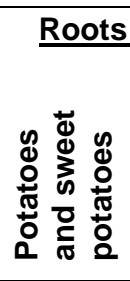 & 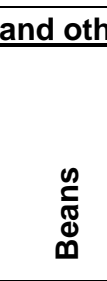 & $\begin{array}{l}\frac{n}{3} \\
\frac{5}{0} \\
\frac{5}{3} \\
\frac{0}{0}\end{array}$ & 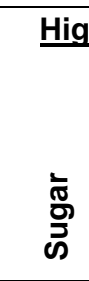 & 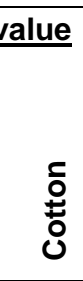 & $\underset{J}{\stackrel{0}{ \pm}}$ & $\begin{array}{l}\frac{c}{d} \\
\frac{v}{0} \\
\frac{c}{0}\end{array}$ & $\frac{n}{20}$ & 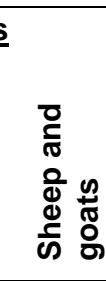 \\
\hline & \multicolumn{15}{|c|}{ (\% of value-added gains attributable to spill-ins, 2009-2015) } \\
\hline Angola & 79.22 & 0.55 & 0.43 & 1.10 & 0.00 & 0.00 & 3.76 & 6.57 & 0.00 & 0.13 & 0.04 & 7.18 & 0.87 & 0.14 & 0.00 \\
\hline Botswana & 17.44 & 0.00 & 0.24 & 0.06 & 12.07 & 0.00 & 0.00 & 3.74 & 0.20 & 0.00 & 0.00 & 9.90 & 47.22 & 0.72 & 8.41 \\
\hline Congo, D. R. & 41.61 & 21.97 & 0.94 & 0.18 & 0.09 & 0.00 & 1.62 & 12.19 & 9.86 & 0.06 & 0.88 & 1.08 & 3.63 & 3.90 & 1.98 \\
\hline Lesotho & 3.61 & 0.00 & 15.68 & 0.00 & 2.92 & 0.00 & 2.39 & 1.07 & 0.00 & 0.00 & 0.00 & 22.87 & 5.00 & 21.67 & 24.79 \\
\hline Madagascar & 9.03 & 62.52 & 0.59 & 0.00 & 0.04 & 0.00 & 0.00 & 0.00 & 0.00 & 1.05 & 0.93 & 24.27 & 0.25 & 0.00 & 1.32 \\
\hline Malawi & 15.73 & 19.81 & 1.01 & 0.00 & 7.00 & 0.00 & 20.75 & 21.48 & 9.11 & 0.00 & 1.16 & 0.00 & 1.14 & 1.72 & 1.10 \\
\hline Mozambique & 24.71 & 16.18 & 0.19 & 0.28 & 9.29 & 37.44 & 2.35 & 2.68 & 0.80 & 0.99 & 1.23 & 2.10 & 1.13 & 0.06 & 0.57 \\
\hline Namibia & 72.47 & 0.00 & 6.26 & 13.71 & 5.79 & 0.00 & 0.00 & 0.00 & 0.20 & 0.00 & 0.00 & 0.00 & 1.45 & 0.11 & 0.00 \\
\hline South Africa & 0.00 & 53.10 & 0.00 & 46.90 & 0.00 & 0.00 & 0.00 & 0.00 & 0.00 & 0.00 & 0.00 & 0.00 & 0.00 & 0.00 & 0.00 \\
\hline Swaziland & 49.71 & 0.00 & 0.94 & 0.00 & 0.36 & 0.00 & 4.71 & 3.07 & 5.27 & 0.00 & 9.42 & 0.00 & 19.56 & 6.96 & 0.00 \\
\hline Tanzania & 26.70 & 15.07 & 7.84 & 0.00 & 7.11 & 0.00 & 1.58 & 7.61 & 1.75 & 0.00 & 0.92 & 22.62 & 4.24 & 1.48 & 3.08 \\
\hline Zambia & 10.29 & 3.34 & 0.00 & 0.00 & 6.53 & 3.74 & 0.33 & 2.00 & 3.90 & 2.67 & 5.33 & 47.87 & 2.76 & 8.87 & 2.36 \\
\hline Zimbabwe & 69.40 & 0.03 & 0.00 & 2.93 & 9.79 & 1.51 & 1.82 & 4.99 & 4.92 & 0.03 & 2.82 & 0.00 & 0.51 & 0.73 & 0.52 \\
\hline SADC & 40.18 & 13.97 & 2.34 & 0.86 & 6.23 & 8.65 & 2.59 & 6.04 & 2.70 & 0.35 & 1.31 & 9.63 & 2.54 & 1.13 & 1.49 \\
\hline Low income & 40.17 & 14.28 & 2.33 & 0.77 & 6.18 & 8.84 & 2.63 & 6.12 & 2.74 & 0.36 & 1.31 & 9.73 & 1.97 & 1.13 & 1.42 \\
\hline
\end{tabular}

Key $\quad$ Rank $1 \quad$ The largest beneficiary commodity (share of total regional spillover gains), across each row

Rank 2 Other commodities gaining at least $10 \%$ at country level and $5 \%$ at regional level

Source: Spillover analysis results and economywide multimarket results.

Notes: $\quad$ SADC $=$ Southern Africa Development Community. Gains are captured as the difference between the growth and base scenarios over six years (2009-2015). 
Table 6.3 Example of suggested rankings based on growth and spillovers, all SADC

\begin{tabular}{|c|c|c|c|c|c|}
\hline $\begin{array}{l}\text { Major } \\
\text { sector }\end{array}$ & $\begin{array}{c}\text { Commodity or } \\
\text { sector } \\
\text { Weight }\end{array}$ & $\begin{array}{c}\text { Contribution } \\
\text { to agricultural } \\
\text { growth }^{\mathrm{a}} \\
0.25\end{array}$ & $\begin{array}{c}\text { Degree of } \\
\text { regional spillover } \\
\text { potential }^{\mathrm{b}} \\
0.25\end{array}$ & $\begin{array}{c}\text { Total weighted } \\
\text { score } \\
1\end{array}$ & Final rank \\
\hline \multirow{5}{*}{ Cereals } & Maize & 25.6 & 34.9 & 30.3 & 1 \\
\hline & Rice & 8.9 & 12.1 & 10.5 & 3 \\
\hline & Wheat & 4.3 & 2.0 & 3.2 & 9 \\
\hline & Millet & 0.5 & 0.7 & 0.6 & 17 \\
\hline & Sorghum & 1.6 & 5.4 & 3.5 & 8 \\
\hline \multirow{2}{*}{$\begin{array}{l}\text { Roots and } \\
\text { tubers }\end{array}$} & Cassava & 14.5 & 7.5 & 11.0 & 2 \\
\hline & $\begin{array}{l}\text { Potatoes/sweet } \\
\text { potatoes }\end{array}$ & 3.5 & 2.3 & 2.9 & 10 \\
\hline \multirow{3}{*}{$\begin{array}{l}\text { Pulses } \\
\text { and oil } \\
\text { nuts }\end{array}$} & Beans & 3.2 & 5.3 & 4.2 & 7 \\
\hline & Groundnuts & 2.3 & 2.3 & 2.3 & 12 \\
\hline & Sugar & 1.1 & 0.3 & 0.7 & 16 \\
\hline \multirow[t]{3}{*}{ High value } & Cotton & 1.2 & 1.1 & 1.2 & 15 \\
\hline & Fruits and veg. & 10.2 & 7.8 & 9.0 & 4 \\
\hline & Cattle and dairy & 9.2 & 8.4 & 8.8 & 5 \\
\hline Livestock & Chickens and eggs & 2.9 & 2.2 & 2.6 & 11 \\
\hline \multirow[t]{2}{*}{ products } & Pigs & 2.1 & 1.0 & 1.6 & 13 \\
\hline & Sheep and goats & 1.6 & 1.3 & 1.4 & 14 \\
\hline Fisheries & $\begin{array}{l}\text { Fisheries } \\
\text { Total }\end{array}$ & $\begin{array}{l}7.3 \\
100.00\end{array}$ & $\begin{array}{l}5.2 \\
100.00\end{array}$ & $\begin{array}{l}6.3 \\
100.00\end{array}$ & 6 \\
\hline
\end{tabular}

Source: Calculated from spillover analysis results and economywide multimarket model results.

Notes: $\quad$ SADC $=$ Southern Africa Development Community. All values have been indexed to sum to a maximum of 100 . The growth and spillover criteria have been equally weighted in this example. ${ }^{a}$ Based on actual share of the sector's contribution to agricultural growth from Table 6.1. For livestock, cattle and dairy were summed together, as well as chickens and eggs, and sheep and goats. ${ }^{\mathrm{b}}$ Based on the SADC row in Table 6.2.

Table 6.4 Example of suggested rankings based on growth and spillovers, low-income countries

\begin{tabular}{|c|c|c|c|c|c|}
\hline $\begin{array}{l}\text { Major } \\
\text { sector }\end{array}$ & $\begin{array}{c}\text { Commodity or } \\
\text { sector } \\
\text { Weight }\end{array}$ & $\begin{array}{l}\text { Contribution } \\
\text { to agricultural } \\
\text { growth }^{\mathrm{a}} \\
0.25\end{array}$ & $\begin{array}{c}\text { Degree of } \\
\text { regional spillover } \\
\text { potential }^{\mathrm{b}} \\
0.25\end{array}$ & $\begin{array}{c}\text { Total weighted } \\
\text { score } \\
1\end{array}$ & Final rank \\
\hline \multirow{5}{*}{ Cereals } & Maize & 25.6 & 34.9 & 33.2 & 1 \\
\hline & Rice & 8.9 & 12.1 & 12.9 & 2 \\
\hline & Wheat & 4.3 & 2.0 & 1.5 & 12 \\
\hline & Millet & 0.5 & 0.7 & 0.5 & 17 \\
\hline & Sorghum & 1.6 & 5.4 & 3.2 & 8 \\
\hline \multirow{2}{*}{$\begin{array}{l}\text { Roots and } \\
\text { tubers }\end{array}$} & Cassava & 14.5 & 7.5 & 10.7 & 3 \\
\hline & $\begin{array}{l}\text { Potatoes/sweet } \\
\text { potatoes }\end{array}$ & 3.5 & 2.3 & 3.0 & 9 \\
\hline \multirow{3}{*}{$\begin{array}{l}\text { Pulses } \\
\text { and oil } \\
\text { nuts }\end{array}$} & Beans & 3.2 & 5.3 & 3.8 & 7 \\
\hline & Groundnuts & 2.3 & 2.3 & 1.8 & 11 \\
\hline & Sugar & 1.1 & 0.3 & 0.9 & 16 \\
\hline \multirow[t]{3}{*}{ High value } & Cotton & 1.2 & 1.1 & 1.3 & 14 \\
\hline & Fruits and veg. & 10.2 & 7.8 & 8.9 & 4 \\
\hline & Cattle and dairy & 9.2 & 8.4 & 7.3 & 5 \\
\hline Livestock & Chickens and eggs & 2.9 & 2.2 & 2.2 & 10 \\
\hline \multirow[t]{2}{*}{ products } & Pigs & 2.1 & 1.0 & 1.5 & 13 \\
\hline & Sheep and goats & 1.6 & 1.3 & 1.2 & 15 \\
\hline Fisheries & $\begin{array}{l}\text { Fisheries } \\
\text { Total }\end{array}$ & $\begin{array}{l}7.3 \\
100.00\end{array}$ & $\begin{array}{l}5.2 \\
100.00\end{array}$ & $\begin{array}{l}6.3 \\
100.00\end{array}$ & 6 \\
\hline
\end{tabular}

Source: Calculated from spillover analysis results and economywide multimarket model results.

Notes: Low-income countries are all SADC member states excluding Angola, Botswana, Mauritius, Namibia, Seychelles, South Africa, and Swaziland. All values have been indexed to sum to a maximum of 100. The growth and spillover criteria have been equally weighted in this example. ${ }^{\text {a }}$ Based on actual share of the sector's contribution to agricultural growth from Table 6.1. For livestock, cattle and dairy were summed together, as well as chickens and eggs, and sheep and goats. ${ }^{\mathrm{b}}$ Based on the SADC row in Table 6.2. 
So far we have considered only the relative importance of commodities based on their potential contribution to future income growth and research spillovers by explicitly drawing from the results of our analysis. Other considerations may also matter, such as their relative contribution to poverty reduction. However, we are sufficiently confident the top rankings, food staples among cereals and livestock products, will also lead to greater poverty reduction in the region. Not only do they drive overall economic growth, but they also contribute the most to income earnings among the rural poor in many countries. Additionally, there is sufficient evidence from a number of country case studies in the region showing this strong link, such as those by Benin and others (2008) for Malawi, Thurlow (2008) for Mozambique, and Thurlow et al. (2008) for Zambia.

Another important issue facing the region has to do with improving food security and nutrition. Ensuring availability of a diversified diet of food staples may also be desirable in order to avoid promoting dominant cereals (such as maize) on their own. Nevertheless, the rankings include a number of commodities that are known to have higher nutritional content (for example, beans, fruits and vegetables, groundnuts, meats, sweet potatoes, dairy, and eggs). To illustrate, we offer a simple diagram in Figure 6.1, which groups each of the 10 highest-ranked commodities by their dominant nutritional value.

Additionally, we would also expect food security and nutrition to improve as incomes grow and diets shift to more diversified and higher-value foods (for example, meats, eggs, and fruits and vegetables).

However, because improving nutrition security cannot come only from agriculture - since it is not only about availability and access, but also about utilization and stability — other investments will be needed to help improve access to health and education services, especially for children and women.

\section{Figure 6.1 Suggested top 10 final rankings grouped by nutritional value, low-income countries only}

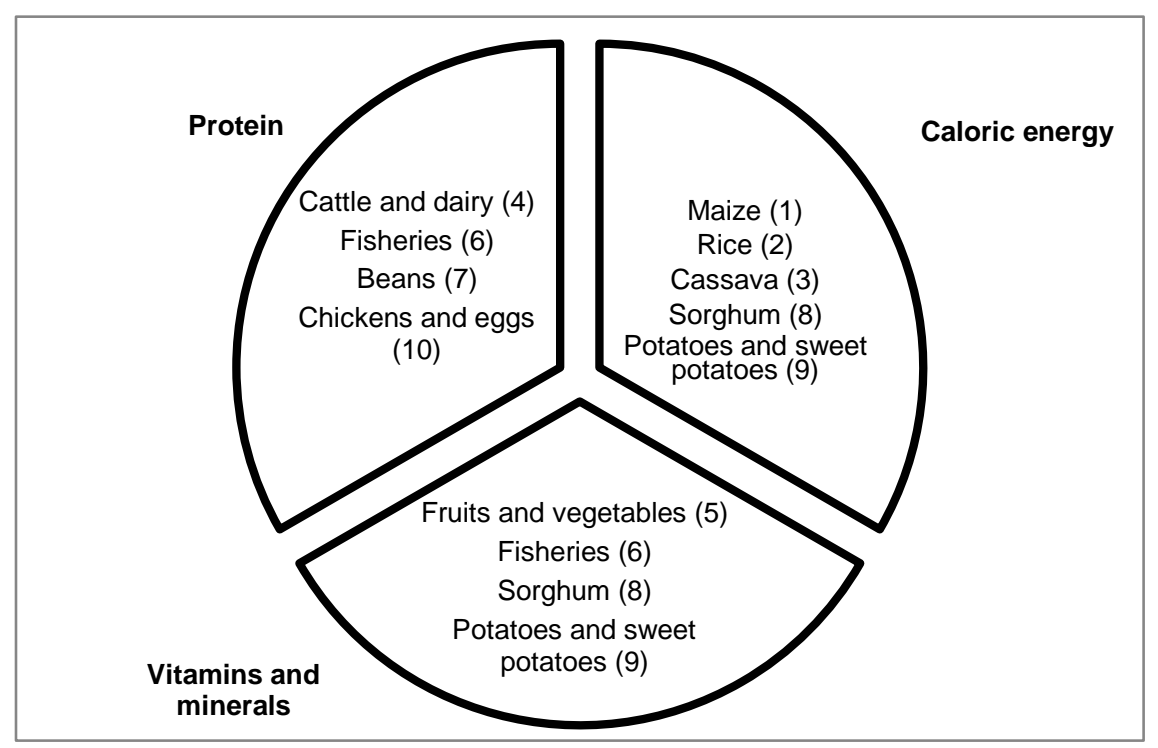

Source: Authors' illustration.

Note: Low-income countries are all SADC member states excluding Angola, Botswana, Mauritius, Namibia, Seychelles, South Africa, and Swaziland.

Finally, while such rankings can help to narrow the key focus commodities for a regional agricultural R\&D strategy, they do not necessarily identify the specific type of R\&D interventions needed for each commodity. Further detailed studies will be required to determine the specific approaches. However, important broader policy and investment implications emerge from the results of analysis and key commodity rankings. Table C.1 in Appendix C suggests a summary of these implications based on the detailed findings in this study. Here are highlights of the key findings: 
- Food staple grains contribute more than 35 percent of projected SADC total agricultural growth, and among these, maize dominates by explaining between 19 and 41 percent of agricultural GDP growth in nine member states: Angola, DRC, Lesotho, Malawi, Mozambique, Swaziland, Tanzania, Zambia, and Zimbabwe. Cassava follows close behind.

- Growth in grain yields and output will reduce the need for imports. For maize, the region gets closer to becoming self-sufficient, with imports likely to fall to about 2 percent of total consumption relative to a current 10 percent.

- The projected modest price reductions from output growth in food staples stand to benefit consumers in both rural and urban areas. In most cases, producers still benefit, given the rate of yield increases. However, investments will still be needed in storage, processing technologies, and links with agro-industries for feed and biofuels (particularly linking lowincome countries with middle-income countries where such industries are already well developed) to absorb any significant output growth in the future.

- For rice, demand is less a problem given that current production is well below demand. In fact, demand is likely to grow over time with urban population growth. The challenge will be meeting local demand and competing with imports.

- Livestock is particularly important among the middle-income countries (especially Botswana, South Africa, Namibia, and Swaziland), with cattle contributing up to 24 percent of the agricultural-sector growth in this group of countries. Because this is a sector that will continue to face increasing demand as incomes rise, demand growth could easily exceed growth in production unless there is significant yield growth.

- Because of the dominance of crop-livestock systems among smallholders, crops such as sorghum and millet may also need consideration (especially in semiarid agricultural regions of Angola, Botswana, Zambia, Zimbabwe, and Namibia).

- Improving access to inputs, especially given the dependence of key crops (maize) on fertilizer, is going to be an important challenge, especially considering the risks associated with rainfall uncertainty and high costs of inputs in many maize-growing areas.

- Reducing the high costs of inputs (for example, fertilizer and irrigation) is going to be imperative. The introduction of targeted input subsidies may be warranted in some regions, but in ways that do not crowd out private-sector input dealers. Complementary investments may also be needed to improve the performance of fertilizer distribution systems, such as through reducing costs of importing, marketing, and distribution, in addition to investments in irrigation and other water management technologies.

- Promoting regional input markets, for example through harmonization of seed laws and regulations across countries, will be important. The creation of a common fertilizer market could also prove beneficial to many of the low-income countries.

- There will be a need to weigh costs and benefits between more intensive input packages, such as hybrids, in high-market-access areas versus low-input packages (for example, openpollinated varieties) in low-market-access areas.

- There is a need to take advantage of significant capacity for R\&D in middle-income countries (for example, South Africa) and advanced programs in low-income countries (for example, Tanzania). Close collaboration, consultation, and coordination across various R\&D efforts in the region need to be promoted. In addition to commodity research, analysis on how to institutionalize the research priorities will be helpful.

- One foreseeable challenge will be generating sufficient incentives among member states to share technologies when they have enjoyed a competitive advantage in regional and global markets as a result of the technology.

- Finally, there is a need to build regional analytical capacity in research priority setting and impact assessment, through strong support from universities, donors, and international institutions. 


\section{CONCLUSION ${ }^{11}$}

The study has shown that carefully planned R\&D spending, which addresses goals formulated at the regional level and takes into account the potential for research spillovers, can help the SADC region meet its overall agricultural-sector growth targets. For 10 of 13 SADC countries, the overall annual agricultural growth reaches more than or close to 6 percent, a target set in the CAADP framework. Across all countries and at the regional level, the principal driver for future agricultural growth can come from the cereals and roots subsectors, especially among the low-income countries. Together, these subsectors have the potential to contribute up to 40 percent of future growth.

Member states have the potential to reap large economic benefits from pooling their R\&D resources to find common technology solutions that can drive growth in the region. As we have shown in this study, many countries in the SADC region have large areas that share similar characteristics of agricultural potential and market access with neighboring countries - in effect, unique development domains that require similar targeted R\&D and technology development solutions. However, there are also differences in terms of comparative advantage, which offer opportunities for specialization in cereals, livestock, or fisheries.

The type of relevant R\&D efforts to promote at the regional level must ultimately focus on those commodities that offer the greatest potential for technology spillovers, in addition to their importance in influencing overall sector growth, incomes, and food security, especially among the majority rural smallholder population in the region. According to the results in this study, the range of commodities that stand to gain the most from spillovers are maize, rice, cattle, cassava, sorghum, and beans. These together show a cumulative value of US $\$ 100$ million in production output due to potential spillovers between 2009 and 2015. Except for cassava, the share of total spillovers across all commodities is also higher among these commodities, ranging between 16.3 and 33.2 percent. Overall, the low-income countries gain the most in spillovers from R\&D in the grains and roots subsectors, explaining about 20 percent of the additional gains in the total value of production from yield growth, compared with only 2.2 percent among middle-income countries in SADC.

In combining both criteria - the contribution to growth and the potential for research spilloversthe study finds that focusing on maize, rice, and cassava provides the highest returns. These are followed closely by cattle and dairy, fruits and vegetables, and beans. Other commodities that rank from the 7th to 10 th positions include fisheries, sorghum, wheat, and potatoes and sweet potatoes. Fisheries would rank higher than beans among the lower-income group of countries.

Potential to spur future economic growth and spillover potential from R\&D investments are indeed useful criteria for setting future regional-level commodity priorities. However, they cannot be the only ones. Other criteria may also matter, such as contribution to nutrition, concerns about climate change, and gender considerations. Nutrition, for example, cannot come solely from agricultural growth, since it is not only about availability and access, but also about utilization and stability. Initially, food security and nutrition should improve as incomes grow and diets shift to more diversified and highervalue foods (for example, meats, eggs, and fruits and vegetables). However, other investments will still be needed to improve access to health and education services, especially for children and women.

\footnotetext{
${ }^{11}$ This section was authored by Michael Johnson and Pius Chilonda.
} 
An important implication of these results is that the regionalization of $R \& D$ investments offers an opportunity to take advantage of the knowledge of research spillover potential to better target technology solutions for similar development domains, irrespective of national boundaries. This idea also implies that for a regional R\&D program to be successful there need to be strong NARS and extension to complement the regional efforts, such as adaptive research for capturing technology spill-ins. Strong NARS that are well established in some countries for basic research in specific commodities or farming practices should be tapped to source existing knowledge and expertise, especially when such research has a high potential for adaptation in neighboring countries. The result will be greater research scope at a lower unit cost while providing a critical mass that is normally beyond the capacity of national systems.

Finally, while the study takes an important first step in identifying strategic entry points for investments to achieve regional targets (CAADP, RISDP and MDG), other analyses would be needed to elaborate specific interventions along the value chain of each selected commodity. 


\section{APPENDIX A: SUPPLEMENTARY TABLES FOR SECTION 4}

Table A.1 Symmetrical matrix of similarity in production environment for beans

\begin{tabular}{|c|c|c|c|c|c|c|c|c|c|c|c|c|c|}
\hline Country & ANG & BOT & DRC & LES & MAD & MAL & MOZ & NAM & SAF & SWZ & TNZ & ZAM & ZIM \\
\hline ANG & 1.00 & 0.08 & 0.18 & 0.28 & 0.25 & 0.16 & 0.30 & 0.23 & 0.20 & 0.38 & 0.27 & 0.30 & 0.36 \\
\hline BOT & 0.08 & 1.00 & 0.08 & 0.14 & 0.40 & 0.09 & 0.18 & 0.52 & 0.24 & 0.10 & 0.12 & 0.14 & 0.29 \\
\hline DRC & 0.18 & 0.08 & 1.00 & 0.26 & 0.11 & 0.22 & 0.11 & 0.07 & 0.17 & 0.14 & 0.24 & 0.12 & 0.11 \\
\hline LES & 0.28 & 0.14 & 0.26 & 1.00 & 0.14 & 0.19 & 0.13 & 0.13 & 0.16 & 0.19 & 0.21 & 0.14 & 0.19 \\
\hline MAD & 0.25 & 0.40 & 0.11 & 0.14 & 1.00 & 0.08 & 0.17 & 0.18 & 0.19 & 0.13 & 0.13 & 0.15 & 0.16 \\
\hline MAL & 0.16 & 0.09 & 0.22 & 0.19 & 0.08 & 1.00 & 0.13 & 0.08 & 0.15 & 0.15 & 0.25 & 0.17 & 0.12 \\
\hline MOZ & 0.30 & 0.18 & 0.11 & 0.13 & 0.17 & 0.13 & 1.00 & 0.14 & 0.19 & 0.21 & 0.21 & 0.26 & 0.18 \\
\hline NAM & 0.23 & 0.52 & 0.07 & 0.13 & 0.18 & 0.08 & 0.14 & 1.00 & 0.22 & 0.19 & 0.13 & 0.16 & 0.29 \\
\hline SAF & 0.20 & 0.24 & 0.17 & 0.16 & 0.19 & 0.15 & 0.19 & 0.22 & 1.00 & 0.09 & 0.13 & 0.11 & 0.10 \\
\hline SWZ & 0.38 & 0.10 & 0.14 & 0.19 & 0.13 & 0.15 & 0.21 & 0.19 & 0.09 & 1.00 & 0.27 & 0.31 & 0.33 \\
\hline TNZ & 0.27 & 0.12 & 0.24 & 0.21 & 0.13 & 0.25 & 0.21 & 0.13 & 0.13 & 0.27 & 1.00 & 0.17 & 0.11 \\
\hline ZAM & 0.30 & 0.14 & 0.12 & 0.14 & 0.15 & 0.17 & 0.26 & 0.16 & 0.11 & 0.31 & 0.17 & 1.00 & 0.19 \\
\hline ZIM & 0.36 & 0.29 & 0.11 & 0.19 & 0.16 & 0.12 & 0.18 & 0.29 & 0.10 & 0.33 & 0.11 & 0.19 & 1.00 \\
\hline
\end{tabular}

Source: Spillover matrix analysis.

Notes: $\quad \mathrm{ANG}=$ Angola, $\mathrm{BOT}=$ Botswana, $\mathrm{DRC}=$ Democratic Republic of the Congo, LES $=$ Lesotho, MAD $=$ Madagascar, MAL $=$ Malawi, $\mathrm{MOZ}=$ Mozambique, $\mathrm{NAM}=$ Namibia, $\mathrm{SAF}=$ South Africa, $\mathrm{SWZ}=$ Swaziland, $\mathrm{TNZ}=$ Tanzania,

ZAM = Zambia, and ZIM = Zimbabwe. Mauritius and Seychelles not included due to lack of data.

Table A.2 Symmetrical matrix of similarity in production environment for cassava

\begin{tabular}{lccccccccccccc}
\hline Country & ANG & BOT & DRC & LES & MAD & MAL & MOZ & NAM & SAF & SWZ & TNZ & ZAM & ZIM \\
\hline ANG & 1.00 & 0.24 & 0.27 & 0.00 & 0.23 & 0.11 & 0.21 & 0.02 & 0.13 & 0.24 & 0.22 & 0.18 & 0.27 \\
BOT & 0.24 & 1.00 & 0.28 & 0.00 & 0.33 & 0.08 & 0.14 & 0.08 & 0.26 & 0.22 & 0.20 & 0.26 & 0.26 \\
DRC & 0.27 & 0.28 & 1.00 & 0.00 & 0.17 & 0.10 & 0.14 & 0.07 & 0.12 & 0.13 & 0.17 & 0.15 & 0.16 \\
LES & 0.00 & 0.00 & 0.00 & 1.00 & 0.00 & 0.00 & 0.00 & 0.00 & 0.00 & 0.00 & 0.00 & 0.00 & 0.00 \\
MAD & 0.23 & 0.33 & 0.17 & 0.00 & 1.00 & 0.07 & 0.14 & 0.12 & 0.20 & 0.12 & 0.18 & 0.22 & 0.15 \\
MAL & 0.11 & 0.08 & 0.10 & 0.00 & 0.07 & 1.00 & 0.12 & 0.01 & 0.06 & 0.09 & 0.22 & 0.07 & 0.11 \\
MOZ & 0.21 & 0.14 & 0.14 & 0.00 & 0.14 & 0.12 & 1.00 & 0.07 & 0.11 & 0.13 & 0.29 & 0.23 & 0.18 \\
NAM & 0.02 & 0.08 & 0.07 & 0.00 & 0.12 & 0.01 & 0.07 & 1.00 & 0.57 & 0.00 & 0.34 & 0.70 & 0.04 \\
SAF & 0.13 & 0.26 & 0.12 & 0.00 & 0.20 & 0.06 & 0.11 & 0.57 & 1.00 & 0.00 & 0.19 & 0.27 & 0.07 \\
SWZ & 0.24 & 0.22 & 0.13 & 0.00 & 0.12 & 0.09 & 0.13 & 0.00 & 0.00 & 1.00 & 0.37 & 0.23 & 0.83 \\
TNZ & 0.22 & 0.20 & 0.17 & 0.00 & 0.18 & 0.22 & 0.29 & 0.34 & 0.19 & 0.37 & 1.00 & 0.13 & 0.10 \\
ZAM & 0.18 & 0.26 & 0.15 & 0.00 & 0.22 & 0.07 & 0.23 & 0.70 & 0.27 & 0.23 & 0.13 & 1.00 & 0.12 \\
ZIM & 0.27 & 0.26 & 0.16 & 0.00 & 0.15 & 0.11 & 0.18 & 0.04 & 0.07 & 0.83 & 0.10 & 0.12 & 1.00 \\
\hline
\end{tabular}

Source: Spillover matrix analysis.

Notes: $\quad$ ANG $=$ Angola, BOT $=$ Botswana, DRC $=$ Democratic Republic of the Congo, LES $=$ Lesotho, MAD = Madagascar , $\mathrm{MAL}=$ Malawi, MOZ = Mozambique, NAM = Namibia, SAF $=$ South Africa, $\mathrm{SWZ}=$ Swaziland, TNZ $=$ Tanzania, ZAM = Zambia, and ZIM = Zimbabwe. Mauritius and Seychelles not included due to lack of data. 
Table A.3 Symmetrical matrix of similarity in production environment for cotton

\begin{tabular}{lccccccccccccc}
\hline Country & ANG & BOT & DRC & LES & MAD & MAL & MOZ & NAM & SAF & SWZ & TNZ & ZAM & ZIM \\
\hline ANG & 1.00 & 0.17 & 0.30 & 0.00 & 0.20 & 0.10 & 0.19 & 0.14 & 0.19 & 0.10 & 0.10 & 0.19 & 0.31 \\
BOT & 0.17 & 1.00 & 0.28 & 0.00 & 0.51 & 0.06 & 0.16 & 0.46 & 0.34 & 0.00 & 0.03 & 0.32 & 0.19 \\
DRC & 0.30 & 0.28 & 1.00 & 0.00 & 0.13 & 0.12 & 0.15 & 0.10 & 0.13 & 0.10 & 0.13 & 0.14 & 0.19 \\
LES & 0.00 & 0.00 & 0.00 & 1.00 & 0.00 & 0.00 & 0.00 & 0.00 & 0.00 & 0.00 & 0.00 & 0.00 & 0.00 \\
MAD & 0.20 & 0.51 & 0.13 & 0.00 & 1.00 & 0.04 & 0.18 & 0.32 & 0.29 & 0.07 & 0.08 & 0.29 & 0.14 \\
MAL & 0.10 & 0.06 & 0.12 & 0.00 & 0.04 & 1.00 & 0.08 & 0.01 & 0.09 & 0.04 & 0.26 & 0.07 & 0.13 \\
MOZ & 0.19 & 0.16 & 0.15 & 0.00 & 0.18 & 0.08 & 1.00 & 0.14 & 0.21 & 0.29 & 0.25 & 0.23 & 0.22 \\
NAM & 0.14 & 0.46 & 0.10 & 0.00 & 0.32 & 0.01 & 0.14 & 1.00 & 0.40 & 0.02 & 0.05 & 0.39 & 0.10 \\
SAF & 0.19 & 0.34 & 0.13 & 0.00 & 0.29 & 0.09 & 0.21 & 0.40 & 1.00 & 0.06 & 0.09 & 0.25 & 0.11 \\
SWZ & 0.10 & 0.00 & 0.10 & 0.00 & 0.07 & 0.04 & 0.29 & 0.02 & 0.06 & 1.00 & 0.73 & 0.32 & 0.45 \\
TNZ & 0.10 & 0.03 & 0.13 & 0.00 & 0.08 & 0.26 & 0.25 & 0.05 & 0.09 & 0.73 & 1.00 & 0.13 & 0.15 \\
ZAM & 0.19 & 0.32 & 0.14 & 0.00 & 0.29 & 0.07 & 0.23 & 0.39 & 0.25 & 0.32 & 0.13 & 1.00 & 0.13 \\
ZIM & 0.31 & 0.19 & 0.19 & 0.00 & 0.14 & 0.13 & 0.22 & 0.10 & 0.11 & 0.45 & 0.15 & 0.13 & 1.00 \\
\hline
\end{tabular}

Source: Spillover matrix analysis.

Notes: $\quad \mathrm{ANG}=$ Angola, $\mathrm{BOT}=$ Botswana, $\mathrm{DRC}=$ Democratic Republic of the Congo, LES $=$ Lesotho, MAD $=$ Madagascar, $\mathrm{MAL}=$ Malawi, $\mathrm{MOZ}=$ Mozambique, $\mathrm{NAM}=$ Namibia, $\mathrm{SAF}=$ South Africa, $\mathrm{SWZ}=$ Swaziland, $\mathrm{TNZ}=\mathrm{Tanzania}$,

ZAM = Zambia, and ZIM = Zimbabwe. Mauritius and Seychelles not included due to lack of data

Table A.4 Symmetrical matrix of similarity in production environment for groundnuts

\begin{tabular}{lccccccccccccc}
\hline Country & ANG & BOT & DRC & LES & MAD & MAL & MOZ & NAM & SAF & SWZ & TNZ & ZAM & ZIM \\
\hline ANG & 1.00 & 0.23 & 0.29 & 0.00 & 0.30 & 0.08 & 0.18 & 0.29 & 0.22 & 0.25 & 0.21 & 0.18 & 0.29 \\
BOT & 0.23 & 1.00 & 0.30 & 0.00 & 0.41 & 0.07 & 0.14 & 0.49 & 0.33 & 0.14 & 0.17 & 0.19 & 0.25 \\
DRC & 0.29 & 0.30 & 1.00 & 0.00 & 0.21 & 0.08 & 0.17 & 0.17 & 0.19 & 0.19 & 0.19 & 0.17 & 0.19 \\
LES & 0.00 & 0.00 & 0.00 & 1.00 & 0.00 & 0.00 & 0.00 & 0.00 & 0.00 & 0.00 & 0.00 & 0.00 & 0.00 \\
MAD & 0.30 & 0.41 & 0.21 & 0.00 & 1.00 & 0.07 & 0.15 & 0.19 & 0.19 & 0.16 & 0.17 & 0.16 & 0.17 \\
MAL & 0.08 & 0.07 & 0.08 & 0.00 & 0.07 & 1.00 & 0.13 & 0.07 & 0.15 & 0.21 & 0.20 & 0.11 & 0.10 \\
MOZ & 0.18 & 0.14 & 0.17 & 0.00 & 0.15 & 0.13 & 1.00 & 0.11 & 0.23 & 0.24 & 0.29 & 0.28 & 0.15 \\
NAM & 0.29 & 0.49 & 0.17 & 0.00 & 0.19 & 0.07 & 0.11 & 1.00 & 0.27 & 0.21 & 0.19 & 0.18 & 0.31 \\
SAF & 0.22 & 0.33 & 0.19 & 0.00 & 0.19 & 0.15 & 0.23 & 0.27 & 1.00 & 0.11 & 0.16 & 0.17 & 0.09 \\
SWZ & 0.25 & 0.14 & 0.19 & 0.00 & 0.16 & 0.21 & 0.24 & 0.21 & 0.11 & 1.00 & 0.25 & 0.18 & 0.24 \\
TNZ & 0.21 & 0.17 & 0.19 & 0.00 & 0.17 & 0.20 & 0.29 & 0.19 & 0.16 & 0.25 & 1.00 & 0.20 & 0.13 \\
ZAM & 0.18 & 0.19 & 0.17 & 0.00 & 0.16 & 0.11 & 0.28 & 0.18 & 0.17 & 0.18 & 0.20 & 1.00 & 0.11 \\
ZIM & 0.29 & 0.25 & 0.19 & 0.00 & 0.17 & 0.10 & 0.15 & 0.31 & 0.09 & 0.24 & 0.13 & 0.11 & 1.00 \\
\hline
\end{tabular}

Source: Spillover matrix analysis.

Notes: $\quad$ ANG $=$ Angola, BOT $=$ Botswana, $\mathrm{DRC}=$ Democratic Republic of the Congo, LES $=$ Lesotho, MAD $=$ Madagascar, MAL $=$ Malawi, MOZ = Mozambique, NAM = Namibia, SAF $=$ South Africa, $S W Z=$ Swaziland, TNZ $=$ Tanzania,

ZAM = Zambia, and ZIM = Zimbabwe. Mauritius and Seychelles not included due to lack of data.

Table A.5 Symmetrical matrix of similarity in production environment for millet

\begin{tabular}{lccccccccccccc}
\hline Country & ANG & BOT & DRC & LES & MAD & MAL & MOZ & NAM & SAF & SWZ & TNZ & ZAM & ZIM \\
\hline ANG & 1.00 & 0.35 & 0.26 & 0.05 & 0.00 & 0.06 & 0.27 & 0.32 & 0.36 & 0.02 & 0.13 & 0.32 & 0.13 \\
BOT & 0.35 & 1.00 & 0.39 & 0.15 & 0.00 & 0.10 & 0.25 & 0.45 & 0.29 & 0.03 & 0.12 & 0.21 & 0.24 \\
DRC & 0.26 & 0.39 & 1.00 & 0.22 & 0.00 & 0.12 & 0.18 & 0.27 & 0.17 & 0.08 & 0.16 & 0.13 & 0.25 \\
LES & 0.05 & 0.15 & 0.22 & 1.00 & 0.00 & 0.25 & 0.28 & 0.64 & 0.21 & 0.14 & 0.40 & 0.13 & 0.96 \\
MAD & 0.00 & 0.00 & 0.00 & 0.00 & 1.00 & 0.00 & 0.00 & 0.00 & 0.00 & 0.00 & 0.00 & 0.00 & 0.00 \\
MAL & 0.06 & 0.10 & 0.12 & 0.25 & 0.00 & 1.00 & 0.11 & 0.09 & 0.10 & 0.07 & 0.17 & 0.06 & 0.11 \\
MOZ & 0.27 & 0.25 & 0.18 & 0.28 & 0.00 & 0.11 & 1.00 & 0.16 & 0.22 & 0.20 & 0.23 & 0.23 & 0.13 \\
NAM & 0.32 & 0.45 & 0.27 & 0.64 & 0.00 & 0.09 & 0.16 & 1.00 & 0.24 & 0.07 & 0.16 & 0.18 & 0.29 \\
SAF & 0.36 & 0.29 & 0.17 & 0.21 & 0.00 & 0.10 & 0.22 & 0.24 & 1.00 & 0.07 & 0.15 & 0.23 & 0.09 \\
SWZ & 0.02 & 0.03 & 0.08 & 0.14 & 0.00 & 0.07 & 0.20 & 0.07 & 0.07 & 1.00 & 0.68 & 0.35 & 0.24 \\
TNZ & 0.13 & 0.12 & 0.16 & 0.40 & 0.00 & 0.17 & 0.23 & 0.16 & 0.15 & 0.68 & 1.00 & 0.17 & 0.14 \\
ZAM & 0.32 & 0.21 & 0.13 & 0.13 & 0.00 & 0.06 & 0.23 & 0.18 & 0.23 & 0.35 & 0.17 & 1.00 & 0.09 \\
ZIM & 0.13 & 0.24 & 0.25 & 0.96 & 0.00 & 0.11 & 0.13 & 0.29 & 0.09 & 0.24 & 0.14 & 0.09 & 1.00 \\
\hline
\end{tabular}

Source: Spillover matrix analysis.

Notes: $\quad$ ANG $=$ Angola, BOT $=$ Botswana, $\mathrm{DRC}=$ Democratic Republic of the Congo, LES $=$ Lesotho, MAD $=$ Madagascar , $\mathrm{MAL}=$ Malawi, $\mathrm{MOZ}=$ Mozambique, $\mathrm{NAM}=$ Namibia, $\mathrm{SAF}=$ South Africa, $\mathrm{SWZ}=$ Swaziland, $\mathrm{TNZ}=$ Tanzania, $\mathrm{ZAM}=$ Zambia, and ZIM = Zimbabwe. Mauritius and Seychelles not included due to lack of data. 
Table A.6 Symmetrical matrix of similarity in production environment for potatoes

\begin{tabular}{|c|c|c|c|c|c|c|c|c|c|c|c|c|c|}
\hline Country & ANG & BOT & DRC & LES & MAD & MAL & MOZ & NAM & SAF & SWZ & TNZ & ZAM & ZIM \\
\hline ANG & 1.00 & 0.38 & 0.22 & 0.32 & 0.34 & 0.18 & 0.23 & 0.11 & 0.21 & 0.32 & 0.25 & 0.20 & 0.38 \\
\hline ВОт & 0.38 & 1.00 & 0.20 & 0.45 & 0.52 & 0.20 & 0.39 & 0.11 & 0.25 & 0.53 & 0.38 & 0.30 & 0.65 \\
\hline DRC & 0.22 & 0.20 & 1.00 & 0.29 & 0.17 & 0.28 & 0.13 & 0.05 & 0.17 & 0.18 & 0.16 & 0.09 & 0.15 \\
\hline LES & 0.32 & 0.45 & 0.29 & 1.00 & 0.19 & 0.20 & 0.17 & 0.03 & 0.13 & 0.21 & 0.18 & 0.11 & 0.19 \\
\hline MAD & 0.34 & 0.52 & 0.17 & 0.19 & 1.00 & 0.11 & 0.13 & 0.12 & 0.19 & 0.19 & 0.19 & 0.14 & 0.18 \\
\hline MAL & 0.18 & 0.20 & 0.28 & 0.20 & 0.11 & 1.00 & 0.25 & 0.00 & 0.10 & 0.19 & 0.17 & 0.11 & 0.13 \\
\hline MOZ & 0.23 & 0.39 & 0.13 & 0.17 & 0.13 & 0.25 & 1.00 & 0.02 & 0.09 & 0.26 & 0.22 & 0.19 & 0.22 \\
\hline NAM & 0.11 & 0.11 & 0.05 & 0.03 & 0.12 & 0.00 & 0.02 & 1.00 & 0.79 & 0.00 & 0.17 & 0.06 & 0.04 \\
\hline SAF & 0.21 & 0.25 & 0.17 & 0.13 & 0.19 & 0.10 & 0.09 & 0.79 & 1.00 & 0.12 & 0.17 & 0.11 & 0.09 \\
\hline SWZ & 0.32 & 0.53 & 0.18 & 0.21 & 0.19 & 0.19 & 0.26 & 0.00 & 0.12 & 1.00 & 0.27 & 0.17 & 0.27 \\
\hline TNZ & 0.25 & 0.38 & 0.16 & 0.18 & 0.19 & 0.17 & 0.22 & 0.17 & 0.17 & 0.27 & 1.00 & 0.17 & 0.13 \\
\hline ZAM & 0.20 & 0.30 & 0.09 & 0.11 & 0.14 & 0.11 & 0.19 & 0.06 & 0.11 & 0.17 & 0.17 & 1.00 & 0.13 \\
\hline ZIM & 0.38 & 0.65 & 0.15 & 0.19 & 0.18 & 0.13 & 0.22 & 0.04 & 0.09 & 0.27 & 0.13 & 0.13 & 1.00 \\
\hline
\end{tabular}

Source: Spillover matrix analysis.

Notes: $\quad \mathrm{ANG}=$ Angola, $\mathrm{BOT}=$ Botswana, $\mathrm{DRC}=$ Democratic Republic of the Congo, LES $=$ Lesotho, MAD $=$ Madagascar, MAL = Malawi, $\mathrm{MOZ}=$ Mozambique, $\mathrm{NAM}=$ Namibia, $\mathrm{SAF}=$ South Africa, $\mathrm{SWZ}=$ Swaziland, $\mathrm{TNZ}=\mathrm{Tanzania}$,

$\mathrm{ZAM}=$ Zambia, and ZIM = Zimbabwe. Mauritius and Seychelles not included due to lack of data.

Table A.7 Symmetrical matrix of similarity in production environment for rice

\begin{tabular}{lccccccccccccc}
\hline Country & ANG & BOT & DRC & LES & MAD & MAL & MOZ & NAM & SAF & SWZ & TNZ & ZAM & ZIM \\
\hline ANG & 1.00 & 0.20 & 0.18 & 0.18 & 0.22 & 0.07 & 0.17 & 0.06 & 0.20 & 0.16 & 0.17 & 0.16 & 0.21 \\
BOT & 0.20 & 1.00 & 0.21 & 0.42 & 0.40 & 0.08 & 0.17 & 0.00 & 0.40 & 0.19 & 0.18 & 0.14 & 0.51 \\
DRC & 0.18 & 0.21 & 1.00 & 0.08 & 0.18 & 0.09 & 0.18 & 0.16 & 0.15 & 0.14 & 0.18 & 0.21 & 0.10 \\
LES & 0.18 & 0.42 & 0.08 & 1.00 & 0.59 & 0.18 & 0.32 & 0.00 & 0.43 & 0.45 & 0.34 & 0.20 & 0.88 \\
MAD & 0.22 & 0.40 & 0.18 & 0.59 & 1.00 & 0.09 & 0.14 & 0.06 & 0.17 & 0.13 & 0.14 & 0.13 & 0.15 \\
MAL & 0.07 & 0.08 & 0.09 & 0.18 & 0.09 & 1.00 & 0.11 & 0.00 & 0.16 & 0.21 & 0.21 & 0.08 & 0.07 \\
MOZ & 0.17 & 0.17 & 0.18 & 0.32 & 0.14 & 0.11 & 1.00 & 0.08 & 0.20 & 0.28 & 0.30 & 0.28 & 0.14 \\
NAM & 0.06 & 0.00 & 0.16 & 0.00 & 0.06 & 0.00 & 0.08 & 1.00 & 0.22 & 0.00 & 0.21 & 0.65 & 0.02 \\
SAF & 0.20 & 0.40 & 0.15 & 0.43 & 0.17 & 0.16 & 0.20 & 0.22 & 1.00 & 0.12 & 0.14 & 0.12 & 0.15 \\
SWZ & 0.16 & 0.19 & 0.14 & 0.45 & 0.13 & 0.21 & 0.28 & 0.00 & 0.12 & 1.00 & 0.30 & 0.20 & 0.15 \\
TNZ & 0.17 & 0.18 & 0.18 & 0.34 & 0.14 & 0.21 & 0.30 & 0.21 & 0.14 & 0.30 & 1.00 & 0.18 & 0.10 \\
ZAM & 0.16 & 0.14 & 0.21 & 0.20 & 0.13 & 0.08 & 0.28 & 0.65 & 0.12 & 0.20 & 0.18 & 1.00 & 0.10 \\
ZIM & 0.21 & 0.51 & 0.10 & 0.88 & 0.15 & 0.07 & 0.14 & 0.02 & 0.15 & 0.15 & 0.10 & 0.10 & 1.00 \\
\hline
\end{tabular}

Source: Spillover matrix analysis.

Notes: $\quad$ ANG $=$ Angola, BOT $=$ Botswana, $\mathrm{DRC}=$ Democratic Republic of the Congo, LES $=$ Lesotho, MAD $=$ Madagascar , $\mathrm{MAL}=$ Malawi, MOZ = Mozambique, NAM = Namibia, $\mathrm{SAF}=$ South Africa, $\mathrm{SWZ}=$ Swaziland, TNZ $=$ Tanzania,

$\mathrm{ZAM}=$ Zambia, and ZIM = Zimbabwe. Mauritius and Seychelles not included due to lack of data.

Table A.8 Symmetrical matrix of similarity in production environment for sorghum

\begin{tabular}{|c|c|c|c|c|c|c|c|c|c|c|c|c|c|}
\hline Country & ANG & BOT & DRC & LES & MAD & MAL & MOZ & NAM & SAF & SWZ & TNZ & ZAM & ZIM \\
\hline ANG & 1.00 & 0.16 & 0.26 & 0.26 & 0.26 & 0.11 & 0.18 & 0.19 & 0.17 & 0.25 & 0.18 & 0.14 & 0.25 \\
\hline BOT & 0.16 & 1.00 & 0.24 & 0.19 & 0.35 & 0.07 & 0.20 & 0.42 & 0.25 & 0.21 & 0.14 & 0.26 & 0.35 \\
\hline DRC & 0.26 & 0.24 & 1.00 & 0.21 & 0.23 & 0.14 & 0.19 & 0.17 & 0.13 & 0.25 & 0.21 & 0.11 & 0.23 \\
\hline LES & 0.26 & 0.19 & 0.21 & 1.00 & 0.23 & 0.18 & 0.12 & 0.15 & 0.12 & 0.23 & 0.17 & 0.07 & 0.21 \\
\hline MAD & 0.26 & 0.35 & 0.23 & 0.23 & 1.00 & 0.09 & 0.16 & 0.19 & 0.15 & 0.18 & 0.15 & 0.14 & 0.20 \\
\hline MAL & 0.11 & 0.07 & 0.14 & 0.18 & 0.09 & 1.00 & 0.10 & 0.06 & 0.08 & 0.18 & 0.23 & 0.07 & 0.09 \\
\hline MOZ & 0.18 & 0.20 & 0.19 & 0.12 & 0.16 & 0.10 & 1.00 & 0.16 & 0.20 & 0.18 & 0.24 & 0.20 & 0.16 \\
\hline NAM & 0.19 & 0.42 & 0.17 & 0.15 & 0.19 & 0.06 & 0.16 & 1.00 & 0.23 & 0.22 & 0.16 & 0.24 & 0.32 \\
\hline SAF & 0.17 & 0.25 & 0.13 & 0.12 & 0.15 & 0.08 & 0.20 & 0.23 & 1.00 & 0.08 & 0.14 & 0.23 & 0.12 \\
\hline SWZ & 0.25 & 0.21 & 0.25 & 0.23 & 0.18 & 0.18 & 0.18 & 0.22 & 0.08 & 1.00 & 0.26 & 0.11 & 0.29 \\
\hline TNZ & 0.18 & 0.14 & 0.21 & 0.17 & 0.15 & 0.23 & 0.24 & 0.16 & 0.14 & 0.26 & 1.00 & 0.13 & 0.12 \\
\hline ZAM & 0.14 & 0.26 & 0.11 & 0.07 & 0.14 & 0.07 & 0.20 & 0.24 & 0.23 & 0.11 & 0.13 & 1.00 & 0.13 \\
\hline ZIM & 0.25 & 0.35 & 0.23 & 0.21 & 0.20 & 0.09 & 0.16 & 0.32 & 0.12 & 0.29 & 0.12 & 0.13 & 1.00 \\
\hline
\end{tabular}

Source: Spillover matrix analysis.

Notes: $\quad$ ANG $=$ Angola, $\mathrm{BOT}=$ Botswana, $\mathrm{DRC}=$ Democratic Republic of the Congo, LES $=$ Lesotho, MAD $=$ Madagascar, $\mathrm{MAL}=$ Malawi, $\mathrm{MOZ}=$ Mozambique, $\mathrm{NAM}=$ Namibia, $\mathrm{SAF}=$ South Africa, $\mathrm{SWZ}=$ Swaziland, $\mathrm{TNZ}=$ Tanzania, ZAM = Zambia, and ZIM = Zimbabwe. Mauritius and Seychelles not included due to lack of data. 
Table A.9 Symmetrical matrix of similarity in production environment for sugarcane

\begin{tabular}{|c|c|c|c|c|c|c|c|c|c|c|c|c|c|}
\hline Country & ANG & BOT & DRC & LES & MAD & MAL & MOZ & NAM & SAF & SWZ & TNZ & ZAM & ZIM \\
\hline ANG & 1.00 & 0.21 & 0.18 & 0.24 & 0.31 & 0.09 & 0.20 & 0.20 & 0.19 & 0.27 & 0.12 & 0.10 & 0.29 \\
\hline BOT & 0.21 & 1.00 & 0.13 & 0.00 & 0.53 & 0.03 & 0.14 & 0.89 & 0.43 & 0.03 & 0.08 & 0.18 & 0.18 \\
\hline DRC & 0.18 & 0.13 & 1.00 & 0.11 & 0.17 & 0.06 & 0.19 & 0.04 & 0.19 & 0.11 & 0.18 & 0.20 & 0.13 \\
\hline LES & 0.24 & 0.00 & 0.11 & 1.00 & 0.69 & 0.08 & 0.45 & 0.00 & 0.29 & 0.84 & 0.28 & 0.18 & 0.97 \\
\hline MAD & 0.31 & 0.53 & 0.17 & 0.69 & 1.00 & 0.06 & 0.16 & 0.13 & 0.17 & 0.16 & 0.13 & 0.13 & 0.19 \\
\hline MAL & 0.09 & 0.03 & 0.06 & 0.08 & 0.06 & 1.00 & 0.28 & 0.00 & 0.07 & 0.18 & 0.27 & 0.07 & 0.08 \\
\hline MOZ & 0.20 & 0.14 & 0.19 & 0.45 & 0.16 & 0.28 & 1.00 & 0.02 & 0.11 & 0.12 & 0.16 & 0.14 & 0.11 \\
\hline NAM & 0.20 & 0.89 & 0.04 & 0.00 & 0.13 & 0.00 & 0.02 & 1.00 & 0.47 & 0.00 & 0.09 & 0.21 & 0.18 \\
\hline SAF & 0.19 & 0.43 & 0.19 & 0.29 & 0.17 & 0.07 & 0.11 & 0.47 & 1.00 & 0.07 & 0.14 & 0.19 & 0.10 \\
\hline SWZ & 0.27 & 0.03 & 0.11 & 0.84 & 0.16 & 0.18 & 0.12 & 0.00 & 0.07 & 1.00 & 0.17 & 0.08 & 0.44 \\
\hline TNZ & 0.12 & 0.08 & 0.18 & 0.28 & 0.13 & 0.27 & 0.16 & 0.09 & 0.14 & 0.17 & 1.00 & 0.16 & 0.08 \\
\hline ZAM & 0.10 & 0.18 & 0.20 & 0.18 & 0.13 & 0.07 & 0.14 & 0.21 & 0.19 & 0.08 & 0.16 & 1.00 & 0.07 \\
\hline ZIM & 0.29 & 0.18 & 0.13 & 0.97 & 0.19 & 0.08 & 0.11 & 0.18 & 0.10 & 0.44 & 0.08 & 0.07 & 1.00 \\
\hline
\end{tabular}

Source: Spillover matrix analysis.

Notes: $\quad \mathrm{ANG}=$ Angola, $\mathrm{BOT}=$ Botswana, $\mathrm{DRC}=$ Democratic Republic of the Congo, LES $=$ Lesotho, MAD $=$ Madagascar, $\mathrm{MAL}=$ Malawi, $\mathrm{MOZ}=$ Mozambique, $\mathrm{NAM}=$ Namibia, $\mathrm{SAF}=$ South Africa, $\mathrm{SWZ}=$ Swaziland, $\mathrm{TNZ}=\mathrm{Tanzania}$,

ZAM = Zambia, and ZIM = Zimbabwe. Mauritius and Seychelles not included due to lack of data.

Table A.10 Symmetrical matrix of similarity in production environment for wheat

\begin{tabular}{|c|c|c|c|c|c|c|c|c|c|c|c|c|c|}
\hline Country & ANG & BOT & DRC & LES & MAD & MAL & MOZ & NAM & SAF & SWZ & TNZ & ZAM & ZIM \\
\hline ANG & 1.00 & 0.38 & 0.09 & 0.10 & 0.32 & 0.09 & 0.36 & 0.51 & 0.41 & 0.04 & 0.27 & 0.11 & 0.12 \\
\hline BOT & 0.38 & 1.00 & 0.07 & 0.33 & 0.44 & 0.13 & 0.37 & 0.39 & 0.26 & 0.19 & 0.30 & 0.10 & 0.35 \\
\hline DRC & 0.09 & 0.07 & 1.00 & 0.24 & 0.17 & 0.21 & 0.20 & 0.06 & 0.10 & 0.12 & 0.14 & 0.07 & 0.16 \\
\hline LES & 0.10 & 0.33 & 0.24 & 1.00 & 0.29 & 0.16 & 0.25 & 0.08 & 0.11 & 0.22 & 0.22 & 0.11 & 0.30 \\
\hline MAD & 0.32 & 0.44 & 0.17 & 0.29 & 1.00 & 0.12 & 0.22 & 0.16 & 0.15 & 0.17 & 0.20 & 0.12 & 0.20 \\
\hline MAL & 0.09 & 0.13 & 0.21 & 0.16 & 0.12 & 1.00 & 0.16 & 0.05 & 0.09 & 0.19 & 0.17 & 0.14 & 0.20 \\
\hline MOZ & 0.36 & 0.37 & 0.20 & 0.25 & 0.22 & 0.16 & 1.00 & 0.12 & 0.15 & 0.13 & 0.17 & 0.12 & 0.13 \\
\hline NAM & 0.51 & 0.39 & 0.06 & 0.08 & 0.16 & 0.05 & 0.12 & 1.00 & 0.40 & 0.06 & 0.28 & 0.10 & 0.19 \\
\hline SAF & 0.41 & 0.26 & 0.10 & 0.11 & 0.15 & 0.09 & 0.15 & 0.40 & 1.00 & 0.09 & 0.22 & 0.14 & 0.09 \\
\hline SWZ & 0.04 & 0.19 & 0.12 & 0.22 & 0.17 & 0.19 & 0.13 & 0.06 & 0.09 & 1.00 & 0.26 & 0.28 & 0.24 \\
\hline TNZ & 0.27 & 0.30 & 0.14 & 0.22 & 0.20 & 0.17 & 0.17 & 0.28 & 0.22 & 0.26 & 1.00 & 0.14 & 0.14 \\
\hline ZAM & 0.11 & 0.10 & 0.07 & 0.11 & 0.12 & 0.14 & 0.12 & 0.10 & 0.14 & 0.28 & 0.14 & 1.00 & 0.12 \\
\hline ZIM & 0.12 & 0.35 & 0.16 & 0.30 & 0.20 & 0.20 & 0.13 & 0.19 & 0.09 & 0.24 & 0.14 & 0.12 & 1.00 \\
\hline
\end{tabular}

Source: Spillover matrix analysis.

Notes: $\quad$ ANG $=$ Angola, $\mathrm{BOT}=$ Botswana, $\mathrm{DRC}=$ Democratic Republic of the Congo, LES $=$ Lesotho, MAD $=$ Madagascar, $\mathrm{MAL}=$ Malawi, MOZ = Mozambique, NAM = Namibia, $\mathrm{SAF}=$ South Africa, $\mathrm{SWZ}=$ Swaziland, TNZ $=$ Tanzania,

ZAM = Zambia, and ZIM = Zimbabwe. Mauritius and Seychelles not included due to lack of data.

Table A.11 Symmetrical matrix of similarity in production environment for pigs

\begin{tabular}{|c|c|c|c|c|c|c|c|c|c|c|c|c|c|}
\hline Country & ANG & BOT & DRC & LES & MAD & MAL & MOZ & NAM & SAF & SWZ & TNZ & ZAM & ZIM \\
\hline ANG & 1.00 & 0.21 & 0.07 & 0.00 & 0.17 & 0.25 & 0.20 & 0.22 & 0.02 & 0.10 & 0.25 & 0.25 & 0.23 \\
\hline BOT & 0.21 & 1.00 & 0.00 & 0.08 & 0.20 & 0.60 & 0.54 & 0.65 & 0.12 & 0.20 & 0.27 & 0.63 & 0.64 \\
\hline DRC & 0.07 & 0.00 & 1.00 & 0.00 & 0.73 & 0.26 & 0.43 & 0.00 & 0.06 & 0.67 & 0.47 & 0.06 & 0.00 \\
\hline LES & 0.00 & 0.08 & 0.00 & 1.00 & 0.00 & 0.00 & 0.00 & 0.00 & 0.50 & 0.12 & 0.00 & 0.00 & 0.00 \\
\hline MAD & 0.17 & 0.20 & 0.73 & 0.00 & 1.00 & 0.26 & 0.32 & 0.13 & 0.04 & 0.37 & 0.32 & 0.17 & 0.13 \\
\hline MAL & 0.25 & 0.60 & 0.26 & 0.00 & 0.26 & 1.00 & 0.37 & 0.37 & 0.03 & 0.22 & 0.27 & 0.38 & 0.37 \\
\hline MOZ & 0.20 & 0.54 & 0.43 & 0.00 & 0.32 & 0.37 & 1.00 & 0.42 & 0.05 & 0.37 & 0.30 & 0.42 & 0.41 \\
\hline NAM & 0.22 & 0.65 & 0.00 & 0.00 & 0.13 & 0.37 & 0.42 & 1.00 & 0.05 & 0.22 & 0.33 & 0.73 & 0.74 \\
\hline SAF & 0.02 & 0.12 & 0.06 & 0.50 & 0.04 & 0.03 & 0.05 & 0.05 & 1.00 & 0.11 & 0.03 & 0.02 & 0.02 \\
\hline SWZ & 0.10 & 0.20 & 0.67 & 0.12 & 0.37 & 0.22 & 0.37 & 0.22 & 0.11 & 1.00 & 0.23 & 0.14 & 0.12 \\
\hline TNZ & 0.25 & 0.27 & 0.47 & 0.00 & 0.32 & 0.27 & 0.30 & 0.33 & 0.03 & 0.23 & 1.00 & 0.15 & 0.13 \\
\hline ZAM & 0.25 & 0.63 & 0.06 & 0.00 & 0.17 & 0.38 & 0.42 & 0.73 & 0.02 & 0.14 & 0.15 & 1.00 & 0.52 \\
\hline ZIM & 0.23 & 0.64 & 0.00 & 0.00 & 0.13 & 0.37 & 0.41 & 0.74 & 0.02 & 0.12 & 0.13 & 0.52 & 1.00 \\
\hline
\end{tabular}

Source: Spillover matrix analysis.

Notes: $\quad \mathrm{ANG}=$ Angola, $\mathrm{BOT}=$ Botswana, $\mathrm{DRC}=$ Democratic Republic of the Congo, $\mathrm{LES}=$ Lesotho, MAD $=$ Madagascar, $\mathrm{MAL}=$ Malawi, $\mathrm{MOZ}=$ Mozambique, $\mathrm{NAM}=$ Namibia, $\mathrm{SAF}=$ South Africa, $\mathrm{SWZ}=$ Swaziland, $\mathrm{TNZ}=$ Tanzania, ZAM = Zambia, and ZIM = Zimbabwe. Mauritius and Seychelles not included due to lack of data. 
Table A.12 Symmetrical matrix of similarity in production environment for sheep and goats

\begin{tabular}{lccccccccccccc}
\hline Country & ANG & BOT & DRC & LES & MAD & MAL & MOZ & NAM & SAF & SWZ & TNZ & ZAM & ZIM \\
\hline ANG & 1.00 & 0.18 & 0.11 & 0.00 & 0.10 & 0.24 & 0.19 & 0.15 & 0.00 & 0.08 & 0.28 & 0.21 & 0.21 \\
BOT & 0.18 & 1.00 & 0.00 & 0.05 & 0.22 & 0.66 & 0.69 & 0.34 & 0.09 & 0.22 & 0.23 & 0.72 & 0.70 \\
DRC & 0.11 & 0.00 & 1.00 & 0.00 & 0.59 & 0.25 & 0.19 & 0.00 & 0.01 & 0.40 & 0.43 & 0.08 & 0.00 \\
LES & 0.00 & 0.05 & 0.00 & 1.00 & 0.00 & 0.00 & 0.00 & 0.13 & 0.39 & 0.27 & 0.00 & 0.00 & 0.00 \\
MAD & 0.10 & 0.22 & 0.59 & 0.00 & 1.00 & 0.37 & 0.35 & 0.07 & 0.01 & 0.43 & 0.35 & 0.24 & 0.17 \\
MAL & 0.24 & 0.66 & 0.25 & 0.00 & 0.37 & 1.00 & 0.36 & 0.19 & 0.00 & 0.19 & 0.25 & 0.36 & 0.34 \\
MOZ & 0.19 & 0.69 & 0.19 & 0.00 & 0.35 & 0.36 & 1.00 & 0.22 & 0.01 & 0.30 & 0.27 & 0.59 & 0.54 \\
NAM & 0.15 & 0.34 & 0.00 & 0.13 & 0.07 & 0.19 & 0.22 & 1.00 & 0.14 & 0.04 & 0.17 & 0.15 & 0.22 \\
SAF & 0.00 & 0.09 & 0.01 & 0.39 & 0.01 & 0.00 & 0.01 & 0.14 & 1.00 & 0.08 & 0.00 & 0.00 & 0.00 \\
SWZ & 0.08 & 0.22 & 0.40 & 0.27 & 0.43 & 0.19 & 0.30 & 0.04 & 0.08 & 1.00 & 0.15 & 0.14 & 0.11 \\
TNZ & 0.28 & 0.23 & 0.43 & 0.00 & 0.35 & 0.25 & 0.27 & 0.17 & 0.00 & 0.15 & 1.00 & 0.12 & 0.12 \\
ZAM & 0.21 & 0.72 & 0.08 & 0.00 & 0.24 & 0.36 & 0.59 & 0.15 & 0.00 & 0.14 & 0.12 & 1.00 & 0.60 \\
ZIM & 0.21 & 0.70 & 0.00 & 0.00 & 0.17 & 0.34 & 0.54 & 0.22 & 0.00 & 0.11 & 0.12 & 0.60 & 1.00 \\
\hline
\end{tabular}

Source: Spillover matrix analysis.

Notes: $\quad \mathrm{ANG}=$ Angola, $\mathrm{BOT}=$ Botswana, $\mathrm{DRC}=$ Democratic Republic of the Congo, $\mathrm{LES}=$ Lesotho, MAD $=$ Madagascar, MAL $=$ Malawi, MOZ = Mozambique, NAM = Namibia, $\mathrm{SAF}=$ South Africa, $\mathrm{SWZ}=$ Swaziland, TNZ $=$ Tanzania, ZAM = Zambia, and ZIM = Zimbabwe. Mauritius and Seychelles not included due to lack of data.

Table A.13 Symmetrical matrix of similarity in production environment for poultry

\begin{tabular}{lccccccccccccc}
\hline Country & ANG & BOT & DRC & LES & MAD & MAL & MOZ & NAM & SAF & SWZ & TNZ & ZAM & ZIM \\
\hline ANG & 1.00 & 0.21 & 0.16 & 0.00 & 0.25 & 0.27 & 0.27 & 0.21 & 0.02 & 0.09 & 0.26 & 0.26 & 0.22 \\
BOT & 0.21 & 1.00 & 0.00 & 0.03 & 0.21 & 0.74 & 0.67 & 0.76 & 0.13 & 0.09 & 0.19 & 0.78 & 0.78 \\
DRC & 0.16 & 0.00 & 1.00 & 0.00 & 0.80 & 0.30 & 0.50 & 0.00 & 0.02 & 0.38 & 0.70 & 0.11 & 0.00 \\
LES & 0.00 & 0.03 & 0.00 & 1.00 & 0.00 & 0.00 & 0.00 & 0.01 & 0.47 & 0.43 & 0.00 & 0.00 & 0.00 \\
MAD & 0.25 & 0.21 & 0.80 & 0.00 & 1.00 & 0.23 & 0.29 & 0.10 & 0.02 & 0.16 & 0.39 & 0.18 & 0.11 \\
MAL & 0.27 & 0.74 & 0.30 & 0.00 & 0.23 & 1.00 & 0.37 & 0.37 & 0.04 & 0.10 & 0.22 & 0.38 & 0.38 \\
MOZ & 0.27 & 0.67 & 0.50 & 0.00 & 0.29 & 0.37 & 1.00 & 0.39 & 0.04 & 0.17 & 0.31 & 0.44 & 0.40 \\
NAM & 0.21 & 0.76 & 0.00 & 0.01 & 0.10 & 0.37 & 0.39 & 1.00 & 0.06 & 0.06 & 0.16 & 0.50 & 0.54 \\
SAF & 0.02 & 0.13 & 0.02 & 0.47 & 0.02 & 0.04 & 0.04 & 0.06 & 1.00 & 0.17 & 0.01 & 0.03 & 0.03 \\
SWZ & 0.09 & 0.09 & 0.38 & 0.43 & 0.16 & 0.10 & 0.17 & 0.06 & 0.17 & 1.00 & 0.16 & 0.08 & 0.05 \\
TNZ & 0.26 & 0.19 & 0.70 & 0.00 & 0.39 & 0.22 & 0.31 & 0.16 & 0.01 & 0.16 & 1.00 & 0.14 & 0.10 \\
ZAM & 0.26 & 0.78 & 0.11 & 0.00 & 0.18 & 0.38 & 0.44 & 0.50 & 0.03 & 0.08 & 0.14 & 1.00 & 0.50 \\
ZIM & 0.22 & 0.78 & 0.00 & 0.00 & 0.11 & 0.38 & 0.40 & 0.54 & 0.03 & 0.05 & 0.10 & 0.50 & 1.00 \\
\hline
\end{tabular}

Source: Spillover matrix analysis.

Notes: $\quad$ ANG $=$ Angola, BOT $=$ Botswana, $\mathrm{DRC}=$ Democratic Republic of the Congo, LES $=$ Lesotho, MAD = Madagascar, $\mathrm{MAL}=$ Malawi, MOZ = Mozambique, NAM = Namibia, SAF $=$ South Africa, $\mathrm{SWZ}=$ Swaziland, TNZ $=$ Tanzania,

ZAM = Zambia, and ZIM = Zimbabwe. Mauritius and Seychelles not included due to lack of data.

Table A.14 Asymmetrical matrix of yield gaps for beans

\begin{tabular}{lccccccccccccc}
\hline Country & ANG & BOT & DRC & LES & MAD & MAL & MOZ & NAM & SAF & SWZ & TNZ & ZAM & ZIM \\
\hline ANG & 1.00 & 2.69 & 1.75 & 3.20 & 3.65 & 2.11 & 1.65 & 3.95 & 4.15 & 2.13 & 2.25 & 1.66 & 2.79 \\
BOT & 0.00 & 1.00 & 0.00 & 0.00 & 1.36 & 0.00 & 0.00 & 1.47 & 1.55 & 0.00 & 0.00 & 0.00 & 0.00 \\
DRC & 0.00 & 1.53 & 1.00 & 1.83 & 2.08 & 0.00 & 0.00 & 2.25 & 2.37 & 0.00 & 1.28 & 0.00 & 1.59 \\
LES & 0.00 & 0.00 & 0.00 & 1.00 & 0.00 & 0.00 & 0.00 & 0.00 & 1.30 & 0.00 & 0.00 & 0.00 & 0.00 \\
MAD & 0.00 & 0.00 & 0.00 & 0.00 & 1.00 & 0.00 & 0.00 & 0.00 & 0.00 & 0.00 & 0.00 & 0.00 & 0.00 \\
MAL & 0.00 & 1.27 & 0.00 & 1.52 & 1.73 & 1.00 & 0.00 & 1.87 & 1.97 & 0.00 & 0.00 & 0.00 & 1.32 \\
MOZ & 0.00 & 1.63 & 0.00 & 1.95 & 2.22 & 1.28 & 1.00 & 2.40 & 2.52 & 1.30 & 1.37 & 0.00 & 1.69 \\
NAM & 0.00 & 0.00 & 0.00 & 0.00 & 0.00 & 0.00 & 0.00 & 1.00 & 0.00 & 0.00 & 0.00 & 0.00 & 0.00 \\
SAF & 0.00 & 0.00 & 0.00 & 0.00 & 0.00 & 0.00 & 0.00 & 0.00 & 1.00 & 0.00 & 0.00 & 0.00 & 0.00 \\
SWZ & 0.00 & 1.26 & 0.00 & 1.50 & 1.71 & 0.00 & 0.00 & 1.85 & 1.95 & 1.00 & 0.00 & 0.00 & 1.31 \\
TNZ & 0.00 & 0.00 & 0.00 & 1.42 & 1.62 & 0.00 & 0.00 & 1.75 & 1.84 & 0.00 & 1.00 & 0.00 & 0.00 \\
ZAM & 0.00 & 1.62 & 0.00 & 1.93 & 2.20 & 1.27 & 0.00 & 2.38 & 2.51 & 1.29 & 1.36 & 1.00 & 1.68 \\
ZIM & 0.00 & 0.00 & 0.00 & 0.00 & 1.31 & 0.00 & 0.00 & 1.41 & 1.49 & 0.00 & 0.00 & 0.00 & 1.00 \\
\hline
\end{tabular}

Source: Spillover matrix analysis.

Notes: $\quad \mathrm{ANG}=$ Angola, $\mathrm{BOT}=$ Botswana, $\mathrm{DRC}=$ Democratic Republic of the Congo, LES $=$ Lesotho, MAD $=$ Madagascar , MAL = Malawi, MOZ = Mozambique, NAM = Namibia, $\mathrm{SAF}=$ South Africa, $\mathrm{SWZ}=$ Swaziland, TNZ $=$ Tanzania, $\mathrm{ZAM}=$ Zambia, and ZIM = Zimbabwe. Mauritius and Seychelles not included due to lack of data. 
Table A.15 Asymmetrical matrix of yield gaps for cassava

\begin{tabular}{lcccccccccccccc}
\hline Country & ANG & BOT & DRC & LES & MAD & MAL & MOZ & NAM & SAF & SWZ & TNZ & ZAM & ZIM \\
\hline ANG & 1.00 & 0.00 & 0.00 & 0.00 & 0.00 & 0.00 & 0.00 & 0.00 & 0.00 & 0.00 & 0.00 & 0.00 & 0.00 \\
BOT & 0.00 & 0.00 & 0.00 & 0.00 & 0.00 & 0.00 & 0.00 & 0.00 & 0.00 & 0.00 & 0.00 & 0.00 & 0.00 \\
DRC & 0.00 & 0.00 & 1.00 & 0.00 & 0.00 & 0.00 & 0.00 & 0.00 & 0.00 & 0.00 & 0.00 & 0.00 & 0.00 \\
LES & 0.00 & 0.00 & 0.00 & 0.00 & 0.00 & 0.00 & 0.00 & 0.00 & 0.00 & 0.00 & 0.00 & 0.00 & 0.00 \\
MAD & 0.00 & 0.00 & 0.00 & 0.00 & 1.00 & 0.00 & 0.00 & 0.00 & 0.00 & 0.00 & 0.00 & 0.00 & 0.00 \\
MAL & 0.00 & 0.00 & 0.00 & 0.00 & 0.00 & 1.00 & 0.00 & 0.00 & 0.00 & 0.00 & 0.00 & 0.00 & 0.00 \\
MOZ & 0.00 & 0.00 & 0.00 & 0.00 & 0.00 & 0.00 & 1.00 & 0.00 & 0.00 & 0.00 & 1.30 & 0.00 & 0.00 \\
NAM & 0.00 & 0.00 & 0.00 & 0.00 & 0.00 & 0.00 & 0.00 & 0.00 & 0.00 & 0.00 & 0.00 & 0.00 & 0.00 \\
SAF & 0.00 & 0.00 & 0.00 & 0.00 & 0.00 & 0.00 & 0.00 & 0.00 & 0.00 & 0.00 & 0.00 & 0.00 & 0.00 \\
SWZ & 0.00 & 0.00 & 0.00 & 0.00 & 0.00 & 0.00 & 0.00 & 0.00 & 0.00 & 0.00 & 0.00 & 0.00 & 0.00 \\
TNZ & 0.00 & 0.00 & 0.00 & 0.00 & 0.00 & 0.00 & 0.00 & 0.00 & 0.00 & 0.00 & 1.00 & 0.00 & 0.00 \\
ZAM & 1.38 & 0.00 & 1.38 & 0.00 & 1.30 & 1.44 & 0.00 & 0.00 & 0.00 & 0.00 & 1.50 & 1.00 & 0.00 \\
ZIM & 1.88 & 0.00 & 1.88 & 0.00 & 1.77 & 1.96 & 1.57 & 0.00 & 0.00 & 0.00 & 2.04 & 1.36 & 1.00 \\
\hline
\end{tabular}

Source: Spillover matrix analysis.

Notes: $\quad \mathrm{ANG}=$ Angola, $\mathrm{BOT}=$ Botswana, $\mathrm{DRC}=$ Democratic Republic of the Congo, LES $=$ Lesotho, MAD $=$ Madagascar, $\mathrm{MAL}=$ Malawi, $\mathrm{MOZ}=$ Mozambique, $\mathrm{NAM}=$ Namibia, $\mathrm{SAF}=$ South Africa, $\mathrm{SWZ}=$ Swaziland, $\mathrm{TNZ}=\mathrm{Tanzania}$,

ZAM = Zambia, and ZIM = Zimbabwe. Mauritius and Seychelles not included due to lack of data.

Table A.16 Asymmetrical matrix of yield gaps for cotton

\begin{tabular}{lccccccccccccc}
\hline Country & ANG & BOT & DRC & LES & MAD & MAL & MOZ & NAM & SAF & SWZ & TNZ & ZAM & ZIM \\
\hline ANG & 1.00 & 1.38 & 0.00 & 0.00 & 0.00 & 0.00 & 0.00 & 1.52 & 1.62 & 0.00 & 0.00 & 0.00 & 0.00 \\
BOT & 0.00 & 1.00 & 0.00 & 0.00 & 0.00 & 0.00 & 0.00 & 0.00 & 0.00 & 0.00 & 0.00 & 0.00 & 0.00 \\
DRC & 2.35 & 3.24 & 1.00 & 0.00 & 2.28 & 2.01 & 1.75 & 3.56 & 3.81 & 0.00 & 1.98 & 2.93 & 2.13 \\
LES & 0.00 & 0.00 & 0.00 & 0.00 & 0.00 & 0.00 & 0.00 & 0.00 & 0.00 & 0.00 & 0.00 & 0.00 & 0.00 \\
MAD & 0.00 & 1.42 & 0.00 & 0.00 & 1.00 & 0.00 & 0.00 & 1.56 & 1.67 & 0.00 & 0.00 & 1.28 & 0.00 \\
MAL & 0.00 & 1.61 & 0.00 & 0.00 & 0.00 & 1.00 & 0.00 & 1.78 & 1.90 & 0.00 & 0.00 & 1.46 & 0.00 \\
MOZ & 1.35 & 1.85 & 0.00 & 0.00 & 1.31 & 0.00 & 1.00 & 2.04 & 2.18 & 0.00 & 0.00 & 1.68 & 0.00 \\
NAM & 0.00 & 0.00 & 0.00 & 0.00 & 0.00 & 0.00 & 0.00 & 1.00 & 0.00 & 0.00 & 0.00 & 0.00 & 0.00 \\
SAF & 0.00 & 0.00 & 0.00 & 0.00 & 0.00 & 0.00 & 0.00 & 0.00 & 1.00 & 0.00 & 0.00 & 0.00 & 0.00 \\
SWZ & 2.47 & 3.40 & 0.00 & 0.00 & 2.40 & 2.11 & 1.83 & 3.74 & 4.00 & 1.00 & 2.08 & 3.08 & 2.24 \\
TNZ & 0.00 & 1.64 & 0.00 & 0.00 & 0.00 & 0.00 & 0.00 & 1.80 & 1.92 & 0.00 & 1.00 & 1.48 & 0.00 \\
ZAM & 0.00 & 0.00 & 0.00 & 0.00 & 0.00 & 0.00 & 0.00 & 0.00 & 1.30 & 0.00 & 0.00 & 1.00 & 0.00 \\
ZIM & 0.00 & 1.52 & 0.00 & 0.00 & 0.00 & 0.00 & 0.00 & 1.67 & 1.79 & 0.00 & 0.00 & 1.38 & 1.00 \\
\hline
\end{tabular}

Source: Spillover matrix analysis.

Notes: $\quad \mathrm{ANG}=$ Angola, $\mathrm{BOT}=$ Botswana, $\mathrm{DRC}=$ Democratic Republic of the Congo, $\mathrm{LES}=$ Lesotho, MAD $=$ Madagascar, $\mathrm{MAL}=$ Malawi, MOZ = Mozambique, NAM = Namibia, $\mathrm{SAF}=$ South Africa, $\mathrm{SWZ}=$ Swaziland, TNZ $=$ Tanzania,

ZAM = Zambia, and ZIM = Zimbabwe. Mauritius and Seychelles not included due to lack of data.

Table A.17 Asymmetrical matrix of yield gaps for groundnuts

\begin{tabular}{|c|c|c|c|c|c|c|c|c|c|c|c|c|c|}
\hline Country & ANG & BOT & DRC & LES & MAD & MAL & MOZ & NAM & SAF & SWZ & TNZ & ZAM & ZIM \\
\hline ANG & 1.00 & 2.75 & 2.14 & 0.00 & 3.08 & 2.28 & 0.00 & 1.28 & 3.71 & 2.11 & 0.00 & 0.00 & 1.91 \\
\hline BOT & 0.00 & 1.00 & 0.00 & 0.00 & 0.00 & 0.00 & 0.00 & 0.00 & 1.35 & 0.00 & 0.00 & 0.00 & 0.00 \\
\hline DRC & 0.00 & 1.29 & 1.00 & 0.00 & 1.44 & 0.00 & 0.00 & 0.00 & 1.73 & 0.00 & 0.00 & 0.00 & 0.00 \\
\hline LES & 0.00 & 0.00 & 0.00 & 0.00 & 0.00 & 0.00 & 0.00 & 0.00 & 0.00 & 0.00 & 0.00 & 0.00 & 0.00 \\
\hline MAD & 0.00 & 0.00 & 0.00 & 0.00 & 1.00 & 0.00 & 0.00 & 0.00 & 0.00 & 0.00 & 0.00 & 0.00 & 0.00 \\
\hline MAL & 0.00 & 0.00 & 0.00 & 0.00 & 1.35 & 1.00 & 0.00 & 0.00 & 1.63 & 0.00 & 0.00 & 0.00 & 0.00 \\
\hline MOZ & 0.00 & 2.31 & 1.80 & 0.00 & 2.59 & 1.91 & 1.00 & 0.00 & 3.12 & 1.78 & 0.00 & 0.00 & 1.61 \\
\hline NAM & 0.00 & 2.15 & 1.67 & 0.00 & 2.40 & 1.78 & 0.00 & 1.00 & 2.89 & 1.65 & 0.00 & 0.00 & 1.49 \\
\hline SAF & 0.00 & 0.00 & 0.00 & 0.00 & 0.00 & 0.00 & 0.00 & 0.00 & 1.00 & 0.00 & 0.00 & 0.00 & 0.00 \\
\hline SWZ & 0.00 & 1.30 & 0.00 & 0.00 & 1.46 & 0.00 & 0.00 & 0.00 & 1.75 & 1.00 & 0.00 & 0.00 & 0.00 \\
\hline TNZ & 0.00 & 2.22 & 1.73 & 0.00 & 2.48 & 1.83 & 0.00 & 0.00 & 2.99 & 1.70 & 1.00 & 0.00 & 1.54 \\
\hline ZAM & 0.00 & 2.55 & 1.98 & 0.00 & 2.85 & 2.10 & 0.00 & 0.00 & 3.43 & 1.95 & 0.00 & 1.00 & 1.77 \\
\hline ZIM & 0.00 & 1.44 & 0.00 & 0.00 & 1.61 & 0.00 & 0.00 & 0.00 & 1.94 & 0.00 & 0.00 & 0.00 & 1.00 \\
\hline
\end{tabular}

Source: Spillover matrix analysis.

Notes: $\quad$ ANG $=$ Angola, $\mathrm{BOT}=$ Botswana, $\mathrm{DRC}=$ Democratic Republic of the Congo, LES $=$ Lesotho, MAD $=$ Madagascar, $\mathrm{MAL}=$ Malawi, $\mathrm{MOZ}=$ Mozambique, $\mathrm{NAM}=$ Namibia, $\mathrm{SAF}=$ South Africa, $\mathrm{SWZ}=$ Swaziland, $\mathrm{TNZ}=$ Tanzania, ZAM = Zambia, and ZIM = Zimbabwe. Mauritius and Seychelles not included due to lack of data. 
Table A.18 Asymmetrical matrix of yield gaps for millet

\begin{tabular}{lccccccccccccc}
\hline Country & ANG & BOT & DRC & LES & MAD & MAL & MOZ & NAM & SAF & SWZ & TNZ & ZAM & ZIM \\
\hline ANG & 1.00 & 0.00 & 1.48 & 0.00 & 0.00 & 1.61 & 0.00 & 0.00 & 1.28 & 0.00 & 1.85 & 1.55 & 0.00 \\
BOT & 1.90 & 1.00 & 2.80 & 0.00 & 0.00 & 3.05 & 2.35 & 1.27 & 2.42 & 0.00 & 3.50 & 2.94 & 0.00 \\
DRC & 0.00 & 0.00 & 1.00 & 0.00 & 0.00 & 0.00 & 0.00 & 0.00 & 0.00 & 0.00 & 1.25 & 0.00 & 0.00 \\
LES & 0.00 & 0.00 & 0.00 & 0.00 & 0.00 & 0.00 & 0.00 & 0.00 & 0.00 & 0.00 & 0.00 & 0.00 & 0.00 \\
MAD & 0.00 & 0.00 & 0.00 & 0.00 & 0.00 & 0.00 & 0.00 & 0.00 & 0.00 & 0.00 & 0.00 & 0.00 & 0.00 \\
MAL & 0.00 & 0.00 & 0.00 & 0.00 & 0.00 & 1.00 & 0.00 & 0.00 & 0.00 & 0.00 & 0.00 & 0.00 & 0.00 \\
MOZ & 0.00 & 0.00 & 0.00 & 0.00 & 0.00 & 1.30 & 1.00 & 0.00 & 0.00 & 0.00 & 1.49 & 1.25 & 0.00 \\
NAM & 1.49 & 0.00 & 2.20 & 0.00 & 0.00 & 2.40 & 1.85 & 1.00 & 1.91 & 0.00 & 2.76 & 2.31 & 0.00 \\
SAF & 0.00 & 0.00 & 0.00 & 0.00 & 0.00 & 1.26 & 0.00 & 0.00 & 1.00 & 0.00 & 1.45 & 0.00 & 0.00 \\
SWZ & 0.00 & 0.00 & 0.00 & 0.00 & 0.00 & 0.00 & 0.00 & 0.00 & 0.00 & 0.00 & 0.00 & 0.00 & 0.00 \\
TNZ & 0.00 & 0.00 & 0.00 & 0.00 & 0.00 & 0.00 & 0.00 & 0.00 & 0.00 & 0.00 & 1.00 & 0.00 & 0.00 \\
ZAM & 0.00 & 0.00 & 0.00 & 0.00 & 0.00 & 0.00 & 0.00 & 0.00 & 0.00 & 0.00 & 0.00 & 1.00 & 0.00 \\
ZIM & 1.56 & 0.00 & 2.31 & 0.00 & 0.00 & 2.51 & 1.94 & 0.00 & 2.00 & 0.00 & 2.89 & 2.42 & 1.00 \\
\hline
\end{tabular}

Source: Spillover matrix analysis.

Notes: $\quad \mathrm{ANG}=$ Angola, $\mathrm{BOT}=$ Botswana, $\mathrm{DRC}=$ Democratic Republic of the Congo, $\mathrm{LES}=$ Lesotho, MAD $=$ Madagascar,

MAL $=$ Malawi, $\mathrm{MOZ}=$ Mozambique, $\mathrm{NAM}=$ Namibia, $\mathrm{SAF}=$ South Africa, $\mathrm{SWZ}=$ Swaziland, $\mathrm{TNZ}=$ Tanzania,

$\mathrm{ZAM}=$ Zambia, and ZIM = Zimbabwe. Mauritius and Seychelles not included due to lack of data.

Table A.19 Asymmetrical matrix of yield gaps for potatoes and sweet potatoes

\begin{tabular}{lccccccccccccc}
\hline Country & ANG & BOT & DRC & LES & MAD & MAL & MOZ & NAM & SAF & SWZ & TNZ & ZAM & ZIM \\
\hline ANG & 1.00 & 0.00 & 0.00 & 0.00 & 1.45 & 0.00 & 0.00 & 0.00 & 0.00 & 0.00 & 0.00 & 0.00 & 0.00 \\
BOT & 0.00 & 0.00 & 0.00 & 0.00 & 0.00 & 0.00 & 0.00 & 0.00 & 0.00 & 0.00 & 0.00 & 0.00 & 0.00 \\
DRC & 0.00 & 0.00 & 1.00 & 0.00 & 1.27 & 0.00 & 0.00 & 0.00 & 0.00 & 0.00 & 0.00 & 0.00 & 0.00 \\
LES & 0.00 & 0.00 & 1.36 & 1.00 & 1.73 & 0.00 & 0.00 & 0.00 & 1.43 & 0.00 & 0.00 & 0.00 & 0.00 \\
MAD & 0.00 & 0.00 & 0.00 & 0.00 & 1.00 & 0.00 & 0.00 & 0.00 & 0.00 & 0.00 & 0.00 & 0.00 & 0.00 \\
MAL & 0.00 & 0.00 & 0.00 & 0.00 & 1.46 & 1.00 & 0.00 & 0.00 & 0.00 & 0.00 & 0.00 & 0.00 & 0.00 \\
MOZ & 0.00 & 0.00 & 0.00 & 0.00 & 1.53 & 0.00 & 1.00 & 0.00 & 1.27 & 0.00 & 0.00 & 0.00 & 0.00 \\
NAM & 0.00 & 0.00 & 0.00 & 0.00 & 0.00 & 0.00 & 0.00 & 0.00 & 0.00 & 0.00 & 0.00 & 0.00 & 0.00 \\
SAF & 0.00 & 0.00 & 0.00 & 0.00 & 0.00 & 0.00 & 0.00 & 0.00 & 1.00 & 0.00 & 0.00 & 0.00 & 0.00 \\
SWZ & 2.05 & 0.00 & 2.33 & 1.71 & 2.96 & 2.03 & 1.94 & 0.00 & 2.46 & 1.00 & 1.71 & 1.98 & 1.60 \\
TNZ & 0.00 & 0.00 & 1.36 & 0.00 & 1.73 & 0.00 & 0.00 & 0.00 & 1.44 & 0.00 & 1.00 & 0.00 & 0.00 \\
ZAM & 0.00 & 0.00 & 0.00 & 0.00 & 1.50 & 0.00 & 0.00 & 0.00 & 0.00 & 0.00 & 0.00 & 1.00 & 0.00 \\
ZIM & 1.28 & 0.00 & 1.45 & 0.00 & 1.85 & 1.27 & 0.00 & 0.00 & 1.54 & 0.00 & 0.00 & 0.00 & 1.00 \\
\hline
\end{tabular}

Source: Spillover matrix analysis.

Notes: $\quad \mathrm{ANG}=$ Angola, $\mathrm{BOT}=$ Botswana, $\mathrm{DRC}=$ Democratic Republic of the Congo, LES $=$ Lesotho, MAD $=$ Madagascar , $\mathrm{MAL}=$ Malawi, $\mathrm{MOZ}=$ Mozambique, $\mathrm{NAM}=$ Namibia, $\mathrm{SAF}=$ South Africa, $\mathrm{SWZ}=$ Swaziland, $\mathrm{TNZ}=\mathrm{Tanzania}$,

$\mathrm{ZAM}=$ Zambia, and ZIM = Zimbabwe. Mauritius and Seychelles not included due to lack of data.

Table A.20 Asymmetrical matrix of yield gaps for rice

\begin{tabular}{|c|c|c|c|c|c|c|c|c|c|c|c|c|c|}
\hline Country & ANG & BOT & DRC & LES & MAD & MAL & MOZ & NAM & SAF & SWZ & TNZ & ZAM & ZIM \\
\hline ANG & 1.00 & 0.00 & 0.00 & 0.00 & 2.76 & 2.07 & 0.00 & 0.00 & 2.85 & 4.24 & 2.32 & 1.63 & 3.01 \\
\hline BOT & 0.00 & 0.00 & 0.00 & 0.00 & 0.00 & 0.00 & 0.00 & 0.00 & 0.00 & 0.00 & 0.00 & 0.00 & 0.00 \\
\hline DRC & 0.00 & 0.00 & 1.00 & 0.00 & 2.93 & 2.20 & 1.30 & 0.00 & 3.03 & 4.50 & 2.47 & 1.73 & 3.20 \\
\hline LES & 0.00 & 0.00 & 0.00 & 0.00 & 0.00 & 0.00 & 0.00 & 0.00 & 0.00 & 0.00 & 0.00 & 0.00 & 0.00 \\
\hline MAD & 0.00 & 0.00 & 0.00 & 0.00 & 1.00 & 0.00 & 0.00 & 0.00 & 0.00 & 1.54 & 0.00 & 0.00 & 0.00 \\
\hline MAL & 0.00 & 0.00 & 0.00 & 0.00 & 1.33 & 1.00 & 0.00 & 0.00 & 1.37 & 2.05 & 0.00 & 0.00 & 1.45 \\
\hline MOZ & 0.00 & 0.00 & 0.00 & 0.00 & 2.25 & 1.69 & 1.00 & 0.00 & 2.33 & 3.46 & 1.90 & 1.33 & 2.46 \\
\hline NAM & 0.00 & 0.00 & 0.00 & 0.00 & 0.00 & 0.00 & 0.00 & 0.00 & 0.00 & 0.00 & 0.00 & 0.00 & 0.00 \\
\hline SAF & 0.00 & 0.00 & 0.00 & 0.00 & 0.00 & 0.00 & 0.00 & 0.00 & 1.00 & 1.49 & 0.00 & 0.00 & 0.00 \\
\hline SWZ & 0.00 & 0.00 & 0.00 & 0.00 & 0.00 & 0.00 & 0.00 & 0.00 & 0.00 & 1.00 & 0.00 & 0.00 & 0.00 \\
\hline TNZ & 0.00 & 0.00 & 0.00 & 0.00 & 0.00 & 0.00 & 0.00 & 0.00 & 0.00 & 1.82 & 1.00 & 0.00 & 1.29 \\
\hline ZAM & 0.00 & 0.00 & 0.00 & 0.00 & 1.69 & 1.27 & 0.00 & 0.00 & 1.75 & 2.60 & 1.43 & 1.00 & 1.84 \\
\hline ZIM & 0.00 & 0.00 & 0.00 & 0.00 & 0.00 & 0.00 & 0.00 & 0.00 & 0.00 & 1.41 & 0.00 & 0.00 & 1.00 \\
\hline
\end{tabular}

Source: Spillover matrix analysis.

Notes: $\quad$ ANG $=$ Angola, $\mathrm{BOT}=$ Botswana, $\mathrm{DRC}=$ Democratic Republic of the Congo, LES $=$ Lesotho, MAD $=$ Madagascar, $\mathrm{MAL}=$ Malawi, MOZ = Mozambique, NAM = Namibia, $\mathrm{SAF}=$ South Africa, $\mathrm{SWZ}=$ Swaziland, TNZ = Tanzania,

ZAM = Zambia, and ZIM = Zimbabwe. Mauritius and Seychelles not included due to lack of data. 
Table A.21 Asymmetrical matrix of yield gaps for sorghum

\begin{tabular}{lccccccccccccc}
\hline Country & ANG & BOT & DRC & LES & MAD & MAL & MOZ & NAM & SAF & SWZ & TNZ & ZAM & ZIM \\
\hline ANG & 0.00 & 0.00 & 0.00 & 0.00 & 0.00 & 0.00 & 0.00 & 0.00 & 0.00 & 0.00 & 0.00 & 0.00 & 0.00 \\
BOT & 0.00 & 1.00 & 2.02 & 2.63 & 1.83 & 2.62 & 2.02 & 0.00 & 10.12 & 1.83 & 3.04 & 2.11 & 1.49 \\
DRC & 0.00 & 0.00 & 1.00 & 1.30 & 0.00 & 1.29 & 0.00 & 0.00 & 5.01 & 0.00 & 1.51 & 0.00 & 0.00 \\
LES & 0.00 & 0.00 & 0.00 & 1.00 & 0.00 & 0.00 & 0.00 & 0.00 & 3.85 & 0.00 & 0.00 & 0.00 & 0.00 \\
MAD & 0.00 & 0.00 & 0.00 & 1.44 & 1.00 & 1.43 & 0.00 & 0.00 & 5.54 & 0.00 & 1.67 & 0.00 & 0.00 \\
MAL & 0.00 & 0.00 & 0.00 & 0.00 & 0.00 & 1.00 & 0.00 & 0.00 & 3.87 & 0.00 & 0.00 & 0.00 & 0.00 \\
MOZ & 0.00 & 0.00 & 0.00 & 1.31 & 0.00 & 1.30 & 1.00 & 0.00 & 5.02 & 0.00 & 1.51 & 0.00 & 0.00 \\
NAM & 0.00 & 0.00 & 1.62 & 2.11 & 1.47 & 2.10 & 1.62 & 1.00 & 8.13 & 1.47 & 2.44 & 1.70 & 0.00 \\
SAF & 0.00 & 0.00 & 0.00 & 0.00 & 0.00 & 0.00 & 0.00 & 0.00 & 1.00 & 0.00 & 0.00 & 0.00 & 0.00 \\
SWZ & 0.00 & 0.00 & 0.00 & 1.44 & 0.00 & 1.43 & 0.00 & 0.00 & 5.54 & 1.00 & 1.67 & 0.00 & 0.00 \\
TNZ & 0.00 & 0.00 & 0.00 & 0.00 & 0.00 & 0.00 & 0.00 & 0.00 & 3.32 & 0.00 & 1.00 & 0.00 & 0.00 \\
ZAM & 0.00 & 0.00 & 0.00 & 0.00 & 0.00 & 0.00 & 0.00 & 0.00 & 4.79 & 0.00 & 1.44 & 1.00 & 0.00 \\
ZIM & 0.00 & 0.00 & 1.36 & 1.77 & 0.00 & 1.76 & 1.36 & 0.00 & 6.81 & 0.00 & 2.05 & 1.42 & 1.00 \\
\hline
\end{tabular}

Source: Spillover matrix analysis.

Notes: $\quad \mathrm{ANG}=$ Angola, $\mathrm{BOT}=$ Botswana, $\mathrm{DRC}=$ Democratic Republic of the Congo, LES $=$ Lesotho, MAD $=$ Madagascar,

$\mathrm{MAL}=$ Malawi, $\mathrm{MOZ}=$ Mozambique, $\mathrm{NAM}=$ Namibia, $\mathrm{SAF}=$ South Africa, $\mathrm{SWZ}=$ Swaziland, $\mathrm{TNZ}=\mathrm{Tanzania}$,

ZAM = Zambia, and ZIM = Zimbabwe. Mauritius and Seychelles not included due to lack of data.

Table A.22 Asymmetrical matrix of yield gaps for sugarcane

\begin{tabular}{lccccccccccccc}
\hline Country & ANG & BOT & DRC & LES & MAD & MAL & MOZ & NAM & SAF & SWZ & TNZ & ZAM & ZIM \\
\hline ANG & 1.00 & 0.00 & 0.00 & 0.00 & 0.00 & 1.29 & 0.00 & 0.00 & 1.46 & 1.29 & 1.26 & 0.00 & 0.00 \\
BOT & 0.00 & 0.00 & 0.00 & 0.00 & 0.00 & 0.00 & 0.00 & 0.00 & 0.00 & 0.00 & 0.00 & 0.00 & 0.00 \\
DRC & 0.00 & 0.00 & 1.00 & 0.00 & 0.00 & 1.26 & 0.00 & 0.00 & 1.42 & 1.26 & 0.00 & 0.00 & 0.00 \\
LES & 0.00 & 0.00 & 0.00 & 0.00 & 0.00 & 0.00 & 0.00 & 0.00 & 0.00 & 0.00 & 0.00 & 0.00 & 0.00 \\
MAD & 0.00 & 0.00 & 0.00 & 0.00 & 1.00 & 1.50 & 0.00 & 0.00 & 1.70 & 1.51 & 1.47 & 1.28 & 0.00 \\
MAL & 0.00 & 0.00 & 0.00 & 0.00 & 0.00 & 1.00 & 0.00 & 0.00 & 0.00 & 0.00 & 0.00 & 0.00 & 0.00 \\
MOZ & 1.76 & 0.00 & 1.81 & 0.00 & 1.51 & 2.27 & 1.00 & 0.00 & 2.57 & 2.28 & 2.23 & 1.94 & 1.88 \\
NAM & 0.00 & 0.00 & 0.00 & 0.00 & 0.00 & 0.00 & 0.00 & 0.00 & 0.00 & 0.00 & 0.00 & 0.00 & 0.00 \\
SAF & 0.00 & 0.00 & 0.00 & 0.00 & 0.00 & 0.00 & 0.00 & 0.00 & 1.00 & 0.00 & 0.00 & 0.00 & 0.00 \\
SWZ & 0.00 & 0.00 & 0.00 & 0.00 & 0.00 & 0.00 & 0.00 & 0.00 & 0.00 & 1.00 & 0.00 & 0.00 & 0.00 \\
TNZ & 0.00 & 0.00 & 0.00 & 0.00 & 0.00 & 0.00 & 0.00 & 0.00 & 0.00 & 0.00 & 1.00 & 0.00 & 0.00 \\
ZAM & 0.00 & 0.00 & 0.00 & 0.00 & 0.00 & 0.00 & 0.00 & 0.00 & 1.33 & 0.00 & 0.00 & 1.00 & 0.00 \\
ZIM & 0.00 & 0.00 & 0.00 & 0.00 & 0.00 & 0.00 & 0.00 & 0.00 & 1.37 & 0.00 & 0.00 & 0.00 & 1.00 \\
\hline
\end{tabular}

Source: Spillover matrix analysis.

Notes: $\quad$ ANG $=$ Angola, BOT $=$ Botswana, $\mathrm{DRC}=$ Democratic Republic of the Congo, LES $=$ Lesotho, MAD = Madagascar, $\mathrm{MAL}=$ Malawi, MOZ = Mozambique, NAM = Namibia, $\mathrm{SAF}=$ South Africa, $\mathrm{SWZ}=$ Swaziland, TNZ $=$ Tanzania,

ZAM = Zambia, and ZIM = Zimbabwe. Mauritius and Seychelles not included due to lack of data.

Table A.23 Asymmetrical matrix of yield gaps for wheat

\begin{tabular}{lccccccccccccc}
\hline Country & ANG & BOT & DRC & LES & MAD & MAL & MOZ & NAM & SAF & SWZ & TNZ & ZAM & ZIM \\
\hline ANG & 1.00 & 0.00 & 0.00 & 0.00 & 0.00 & 0.00 & 0.00 & 0.00 & 1.34 & 0.00 & 0.00 & 0.00 & 1.46 \\
BOT & 1.28 & 1.00 & 0.00 & 0.00 & 1.42 & 0.00 & 0.00 & 1.41 & 1.71 & 0.00 & 0.00 & 0.00 & 1.87 \\
DRC & 1.49 & 0.00 & 1.00 & 0.00 & 1.66 & 1.32 & 0.00 & 1.64 & 2.00 & 0.00 & 0.00 & 0.00 & 2.18 \\
LES & 0.00 & 0.00 & 0.00 & 0.00 & 1.26 & 0.00 & 0.00 & 0.00 & 1.51 & 0.00 & 0.00 & 0.00 & 1.65 \\
MAD & 0.00 & 0.00 & 0.00 & 0.00 & 1.00 & 0.00 & 0.00 & 0.00 & 0.00 & 0.00 & 0.00 & 0.00 & 1.31 \\
MAL & 0.00 & 0.00 & 0.00 & 0.00 & 1.26 & 1.00 & 0.00 & 0.00 & 1.52 & 0.00 & 0.00 & 0.00 & 1.66 \\
MOZ & 1.54 & 0.00 & 0.00 & 0.00 & 1.71 & 1.35 & 1.00 & 1.69 & 2.06 & 0.00 & 0.00 & 0.00 & 2.24 \\
NAM & 0.00 & 0.00 & 0.00 & 0.00 & 0.00 & 0.00 & 0.00 & 1.00 & 0.00 & 0.00 & 0.00 & 0.00 & 1.33 \\
SAF & 0.00 & 0.00 & 0.00 & 0.00 & 0.00 & 0.00 & 0.00 & 0.00 & 1.00 & 0.00 & 0.00 & 0.00 & 0.00 \\
SWZ & 1.30 & 0.00 & 0.00 & 0.00 & 1.44 & 0.00 & 0.00 & 1.43 & 1.74 & 1.00 & 0.00 & 0.00 & 1.90 \\
TNZ & 1.54 & 0.00 & 0.00 & 0.00 & 1.71 & 1.35 & 0.00 & 1.69 & 2.06 & 0.00 & 1.00 & 0.00 & 2.24 \\
ZAM & 0.00 & 0.00 & 0.00 & 0.00 & 0.00 & 0.00 & 0.00 & 0.00 & 0.00 & 0.00 & 0.00 & 0.00 & 0.00 \\
ZIM & 0.00 & 0.00 & 0.00 & 0.00 & 0.00 & 0.00 & 0.00 & 0.00 & 0.00 & 0.00 & 0.00 & 0.00 & 1.00 \\
\hline
\end{tabular}

Source: Spillover matrix analysis.

Notes: $\quad \mathrm{ANG}=$ Angola, $\mathrm{BOT}=$ Botswana, $\mathrm{DRC}=$ Democratic Republic of the Congo, LES $=$ Lesotho, MAD $=$ Madagascar, $\mathrm{MAL}=$ Malawi, $\mathrm{MOZ}=$ Mozambique, $\mathrm{NAM}=$ Namibia, $\mathrm{SAF}=$ South Africa, $\mathrm{SWZ}=$ Swaziland, $\mathrm{TNZ}=$ Tanzania, ZAM = Zambia, and ZIM = Zimbabwe. Mauritius and Seychelles not included due to lack of data. 
Table A.24 Asymmetrical matrix of yield gaps for cattle

\begin{tabular}{|c|c|c|c|c|c|c|c|c|c|c|c|c|c|}
\hline Country & ANG & BOT & DRC & LES & MAD & MAL & MOZ & NAM & SAF & SWZ & TNZ & ZAM & ZIM \\
\hline ANG & 1.00 & 0.00 & 0.00 & 0.00 & 0.00 & 0.00 & 0.00 & 1.36 & 1.45 & 1.38 & 0.00 & 0.00 & 1.31 \\
\hline BOT & 0.00 & 1.00 & 0.00 & 0.00 & 0.00 & 0.00 & 0.00 & 0.00 & 1.26 & 0.00 & 0.00 & 0.00 & 0.00 \\
\hline DRC & 0.00 & 1.26 & 1.00 & 0.00 & 0.00 & 1.32 & 0.00 & 1.49 & 1.59 & 1.52 & 0.00 & 0.00 & 1.45 \\
\hline LES & 1.32 & 1.51 & 0.00 & 1.00 & 0.00 & 1.58 & 0.00 & 1.79 & 1.90 & 1.82 & 0.00 & 0.00 & 1.73 \\
\hline MAD & 1.34 & 1.54 & 0.00 & 0.00 & 1.00 & 1.61 & 0.00 & 1.82 & 1.94 & 1.86 & 0.00 & 1.25 & 1.76 \\
\hline MAL & 0.00 & 0.00 & 0.00 & 0.00 & 0.00 & 1.00 & 0.00 & 0.00 & 0.00 & 0.00 & 0.00 & 0.00 & 0.00 \\
\hline MOZ & 0.00 & 1.31 & 0.00 & 0.00 & 0.00 & 1.37 & 1.00 & 1.55 & 1.65 & 1.58 & 0.00 & 0.00 & 1.50 \\
\hline NAM & 0.00 & 0.00 & 0.00 & 0.00 & 0.00 & 0.00 & 0.00 & 1.00 & 0.00 & 0.00 & 0.00 & 0.00 & 0.00 \\
\hline SAF & 0.00 & 0.00 & 0.00 & 0.00 & 0.00 & 0.00 & 0.00 & 0.00 & 1.00 & 0.00 & 0.00 & 0.00 & 0.00 \\
\hline SWZ & 0.00 & 0.00 & 0.00 & 0.00 & 0.00 & 0.00 & 0.00 & 0.00 & 0.00 & 1.00 & 0.00 & 0.00 & 0.00 \\
\hline TNZ & 1.59 & 1.82 & 1.44 & 0.00 & 0.00 & 1.90 & 1.39 & 2.16 & 2.30 & 2.20 & 1.00 & 1.48 & 2.09 \\
\hline ZAM & 0.00 & 0.00 & 0.00 & 0.00 & 0.00 & 1.28 & 0.00 & 1.45 & 1.55 & 1.48 & 0.00 & 1.00 & 1.41 \\
\hline ZIM & 0.00 & 0.00 & 0.00 & 0.00 & 0.00 & 0.00 & 0.00 & 0.00 & 0.00 & 0.00 & 0.00 & 0.00 & 1.00 \\
\hline
\end{tabular}

Source: Spillover matrix analysis.

Notes: $\quad \mathrm{ANG}=$ Angola, $\mathrm{BOT}=$ Botswana, $\mathrm{DRC}=$ Democratic Republic of the Congo, $\mathrm{LES}=$ Lesotho, MAD $=$ Madagascar,

MAL $=$ Malawi, MOZ = Mozambique, $\mathrm{NAM}=$ Namibia, $\mathrm{SAF}=$ South Africa, $\mathrm{SWZ}=$ Swaziland, $\mathrm{TNZ}=\mathrm{Tanzania}$,

ZAM = Zambia, and ZIM = Zimbabwe. Mauritius and Seychelles not included due to lack of data.

Table A.25 Asymmetrical matrix of yield gaps for pigs

\begin{tabular}{|c|c|c|c|c|c|c|c|c|c|c|c|c|c|}
\hline Country & ANG & BOT & DRC & LES & MAD & MAL & MOZ & NAM & SAF & SWZ & TNZ & ZAM & ZIM \\
\hline ANG & 1.00 & 0.00 & 0.00 & 0.00 & 0.00 & 0.00 & 0.00 & 0.00 & 1.28 & 0.00 & 0.00 & 0.00 & 0.00 \\
\hline BOT & 1.30 & 1.00 & 0.00 & 0.00 & 1.40 & 0.00 & 0.00 & 0.00 & 1.66 & 0.00 & 0.00 & 0.00 & 0.00 \\
\hline DRC & 1.48 & 0.00 & 1.00 & 0.00 & 1.59 & 0.00 & 1.36 & 0.00 & 1.88 & 0.00 & 0.00 & 0.00 & 0.00 \\
\hline LES & 1.30 & 0.00 & 0.00 & 1.00 & 1.40 & 0.00 & 0.00 & 0.00 & 1.66 & 0.00 & 0.00 & 0.00 & 0.00 \\
\hline MAD & 0.00 & 0.00 & 0.00 & 0.00 & 1.00 & 0.00 & 0.00 & 0.00 & 0.00 & 0.00 & 0.00 & 0.00 & 0.00 \\
\hline MAL & 1.30 & 0.00 & 0.00 & 0.00 & 1.40 & 1.00 & 0.00 & 0.00 & 1.66 & 0.00 & 0.00 & 0.00 & 0.00 \\
\hline MOZ & 0.00 & 0.00 & 0.00 & 0.00 & 0.00 & 0.00 & 1.00 & 0.00 & 1.38 & 0.00 & 0.00 & 0.00 & 0.00 \\
\hline NAM & 0.00 & 0.00 & 0.00 & 0.00 & 1.27 & 0.00 & 0.00 & 1.00 & 1.51 & 0.00 & 0.00 & 0.00 & 0.00 \\
\hline SAF & 0.00 & 0.00 & 0.00 & 0.00 & 0.00 & 0.00 & 0.00 & 0.00 & 1.00 & 0.00 & 0.00 & 0.00 & 0.00 \\
\hline SWZ & 1.30 & 0.00 & 0.00 & 0.00 & 1.40 & 0.00 & 0.00 & 0.00 & 1.66 & 1.00 & 0.00 & 0.00 & 0.00 \\
\hline TNZ & 1.63 & 1.25 & 0.00 & 1.25 & 1.75 & 1.25 & 1.50 & 1.38 & 2.07 & 1.25 & 1.00 & 0.00 & 1.38 \\
\hline ZAM & 1.48 & 0.00 & 0.00 & 0.00 & 1.59 & 0.00 & 1.36 & 1.25 & 1.88 & 0.00 & 0.00 & 1.00 & 1.25 \\
\hline ZIM & 0.00 & 0.00 & 0.00 & 0.00 & 1.27 & 0.00 & 0.00 & 0.00 & 1.51 & 0.00 & 0.00 & 0.00 & 1.00 \\
\hline
\end{tabular}

Source: Spillover matrix analysis.

Notes: $\quad \mathrm{ANG}=$ Angola, $\mathrm{BOT}=$ Botswana, $\mathrm{DRC}=$ Democratic Republic of the Congo, LES $=$ Lesotho, MAD $=$ Madagascar, MAL $=$ Malawi, MOZ = Mozambique, NAM = Namibia, $\mathrm{SAF}=$ South Africa, $\mathrm{SWZ}=$ Swaziland, TNZ $=$ Tanzania,

ZAM = Zambia, and ZIM = Zimbabwe. Mauritius and Seychelles not included due to lack of data.

Table A.26 Asymmetrical matrix of yield gaps for sheep and goats

\begin{tabular}{|c|c|c|c|c|c|c|c|c|c|c|c|c|c|}
\hline Country & ANG & BOT & DRC & LES & MAD & MAL & MOZ & NAM & SAF & SWZ & TNZ & ZAM & ZIM \\
\hline ANG & 1.00 & 0.00 & 0.00 & 0.00 & 0.00 & 0.00 & 0.00 & 0.00 & 0.00 & 0.00 & 0.00 & 0.00 & 0.00 \\
\hline ВOT & 0.00 & 1.00 & 0.00 & 0.00 & 0.00 & 0.00 & 0.00 & 1.28 & 1.26 & 1.29 & 0.00 & 0.00 & 0.00 \\
\hline DRC & 1.51 & 1.41 & 1.00 & 0.00 & 0.00 & 1.41 & 0.00 & 1.81 & 1.78 & 1.81 & 0.00 & 1.41 & 1.41 \\
\hline LES & 1.50 & 1.40 & 0.00 & 1.00 & 0.00 & 1.40 & 0.00 & 1.80 & 1.77 & 1.80 & 0.00 & 1.40 & 1.40 \\
\hline MAD & 1.25 & 0.00 & 0.00 & 0.00 & 1.00 & 0.00 & 0.00 & 1.50 & 1.47 & 1.50 & 0.00 & 0.00 & 0.00 \\
\hline MAL & 0.00 & 0.00 & 0.00 & 0.00 & 0.00 & 1.00 & 0.00 & 1.28 & 1.27 & 1.29 & 0.00 & 0.00 & 0.00 \\
\hline MOZ & 1.25 & 0.00 & 0.00 & 0.00 & 0.00 & 0.00 & 1.00 & 1.50 & 1.47 & 1.50 & 0.00 & 0.00 & 0.00 \\
\hline NAM & 0.00 & 0.00 & 0.00 & 0.00 & 0.00 & 0.00 & 0.00 & 1.00 & 0.00 & 0.00 & 0.00 & 0.00 & 0.00 \\
\hline SAF & 0.00 & 0.00 & 0.00 & 0.00 & 0.00 & 0.00 & 0.00 & 0.00 & 1.00 & 0.00 & 0.00 & 0.00 & 0.00 \\
\hline SWZ & 0.00 & 0.00 & 0.00 & 0.00 & 0.00 & 0.00 & 0.00 & 0.00 & 0.00 & 1.00 & 0.00 & 0.00 & 0.00 \\
\hline TNZ & 1.25 & 0.00 & 0.00 & 0.00 & 0.00 & 0.00 & 0.00 & 1.50 & 1.47 & 1.50 & 1.00 & 0.00 & 0.00 \\
\hline ZAM & 0.00 & 0.00 & 0.00 & 0.00 & 0.00 & 0.00 & 0.00 & 1.28 & 1.26 & 1.29 & 0.00 & 1.00 & 0.00 \\
\hline ZIM & 0.00 & 0.00 & 0.00 & 0.00 & 0.00 & 0.00 & 0.00 & 1.28 & 1.26 & 1.29 & 0.00 & 0.00 & 1.00 \\
\hline
\end{tabular}

Source: Spillover matrix analysis.

Notes: $\quad \mathrm{ANG}=$ Angola, $\mathrm{BOT}=$ Botswana, $\mathrm{DRC}=$ Democratic Republic of the Congo, LES $=$ Lesotho, MAD $=$ Madagascar,

$\mathrm{MAL}=$ Malawi, $\mathrm{MOZ}=$ Mozambique, $\mathrm{NAM}=$ Namibia, $\mathrm{SAF}=$ South Africa, $\mathrm{SWZ}=$ Swaziland, $\mathrm{TNZ}=$ Tanzania,

ZAM = Zambia, and ZIM = Zimbabwe. Mauritius and Seychelles not included due to lack of data. 
Table A.27 Asymmetrical matrix of yield gaps for poultry

\begin{tabular}{|c|c|c|c|c|c|c|c|c|c|c|c|c|c|}
\hline Country & ANG & BOT & DRC & LES & MAD & MAL & MOZ & NAM & SAF & SWZ & TNZ & ZAM & ZIM \\
\hline ANG & 1.00 & 0.00 & 0.00 & 0.00 & 1.32 & 0.00 & 0.00 & 0.00 & 1.71 & 0.00 & 0.00 & 0.00 & 1.28 \\
\hline BOT & 0.00 & 1.00 & 0.00 & 0.00 & 1.48 & 0.00 & 0.00 & 1.28 & 1.93 & 1.25 & 0.00 & 1.25 & 1.44 \\
\hline DRC & 1.49 & 1.32 & 1.00 & 1.32 & 1.96 & 1.32 & 1.51 & 1.69 & 2.55 & 1.65 & 1.51 & 1.65 & 1.91 \\
\hline LES & 0.00 & 0.00 & 0.00 & 1.00 & 1.48 & 0.00 & 0.00 & 1.28 & 1.93 & 1.25 & 0.00 & 1.25 & 1.44 \\
\hline MAD & 0.00 & 0.00 & 0.00 & 0.00 & 1.00 & 0.00 & 0.00 & 0.00 & 1.30 & 0.00 & 0.00 & 0.00 & 0.00 \\
\hline MAL & 0.00 & 0.00 & 0.00 & 0.00 & 1.48 & 1.00 & 0.00 & 1.28 & 1.93 & 0.00 & 0.00 & 0.00 & 1.44 \\
\hline MOZ & 0.00 & 0.00 & 0.00 & 0.00 & 1.30 & 0.00 & 1.00 & 0.00 & 1.69 & 0.00 & 0.00 & 0.00 & 1.26 \\
\hline NAM & 0.00 & 0.00 & 0.00 & 0.00 & 0.00 & 0.00 & 0.00 & 1.00 & 1.51 & 0.00 & 0.00 & 0.00 & 0.00 \\
\hline SAF & 0.00 & 0.00 & 0.00 & 0.00 & 0.00 & 0.00 & 0.00 & 0.00 & 1.00 & 0.00 & 0.00 & 0.00 & 0.00 \\
\hline SWZ & 0.00 & 0.00 & 0.00 & 0.00 & 0.00 & 0.00 & 0.00 & 0.00 & 1.54 & 1.00 & 0.00 & 0.00 & 0.00 \\
\hline TNZ & 0.00 & 0.00 & 0.00 & 0.00 & 1.30 & 0.00 & 0.00 & 0.00 & 1.69 & 0.00 & 1.00 & 0.00 & 1.26 \\
\hline ZAM & 0.00 & 0.00 & 0.00 & 0.00 & 0.00 & 0.00 & 0.00 & 0.00 & 1.54 & 0.00 & 0.00 & 1.00 & 0.00 \\
\hline ZIM & 0.00 & 0.00 & 0.00 & 0.00 & 0.00 & 0.00 & 0.00 & 0.00 & 1.34 & 0.00 & 0.00 & 0.00 & 1.00 \\
\hline
\end{tabular}

Source: Spillover matrix analysis.

Notes: $\quad \mathrm{ANG}=$ Angola, $\mathrm{BOT}=$ Botswana, $\mathrm{DRC}=$ Democratic Republic of the Congo, $\mathrm{LES}=$ Lesotho, MAD $=$ Madagascar, $\mathrm{MAL}=$ Malawi, $\mathrm{MOZ}=$ Mozambique, $\mathrm{NAM}=$ Namibia, $\mathrm{SAF}=$ South Africa, $\mathrm{SWZ}=$ Swaziland, $\mathrm{TNZ}=$ Tanzania, ZAM = Zambia, and ZIM = Zimbabwe. Mauritius and Seychelles not included due to lack of data. 
Table A.28 Final spillover coefficient matrix for maize

\begin{tabular}{|c|c|c|c|c|c|c|c|c|c|c|c|c|c|c|c|}
\hline Country & ANG & ВOT & DRC & LES & MAD & MAL & MOZ & NAM & SAF & SWZ & TNZ & ZAM & ZIM & $\begin{array}{l}\text { Ave spill- } \\
\text { in }\end{array}$ & $\begin{array}{c}\text { spill-in } \\
\text { index }\end{array}$ \\
\hline ANG & 1.00 & 0.00 & 0.00 & 0.04 & 0.23 & 0.04 & 0.13 & 0.30 & 0.54 & 0.05 & 0.11 & 0.21 & 0.08 & 0.25 & 100.0 \\
\hline BOT & 0.15 & 1.00 & 0.14 & 0.12 & 0.40 & 0.09 & 0.17 & 0.45 & 0.39 & 0.16 & 0.14 & 0.21 & 0.21 & 0.25 & 99.7 \\
\hline DRC & 0.00 & 0.00 & 1.00 & 0.00 & 0.16 & 0.09 & 0.10 & 0.06 & 0.18 & 0.17 & 0.00 & 0.14 & 0.13 & 0.10 & 41.3 \\
\hline LES & 0.00 & 0.00 & 0.00 & 1.00 & 0.02 & 0.02 & 0.00 & 0.00 & 0.01 & 0.02 & 0.00 & 0.01 & 0.01 & 0.01 & 3.1 \\
\hline MAD & 0.00 & 0.00 & 0.00 & 0.00 & 1.00 & 0.05 & 0.00 & 0.00 & 0.12 & 0.00 & 0.00 & 0.00 & 0.00 & 0.04 & 16.7 \\
\hline MAL & 0.00 & 0.00 & 0.00 & 0.00 & 0.00 & 1.00 & 0.00 & 0.00 & 0.03 & 0.00 & 0.00 & 0.00 & 0.00 & 0.01 & 4.1 \\
\hline MOZ & 0.00 & 0.00 & 0.00 & 0.00 & 0.14 & 0.13 & 1.00 & 0.08 & 0.26 & 0.16 & 0.00 & 0.20 & 0.00 & 0.12 & 46.5 \\
\hline NAM & 0.00 & 0.00 & 0.00 & 0.00 & 0.00 & 0.01 & 0.00 & 1.00 & 0.16 & 0.00 & 0.00 & 0.00 & 0.00 & 0.05 & 20.9 \\
\hline SAF & 0.00 & 0.00 & 0.00 & 0.00 & 0.00 & 0.00 & 0.00 & 0.00 & 1.00 & 0.00 & 0.00 & 0.00 & 0.00 & 0.00 & 0.0 \\
\hline SWZ & 0.00 & 0.00 & 0.00 & 0.00 & 0.00 & 0.00 & 0.00 & 0.00 & 0.05 & 1.00 & 0.00 & 0.00 & 0.00 & 0.02 & 7.1 \\
\hline TNZ & 0.00 & 0.00 & 0.00 & 0.00 & 0.19 & 0.29 & 0.00 & 0.21 & 0.43 & 0.28 & 1.00 & 0.19 & 0.11 & 0.20 & 78.4 \\
\hline ZAM & 0.00 & 0.00 & 0.00 & 0.00 & 0.00 & 0.04 & 0.00 & 0.00 & 0.12 & 0.00 & 0.00 & 1.00 & 0.00 & 0.04 & 16.2 \\
\hline ZIM & 0.00 & 0.00 & 0.00 & 0.00 & 0.00 & 0.09 & 0.00 & 0.00 & 0.11 & 0.20 & 0.00 & 0.10 & 1.00 & 0.05 & 21.3 \\
\hline $\begin{array}{l}\text { Ave spillout } \\
\text { Spillout index }\end{array}$ & $\begin{array}{c}0.00 \\
0.2\end{array}$ & $\begin{array}{c}0.00 \\
0.0\end{array}$ & $\begin{array}{c}0.00 \\
0.2\end{array}$ & $\begin{array}{c}0.00 \\
1.4\end{array}$ & $\begin{array}{l}0.07 \\
46.2\end{array}$ & $\begin{array}{l}0.08 \\
50.0\end{array}$ & $\begin{array}{l}0.02 \\
11.7\end{array}$ & $\begin{array}{l}0.06 \\
37.9\end{array}$ & $\begin{array}{c}0.16 \\
100.0\end{array}$ & $\begin{array}{l}0.10 \\
63.5\end{array}$ & $\begin{array}{c}0.01 \\
3.6\end{array}$ & $\begin{array}{l}0.09 \\
54.8\end{array}$ & $\begin{array}{l}0.03 \\
20.9\end{array}$ & & \\
\hline
\end{tabular}

Source: Spillover matrix analysis.

Notes: $\quad$ ANG $=$ Angola, BOT $=$ Botswana, DRC $=$ Democratic Republic of the Congo, $\mathrm{LES}=$ Lesotho, MAD $=$ Madagascar, $\mathrm{MAL}=\mathrm{Malawi}, \mathrm{MOZ}=\mathrm{Mozambique}, \mathrm{NAM}=$ Namibia, SAF = South Africa, SWZ = Swaziland, TNZ = Tanzania, ZAM = Zambia, and ZIM = Zimbabwe. Mauritius and Seychelles not included due to lack of data.

Table A.29 Final spillover coefficient matrix for beans

\begin{tabular}{|c|c|c|c|c|c|c|c|c|c|c|c|c|c|c|c|}
\hline Country & ANG & ВOT & DRC & LES & MAD & MAL & MOZ & NAM & SAF & SWZ & TNZ & ZAM & ZIM & $\begin{array}{l}\text { Ave spill- } \\
\text { in }\end{array}$ & $\begin{array}{c}\text { Spill-in } \\
\text { index }\end{array}$ \\
\hline ANG & 1.00 & 0.08 & 0.12 & 0.34 & 0.34 & 0.13 & 0.18 & 0.34 & 0.31 & 0.31 & 0.22 & 0.19 & 0.38 & 0.25 & 100.0 \\
\hline BOT & 0.00 & 1.00 & 0.00 & 0.00 & 0.08 & 0.00 & 0.00 & 0.11 & 0.05 & 0.00 & 0.00 & 0.00 & 0.00 & 0.02 & 9.8 \\
\hline DRC & 0.00 & 0.05 & 1.00 & 0.19 & 0.09 & 0.00 & 0.00 & 0.06 & 0.16 & 0.00 & 0.12 & 0.00 & 0.07 & 0.09 & 35.8 \\
\hline LES & 0.00 & 0.00 & 0.00 & 1.00 & 0.00 & 0.00 & 0.00 & 0.00 & 0.01 & 0.00 & 0.00 & 0.00 & 0.00 & 0.00 & 1.4 \\
\hline MAD & 0.00 & 0.00 & 0.00 & 0.00 & 1.00 & 0.00 & 0.00 & 0.00 & 0.00 & 0.00 & 0.00 & 0.00 & 0.00 & 0.00 & 0.0 \\
\hline MAL & 0.00 & 0.03 & 0.00 & 0.09 & 0.04 & 1.00 & 0.00 & 0.05 & 0.09 & 0.00 & 0.00 & 0.00 & 0.05 & 0.04 & 16.2 \\
\hline MOZ & 0.00 & 0.16 & 0.00 & 0.13 & 0.20 & 0.09 & 1.00 & 0.18 & 0.26 & 0.15 & 0.16 & 0.00 & 0.16 & 0.16 & 63.8 \\
\hline NAM & 0.00 & 0.00 & 0.00 & 0.00 & 0.00 & 0.00 & 0.00 & 1.00 & 0.00 & 0.00 & 0.00 & 0.00 & 0.00 & 0.00 & 0.0 \\
\hline SAF & 0.00 & 0.00 & 0.00 & 0.00 & 0.00 & 0.00 & 0.00 & 0.00 & 1.00 & 0.00 & 0.00 & 0.00 & 0.00 & 0.00 & 0.0 \\
\hline SWZ & 0.00 & 0.04 & 0.00 & 0.10 & 0.07 & 0.00 & 0.00 & 0.12 & 0.06 & 1.00 & 0.00 & 0.00 & 0.14 & 0.04 & 15.7 \\
\hline TNZ & 0.00 & 0.00 & 0.00 & 0.19 & 0.13 & 0.00 & 0.00 & 0.14 & 0.15 & 0.00 & 1.00 & 0.00 & 0.00 & 0.06 & 25.5 \\
\hline ZAM & 0.00 & 0.06 & 0.00 & 0.07 & 0.09 & 0.06 & 0.00 & 0.10 & 0.08 & 0.11 & 0.06 & 1.00 & 0.09 & 0.06 & 23.7 \\
\hline ZIM & 0.00 & 0.00 & 0.00 & 0.00 & 0.12 & 0.00 & 0.00 & 0.25 & 0.09 & 0.00 & 0.00 & 0.00 & 1.00 & 0.04 & 16.5 \\
\hline $\begin{array}{l}\text { Ave spillout } \\
\text { Spillout index }\end{array}$ & $\begin{array}{c}0.00 \\
0.0\end{array}$ & $\begin{array}{l}0.07 \\
41.9\end{array}$ & $\begin{array}{c}0.00 \\
0.2\end{array}$ & $\begin{array}{l}0.13 \\
74.8\end{array}$ & $\begin{array}{l}0.13 \\
77.0\end{array}$ & $\begin{array}{l}0.04 \\
21.4\end{array}$ & $\begin{array}{c}0.00 \\
0.3\end{array}$ & $\begin{array}{l}0.13 \\
73.8\end{array}$ & $\begin{array}{c}0.17 \\
100.0\end{array}$ & $\begin{array}{l}0.06 \\
34.4\end{array}$ & $\begin{array}{l}0.08 \\
46.1\end{array}$ & $\begin{array}{c}0.00 \\
0.3\end{array}$ & $\begin{array}{l}0.08 \\
45.8\end{array}$ & & \\
\hline
\end{tabular}

Source: Spillover matrix analysis.

Notes: $\quad$ ANG $=$ Angola, BOT $=$ Botswana, $\mathrm{DRC}=$ Democratic Republic of the Congo, $\mathrm{LES}=$ Lesotho, MAD $=$ Madagascar, $\mathrm{MAL}=\mathrm{Malawi}, \mathrm{MOZ}=\mathrm{Mozambique}, \mathrm{NAM}=$ Namibia, SAF = South Africa, SWZ = Swaziland, TNZ = Tanzania, ZAM = Zambia, and ZIM = Zimbabwe. Mauritius and Seychelles not included due to lack of data. 
Table A.30 Final spillover coefficient matrix for cassava

\begin{tabular}{|c|c|c|c|c|c|c|c|c|c|c|c|c|c|c|c|}
\hline Country & ANG & BOT & DRC & LES & MAD & MAL & MOZ & NAM & SAF & SWZ & TNZ & ZAM & ZIM & $\begin{array}{c}\text { Ave spill- } \\
\text { in }\end{array}$ & $\begin{array}{c}\text { Spill-in } \\
\text { index }\end{array}$ \\
\hline ANG & 1.00 & 0.00 & 0.00 & 0.00 & 0.00 & 0.00 & 0.00 & 0.00 & 0.00 & 0.00 & 0.00 & 0.00 & 0.00 & 0.00 & 0.0 \\
\hline BOT & 0.00 & 1.00 & 0.00 & 0.00 & 0.00 & 0.00 & 0.00 & 0.00 & 0.00 & 0.00 & 0.00 & 0.00 & 0.00 & 0.00 & 0.0 \\
\hline DRC & 0.00 & 0.00 & 1.00 & 0.00 & 0.00 & 0.00 & 0.00 & 0.00 & 0.00 & 0.00 & 0.00 & 0.00 & 0.00 & 0.00 & 0.0 \\
\hline LES & 0.00 & 0.00 & 0.00 & 1.00 & 0.00 & 0.00 & 0.00 & 0.00 & 0.00 & 0.00 & 0.00 & 0.00 & 0.00 & 0.00 & 0.0 \\
\hline MAD & 0.00 & 0.00 & 0.00 & 0.00 & 1.00 & 0.00 & 0.00 & 0.00 & 0.00 & 0.00 & 0.00 & 0.00 & 0.00 & 0.00 & 0.0 \\
\hline MAL & 0.00 & 0.00 & 0.00 & 0.00 & 0.00 & 1.00 & 0.00 & 0.00 & 0.00 & 0.00 & 0.00 & 0.00 & 0.00 & 0.00 & 0.0 \\
\hline MOZ & 0.00 & 0.00 & 0.00 & 0.00 & 0.00 & 0.00 & 1.00 & 0.00 & 0.00 & 0.00 & 0.20 & 0.00 & 0.00 & 0.04 & 47.3 \\
\hline NAM & 0.00 & 0.00 & 0.00 & 0.00 & 0.00 & 0.00 & 0.00 & 1.00 & 0.00 & 0.00 & 0.00 & 0.00 & 0.00 & 0.00 & 0.0 \\
\hline SAF & 0.00 & 0.00 & 0.00 & 0.00 & 0.00 & 0.00 & 0.00 & 0.00 & 1.00 & 0.00 & 0.00 & 0.00 & 0.00 & 0.00 & 0.0 \\
\hline SWZ & 0.00 & 0.00 & 0.00 & 0.00 & 0.00 & 0.00 & 0.00 & 0.00 & 0.00 & 1.00 & 0.00 & 0.00 & 0.00 & 0.00 & 0.0 \\
\hline TNZ & 0.00 & 0.00 & 0.00 & 0.00 & 0.00 & 0.00 & 0.00 & 0.00 & 0.00 & 0.00 & 1.00 & 0.00 & 0.00 & 0.00 & 0.0 \\
\hline ZAM & 0.07 & 0.00 & 0.06 & 0.00 & 0.08 & 0.03 & 0.00 & 0.00 & 0.00 & 0.00 & 0.05 & 1.00 & 0.00 & 0.02 & 26.5 \\
\hline ZIM & 0.30 & 0.00 & 0.17 & 0.00 & 0.16 & 0.13 & 0.17 & 0.00 & 0.00 & 0.00 & 0.13 & 0.09 & 1.00 & 0.08 & 100.0 \\
\hline Ave spillout & 0.01 & 0.00 & 0.00 & 0.00 & 0.00 & 0.00 & 0.00 & 0.00 & 0.00 & 0.00 & 0.04 & 0.00 & 0.00 & & \\
\hline Spillout index & 13.4 & 0.0 & 9.3 & 0.0 & 10.9 & 5.4 & 3.9 & 0.0 & 0.0 & 0.0 & 100.0 & 2.1 & 0.0 & & \\
\hline
\end{tabular}

Source: Spillover matrix analysis.

Notes: $\quad \mathrm{ANG}=$ Angola, $\mathrm{BOT}=$ Botswana, $\mathrm{DRC}=$ Democratic Republic of the Congo, $\mathrm{LES}=$ Lesotho, MAD $=\mathrm{Madagascar}, \mathrm{MAL}=\mathrm{Malawi}, \mathrm{MOZ}=\mathrm{Mozambique}, \mathrm{NAM}=$

Namibia, SAF = South Africa, SWZ = Swaziland, TNZ = Tanzania, ZAM = Zambia, and ZIM = Zimbabwe. Mauritius and Seychelles not included due to lack of data

Table A.31 Final spillover coefficient matrix for cotton

\begin{tabular}{|c|c|c|c|c|c|c|c|c|c|c|c|c|c|c|c|}
\hline Country & ANG & BOT & DRC & LES & MAD & MAL & MOZ & NAM & SAF & SWZ & TNZ & ZAM & ZIM & $\begin{array}{l}\text { Ave spill- } \\
\text { in }\end{array}$ & $\begin{array}{c}\text { Spill-in } \\
\text { index }\end{array}$ \\
\hline ANG & 1.00 & 0.09 & 0.00 & 0.00 & 0.00 & 0.00 & 0.00 & 0.08 & 0.11 & 0.00 & 0.00 & 0.00 & 0.00 & 0.04 & 22.3 \\
\hline BOT & 0.00 & 1.00 & 0.00 & 0.00 & 0.00 & 0.00 & 0.00 & 0.00 & 0.00 & 0.00 & 0.00 & 0.00 & 0.00 & 0.00 & 0.0 \\
\hline DRC & 0.28 & 0.36 & 1.00 & 0.00 & 0.12 & 0.09 & 0.10 & 0.13 & 0.20 & 0.00 & 0.10 & 0.16 & 0.16 & 0.15 & 82.2 \\
\hline LES & 0.00 & 0.00 & 0.00 & 1.00 & 0.00 & 0.00 & 0.00 & 0.00 & 0.00 & 0.00 & 0.00 & 0.00 & 0.00 & 0.00 & 0.0 \\
\hline MAD & 0.00 & 0.37 & 0.00 & 0.00 & 1.00 & 0.00 & 0.00 & 0.25 & 0.25 & 0.00 & 0.00 & 0.19 & 0.00 & 0.11 & 58.4 \\
\hline MAL & 0.00 & 0.03 & 0.00 & 0.00 & 0.00 & 1.00 & 0.00 & 0.01 & 0.05 & 0.00 & 0.00 & 0.03 & 0.00 & 0.02 & 10.9 \\
\hline MOZ & 0.14 & 0.16 & 0.00 & 0.00 & 0.13 & 0.00 & 1.00 & 0.15 & 0.24 & 0.00 & 0.00 & 0.21 & 0.00 & 0.12 & 62.5 \\
\hline NAM & 0.00 & 0.00 & 0.00 & 0.00 & 0.00 & 0.00 & 0.00 & 1.00 & 0.00 & 0.00 & 0.00 & 0.00 & 0.00 & 0.00 & 0.0 \\
\hline SAF & 0.00 & 0.00 & 0.00 & 0.00 & 0.00 & 0.00 & 0.00 & 0.00 & 1.00 & 0.00 & 0.00 & 0.00 & 0.00 & 0.00 & 0.0 \\
\hline SWZ & 0.08 & 0.00 & 0.00 & 0.00 & 0.05 & 0.03 & 0.18 & 0.03 & 0.08 & 1.00 & 0.50 & 0.33 & 0.33 & 0.19 & 100.0 \\
\hline TNZ & 0.00 & 0.03 & 0.00 & 0.00 & 0.00 & 0.00 & 0.00 & 0.05 & 0.11 & 0.00 & 1.00 & 0.12 & 0.00 & 0.05 & 24.5 \\
\hline ZAM & 0.00 & 0.00 & 0.00 & 0.00 & 0.00 & 0.00 & 0.00 & 0.00 & 0.09 & 0.00 & 0.00 & 1.00 & 0.00 & 0.03 & 15.5 \\
\hline ZIM & 0.00 & 0.17 & 0.00 & 0.00 & 0.00 & 0.00 & 0.00 & 0.10 & 0.12 & 0.00 & 0.00 & 0.10 & 1.00 & 0.05 & 27.8 \\
\hline Ave spillout & 0.04 & 0.11 & 0.00 & 0.00 & 0.03 & 0.01 & 0.01 & 0.08 & 0.13 & 0.00 & 0.01 & 0.11 & 0.01 & & \\
\hline Spillout index & 31.2 & 87.2 & 0.0 & 0.0 & 21.5 & 4.7 & 5.3 & 62.1 & 100.0 & 0.0 & 5.0 & 85.9 & 8.2 & & \\
\hline
\end{tabular}

Source: Spillover matrix analysis.

Notes: $\quad \mathrm{ANG}=$ Angola, $\mathrm{BOT}=$ Botswana, $\mathrm{DRC}=$ Democratic Republic of the Congo, $\mathrm{LES}=$ Lesotho, $\mathrm{MAD}=\mathrm{Madagascar}, \mathrm{MAL}=\mathrm{Malawi}, \mathrm{MOZ}=\mathrm{Mozambique}, \mathrm{NAM}=$

Namibia, SAF = South Africa, SWZ = Swaziland, TNZ = Tanzania, ZAM = Zambia, and ZIM = Zimbabwe. Mauritius and Seychelles not included due to lack of data. 
Table A.32 Final spillover coefficient matrix for groundnuts

\begin{tabular}{|c|c|c|c|c|c|c|c|c|c|c|c|c|c|c|c|}
\hline Country & ANG & BOT & DRC & LES & MAD & MAL & MOZ & NAM & SAF & SWZ & TNZ & ZAM & ZIM & $\begin{array}{l}\text { Ave spill- } \\
\text { in }\end{array}$ & $\begin{array}{l}\text { Spill-in } \\
\text { index }\end{array}$ \\
\hline ANG & 1.00 & 0.24 & 0.24 & 0.00 & 0.34 & 0.07 & 0.00 & 0.14 & 0.31 & 0.20 & 0.00 & 0.00 & 0.21 & 0.16 & 95.1 \\
\hline BOT & 0.00 & 1.00 & 0.00 & 0.00 & 0.00 & 0.00 & 0.00 & 0.00 & 0.06 & 0.00 & 0.00 & 0.00 & 0.00 & 0.02 & 11.9 \\
\hline DRC & 0.00 & 0.15 & 1.00 & 0.00 & 0.12 & 0.00 & 0.00 & 0.00 & 0.12 & 0.00 & 0.00 & 0.00 & 0.00 & 0.05 & 30.7 \\
\hline LES & 0.00 & 0.00 & 0.00 & 1.00 & 0.00 & 0.00 & 0.00 & 0.00 & 0.00 & 0.00 & 0.00 & 0.00 & 0.00 & 0.00 & 0.0 \\
\hline MAD & 0.00 & 0.00 & 0.00 & 0.00 & 1.00 & 0.00 & 0.00 & 0.00 & 0.00 & 0.00 & 0.00 & 0.00 & 0.00 & 0.00 & 0.0 \\
\hline MAL & 0.00 & 0.00 & 0.00 & 0.00 & 0.03 & 1.00 & 0.00 & 0.00 & 0.08 & 0.00 & 0.00 & 0.00 & 0.00 & 0.03 & 16.4 \\
\hline MOZ & 0.00 & 0.17 & 0.17 & 0.00 & 0.21 & 0.14 & 1.00 & 0.00 & 0.38 & 0.23 & 0.00 & 0.00 & 0.13 & 0.17 & 100.0 \\
\hline NAM & 0.00 & 0.27 & 0.07 & 0.00 & 0.12 & 0.03 & 0.00 & 1.00 & 0.20 & 0.09 & 0.00 & 0.00 & 0.12 & 0.09 & 54.9 \\
\hline SAF & 0.00 & 0.00 & 0.00 & 0.00 & 0.00 & 0.00 & 0.00 & 0.00 & 1.00 & 0.00 & 0.00 & 0.00 & 0.00 & 0.00 & 0.0 \\
\hline SWZ & 0.00 & 0.06 & 0.00 & 0.00 & 0.08 & 0.00 & 0.00 & 0.00 & 0.06 & 1.00 & 0.00 & 0.00 & 0.00 & 0.03 & 16.1 \\
\hline TNZ & 0.00 & 0.24 & 0.20 & 0.00 & 0.26 & 0.22 & 0.00 & 0.00 & 0.29 & 0.26 & 1.00 & 0.00 & 0.12 & 0.15 & 88.0 \\
\hline ZAM & 0.00 & 0.13 & 0.09 & 0.00 & 0.13 & 0.06 & 0.00 & 0.00 & 0.15 & 0.10 & 0.00 & 1.00 & 0.05 & 0.07 & 43.2 \\
\hline ZIM & 0.00 & 0.21 & 0.00 & 0.00 & 0.16 & 0.00 & 0.00 & 0.00 & 0.11 & 0.00 & 0.00 & 0.00 & 1.00 & 0.05 & 29.7 \\
\hline Ave spillout & 0.00 & 0.14 & 0.05 & 0.00 & 0.13 & 0.05 & 0.00 & 0.00 & 0.17 & 0.07 & 0.00 & 0.00 & 0.04 & & \\
\hline Spillout index & 0.0 & 82.3 & 32.1 & 0.0 & 79.3 & 27.6 & 0.0 & 0.1 & 100.0 & 41.0 & 0.0 & 0.0 & 22.2 & & \\
\hline
\end{tabular}

Source: Spillover matrix analysis.

Notes: $\quad \mathrm{ANG}=$ Angola, $\mathrm{BOT}=$ Botswana, $\mathrm{DRC}=$ Democratic Republic of the Congo, $\mathrm{LES}=$ Lesotho, MAD $=$ Madagascar, $\mathrm{MAL}=\mathrm{Malawi}, \mathrm{MOZ}=\mathrm{Mozambique}, \mathrm{NAM}=$

Namibia, SAF = South Africa, SWZ = Swaziland, TNZ = Tanzania, ZAM = Zambia, and ZIM = Zimbabwe. Mauritius and Seychelles not included due to lack of data

Table A.33 Final spillover coefficient matrix for millet

\begin{tabular}{|c|c|c|c|c|c|c|c|c|c|c|c|c|c|c|c|}
\hline Country & ANG & ВOT & DRC & LES & MAD & MAL & MOZ & NAM & SAF & sWZ & TNZ & ZAM & ZIM & $\begin{array}{l}\text { Ave spill- } \\
\text { in }\end{array}$ & $\begin{array}{c}\text { Spill-in } \\
\text { index }\end{array}$ \\
\hline ANG & 1.00 & 0.00 & 0.15 & 0.00 & 0.00 & 0.04 & 0.00 & 0.00 & 0.17 & 0.00 & 0.09 & 0.19 & 0.00 & 0.09 & 74.5 \\
\hline BOT & 0.09 & 1.00 & 0.15 & 0.00 & 0.00 & 0.04 & 0.08 & 0.08 & 0.10 & 0.00 & 0.06 & 0.08 & 0.00 & 0.07 & 54.7 \\
\hline DRC & 0.00 & 0.00 & 1.00 & 0.00 & 0.00 & 0.00 & 0.00 & 0.00 & 0.00 & 0.00 & 0.08 & 0.00 & 0.00 & 0.01 & 11.7 \\
\hline LES & 0.00 & 0.00 & 0.00 & 1.00 & 0.00 & 0.00 & 0.00 & 0.00 & 0.00 & 0.00 & 0.00 & 0.00 & 0.00 & 0.00 & 0.0 \\
\hline MAD & 0.00 & 0.00 & 0.00 & 0.00 & 1.00 & 0.00 & 0.00 & 0.00 & 0.00 & 0.00 & 0.00 & 0.00 & 0.00 & 0.00 & 0.0 \\
\hline MAL & 0.00 & 0.00 & 0.00 & 0.00 & 0.00 & 1.00 & 0.00 & 0.00 & 0.00 & 0.00 & 0.00 & 0.00 & 0.00 & 0.00 & 0.0 \\
\hline MOZ & 0.00 & 0.00 & 0.00 & 0.00 & 0.00 & 0.07 & 1.00 & 0.00 & 0.00 & 0.00 & 0.19 & 0.15 & 0.00 & 0.05 & 38.7 \\
\hline NAM & 0.12 & 0.00 & 0.15 & 0.00 & 0.00 & 0.05 & 0.07 & 1.00 & 0.11 & 0.00 & 0.11 & 0.11 & 0.00 & 0.08 & 67.8 \\
\hline SAF & 0.00 & 0.00 & 0.00 & 0.00 & 0.00 & 0.04 & 0.00 & 0.00 & 1.00 & 0.00 & 0.06 & 0.00 & 0.00 & 0.01 & 10.5 \\
\hline SWZ & 0.00 & 0.00 & 0.00 & 0.00 & 0.00 & 0.00 & 0.00 & 0.00 & 0.00 & 1.00 & 0.00 & 0.00 & 0.00 & 0.00 & 0.0 \\
\hline TNZ & 0.00 & 0.00 & 0.00 & 0.00 & 0.00 & 0.00 & 0.00 & 0.00 & 0.00 & 0.00 & 1.00 & 0.00 & 0.00 & 0.00 & 0.0 \\
\hline ZAM & 0.00 & 0.00 & 0.00 & 0.00 & 0.00 & 0.00 & 0.00 & 0.00 & 0.00 & 0.00 & 0.00 & 1.00 & 0.00 & 0.00 & 0.0 \\
\hline ZIM & 0.12 & 0.00 & 0.34 & 0.00 & 0.00 & 0.16 & 0.14 & 0.00 & 0.11 & 0.00 & 0.25 & 0.14 & 1.00 & 0.12 & 100.0 \\
\hline Ave spillout & 0.05 & 0.00 & 0.11 & 0.00 & 0.00 & 0.05 & 0.04 & 0.00 & 0.08 & 0.00 & 0.09 & 0.09 & 0.00 & & \\
\hline Spillout index & 40.3 & 0.0 & 100.0 & 0.0 & 0.0 & 42.6 & 34.0 & 0.4 & 66.8 & 0.0 & 83.9 & 77.5 & 0.0 & & \\
\hline
\end{tabular}

Source: Spillover matrix analysis.

Notes: $\quad \mathrm{ANG}=$ Angola, $\mathrm{BOT}=$ Botswana, $\mathrm{DRC}=$ Democratic Republic of the Congo, $\mathrm{LES}=$ Lesotho, $\mathrm{MAD}=\mathrm{Madagascar}, \mathrm{MAL}=\mathrm{Malawi}, \mathrm{MOZ}=\mathrm{Mozambique}, \mathrm{NAM}=$

Namibia, SAF = South Africa, SWZ = Swaziland, TNZ = Tanzania, ZAM = Zambia, and ZIM = Zimbabwe. Mauritius and Seychelles not included due to lack of data. 
Table A.34 Final spillover coefficient matrix for potatoes and sweet potatoes

\begin{tabular}{|c|c|c|c|c|c|c|c|c|c|c|c|c|c|c|c|}
\hline Country & ANG & BOT & DRC & LES & MAD & MAL & MOZ & NAM & SAF & SWZ & TNZ & ZAM & ZIM & $\begin{array}{l}\text { Ave spill- } \\
\text { in }\end{array}$ & $\begin{array}{c}\text { Spill-in } \\
\text { index }\end{array}$ \\
\hline ANG & 1.00 & 0.00 & 0.00 & 0.00 & 0.18 & 0.00 & 0.00 & 0.00 & 0.00 & 0.00 & 0.00 & 0.00 & 0.00 & 0.01 & 9.0 \\
\hline BOT & 0.00 & 1.00 & 0.00 & 0.00 & 0.00 & 0.00 & 0.00 & 0.00 & 0.00 & 0.00 & 0.00 & 0.00 & 0.00 & 0.00 & 0.0 \\
\hline DRC & 0.00 & 0.00 & 1.00 & 0.00 & 0.09 & 0.00 & 0.00 & 0.00 & 0.00 & 0.00 & 0.00 & 0.00 & 0.00 & 0.01 & 4.2 \\
\hline LES & 0.00 & 0.00 & 0.02 & 1.00 & 0.02 & 0.00 & 0.00 & 0.00 & 0.01 & 0.00 & 0.00 & 0.00 & 0.00 & 0.00 & 3.6 \\
\hline MAD & 0.00 & 0.00 & 0.00 & 0.00 & 1.00 & 0.00 & 0.00 & 0.00 & 0.00 & 0.00 & 0.00 & 0.00 & 0.00 & 0.00 & 0.0 \\
\hline MAL & 0.00 & 0.00 & 0.00 & 0.00 & 0.05 & 1.00 & 0.00 & 0.00 & 0.00 & 0.00 & 0.00 & 0.00 & 0.00 & 0.00 & 2.5 \\
\hline MOZ & 0.00 & 0.00 & 0.00 & 0.00 & 0.11 & 0.00 & 1.00 & 0.00 & 0.06 & 0.00 & 0.00 & 0.00 & 0.00 & 0.03 & 21.9 \\
\hline NAM & 0.00 & 0.00 & 0.00 & 0.00 & 0.00 & 0.00 & 0.00 & 1.00 & 0.00 & 0.00 & 0.00 & 0.00 & 0.00 & 0.00 & 0.0 \\
\hline SAF & 0.00 & 0.00 & 0.00 & 0.00 & 0.00 & 0.00 & 0.00 & 0.00 & 1.00 & 0.00 & 0.00 & 0.00 & 0.00 & 0.00 & 0.0 \\
\hline SWZ & 0.21 & 0.00 & 0.14 & 0.12 & 0.19 & 0.13 & 0.17 & 0.00 & 0.10 & 1.00 & 0.15 & 0.11 & 0.14 & 0.12 & 100.0 \\
\hline TNZ & 0.00 & 0.00 & 0.13 & 0.00 & 0.21 & 0.00 & 0.00 & 0.00 & 0.15 & 0.00 & 1.00 & 0.00 & 0.00 & 0.07 & 53.8 \\
\hline ZAM & 0.00 & 0.00 & 0.00 & 0.00 & 0.05 & 0.00 & 0.00 & 0.00 & 0.00 & 0.00 & 0.00 & 1.00 & 0.00 & 0.00 & 2.7 \\
\hline ZIM & 0.29 & 0.00 & 0.13 & 0.00 & 0.19 & 0.10 & 0.00 & 0.00 & 0.08 & 0.00 & 0.00 & 0.00 & 1.00 & 0.06 & 49.5 \\
\hline $\begin{array}{l}\text { Ave spillout } \\
\text { Spillout index }\end{array}$ & $\begin{array}{c}0.00 \\
4.9\end{array}$ & $\begin{array}{c}0.00 \\
0.0\end{array}$ & $\begin{array}{l}0.02 \\
23.1\end{array}$ & $\begin{array}{c}0.00 \\
1.4\end{array}$ & $\begin{array}{c}0.07 \\
100.0\end{array}$ & $\begin{array}{c}0.00 \\
2.3\end{array}$ & $\begin{array}{c}0.00 \\
2.0\end{array}$ & $\begin{array}{c}0.00 \\
0.0\end{array}$ & $\begin{array}{l}0.02 \\
33.8\end{array}$ & $\begin{array}{c}0.00 \\
0.0\end{array}$ & $\begin{array}{c}0.00 \\
1.8\end{array}$ & $\begin{array}{c}0.00 \\
1.3\end{array}$ & $\begin{array}{c}0.00 \\
1.7\end{array}$ & & \\
\hline
\end{tabular}

Source: Spillover matrix analysis.

Notes: $\quad \mathrm{ANG}=$ Angola, $\mathrm{BOT}=$ Botswana, $\mathrm{DRC}=$ Democratic Republic of the Congo, $\mathrm{LES}=$ Lesotho, MAD $=$ Madagascar, $\mathrm{MAL}=\mathrm{Malawi}, \mathrm{MOZ}=\mathrm{Mozambique}, \mathrm{NAM}=$

Namibia, SAF $=$ South Africa, $S W Z=$ Swaziland, TNZ = Tanzania, ZAM = Zambia, and ZIM = Zimbabwe. Mauritius and Seychelles not included due to lack of data

Table A.35 Final spillover coefficient matrix for rice

\begin{tabular}{|c|c|c|c|c|c|c|c|c|c|c|c|c|c|c|c|}
\hline Country & ANG & BOT & DRC & LES & MAD & MAL & MOZ & NAM & SAF & SWZ & TNZ & ZAM & ZIM & $\begin{array}{l}\text { Ave spill- } \\
\text { in }\end{array}$ & $\begin{array}{c}\text { Spill-in } \\
\text { index }\end{array}$ \\
\hline ANG & 1.00 & 0.00 & 0.00 & 0.00 & 0.23 & 0.05 & 0.00 & 0.00 & 0.21 & 0.25 & 0.15 & 0.10 & 0.24 & 0.14 & 74.0 \\
\hline BOT & 0.00 & 1.00 & 0.00 & 0.00 & 0.00 & 0.00 & 0.00 & 0.00 & 0.00 & 0.00 & 0.00 & 0.00 & 0.00 & 0.00 & 0.0 \\
\hline DRC & 0.00 & 0.00 & 1.00 & 0.00 & 0.21 & 0.08 & 0.09 & 0.00 & 0.18 & 0.25 & 0.17 & 0.14 & 0.13 & 0.14 & 70.9 \\
\hline LES & 0.00 & 0.00 & 0.00 & 1.00 & 0.00 & 0.00 & 0.00 & 0.00 & 0.00 & 0.00 & 0.00 & 0.00 & 0.00 & 0.00 & 0.0 \\
\hline MAD & 0.00 & 0.00 & 0.00 & 0.00 & 1.00 & 0.00 & 0.00 & 0.00 & 0.00 & 0.10 & 0.00 & 0.00 & 0.00 & 0.00 & 1.5 \\
\hline MAL & 0.00 & 0.00 & 0.00 & 0.00 & 0.04 & 1.00 & 0.00 & 0.00 & 0.07 & 0.14 & 0.00 & 0.00 & 0.03 & 0.03 & 16.1 \\
\hline MOZ & 0.00 & 0.00 & 0.00 & 0.00 & 0.16 & 0.10 & 1.00 & 0.00 & 0.25 & 0.53 & 0.30 & 0.20 & 0.18 & 0.20 & 100.0 \\
\hline NAM & 0.00 & 0.00 & 0.00 & 0.00 & 0.00 & 0.00 & 0.00 & 1.00 & 0.00 & 0.00 & 0.00 & 0.00 & 0.00 & 0.00 & 0.0 \\
\hline SAF & 0.00 & 0.00 & 0.00 & 0.00 & 0.00 & 0.00 & 0.00 & 0.00 & 1.00 & 0.05 & 0.00 & 0.00 & 0.00 & 0.00 & 0.7 \\
\hline SWZ & 0.00 & 0.00 & 0.00 & 0.00 & 0.00 & 0.00 & 0.00 & 0.00 & 0.00 & 1.00 & 0.00 & 0.00 & 0.00 & 0.00 & 0.0 \\
\hline TNZ & 0.00 & 0.00 & 0.00 & 0.00 & 0.00 & 0.00 & 0.00 & 0.00 & 0.00 & 0.34 & 1.00 & 0.00 & 0.08 & 0.02 & 8.1 \\
\hline ZAM & 0.00 & 0.00 & 0.00 & 0.00 & 0.06 & 0.03 & 0.00 & 0.00 & 0.06 & 0.14 & 0.07 & 1.00 & 0.05 & 0.04 & 23.0 \\
\hline ZIM & 0.00 & 0.00 & 0.00 & 0.00 & 0.00 & 0.00 & 0.00 & 0.00 & 0.00 & 0.12 & 0.00 & 0.00 & 1.00 & 0.00 & 1.8 \\
\hline Ave spillout & 0.00 & 0.00 & 0.00 & 0.00 & 0.06 & 0.03 & 0.02 & 0.00 & 0.07 & 0.23 & 0.07 & 0.05 & 0.06 & & \\
\hline Spillout index & 0.0 & 0.0 & 0.0 & 0.0 & 26.3 & 12.1 & 6.8 & 0.0 & 30.0 & 100.0 & 31.4 & 22.8 & 28.1 & & \\
\hline
\end{tabular}

Source: Spillover matrix analysis.

Notes: $\quad \mathrm{ANG}=$ Angola, $\mathrm{BOT}=$ Botswana, $\mathrm{DRC}=$ Democratic Republic of the Congo, $\mathrm{LES}=$ Lesotho, $\mathrm{MAD}=\mathrm{Madagascar}, \mathrm{MAL}=\mathrm{Malawi}, \mathrm{MOZ}=\mathrm{Mozambique}, \mathrm{NAM}=$

Namibia, SAF = South Africa, SWZ = Swaziland, TNZ = Tanzania, ZAM = Zambia, and ZIM = Zimbabwe. Mauritius and Seychelles not included due to lack of data. 
Table A.36 Final spillover coefficient matrix for sorghum

\begin{tabular}{|c|c|c|c|c|c|c|c|c|c|c|c|c|c|c|c|}
\hline Country & ANG & BOT & DRC & LES & MAD & MAL & MOZ & NAM & SAF & SWZ & TNZ & ZAM & ZIM & $\begin{array}{l}\text { Ave spill- } \\
\text { in }\end{array}$ & $\begin{array}{l}\text { Spill-in } \\
\text { index }\end{array}$ \\
\hline ANG & 1.00 & 0.00 & 0.00 & 0.00 & 0.00 & 0.00 & 0.00 & 0.00 & 0.00 & 0.00 & 0.00 & 0.00 & 0.00 & 0.00 & 0.0 \\
\hline BOT & 0.00 & 1.00 & 0.07 & 0.07 & 0.09 & 0.03 & 0.06 & 0.00 & 0.35 & 0.05 & 0.06 & 0.08 & 0.07 & 0.15 & 70.5 \\
\hline DRC & 0.00 & 0.00 & 1.00 & 0.10 & 0.00 & 0.07 & 0.00 & 0.00 & 0.24 & 0.00 & 0.12 & 0.00 & 0.00 & 0.11 & 49.3 \\
\hline LES & 0.00 & 0.00 & 0.00 & 1.00 & 0.00 & 0.00 & 0.00 & 0.00 & 0.02 & 0.00 & 0.00 & 0.00 & 0.00 & 0.01 & 3.4 \\
\hline MAD & 0.00 & 0.00 & 0.00 & 0.17 & 1.00 & 0.07 & 0.00 & 0.00 & 0.44 & 0.00 & 0.13 & 0.00 & 0.00 & 0.17 & 79.4 \\
\hline MAL & 0.00 & 0.00 & 0.00 & 0.00 & 0.00 & 1.00 & 0.00 & 0.00 & 0.10 & 0.00 & 0.00 & 0.00 & 0.00 & 0.03 & 15.7 \\
\hline MOZ & 0.00 & 0.00 & 0.00 & 0.08 & 0.00 & 0.07 & 1.00 & 0.00 & 0.54 & 0.00 & 0.19 & 0.00 & 0.00 & 0.22 & 100.0 \\
\hline NAM & 0.00 & 0.00 & 0.07 & 0.08 & 0.07 & 0.03 & 0.06 & 1.00 & 0.47 & 0.08 & 0.10 & 0.10 & 0.00 & 0.20 & 90.1 \\
\hline SAF & 0.00 & 0.00 & 0.00 & 0.00 & 0.00 & 0.00 & 0.00 & 0.00 & 1.00 & 0.00 & 0.00 & 0.00 & 0.00 & 0.00 & 0.0 \\
\hline SWZ & 0.00 & 0.00 & 0.00 & 0.11 & 0.00 & 0.08 & 0.00 & 0.00 & 0.16 & 1.00 & 0.14 & 0.00 & 0.00 & 0.08 & 37.8 \\
\hline TNZ & 0.00 & 0.00 & 0.00 & 0.00 & 0.00 & 0.00 & 0.00 & 0.00 & 0.30 & 0.00 & 1.00 & 0.00 & 0.00 & 0.10 & 45.5 \\
\hline ZAM & 0.00 & 0.00 & 0.00 & 0.00 & 0.00 & 0.00 & 0.00 & 0.00 & 0.30 & 0.00 & 0.05 & 1.00 & 0.00 & 0.11 & 49.3 \\
\hline ZIM & 0.00 & 0.00 & 0.18 & 0.22 & 0.00 & 0.10 & 0.13 & 0.00 & 0.47 & 0.00 & 0.14 & 0.11 & 1.00 & 0.21 & 95.6 \\
\hline Ave spillout & 0.00 & 0.00 & 0.02 & 0.05 & 0.00 & 0.03 & 0.02 & 0.00 & 0.34 & 0.00 & 0.07 & 0.02 & 0.00 & & \\
\hline Spillout index & 0.0 & 0.0 & 6.8 & 15.6 & 1.1 & 9.8 & 5.0 & 0.0 & 100.0 & 0.8 & 21.7 & 4.7 & 0.6 & & \\
\hline
\end{tabular}

Source: Spillover matrix analysis.

Notes: $\quad \mathrm{ANG}=$ Angola, $\mathrm{BOT}=$ Botswana, $\mathrm{DRC}=$ Democratic Republic of the Congo, $\mathrm{LES}=$ Lesotho, MAD $=$ Madagascar, $\mathrm{MAL}=\mathrm{Malawi}, \mathrm{MOZ}=\mathrm{Mozambique}, \mathrm{NAM}=$

Namibia, SAF = South Africa, SWZ = Swaziland, TNZ = Tanzania, ZAM = Zambia, and ZIM = Zimbabwe. Mauritius and Seychelles not included due to lack of data

Table A.37 Final spillover coefficient matrix for sugarcane

\begin{tabular}{|c|c|c|c|c|c|c|c|c|c|c|c|c|c|c|c|}
\hline Country & ANG & BOT & DRC & LES & MAD & MAL & MOZ & NAM & SAF & SWZ & TNZ & ZAM & ZIM & $\begin{array}{l}\text { Ave spill- } \\
\text { in }\end{array}$ & $\begin{array}{c}\text { Spill-in } \\
\text { index }\end{array}$ \\
\hline ANG & 1.00 & 0.00 & 0.00 & 0.00 & 0.00 & 0.04 & 0.00 & 0.00 & 0.10 & 0.13 & 0.06 & 0.00 & 0.00 & 0.05 & 33.2 \\
\hline BOT & 0.00 & 1.00 & 0.00 & 0.00 & 0.00 & 0.00 & 0.00 & 0.00 & 0.00 & 0.00 & 0.00 & 0.00 & 0.00 & 0.00 & 0.0 \\
\hline DRC & 0.00 & 0.00 & 1.00 & 0.00 & 0.00 & 0.03 & 0.00 & 0.00 & 0.11 & 0.05 & 0.00 & 0.00 & 0.00 & 0.04 & 25.5 \\
\hline LES & 0.00 & 0.00 & 0.00 & 1.00 & 0.00 & 0.00 & 0.00 & 0.00 & 0.00 & 0.00 & 0.00 & 0.00 & 0.00 & 0.00 & 0.0 \\
\hline MAD & 0.00 & 0.00 & 0.00 & 0.00 & 1.00 & 0.04 & 0.00 & 0.00 & 0.15 & 0.12 & 0.10 & 0.09 & 0.00 & 0.08 & 52.5 \\
\hline MAL & 0.00 & 0.00 & 0.00 & 0.00 & 0.00 & 1.00 & 0.00 & 0.00 & 0.00 & 0.00 & 0.00 & 0.00 & 0.00 & 0.00 & 0.0 \\
\hline MOZ & 0.19 & 0.00 & 0.18 & 0.00 & 0.13 & 0.34 & 1.00 & 0.00 & 0.16 & 0.15 & 0.20 & 0.14 & 0.11 & 0.15 & 100.0 \\
\hline NAM & 0.00 & 0.00 & 0.00 & 0.00 & 0.00 & 0.00 & 0.00 & 1.00 & 0.00 & 0.00 & 0.00 & 0.00 & 0.00 & 0.00 & 0.0 \\
\hline SAF & 0.00 & 0.00 & 0.00 & 0.00 & 0.00 & 0.00 & 0.00 & 0.00 & 1.00 & 0.00 & 0.00 & 0.00 & 0.00 & 0.00 & 0.0 \\
\hline SWZ & 0.00 & 0.00 & 0.00 & 0.00 & 0.00 & 0.00 & 0.00 & 0.00 & 0.00 & 1.00 & 0.00 & 0.00 & 0.00 & 0.00 & 0.0 \\
\hline TNZ & 0.00 & 0.00 & 0.00 & 0.00 & 0.00 & 0.00 & 0.00 & 0.00 & 0.00 & 0.00 & 1.00 & 0.00 & 0.00 & 0.00 & 0.0 \\
\hline ZAM & 0.00 & 0.00 & 0.00 & 0.00 & 0.00 & 0.00 & 0.00 & 0.00 & 0.07 & 0.00 & 0.00 & 1.00 & 0.00 & 0.02 & 15.4 \\
\hline ZIM & 0.00 & 0.00 & 0.00 & 0.00 & 0.00 & 0.00 & 0.00 & 0.00 & 0.08 & 0.00 & 0.00 & 0.00 & 1.00 & 0.03 & 17.6 \\
\hline Ave spillout & 0.01 & 0.00 & 0.01 & 0.00 & 0.01 & 0.03 & 0.00 & 0.00 & 0.04 & 0.03 & 0.02 & 0.02 & 0.01 & & \\
\hline Spillout index & 29.3 & 0.0 & 27.6 & 0.0 & 20.6 & 68.6 & 0.0 & 0.0 & 100.0 & 63.4 & 56.8 & 45.8 & 16.6 & & \\
\hline
\end{tabular}

Source: Spillover matrix analysis.

Notes: $\quad \mathrm{ANG}=$ Angola, $\mathrm{BOT}=$ Botswana, $\mathrm{DRC}=$ Democratic Republic of the Congo, $\mathrm{LES}=$ Lesotho, $\mathrm{MAD}=\mathrm{Madagascar}, \mathrm{MAL}=\mathrm{Malawi}, \mathrm{MOZ}=\mathrm{Mozambique}, \mathrm{NAM}=$

Namibia, SAF = South Africa, SWZ = Swaziland, TNZ = Tanzania, ZAM = Zambia, and ZIM = Zimbabwe. Mauritius and Seychelles not included due to lack of data. 
Table A.38 Final spillover coefficient matrix for wheat

\begin{tabular}{|c|c|c|c|c|c|c|c|c|c|c|c|c|c|c|c|}
\hline Country & ANG & BOT & DRC & LES & MAD & MAL & MOZ & NAM & SAF & SWZ & TNZ & ZAM & ZIM & $\begin{array}{c}\text { Ave spill- } \\
\text { in }\end{array}$ & $\begin{array}{c}\text { Spill-in } \\
\text { index }\end{array}$ \\
\hline ANG & 1.00 & 0.00 & 0.00 & 0.00 & 0.00 & 0.00 & 0.00 & 0.00 & 0.21 & 0.00 & 0.00 & 0.00 & 0.06 & 0.07 & 49.7 \\
\hline BOT & 0.07 & 1.00 & 0.00 & 0.00 & 0.09 & 0.00 & 0.00 & 0.08 & 0.06 & 0.00 & 0.00 & 0.00 & 0.09 & 0.04 & 26.1 \\
\hline DRC & 0.05 & 0.00 & 1.00 & 0.00 & 0.11 & 0.11 & 0.00 & 0.04 & 0.08 & 0.00 & 0.00 & 0.00 & 0.14 & 0.05 & 34.6 \\
\hline LES & 0.00 & 0.00 & 0.00 & 1.00 & 0.02 & 0.00 & 0.00 & 0.00 & 0.01 & 0.00 & 0.00 & 0.00 & 0.02 & 0.01 & 3.9 \\
\hline MAD & 0.00 & 0.00 & 0.00 & 0.00 & 1.00 & 0.00 & 0.00 & 0.00 & 0.00 & 0.00 & 0.00 & 0.00 & 0.14 & 0.01 & 7.1 \\
\hline MAL & 0.00 & 0.00 & 0.00 & 0.00 & 0.05 & 1.00 & 0.00 & 0.00 & 0.04 & 0.00 & 0.00 & 0.00 & 0.11 & 0.03 & 17.0 \\
\hline MOZ & 0.30 & 0.00 & 0.00 & 0.00 & 0.21 & 0.12 & 1.00 & 0.11 & 0.17 & 0.00 & 0.00 & 0.00 & 0.16 & 0.10 & 70.6 \\
\hline NAM & 0.00 & 0.00 & 0.00 & 0.00 & 0.00 & 0.00 & 0.00 & 1.00 & 0.00 & 0.00 & 0.00 & 0.00 & 0.06 & 0.00 & 3.3 \\
\hline SAF & 0.00 & 0.00 & 0.00 & 0.00 & 0.00 & 0.00 & 0.00 & 0.00 & 1.00 & 0.00 & 0.00 & 0.00 & 0.00 & 0.00 & 0.0 \\
\hline SWZ & 0.02 & 0.00 & 0.00 & 0.00 & 0.08 & 0.00 & 0.00 & 0.03 & 0.05 & 1.00 & 0.00 & 0.00 & 0.15 & 0.04 & 24.1 \\
\hline TNZ & 0.26 & 0.00 & 0.00 & 0.00 & 0.21 & 0.15 & 0.00 & 0.29 & 0.28 & 0.00 & 1.00 & 0.00 & 0.19 & 0.15 & 100.0 \\
\hline ZAM & 0.00 & 0.00 & 0.00 & 0.00 & 0.00 & 0.00 & 0.00 & 0.00 & 0.00 & 0.00 & 0.00 & 1.00 & 0.00 & 0.00 & 0.00 \\
\hline ZIM & 0.00 & 0.00 & 0.00 & 0.00 & 0.00 & 0.00 & 0.00 & 0.00 & 0.00 & 0.00 & 0.00 & 0.00 & 1.00 & 0.00 & 0.00 \\
\hline Ave spillout & 0.02 & 0.00 & 0.00 & 0.00 & 0.02 & 0.01 & 0.00 & 0.02 & 0.02 & 0.00 & 0.00 & 0.00 & 0.02 & & \\
\hline Spillout index & 89.3 & 0.0 & 0.0 & 0.0 & 78.1 & 52.9 & 0.0 & 97.5 & 100.0 & 0.0 & 0.0 & 0.0 & 79.4 & & \\
\hline
\end{tabular}

Source: Spillover matrix analysis.

Notes: $\quad \mathrm{ANG}=$ Angola, $\mathrm{BOT}=$ Botswana, $\mathrm{DRC}=$ Democratic Republic of the Congo, $\mathrm{LES}=$ Lesotho, MAD $=$ Madagascar, $\mathrm{MAL}=\mathrm{Malawi}, \mathrm{MOZ}=\mathrm{Mozambique}, \mathrm{NAM}=$

Namibia, SAF = South Africa, SWZ = Swaziland, TNZ = Tanzania, ZAM = Zambia, and ZIM = Zimbabwe. Mauritius and Seychelles not included due to lack of data

Table A.39 Final spillover coefficient matrix for cattle

\begin{tabular}{|c|c|c|c|c|c|c|c|c|c|c|c|c|c|c|c|}
\hline Country & ANG & ВОт & DRC & LES & MAD & MAL & MOZ & NAM & SAF & SWZ & TNZ & ZAM & ZIM & $\begin{array}{c}\text { Ave } \\
\text { spill-in }\end{array}$ & $\begin{array}{c}\text { Spill-in } \\
\text { index }\end{array}$ \\
\hline ANG & 1.00 & 0.00 & 0.00 & 0.00 & 0.00 & 0.00 & 0.00 & 0.14 & 0.03 & 0.07 & 0.00 & 0.00 & 0.14 & 0.03 & 22.3 \\
\hline BOT & 0.00 & 1.00 & 0.00 & 0.00 & 0.00 & 0.00 & 0.00 & 0.00 & 0.10 & 0.00 & 0.00 & 0.00 & 0.00 & 0.04 & 35.1 \\
\hline DRC & 0.00 & 0.00 & 1.00 & 0.00 & 0.00 & 0.02 & 0.00 & 0.00 & 0.01 & 0.07 & 0.00 & 0.00 & 0.00 & 0.01 & 5.0 \\
\hline LES & 0.00 & 0.01 & 0.00 & 1.00 & 0.00 & 0.00 & 0.00 & 0.00 & 0.11 & 0.03 & 0.00 & 0.00 & 0.00 & 0.05 & 39.6 \\
\hline MAD & 0.07 & 0.18 & 0.00 & 0.00 & 1.00 & 0.12 & 0.00 & 0.09 & 0.03 & 0.17 & 0.00 & 0.08 & 0.10 & 0.05 & 41.6 \\
\hline MAL & 0.00 & 0.00 & 0.00 & 0.00 & 0.00 & 1.00 & 0.00 & 0.00 & 0.00 & 0.00 & 0.00 & 0.00 & 0.00 & 0.00 & 0.0 \\
\hline MOZ & 0.00 & 0.12 & 0.00 & 0.00 & 0.00 & 0.06 & 1.00 & 0.08 & 0.02 & 0.06 & 0.00 & 0.00 & 0.08 & 0.03 & 21.9 \\
\hline NAM & 0.00 & 0.00 & 0.00 & 0.00 & 0.00 & 0.00 & 0.00 & 1.00 & 0.00 & 0.00 & 0.00 & 0.00 & 0.00 & 0.00 & 0.0 \\
\hline SAF & 0.00 & 0.00 & 0.00 & 0.00 & 0.00 & 0.00 & 0.00 & 0.00 & 1.00 & 0.00 & 0.00 & 0.00 & 0.00 & 0.00 & 0.0 \\
\hline SWZ & 0.00 & 0.00 & 0.00 & 0.00 & 0.00 & 0.00 & 0.00 & 0.00 & 0.00 & 1.00 & 0.00 & 0.00 & 0.00 & 0.00 & 0.0 \\
\hline TNZ & 0.30 & 0.37 & 0.48 & 0.00 & 0.00 & 0.34 & 0.28 & 0.37 & 0.05 & 0.36 & 1.00 & 0.12 & 0.18 & 0.12 & 100.0 \\
\hline ZAM & 0.00 & 0.00 & 0.00 & 0.00 & 0.00 & 0.14 & 0.00 & 0.20 & 0.03 & 0.07 & 0.00 & 1.00 & 0.27 & 0.04 & 29.4 \\
\hline ZIM & 0.00 & 0.00 & 0.00 & 0.00 & 0.00 & 0.00 & 0.00 & 0.00 & 0.00 & 0.00 & 0.00 & 0.00 & 1.00 & 0.00 & 0.0 \\
\hline Ave spillout & 0.10 & 0.14 & 0.15 & 0.00 & 0.00 & 0.13 & 0.09 & 0.14 & 0.03 & 0.14 & 0.00 & 0.05 & 0.09 & & \\
\hline Spillout index & 69.4 & 93.0 & 100.0 & 0.0 & 0.0 & 86.6 & 58.4 & 98.0 & 20.7 & 95.7 & 0.0 & 31.8 & 61.3 & & \\
\hline
\end{tabular}

Source: Spillover matrix analysis.

Notes: $\quad \mathrm{ANG}=$ Angola, $\mathrm{BOT}=$ Botswana, $\mathrm{DRC}=$ Democratic Republic of the Congo, $\mathrm{LES}=$ Lesotho, $\mathrm{MAD}=\mathrm{Madagascar}, \mathrm{MAL}=\mathrm{Malawi}, \mathrm{MOZ}=\mathrm{Mozambique}, \mathrm{NAM}=$

Namibia, SAF = South Africa, SWZ = Swaziland, TNZ = Tanzania, ZAM = Zambia, and ZIM = Zimbabwe. Mauritius and Seychelles not included due to lack of data. 
Table A.40 Final spillover coefficient matrix for pigs

\begin{tabular}{|c|c|c|c|c|c|c|c|c|c|c|c|c|c|c|c|}
\hline Country & ANG & ВOT & DRC & LES & MAD & MAL & MOZ & NAM & SAF & SWZ & TNZ & ZAM & ZIM & $\begin{array}{c}\text { Ave } \\
\text { spill-in }\end{array}$ & $\begin{array}{c}\text { Spill-in } \\
\text { index }\end{array}$ \\
\hline ANG & 1.00 & 0.00 & 0.00 & 0.00 & 0.00 & 0.00 & 0.00 & 0.00 & 0.01 & 0.00 & 0.00 & 0.00 & 0.00 & 0.00 & 3.1 \\
\hline BOT & 0.11 & 1.00 & 0.00 & 0.00 & 0.11 & 0.00 & 0.00 & 0.00 & 0.07 & 0.00 & 0.00 & 0.00 & 0.00 & 0.04 & 41.2 \\
\hline DRC & 0.01 & 0.00 & 1.00 & 0.00 & 0.12 & 0.00 & 0.06 & 0.00 & 0.01 & 0.00 & 0.00 & 0.00 & 0.00 & 0.01 & 11.7 \\
\hline LES & 0.00 & 0.00 & 0.00 & 1.00 & 0.00 & 0.00 & 0.00 & 0.00 & 0.10 & 0.00 & 0.00 & 0.00 & 0.00 & 0.04 & 43.0 \\
\hline MAD & 0.00 & 0.00 & 0.00 & 0.00 & 1.00 & 0.00 & 0.00 & 0.00 & 0.00 & 0.00 & 0.00 & 0.00 & 0.00 & 0.00 & 0.0 \\
\hline MAL & 0.03 & 0.00 & 0.00 & 0.00 & 0.03 & 1.00 & 0.00 & 0.00 & 0.00 & 0.00 & 0.00 & 0.00 & 0.00 & 0.01 & 4.9 \\
\hline MOZ & 0.00 & 0.00 & 0.00 & 0.00 & 0.00 & 0.00 & 1.00 & 0.00 & 0.01 & 0.00 & 0.00 & 0.00 & 0.00 & 0.00 & 3.0 \\
\hline NAM & 0.00 & 0.00 & 0.00 & 0.00 & 0.02 & 0.00 & 0.00 & 1.00 & 0.01 & 0.00 & 0.00 & 0.00 & 0.00 & 0.00 & 4.3 \\
\hline SAF & 0.00 & 0.00 & 0.00 & 0.00 & 0.00 & 0.00 & 0.00 & 0.00 & 1.00 & 0.00 & 0.00 & 0.00 & 0.00 & 0.00 & 0.0 \\
\hline SWZ & 0.03 & 0.00 & 0.00 & 0.00 & 0.13 & 0.00 & 0.00 & 0.00 & 0.05 & 1.00 & 0.00 & 0.00 & 0.00 & 0.03 & 26.5 \\
\hline TNZ & 0.30 & 0.25 & 0.00 & 0.00 & 0.41 & 0.26 & 0.34 & 0.34 & 0.04 & 0.22 & 1.00 & 0.00 & 0.14 & 0.10 & 100.0 \\
\hline ZAM & 0.10 & 0.00 & 0.00 & 0.00 & 0.07 & 0.00 & 0.16 & 0.25 & 0.01 & 0.00 & 0.00 & 1.00 & 0.18 & 0.03 & 31.6 \\
\hline ZIM & 0.00 & 0.00 & 0.00 & 0.00 & 0.06 & 0.00 & 0.00 & 0.00 & 0.01 & 0.00 & 0.00 & 0.00 & 1.00 & 0.01 & 7.3 \\
\hline Ave spillout & 0.02 & 0.01 & 0.00 & 0.00 & 0.05 & 0.01 & 0.04 & 0.03 & 0.01 & 0.01 & 0.00 & 0.00 & 0.01 & & \\
\hline Spillout index & 44.5 & 24.4 & 0.0 & 0.0 & 100.0 & 24.9 & 68.5 & 51.2 & 16.4 & 21.3 & 0.0 & 0.0 & 25.9 & & \\
\hline
\end{tabular}

Source: Spillover matrix analysis.

Notes: $\quad \mathrm{ANG}=$ Angola, $\mathrm{BOT}=$ Botswana, $\mathrm{DRC}=$ Democratic Republic of the Congo, $\mathrm{LES}=$ Lesotho, MAD $=$ Madagascar, $\mathrm{MAL}=\mathrm{Malawi}, \mathrm{MOZ}=\mathrm{Mozambique}, \mathrm{NAM}=$

Namibia, SAF = South Africa, $\mathrm{SWZ}=$ Swaziland, TNZ = Tanzania, ZAM = Zambia, and ZIM = Zimbabwe. Mauritius and Seychelles not included due to lack of data

Table A.41 Final spillover coefficient matrix for sheep and goats

\begin{tabular}{|c|c|c|c|c|c|c|c|c|c|c|c|c|c|c|c|}
\hline Country & ANG & ВOT & DRC & LES & MAD & MAL & MOZ & NAM & SAF & SWZ & TNZ & ZAM & ZIM & $\begin{array}{c}\text { Ave } \\
\text { spill-in }\end{array}$ & $\begin{array}{c}\text { Spill-in } \\
\text { index }\end{array}$ \\
\hline ANG & 1.00 & 0.00 & 0.00 & 0.00 & 0.00 & 0.00 & 0.00 & 0.00 & 0.00 & 0.00 & 0.00 & 0.00 & 0.00 & 0.00 & 0.0 \\
\hline BOT & 0.00 & 1.00 & 0.00 & 0.00 & 0.00 & 0.00 & 0.00 & 0.17 & 0.04 & 0.11 & 0.00 & 0.00 & 0.00 & 0.03 & 66.2 \\
\hline DRC & 0.02 & 0.00 & 1.00 & 0.00 & 0.00 & 0.04 & 0.00 & 0.00 & 0.00 & 0.08 & 0.00 & 0.01 & 0.00 & 0.01 & 14.9 \\
\hline LES & 0.00 & 0.01 & 0.00 & 1.00 & 0.00 & 0.00 & 0.00 & 0.03 & 0.09 & 0.06 & 0.00 & 0.00 & 0.00 & 0.04 & 100.0 \\
\hline MAD & 0.03 & 0.00 & 0.00 & 0.00 & 1.00 & 0.00 & 0.00 & 0.02 & 0.00 & 0.16 & 0.00 & 0.00 & 0.00 & 0.01 & 24.5 \\
\hline MAL & 0.00 & 0.00 & 0.00 & 0.00 & 0.00 & 1.00 & 0.00 & 0.02 & 0.00 & 0.02 & 0.00 & 0.00 & 0.00 & 0.00 & 3.8 \\
\hline MOZ & 0.03 & 0.00 & 0.00 & 0.00 & 0.00 & 0.00 & 1.00 & 0.04 & 0.00 & 0.05 & 0.00 & 0.00 & 0.00 & 0.00 & 11.8 \\
\hline NAM & 0.00 & 0.00 & 0.00 & 0.00 & 0.00 & 0.00 & 0.00 & 1.00 & 0.00 & 0.00 & 0.00 & 0.00 & 0.00 & 0.00 & 0.0 \\
\hline SAF & 0.00 & 0.00 & 0.00 & 0.00 & 0.00 & 0.00 & 0.00 & 0.00 & 1.00 & 0.00 & 0.00 & 0.00 & 0.00 & 0.00 & 0.0 \\
\hline SWZ & 0.00 & 0.00 & 0.00 & 0.00 & 0.00 & 0.00 & 0.00 & 0.00 & 0.00 & 1.00 & 0.00 & 0.00 & 0.00 & 0.00 & 0.0 \\
\hline TNZ & 0.26 & 0.00 & 0.00 & 0.00 & 0.00 & 0.00 & 0.00 & 0.19 & 0.00 & 0.17 & 1.00 & 0.00 & 0.00 & 0.03 & 67.4 \\
\hline ZAM & 0.00 & 0.00 & 0.00 & 0.00 & 0.00 & 0.00 & 0.00 & 0.05 & 0.00 & 0.05 & 0.00 & 1.00 & 0.00 & 0.00 & 9.1 \\
\hline ZIM & 0.00 & 0.00 & 0.00 & 0.00 & 0.00 & 0.00 & 0.00 & 0.10 & 0.00 & 0.05 & 0.00 & 0.00 & 1.00 & 0.00 & 12.1 \\
\hline Ave spillout & 0.03 & 0.00 & 0.00 & 0.00 & 0.00 & 0.00 & 0.00 & 0.02 & 0.00 & 0.03 & 0.00 & 0.00 & 0.00 & & \\
\hline Spillout index & 100.0 & 1.2 & 0.0 & 0.0 & 0.0 & 4.2 & 0.0 & 88.6 & 14.1 & 97.5 & 0.0 & 1.4 & 0.0 & & \\
\hline
\end{tabular}

Source: Spillover matrix analysis.

Notes: $\quad \mathrm{ANG}=$ Angola, $\mathrm{BOT}=$ Botswana, $\mathrm{DRC}=$ Democratic Republic of the Congo, $\mathrm{LES}=$ Lesotho, $\mathrm{MAD}=\mathrm{Madagascar}, \mathrm{MAL}=\mathrm{Malawi}, \mathrm{MOZ}=\mathrm{Mozambique}, \mathrm{NAM}=$

Namibia, SAF = South Africa, SWZ = Swaziland, TNZ = Tanzania, ZAM = Zambia, and ZIM = Zimbabwe. Mauritius and Seychelles not included due to lack of data. 
Table A.42 Final spillover coefficient matrix for poultry

\begin{tabular}{|c|c|c|c|c|c|c|c|c|c|c|c|c|c|c|c|}
\hline Country & ANG & ВOT & DRC & LES & MAD & MAL & MOZ & NAM & SAF & SWZ & TNZ & ZAM & ZIM & $\begin{array}{c}\text { Ave } \\
\text { spill-in }\end{array}$ & $\begin{array}{c}\text { Spill-in } \\
\text { index }\end{array}$ \\
\hline ANG & 1.00 & 0.00 & 0.00 & 0.00 & 0.11 & 0.00 & 0.00 & 0.00 & 0.01 & 0.00 & 0.00 & 0.00 & 0.09 & 0.02 & 15.4 \\
\hline BOT & 0.00 & 1.00 & 0.00 & 0.00 & 0.12 & 0.00 & 0.00 & 0.38 & 0.09 & 0.05 & 0.00 & 0.38 & 0.44 & 0.10 & 100.0 \\
\hline DRC & 0.03 & 0.00 & 1.00 & 0.00 & 0.17 & 0.04 & 0.08 & 0.00 & 0.01 & 0.07 & 0.11 & 0.02 & 0.00 & 0.03 & 34.7 \\
\hline LES & 0.00 & 0.00 & 0.00 & 1.00 & 0.00 & 0.00 & 0.00 & 0.00 & 0.11 & 0.07 & 0.00 & 0.00 & 0.00 & 0.05 & 50.5 \\
\hline MAD & 0.00 & 0.00 & 0.00 & 0.00 & 1.00 & 0.00 & 0.00 & 0.00 & 0.01 & 0.00 & 0.00 & 0.00 & 0.00 & 0.00 & 2.3 \\
\hline MAL & 0.00 & 0.00 & 0.00 & 0.00 & 0.03 & 1.00 & 0.00 & 0.04 & 0.01 & 0.00 & 0.00 & 0.00 & 0.05 & 0.01 & 7.8 \\
\hline MOZ & 0.00 & 0.00 & 0.00 & 0.00 & 0.04 & 0.00 & 1.00 & 0.00 & 0.01 & 0.00 & 0.00 & 0.00 & 0.06 & 0.01 & 8.8 \\
\hline NAM & 0.00 & 0.00 & 0.00 & 0.00 & 0.00 & 0.00 & 0.00 & 1.00 & 0.01 & 0.00 & 0.00 & 0.00 & 0.00 & 0.00 & 4.3 \\
\hline SAF & 0.00 & 0.00 & 0.00 & 0.00 & 0.00 & 0.00 & 0.00 & 0.00 & 1.00 & 0.00 & 0.00 & 0.00 & 0.00 & 0.00 & 0.0 \\
\hline SWZ & 0.00 & 0.00 & 0.00 & 0.00 & 0.00 & 0.00 & 0.00 & 0.00 & 0.07 & 1.00 & 0.00 & 0.00 & 0.00 & 0.03 & 28.4 \\
\hline TNZ & 0.00 & 0.00 & 0.00 & 0.00 & 0.38 & 0.00 & 0.00 & 0.00 & 0.02 & 0.00 & 1.00 & 0.00 & 0.09 & 0.03 & 28.7 \\
\hline ZAM & 0.00 & 0.00 & 0.00 & 0.00 & 0.00 & 0.00 & 0.00 & 0.00 & 0.01 & 0.00 & 0.00 & 1.00 & 0.00 & 0.01 & 5.4 \\
\hline ZIM & 0.00 & 0.00 & 0.00 & 0.00 & 0.00 & 0.00 & 0.00 & 0.00 & 0.01 & 0.00 & 0.00 & 0.00 & 1.00 & 0.01 & 6.2 \\
\hline Ave spillout & 0.00 & 0.00 & 0.00 & 0.00 & 0.08 & 0.00 & 0.01 & 0.00 & 0.01 & 0.01 & 0.01 & 0.00 & 0.02 & & \\
\hline Spillout index & 3.4 & 0.0 & 0.0 & 0.0 & 100.0 & 5.4 & 10.4 & 3.6 & 12.2 & 10.2 & 14.6 & 4.3 & 32.5 & & \\
\hline
\end{tabular}

Source: Spillover matrix analysis.

Notes: $\quad \mathrm{ANG}=$ Angola, $\mathrm{BOT}=$ Botswana, $\mathrm{DRC}=$ Democratic Republic of the Congo, $\mathrm{LES}=$ Lesotho, $\mathrm{MAD}=\mathrm{Madagascar}, \mathrm{MAL}=\mathrm{Malawi}, \mathrm{MOZ}=\mathrm{Mozambique}, \mathrm{NAM}=$ Namibia, SAF $=$ South Africa, $S W Z=$ Swaziland, TNZ = Tanzania, ZAM = Zambia, and ZIM = Zimbabwe. Mauritius and Seychelles not included due to lack of data. 


\section{APPENDIX B: SUPPLEMENTARY TABLES FOR SECTION 5}

Table B.1 Initial yield level for selected crops, 2007 (metric tons/hectare)

\begin{tabular}{|c|c|c|c|c|c|c|c|c|c|c|c|}
\hline Country & Maize & Rice & Millet & Sorghum & Wheat & Cassava & $\begin{array}{c}\text { Potatoes and } \\
\text { sweet } \\
\text { potatoes }\end{array}$ & Groundnuts & Beans & Cotton & Sugar \\
\hline Angola & 0.65 & 0.80 & 0.45 & - & 1.92 & 8.11 & 4.10 & 0.36 & 0.29 & 0.99 & 37.89 \\
\hline Botswana & 0.20 & - & 0.24 & 0.33 & 1.50 & - & - & 1.00 & 0.78 & 1.36 & - \\
\hline Congo, D. R. & 0.80 & 0.76 & 0.66 & 0.66 & 1.28 & 8.11 & 4.65 & 0.78 & 0.51 & 0.42 & 38.81 \\
\hline Lesotho & 0.89 & - & - & 0.86 & 1.70 & - & 3.43 & - & 0.93 & - & - \\
\hline Madagascar & 1.52 & 2.21 & - & 0.60 & 2.13 & 7.62 & 5.93 & 1.12 & 1.06 & 0.96 & 32.53 \\
\hline Malawi & 2.04 & 1.66 & 0.72 & 0.86 & 1.69 & 8.47 & 4.06 & 0.83 & 0.61 & 0.84 & 48.75 \\
\hline Mauritius & - & - & - & - & - & - & - & - & - & - & - \\
\hline Mozambique & 1.05 & 0.98 & 0.55 & 0.66 & 1.25 & 6.79 & 3.87 & 0.43 & 0.48 & 0.74 & 21.49 \\
\hline Namibia & 1.38 & - & 0.30 & 0.41 & 2.11 & - & - & 0.47 & 1.14 & 1.50 & - \\
\hline Seychelles & - & - & - & - & - & - & - & - & - & - & - \\
\hline South Africa & 2.92 & 2.29 & 0.57 & 3.32 & 2.57 & - & 4.91 & 1.35 & 1.20 & 1.60 & 55.27 \\
\hline Swaziland & 1.65 & 3.40 & - & 0.60 & 1.48 & - & 2.00 & 0.77 & 0.62 & 0.40 & 49.06 \\
\hline Tanzania & 0.92 & 1.86 & 0.83 & 1.00 & 1.25 & 8.79 & 3.42 & 0.45 & 0.65 & 0.83 & 47.83 \\
\hline Zambia & 1.63 & 1.31 & 0.69 & 0.69 & 2.48 & 5.87 & 3.95 & 0.39 & 0.48 & 1.23 & 41.67 \\
\hline Zimbabwe & 1.22 & 2.41 & 0.29 & 0.49 & 2.80 & 4.31 & 3.20 & 0.69 & 0.81 & 0.90 & 40.29 \\
\hline
\end{tabular}

Source: Calculated from FAO (2010), based on the most recent 10 years.

Table B.2 Yield level for selected crops in the base run, 2015 (metric tons/hectare)

\begin{tabular}{|c|c|c|c|c|c|c|c|c|c|c|c|}
\hline Country & Maize & Rice & Millet & Sorghum & Wheat & Cassava & $\begin{array}{c}\text { Potatoes } \\
\text { and sweet } \\
\text { potatoes }\end{array}$ & Groundnuts & Beans & Cotton & Sugar \\
\hline Angola & 0.65 & 0.80 & 0.46 & - & 2.03 & 9.07 & 3.99 & 0.36 & 0.29 & 1.08 & 37.90 \\
\hline Botswana & 0.20 & - & 0.24 & 0.36 & 1.50 & - & - & 1.02 & 0.78 & 1.36 & - \\
\hline Congo, D. R. & 0.83 & 0.76 & 0.71 & 0.71 & 1.29 & 8.71 & 4.66 & 0.83 & 0.51 & 0.42 & 38.84 \\
\hline Lesotho & 0.89 & - & - & 0.86 & 1.70 & - & 3.64 & - & 0.93 & - & - \\
\hline Madagascar & 1.63 & 2.28 & - & 0.62 & 2.20 & 9.07 & - & - & - & - & - \\
\hline Malawi & 2.15 & 1.66 & 0.78 & 0.95 & 2.06 & 10.10 & 4.61 & 0.85 & 0.69 & 0.85 & 53.24 \\
\hline Mauritius & - & - & - & - & - & - & - & - & - & - & - \\
\hline Mozambique & 1.23 & 1.17 & 0.58 & 0.63 & 1.49 & 7.64 & 3.87 & 0.43 & 0.50 & 0.86 & 20.95 \\
\hline Namibia & 1.58 & - & 0.32 & 0.43 & 2.11 & - & - & 0.47 & 1.25 & 1.50 & $\begin{array}{c}20.00 \\
-\end{array}$ \\
\hline Seychelles & - & - & - & - & - & - & - & - & - & - & - \\
\hline South Africa & 2.99 & 2.29 & 0.57 & 3.33 & 2.68 & - & 5.19 & 1.40 & 1.20 & 1.97 & 57.99 \\
\hline Swaziland & 1.65 & 3.40 & - & 0.60 & 1.48 & - & 2.00 & 0.77 & 0.62 & 0.40 & 49.09 \\
\hline Tanzania & 1.02 & 1.87 & 0.88 & 0.97 & 1.25 & 9.34 & 3.61 & 0.51 & 0.69 & 1.02 & 56.43 \\
\hline Zambia & 1.80 & 1.33 & 0.73 & 0.69 & 2.49 & 6.18 & 4.66 & 0.47 & 0.50 & 1.35 & 42.15 \\
\hline Zimbabwe & 1.22 & 2.42 & 0.26 & 0.49 & 2.81 & 4.15 & 3.21 & 0.69 & 0.81 & 0.90 & 39.97 \\
\hline
\end{tabular}

Source: Economywide multimarket model results. 
Table B.3 Yield level for selected crops in growth scenario, 2015 (metric tons/hectare)

\begin{tabular}{|c|c|c|c|c|c|c|c|c|c|c|c|}
\hline Country & Maize & Rice & Millet & Sorghum & Wheat & Cassava & $\begin{array}{c}\text { Potatoes } \\
\text { and sweet } \\
\text { potatoes }\end{array}$ & Groundnuts & Beans & Cotton & Sugar \\
\hline Angola & 0.94 & 1.23 & 0.63 & & 3.09 & 11.11 & 4.63 & 0.43 & 0.37 & 1.19 & 42.06 \\
\hline Botswana & 0.30 & - & 0.35 & 0.55 & 2.29 & - & - & 1.26 & 1.01 & 1.51 & - \\
\hline Congo, D. R. & 1.23 & 1.20 & 0.98 & 0.98 & 2.04 & 10.94 & 6.51 & 1.06 & 0.75 & 0.47 & 43.11 \\
\hline Lesotho & 1.15 & - & - & 1.27 & 2.59 & - & 4.24 & - & 1.20 & - & - \\
\hline Madagascar & 2.30 & 3.47 & - & 0.94 & 3.35 & 10.57 & - & - & - & - & - \\
\hline Malawi & 2.86 & 2.54 & 1.08 & 1.45 & 3.11 & 12.38 & 5.52 & 1.05 & 0.85 & 0.94 & 57.94 \\
\hline Mauritius & - & - & - & - & - & - & - & - & 0.00 & - & - \\
\hline Mozambique & 1.70 & 1.77 & 0.78 & 0.94 & 2.25 & 9.89 & 5.33 & 0.60 & 0.66 & 0.95 & 23.17 \\
\hline Namibia & 2.40 & - & 0.43 & 0.59 & 3.23 & - & - & 0.58 & 1.51 & 1.66 & - \\
\hline Seychelles & - & - & - & - & - & - & - & - & - & - & - \\
\hline South Africa & 3.26 & 2.49 & 0.62 & 3.63 & 2.93 & - & 5.34 & 1.47 & 1.26 & 2.06 & 60.06 \\
\hline Swaziland & 2.51 & 5.19 & - & 0.92 & 2.26 & - & 2.48 & 0.95 & 0.80 & 0.45 & 54.48 \\
\hline Tanzania & 1.26 & 2.31 & 1.19 & 1.41 & 1.91 & 10.63 & 4.08 & 0.55 & 0.83 & 1.13 & 62.44 \\
\hline Zambia & 2.10 & 2.03 & 0.99 & 1.06 & 3.79 & 6.81 & 5.30 & 0.52 & 0.58 & 1.50 & 45.94 \\
\hline Zimbabwe & 1.64 & 3.69 & 0.40 & 0.75 & 4.28 & 5.30 & 4.33 & 0.90 & 1.16 & 1.00 & 44.46 \\
\hline
\end{tabular}

Source: Economywide multimarket model results. 
Table B.4 Annual yield growth rates to 2015 to achieve target yields, regional averages

\begin{tabular}{|c|c|c|c|c|c|c|c|c|}
\hline \multirow[b]{2}{*}{ Crop } & \multirow[b]{2}{*}{ Current } & \multicolumn{2}{|c|}{ Yields by 2015} & \multicolumn{3}{|c|}{ \% change } & \multicolumn{2}{|c|}{ Growth rates } \\
\hline & & Baseline & Growth & Baseline & Growth & Additional from & Baseline & Growth \\
\hline \multicolumn{9}{|c|}{ Cereals } \\
\hline Maize & 1.3 & 1.5 & 1.8 & 14.7 & 42.0 & 27.2 & 1.7 & 4.5 \\
\hline Rice & 1.8 & 1.9 & 2.8 & 5.7 & 52.5 & 46.8 & 0.7 & 5.4 \\
\hline Millet & 0.5 & 0.5 & 0.8 & 1.1 & 57.5 & 56.4 & 0.1 & 5.8 \\
\hline Sorghum & 0.9 & 0.9 & 1.3 & 3.0 & 46.2 & 43.3 & 0.4 & 4.9 \\
\hline Wheat & 2.8 & 2.9 & 4.4 & 3.7 & 58.7 & 55.0 & 0.5 & 5.9 \\
\hline \multicolumn{9}{|c|}{ Root crops } \\
\hline Cassava & 8.8 & 9.5 & 11.5 & 9.0 & 31.6 & 22.7 & 1.1 & 3.5 \\
\hline Yams & 5.3 & 5.3 & 7.1 & 0.2 & 32.9 & 32.7 & 0.0 & 3.6 \\
\hline Sweet potatoes & 4.0 & 4.4 & 5.3 & 8.4 & 31.3 & 22.9 & 1.0 & 3.5 \\
\hline Potatoes & 11.8 & 12.3 & 14.8 & 3.9 & 25.0 & 21.1 & 0.5 & 2.8 \\
\hline \multicolumn{9}{|c|}{ Oil nuts and pulses } \\
\hline Groundnuts & 0.7 & 0.8 & 0.9 & 5.3 & 27.4 & 22.0 & 0.7 & 3.1 \\
\hline Soybeans & 1.3 & 1.3 & 1.6 & 5.5 & 24.7 & 19.2 & 0.7 & 2.8 \\
\hline Sesame seeds & 0.5 & 0.5 & 0.7 & 4.8 & 46.5 & 41.7 & 0.6 & 4.9 \\
\hline Pulses & 0.7 & 0.8 & 1.0 & 3.4 & 33.2 & 29.9 & 0.4 & 3.7 \\
\hline \multicolumn{9}{|c|}{ High value } \\
\hline Cotton & 1.1 & 1.2 & 1.2 & 7.2 & 11.7 & 4.6 & 0.9 & $\overline{1.4}$ \\
\hline Sugar & 71.0 & 74.6 & 79.5 & 5.1 & 12.1 & 7.0 & 0.6 & 1.4 \\
\hline Coffee & 0.6 & 0.7 & 0.7 & 6.8 & 12.6 & 5.8 & 0.8 & 1.5 \\
\hline Vegetables & 7.9 & 8.1 & 9.3 & 3.1 & 18.9 & 15.8 & 0.4 & 2.2 \\
\hline Bananas/plantains & 7.5 & 8.4 & 8.8 & 12.2 & 17.2 & 5.0 & 1.5 & 2.0 \\
\hline Fruits & 7.8 & 8.7 & 9.2 & 11.5 & 18.9 & 7.4 & 1.4 & 2.2 \\
\hline Spices & 1.2 & 1.2 & 1.5 & 0.9 & 19.2 & 18.3 & 0.1 & 2.2 \\
\hline Nuts & 1.2 & 1.3 & 1.4 & 4.5 & 15.7 & 11.2 & 0.5 & 1.8 \\
\hline
\end{tabular}

Source: Economywide multimarket model results.

Note: Mauritius and Seychelles not included due to lack of data. 
Table B.5 Value of production gains from the base over 2009-2015 (six years) in real terms, US\$ thousands

\begin{tabular}{|c|c|c|c|c|c|c|c|c|c|c|c|}
\hline Country & Maize & Rice & Millet & Sorghum & Wheat & Cassava & $\begin{array}{c}\text { Potatoes } \\
\text { and sweet } \\
\text { potatoes }\end{array}$ & Groundnuts & Beans & Cotton & Sugar \\
\hline Angola & 537,993 & 8,100 & 21,893 & 0 & 7,741 & 490,377 & 75,349 & 22,604 & 63,854 & 1,337 & 3,537 \\
\hline Botswana & 13,893 & 0 & 130 & 12,232 & 920 & 0 & 0 & 685 & 12,523 & 366 & 0 \\
\hline Congo, D. R. & 569,057 & 212,749 & 5,484 & 927 & 16,449 & 873,957 & 45,145 & 147,864 & 157,253 & 5,877 & 1,279 \\
\hline Lesotho & 15,522 & 0 & 0 & 11,657 & 56,142 & 0 & 10,802 & 0 & 9,195 & 0 & 0 \\
\hline Madagascar & 147,138 & $1,244,740$ & 0 & 172 & 8,421 & 169,119 & 17,059 & 19,758 & 41,482 & 4,915 & 13,333 \\
\hline Malawi & 301,810 & 154,458 & 15,243 & 71,503 & 10,120 & 504,216 & 431,203 & 156,696 & 240,158 & 23,288 & 17,121 \\
\hline Mauritius & - & - & - & - & - & - & - & - & - & - & - \\
\hline Mozambique & 658,293 & 204,162 & 10,543 & 121,333 & 4306 & $1,328,348$ & 141,254 & 106,208 & 71,400 & 32,255 & 21,375 \\
\hline Namibia & 107,592 & 0 & 21,835 & 2,879 & 23,414 & 0 & 0 & 178 & 3,696 & 11,109 & 0 \\
\hline Seychelles & - & - & - & - & - & - & - & - & - & - & - \\
\hline South Africa & 902,889 & 921 & 698 & 42,174 & 520,801 & 0 & 40,340 & 30,387 & 23,193 & 10,580 & 51,156 \\
\hline Swaziland & 71,588 & 90 & 0 & 182 & 478 & 0 & 1,709 & 5,359 & 1,676 & 1,466 & 42,677 \\
\hline Tanzania & 460,704 & 347,594 & 30,746 & 184,385 & 209,846 & 183,336 & 58,278 & 15,493 & 312,103 & 58,492 & 25,511 \\
\hline Zambia & 20,312 & 10,791 & 6,225 & 10,030 & 199,145 & 22,152 & 2,709 & 13,079 & 8,411 & 27,446 & 17,291 \\
\hline Zimbabwe & $2,012,098$ & 1,236 & 48,086 & 118,346 & $1,280,372$ & 28,353 & 35,406 & 140,354 & 114,901 & 94,937 & 2,113 \\
\hline Total & $5,818,888$ & $2,184,842$ & 160,883 & 575,820 & $2,338,155$ & $3,599,858$ & 859,255 & 658,665 & $\begin{array}{c}1,059,84 \\
5 \\
\end{array}$ & $\begin{array}{c}272,06 \\
8\end{array}$ & 195,392 \\
\hline
\end{tabular}

Source: Economywide multimarket model results.

Table B.6 Regional shares of the value of production gains from the base over 2009-2015 (six years) in real terms, \%

\begin{tabular}{|c|c|c|c|c|c|c|c|c|c|c|c|}
\hline Country & Maize & Rice & Millet & Sorghum & Wheat & Cassava & $\begin{array}{c}\text { Potatoes } \\
\text { and sweet } \\
\text { potatoes }\end{array}$ & Groundnuts & Beans & Cotton & Sugar \\
\hline Angola & 9.2 & 0.4 & 13.6 & 0.0 & 0.3 & 13.6 & 8.8 & 3.4 & 6.0 & 0.5 & 1.8 \\
\hline Botswana & 0.0 & 0.0 & 0.1 & 2.1 & 0.0 & 0.0 & 0.0 & 0.1 & 1.2 & 0.1 & 0.0 \\
\hline Congo, D. R. & 9.8 & 9.7 & 3.4 & 0.2 & 0.7 & 24.3 & 5.3 & 22.4 & 14.8 & 2.2 & 0.7 \\
\hline Lesotho & 0.0 & 0.0 & 0.0 & 2.0 & 2.4 & 0.0 & 1.3 & 0.0 & 0.9 & 0.0 & 0.0 \\
\hline Madagascar & 2.5 & 57.0 & 0.0 & 0.0 & 0.4 & 4.7 & 2.0 & 3.0 & 3.9 & 1.8 & 6.8 \\
\hline Malawi & 5.2 & 7.1 & 9.5 & 12.4 & 0.4 & 14.0 & 50.2 & 23.8 & 22.7 & 8.6 & 8.8 \\
\hline Mauritius & - & - & - & - & - & - & - & - & - & - & - \\
\hline Mozambique & 11.3 & 9.3 & 6.6 & 21.1 & 0.2 & 36.9 & 16.4 & 16.1 & 6.7 & 11.9 & 10.9 \\
\hline Namibia & 0.0 & 0.0 & 13.6 & 0.5 & 1.0 & 0.0 & 0.0 & 0.0 & 0.3 & 4.1 & 0.0 \\
\hline Seychelles & - & - & - & - & - & - & - & - & - & - & - \\
\hline South Africa & 15.5 & 0.0 & 0.4 & 7.3 & 22.3 & 0.0 & 4.7 & 4.6 & 2.2 & 3.9 & 26.2 \\
\hline Swaziland & 1.2 & 0.0 & 0.0 & 0.0 & 0.0 & 0.0 & 0.2 & 0.8 & 0.2 & 0.5 & 21.8 \\
\hline Tanzania & 7.9 & 15.9 & 19.1 & 32.0 & 9.0 & 5.1 & 6.8 & 2.4 & 29.4 & 21.5 & 13.1 \\
\hline Zambia & 0.3 & 0.5 & 3.9 & 1.7 & 8.5 & 0.6 & 0.3 & 2.0 & 0.8 & 10.1 & 8.8 \\
\hline Zimbabwe & 34.6 & 0.1 & 29.9 & 20.6 & 54.8 & 0.8 & 4.1 & 21.3 & 10.8 & 34.9 & 1.1 \\
\hline
\end{tabular}

Source: Economywide multimarket model results. 
Table B.7 Annual growth rate in the aggregate by economic indicator, 2009-2015 (\%)

\begin{tabular}{|c|c|c|c|c|c|c|c|c|c|c|c|c|}
\hline \multirow[b]{2}{*}{ Country } & \multicolumn{2}{|c|}{ Total GDP } & \multicolumn{2}{|c|}{ Agricultural GDP } & \multicolumn{2}{|c|}{ Nonagricultural GDP } & \multicolumn{2}{|c|}{ GDP per capita } & \multicolumn{2}{|c|}{$\begin{array}{c}\text { Per capita income } \\
\text { (rural) }\end{array}$} & \multicolumn{2}{|c|}{$\begin{array}{c}\text { Per capita income } \\
\text { (urban) }\end{array}$} \\
\hline & Base run & $\begin{array}{l}\text { Growth } \\
\text { run }\end{array}$ & Base run & $\begin{array}{l}\text { Growth } \\
\text { run }\end{array}$ & Base run & $\begin{array}{l}\text { Growth } \\
\text { run }\end{array}$ & $\begin{array}{l}\text { Base } \\
\text { run }\end{array}$ & $\begin{array}{l}\text { Growth } \\
\text { run }\end{array}$ & $\begin{array}{l}\text { Base } \\
\text { run }\end{array}$ & $\begin{array}{l}\text { Growth } \\
\text { run }\end{array}$ & Base run & $\begin{array}{c}\text { Growth } \\
\text { run }\end{array}$ \\
\hline Angola & 7.63 & 8.10 & 2.90 & 7.01 & 7.92 & 8.17 & 4.61 & 5.06 & 3.71 & 4.47 & 3.55 & 3.79 \\
\hline Botswana & 5.40 & 5.50 & 1.88 & 6.13 & 5.46 & 5.49 & 3.94 & 4.03 & 4.10 & 4.22 & 3.85 & 3.87 \\
\hline Congo, D. R. & 4.37 & 6.05 & 1.43 & 5.42 & 6.06 & 6.45 & 1.44 & 3.08 & -0.04 & -1.12 & 3.71 & 4.04 \\
\hline Lesotho & 4.88 & 5.32 & 2.14 & 6.26 & 5.09 & 5.24 & 3.75 & 4.19 & 3.16 & 3.82 & 5.13 & 5.28 \\
\hline Madagascar & 4.77 & 5.85 & 4.71 & 7.32 & 4.79 & 5.34 & 1.90 & 2.94 & 2.79 & 3.30 & 3.64 & 4.22 \\
\hline Malawi & 4.43 & 5.69 & 4.85 & 7.93 & 4.21 & 4.44 & 1.51 & 2.74 & 4.21 & 4.63 & 3.36 & 3.70 \\
\hline $\begin{array}{l}\text { Mauritius } \\
\text { Mozambique }\end{array}$ & $\begin{array}{l}\text { n.a. } \\
7.68\end{array}$ & $\begin{array}{l}\text { n.a. } \\
9.02\end{array}$ & $\begin{array}{l}\text { n.a. } \\
4.53\end{array}$ & $\begin{array}{l}\text { n.a. } \\
8.84\end{array}$ & $\begin{array}{l}\text { n.a. } \\
8.78\end{array}$ & $\begin{array}{l}\text { n.a. } \\
9.09\end{array}$ & $\begin{array}{l}\text { n.a. } \\
4.99\end{array}$ & $\begin{array}{l}\text { n.a. } \\
6.30\end{array}$ & $\begin{array}{l}\text { n.a. } \\
-3.70\end{array}$ & $\begin{array}{l}\text { n.a. } \\
-5.89\end{array}$ & $\begin{array}{l}\text { n.a. } \\
10.28\end{array}$ & $\begin{array}{l}\text { n.a. } \\
10.33\end{array}$ \\
\hline Namibia & 5.11 & 5.44 & 0.37 & 3.11 & 5.54 & 5.67 & 3.09 & 3.41 & 1.92 & 2.62 & 3.92 & 4.05 \\
\hline South Africa & 4.13 & 4.20 & 1.50 & 2.86 & 4.21 & 4.24 & 2.69 & 2.76 & 1.18 & 1.32 & 3.75 & 3.80 \\
\hline Swaziland & 2.35 & 2.88 & 1.67 & 5.84 & 2.40 & 2.62 & 1.28 & 1.80 & 0.80 & 2.57 & 0.34 & 0.40 \\
\hline Seychelles & n.a. & n.a. & n.a. & n.a. & n.a. & n.a. & n.a. & n.a. & n.a. & n.a. & n.a. & n.a. \\
\hline Tanzania & 5.34 & 6.92 & 3.10 & 6.29 & 6.95 & 7.41 & 2.55 & 4.10 & -1.22 & 0.64 & 6.64 & 7.79 \\
\hline Zambia & 7.23 & 7.95 & 4.79 & 7.64 & 7.78 & 8.03 & 4.75 & 5.46 & 4.98 & 5.66 & 5.40 & 5.62 \\
\hline Zimbabwe & 0.57 & 2.05 & 0.56 & 5.80 & 0.57 & 1.36 & 0.48 & 1.96 & -4.58 & -0.98 & 1.96 & 3.87 \\
\hline SADC & 5.00 & 5.80 & 3.08 & 6.18 & 5.41 & 5.71 & 2.36 & 3.14 & & & & \\
\hline
\end{tabular}

Source: Economywide multimarket model results.

Notes: GDP $=$ gross domestic product. n.a. $=$ data not available. SADC $=$ Southern Africa Development Community.

Table B.8 Annual growth rate by agricultural subsector, 2009-2015 (\%)

\begin{tabular}{|c|c|c|c|c|c|c|c|c|c|c|c|c|c|c|}
\hline \multirow[b]{2}{*}{ Country } & \multicolumn{2}{|c|}{ Cereals } & \multicolumn{2}{|c|}{ Root crops } & \multicolumn{2}{|c|}{ Other food crops } & \multicolumn{2}{|c|}{ Other cash crops } & \multicolumn{2}{|c|}{ Livestock } & \multicolumn{2}{|c|}{ Fisheries } & \multicolumn{2}{|c|}{ Total agriculture } \\
\hline & $\begin{array}{c}\text { Base } \\
\text { run }\end{array}$ & $\begin{array}{c}\text { Growth } \\
\text { run }\end{array}$ & $\begin{array}{c}\text { Base } \\
\text { run }\end{array}$ & $\begin{array}{c}\text { Growth } \\
\text { run }\end{array}$ & $\begin{array}{c}\text { Base } \\
\text { run }\end{array}$ & $\begin{array}{c}\text { Growth } \\
\text { run }\end{array}$ & $\begin{array}{c}\text { Base } \\
\text { run }\end{array}$ & $\begin{array}{c}\text { Growth } \\
\text { run }\end{array}$ & $\begin{array}{c}\text { Base } \\
\text { run }\end{array}$ & $\begin{array}{c}\text { Growth } \\
\text { run }\end{array}$ & $\begin{array}{c}\text { Base } \\
\text { run }\end{array}$ & $\begin{array}{c}\text { Growth } \\
\text { run }\end{array}$ & $\begin{array}{c}\text { Base } \\
\text { run }\end{array}$ & $\begin{array}{c}\text { Growth } \\
\text { run }\end{array}$ \\
\hline Angola & 6.10 & 13.14 & 3.88 & 7.74 & 6.24 & 9.48 & 1.95 & 5.02 & 0.29 & 6.16 & 1.09 & 2.84 & 2.90 & 7.01 \\
\hline Botswana & 4.87 & 13.65 & 0.00 & 0.00 & 1.09 & 6.21 & 0.01 & 3.31 & 1.79 & 5.66 & 0.01 & 1.76 & 1.88 & 6.13 \\
\hline Congo, D. R. & 1.85 & 8.50 & 1.60 & 5.29 & 1.12 & 6.29 & 1.79 & 4.62 & 0.43 & 6.20 & 0.89 & 2.66 & 1.43 & 5.42 \\
\hline Lesotho & 2.37 & 6.48 & 1.75 & 4.01 & -0.04 & 5.24 & -0.05 & 2.64 & 2.42 & 7.02 & 2.85 & 4.60 & 2.14 & 6.26 \\
\hline Madagascar & 7.05 & 9.21 & 2.87 & 5.39 & 5.40 & 7.36 & 2.97 & 5.57 & 3.27 & 7.43 & 2.99 & 4.42 & 4.71 & 7.32 \\
\hline Malawi & 6.88 & 9.98 & 3.70 & 7.21 & 2.94 & 6.05 & 2.77 & 5.40 & 5.57 & 8.78 & 7.44 & 9.20 & 4.85 & 7.93 \\
\hline Mauritius & n.a. & n.a. & n.a. & n.a. & n.a. & n.a. & n.a. & n.a. & n.a. & n.a. & n.a. & n.a. & n.a. & n.a. \\
\hline Mozambique & 6.17 & 11.57 & 3.51 & 8.06 & 4.35 & 7.17 & 5.92 & 8.29 & 3.34 & 9.22 & 4.97 & 6.72 & 4.53 & 8.84 \\
\hline Namibia & 4.30 & 11.99 & 0.00 & 0.00 & 1.55 & 4.54 & 0.08 & 2.76 & 0.73 & 5.61 & 0.01 & 1.76 & 0.37 & 3.11 \\
\hline South Africa & 0.01 & 8.68 & 0.30 & 4.51 & 0.16 & 4.60 & 2.71 & 5.29 & 0.88 & 5.63 & 0.01 & 1.76 & 1.67 & 2.86 \\
\hline Swaziland & 5.64 & 9.82 & 1.78 & 3.97 & 1.79 & 5.12 & 3.39 & 6.14 & 2.11 & 5.96 & 0.01 & 1.76 & 3.10 & 5.84 \\
\hline Seychelles & n.a. & n.a. & n.a. & n.a. & n.a. & n.a. & n.a. & n.a. & n.a. & n.a. & n.a. & n.a. & n.a. & n.a. \\
\hline Tanzania & 7.00 & 9.69 & 3.23 & 4.96 & 4.13 & 6.00 & 5.10 & 7.54 & 3.15 & 7.53 & 1.08 & 2.83 & 4.79 & 6.29 \\
\hline Zambia & 0.19 & 6.75 & 0.28 & 5.30 & -0.05 & 5.86 & 0.25 & 2.78 & 2.15 & 6.04 & 0.99 & 2.39 & 0.56 & 7.64 \\
\hline Zimbabwe & 5.30 & 9.50 & 2.66 & 6.17 & 2.07 & 5.66 & 3.36 & 5.82 & 4.12 & 6.50 & 0.25 & 2.00 & 3.08 & 5.80 \\
\hline SADC & 4.64 & 9.13 & 3.03 & 6.58 & 2.16 & 6.10 & 2.85 & 5.51 & 2.38 & 6.73 & 1.42 & 3.12 & 3.08 & 6.18 \\
\hline
\end{tabular}

Source: Economywide multimarket model results.

Notes: $\quad$ n.a. $=$ data not available. SADC $=$ Southern Africa Development Community. 
Table B.9 Agricultural commodity-level annual growth and contribution to overall agricultural growth, 2009-2015 (\%), total SADC without South Africa

\begin{tabular}{|c|c|c|c|c|c|}
\hline \multirow[t]{2}{*}{$\begin{array}{l}\text { SADC (without } \\
\text { South Africa) }\end{array}$} & \multirow{2}{*}{$\begin{array}{c}\text { Share in } \\
\text { agriculture, } \\
\text { excluding } \\
\text { processed } \\
(2008)\end{array}$} & \multicolumn{2}{|c|}{$\begin{array}{l}\text { Annual growth rate, including } \\
\text { agriculture-related (\%) }\end{array}$} & \multicolumn{2}{|c|}{$\begin{array}{c}\text { Contribution to agricultural } \\
\text { growth, excluding } \\
\text { agriculture-related (\%) }\end{array}$} \\
\hline & & Base run & Growth run & Base run & Growth run \\
\hline Maize & 17.97 & 4.60 & 8.66 & 27.3 & 23.3 \\
\hline Rice & 5.47 & 6.60 & 9.92 & 11.9 & 8.1 \\
\hline Millet & 0.38 & 2.69 & 8.44 & 0.3 & 0.5 \\
\hline Sorghum & 0.87 & 3.11 & 11.17 & 0.9 & 1.5 \\
\hline Wheat & 2.71 & 1.07 & 9.60 & 1.0 & 3.9 \\
\hline Other cereals & 0.29 & 5.36 & 12.30 & 0.5 & 0.5 \\
\hline Cassava & 12.99 & 2.96 & 6.79 & 12.7 & 13.2 \\
\hline Yams & 0.00 & 1.58 & 5.13 & 0.0 & 0.0 \\
\hline Sweet potatoes & 0.90 & 3.34 & 6.05 & 1.0 & 0.8 \\
\hline Potatoes & 3.40 & 2.93 & 6.20 & 3.3 & 3.2 \\
\hline Cocoyams & 0.09 & 2.47 & 5.34 & 0.1 & 0.1 \\
\hline Groundnuts & 2.33 & 3.05 & 5.90 & 2.3 & 2.1 \\
\hline Soybeans & 1.02 & 0.44 & 6.18 & 0.1 & 0.9 \\
\hline Oil palm & 0.00 & 0.20 & 5.93 & 0.0 & 0.0 \\
\hline Sesame seeds & 0.03 & 4.63 & 9.22 & 0.0 & 0.0 \\
\hline Other oils & 0.00 & 1.15 & 7.41 & 0.0 & 0.0 \\
\hline Total pulses & 2.97 & 2.02 & 6.49 & 2.0 & 2.9 \\
\hline Cotton & 1.47 & 2.65 & 5.02 & 1.3 & 1.1 \\
\hline Total sugar & 0.96 & 4.83 & 7.01 & 1.5 & 1.0 \\
\hline Cocoa & 0.04 & 3.66 & 6.21 & 0.0 & 0.0 \\
\hline Coffee & 0.23 & 0.99 & 3.38 & 0.1 & 0.1 \\
\hline Tea & 0.56 & 2.81 & 5.36 & 0.5 & 0.4 \\
\hline Tobacco & 2.21 & 5.11 & 6.35 & 3.7 & 2.1 \\
\hline Total vegetables & 4.06 & 1.81 & 4.85 & 2.4 & 2.9 \\
\hline Total plantains & 0.72 & 2.04 & 4.88 & 0.5 & 0.5 \\
\hline Other fruits & 7.50 & 2.59 & 5.60 & 6.4 & 6.3 \\
\hline Total spices & 0.21 & 1.65 & 5.13 & 0.1 & 0.2 \\
\hline Nuts & 0.17 & -0.05 & 4.14 & 0.0 & 0.1 \\
\hline Cattle & 4.83 & 2.05 & 6.22 & 3.3 & 4.5 \\
\hline Chickens & 2.38 & 3.02 & 7.39 & 2.4 & 2.6 \\
\hline Sheep/goats & 1.38 & 2.61 & 6.91 & 1.2 & 1.4 \\
\hline Pigs & 1.64 & 3.51 & 7.96 & 1.9 & 2.0 \\
\hline Other livestock & 0.84 & 1.47 & 6.64 & 0.4 & 0.8 \\
\hline Cattle meat & & 2.03 & 6.23 & & \\
\hline Pig meat & & 3.00 & 7.84 & & \\
\hline Other meat & 1.10 & 1.59 & 6.74 & 0.6 & 1.1 \\
\hline Milk & 3.02 & 1.90 & 6.08 & 1.9 & 2.7 \\
\hline Eggs & 0.96 & 2.35 & 7.42 & 0.7 & 1.1 \\
\hline Skin & 1.18 & 2.34 & 6.57 & 0.9 & 1.2 \\
\hline Seawater fish & 7.02 & 0.78 & 2.53 & 1.8 & 2.7 \\
\hline Freshwater fish & 7.21 & 2.02 & 3.68 & 4.8 & 4.0 \\
\hline Cottonseed oil & & 16.25 & 7.88 & & \\
\hline Groundnut oil & & 14.77 & 8.83 & & \\
\hline Soybean oil & & 3.40 & 3.58 & & \\
\hline Sesame oil & & 18.93 & 9.71 & & \\
\hline Palm oil & & 19.93 & 10.59 & & \\
\hline $\begin{array}{l}\text { Other processed } \\
\text { oils }\end{array}$ & & 19.97 & 10.53 & & \\
\hline
\end{tabular}

Source: Economywide multimarket model results.

Note: $\quad \mathrm{SADC}=$ Southern Africa Development Community. 
Table B.10 Net imports, total SADC (without South Africa)

\begin{tabular}{|c|c|c|c|c|c|c|c|c|c|}
\hline \multirow{3}{*}{$\begin{array}{l}\text { SADC (without } \\
\text { South Africa) }\end{array}$} & \multicolumn{3}{|c|}{ Imports, $1,000 \mathrm{mt}$} & \multicolumn{3}{|c|}{ Exports, $1,000 \mathrm{mt}$} & \multicolumn{3}{|c|}{ Net imports, $1,000 \mathrm{mt}$} \\
\hline & & Base run & Growth run & & Base run & Growth run & & Base run & Growth run \\
\hline & 2008 & 2015 & 2015 & 2008 & 2015 & 2015 & 2008 & 2015 & 2015 \\
\hline Maize & 2,080 & 1,549 & 741 & 392 & 1,537 & 3,135 & 1,688 & 12 & $-2,394$ \\
\hline Rice & 2,515 & 3,752 & 2,794 & 0 & 0 & 0 & 2,515 & 3,752 & 2,794 \\
\hline Millet & 0 & 0 & 0 & 0 & 6 & 75 & 0 & -6 & -75 \\
\hline Sorghum & 208 & 255 & 164 & 0 & 0 & 456 & 208 & 255 & -293 \\
\hline Wheat & 3,746 & 5,735 & 5,628 & 0 & 0 & 0 & 3,746 & 5,735 & 5,628 \\
\hline Other cereals & 420 & 517 & 517 & 0 & 0 & 0 & 420 & 517 & 517 \\
\hline Cassava & 2 & 227 & 2 & 0 & 0 & 1,644 & 2 & 227 & $-1,642$ \\
\hline Yams & 0 & 0 & 0 & 0 & 0 & 0 & 0 & 0 & 0 \\
\hline Sweet potatoes & 1 & 2 & 2 & 0 & 0 & 23 & 1 & 2 & -21 \\
\hline Potatoes & 215 & 342 & 225 & 7 & 9 & 35 & 207 & 333 & 190 \\
\hline Cocoyams & 0 & 0 & 1 & 0 & 0 & 0 & 0 & 0 & 1 \\
\hline Groundnuts & 1 & 191 & 1 & 79 & 10 & 46 & -78 & 182 & -45 \\
\hline Soybeans & 89 & 99 & 99 & 10 & 0 & 14 & 79 & 99 & 85 \\
\hline Oil palm & 869 & 1,280 & 1,070 & 0 & 0 & 0 & 869 & 1,280 & 1,070 \\
\hline Sesame seeds & 0 & 0 & 0 & 51 & 2 & 66 & -51 & -2 & -65 \\
\hline Other oils & 60 & 99 & 80 & 122 & 97 & 224 & -62 & 2 & -145 \\
\hline Total pulses & 163 & 278 & 92 & 77 & 0 & 158 & 86 & 278 & -65 \\
\hline Cotton & 18 & 76 & 47 & 564 & 466 & 777 & -546 & -390 & -730 \\
\hline Total sugar & 722 & 4,417 & 1,478 & 965 & 1,298 & 1,563 & -242 & 3,119 & -85 \\
\hline Cocoa & 16 & 23 & 23 & 14 & 16 & 21 & 2 & 7 & 2 \\
\hline Coffee & 14 & 19 & 20 & 116 & 74 & 113 & -102 & -55 & -94 \\
\hline Tea & 6 & 9 & 9 & 108 & 128 & 155 & -102 & -118 & -146 \\
\hline Tobacco & 6 & 30 & 17 & 529 & 524 & 732 & -523 & -494 & -715 \\
\hline Total vegetables & 345 & 724 & 607 & 0 & 0 & 0 & 345 & 724 & 607 \\
\hline Total plantains & 27 & 39 & 39 & 63 & 49 & 73 & -36 & -10 & -34 \\
\hline Other fruits & 287 & 581 & 438 & 230 & 233 & 321 & 57 & 347 & 118 \\
\hline Total spices & 14 & 18 & 18 & 44 & 38 & 59 & -30 & -20 & -41 \\
\hline Nuts & 4 & 6 & 6 & 185 & 143 & 215 & -181 & -137 & -209 \\
\hline Cattle & 31 & 32 & 43 & 57 & 57 & 78 & -26 & -25 & -35 \\
\hline Chickens & 29 & 32 & 47 & 8 & 18 & 21 & 22 & 14 & 27 \\
\hline Sheep/goats & 90 & 186 & 156 & 785 & 871 & 1,072 & -695 & -684 & -917 \\
\hline Pigs & 19 & 19 & 25 & 0 & 0 & 0 & 19 & 19 & 25 \\
\hline Other livestock & 0 & 0 & 0 & 1 & 9 & 11 & -1 & -9 & -11 \\
\hline Cattle meat & 80 & 189 & 134 & 90 & 77 & 140 & -10 & 111 & -7 \\
\hline Chicken meat & 233 & 433 & 405 & 0 & 0 & 0 & 233 & 433 & 405 \\
\hline Sheep/goat meat & 1 & 6 & 2 & 7 & 2 & 9 & -6 & 4 & -7 \\
\hline Pig meat & 70 & 156 & 127 & 5 & 8 & 25 & 66 & 148 & 102 \\
\hline Other meat & 86 & 213 & 197 & 2 & 0 & 0 & 84 & 213 & 197 \\
\hline Milk & 585 & 1,134 & 942 & 76 & 96 & 189 & 508 & 1,038 & 753 \\
\hline Eggs & 35 & 60 & 56 & 7 & 17 & 21 & 28 & 43 & 35 \\
\hline Skin & 0 & 181 & 18 & 47 & 2 & 31 & -47 & 179 & -13 \\
\hline
\end{tabular}


Table B.10 Continued

\begin{tabular}{|c|c|c|c|c|c|c|c|c|c|}
\hline \multirow{3}{*}{$\begin{array}{l}\text { SADC (without } \\
\text { South Africa) }\end{array}$} & \multicolumn{3}{|c|}{ Imports, 1,000 mt } & \multicolumn{3}{|c|}{ Exports, $1,000 \mathrm{mt}$} & \multicolumn{3}{|c|}{ Net imports, $1,000 \mathrm{mt}$} \\
\hline & \multicolumn{2}{|c|}{ Base run } & Growth run & \multicolumn{2}{|c|}{ Base run } & Growth run & \multicolumn{2}{|c|}{ Base run } & \multirow{2}{*}{$\begin{array}{c}\text { Growth run } \\
2015\end{array}$} \\
\hline & 2008 & 2015 & 2015 & 2008 & 2015 & 2015 & 2008 & 2015 & \\
\hline Seawater fish & 302 & 421 & 423 & 696 & 666 & 695 & -393 & -245 & -272 \\
\hline Freshwater fish & 8 & 56 & 18 & 103 & 116 & 173 & -95 & -61 & -155 \\
\hline Cottonseed oil & 9 & 3 & 4 & 0 & 71 & 4 & 9 & -68 & 0 \\
\hline Groundnut oil & 2 & 0 & 0 & 0 & 81 & 10 & 2 & -81 & -10 \\
\hline Soybean oil & 275 & 417 & 438 & 0 & 0 & 0 & $27 \overline{5}$ & 417 & 438 \\
\hline Sesame oil & 0 & 0 & 0 & 0 & 26 & 3 & 0 & -26 & -3 \\
\hline Palm oil & 1,073 & 1,413 & 1,595 & 0 & 0 & 0 & 1,073 & 1,413 & 1,595 \\
\hline Other processed oils & 208 & 274 & 301 & 0 & 0 & 0 & 208 & 274 & 301 \\
\hline
\end{tabular}

Source: Economywide multimarket model results.

Note: $\quad \mathrm{SADC}=$ Southern Africa Development Community; $\mathrm{mt}=$ metric tons.

Table B.11 Price changes by 2015, total SADC (without South Africa)

\begin{tabular}{|c|c|c|c|c|c|}
\hline Commodity & Base run & Growth run & Commodity & Base run & Growth run \\
\hline Maize & 0.98 & 0.88 & Other fruits & 1.17 & 1.02 \\
\hline Rice & 1.00 & 1.00 & Total spices & 1.07 & 1.01 \\
\hline Millet & 1.16 & 0.70 & Nuts & 1.00 & 1.00 \\
\hline Sorghum & 0.90 & 0.79 & Cattle & 1.13 & 1.04 \\
\hline Wheat & 1.00 & 1.00 & Chickens & 1.09 & 1.00 \\
\hline Other cereals & 1.00 & 0.77 & Sheep/goats & 1.17 & 1.01 \\
\hline Cassava & 1.24 & 0.89 & Pigs & 1.13 & 1.03 \\
\hline Yams & 1.47 & 0.84 & Other livestock & 1.35 & 1.19 \\
\hline Sweet potatoes & 1.14 & 0.74 & Cattle meat & 1.15 & 1.05 \\
\hline Potatoes & 1.55 & 1.17 & Chicken meat & 1.04 & 0.95 \\
\hline Cocoyams & 1.53 & 1.10 & Sheep/goat meat & 1.22 & 1.02 \\
\hline Groundnuts & 1.49 & 0.94 & Pig meat & 1.22 & 1.02 \\
\hline Soybeans & 1.02 & 0.99 & Other meat & 1.13 & 1.01 \\
\hline Oil palm & 0.00 & 0.00 & Milk & 1.13 & 1.04 \\
\hline Sesame seeds & 1.53 & 1.00 & Eggs & 1.27 & 1.05 \\
\hline Other oils & 1.12 & 1.02 & Skin & 2.44 & 1.85 \\
\hline Total pulses & 1.28 & 1.02 & Seawater fish & 1.00 & 1.00 \\
\hline Cotton & 1.00 & 1.00 & Freshwater fish & 1.17 & 1.13 \\
\hline Total sugar & 1.11 & 1.07 & Cottonseed oil & 0.76 & 0.89 \\
\hline Cocoa & 1.00 & 1.00 & Groundnut oil & 0.81 & 0.87 \\
\hline Coffee & 1.01 & 1.00 & Soybean oil & 1.00 & 1.00 \\
\hline Tea & 1.00 & 1.00 & Sesame oil & 0.81 & 0.81 \\
\hline Tobacco & 1.19 & 1.00 & Palm oil & 0.94 & 1.00 \\
\hline Total vegetables & 1.21 & 1.07 & Other proc. Oils & 1.00 & 1.00 \\
\hline Total plantains & 1.28 & 1.10 & & & \\
\hline
\end{tabular}

Source: Economywide multimarket model results.

Note: $\quad \mathrm{SADC}=$ Southern Africa Development Community. 
APPENDIX C: SUPPLEMENTARY TABLE FOR SECTION 6

Table C.1 Summary and implications for agricultural research and development strategies in SADC

\begin{tabular}{|c|c|c|c|c|c|c|}
\hline $\begin{array}{l}\text { Key } \\
\text { commodity } \\
\text { or sector }\end{array}$ & $\begin{array}{l}\text { Contribution to } \\
\text { total agricultural } \\
\text { growth }\end{array}$ & $\begin{array}{l}\text { Other welfare } \\
\text { considerations }\end{array}$ & $\begin{array}{c}\text { Research } \\
\text { benefits and } \\
\text { otential spillover } \\
\text { ranking }\end{array}$ & $\begin{array}{c}\text { Other } \\
\text { considerations } \\
\text {-key } \\
\text { constraints, } \\
\text { opportunities }\end{array}$ & $\begin{array}{l}\text { Implications for } \\
\text { regional R\&D policy } \\
\text { and investments }\end{array}$ & $\begin{array}{l}\text { Implications for other } \\
\text { policy considerations }\end{array}$ \\
\hline Maize & $\begin{array}{l}\text { Grains contribute } \\
\text { more than } 35 \\
\text { percent of } \\
\text { projected SADC } \\
\text { total agricultural } \\
\text { growth (ranks } \\
\text { first). Maize is the } \\
\text { dominant grain in } \\
\text { the region, } \\
\text { contributing on its } \\
\text { own about } 22 \\
\text { percent to SADC } \\
\text { AgGDP growth } \\
\text { (ranks first). } \\
\text { Contributes } \\
\text { between } 19 \text { and } \\
41 \text { percent of } \\
\text { AgGDP growth for } \\
\text { nine countries in } \\
\text { SADC (Angola, } \\
\text { DRC, Lesotho, } \\
\text { Malawi, } \\
\text { Mozambique, } \\
\text { Swaziland, } \\
\text { Tanzania, } \\
\text { Zambia, and } \\
\text { Zimbabwe), } \\
\text { ranking first in five } \\
\text { of these and } \\
\text { second in the rest. }\end{array}$ & $\begin{array}{l}\text { Reduces the need for } \\
\text { imports as region gets } \\
\text { closer to becoming } \\
\text { self-sufficient in maize } \\
\text { production-with } \\
\text { imports falling to about } \\
2 \text { percent of total } \\
\text { consumption relative } \\
\text { to the current } 10 \\
\text { percent. } \\
\text { Price reductions from } \\
\text { increased production } \\
\text { will benefit consumers } \\
\text { in both rural and urban } \\
\text { areas. The reductions } \\
\text { are sufficiently modest } \\
\text { to still benefit } \\
\text { producers (given } \\
\text { production and yield } \\
\text { increases). } \\
\text { Consumers in all } \\
\text { SADC countries would } \\
\text { benefits from lowered } \\
\text { price and fewer } \\
\text { imports. }\end{array}$ & $\begin{array}{l}\text { Highest total } \\
\text { research } \\
\text { spillover benefits } \\
\text { in SADC (valued } \\
\text { at US } \$ 12 \text { million } \\
\text { over six years), } \\
\text { ranking first by } \\
\text { accounting for } \\
12 \text { percent of the } \\
\text { total value of } \\
\text { production in the } \\
\text { region. } \\
\text { Key beneficiary } \\
\text { countries are } \\
\text { among the low- } \\
\text { income } \\
\text { countries. }\end{array}$ & $\begin{array}{l}\text { Access to inputs } \\
\text { (given } \\
\text { dependence of } \\
\text { maize on } \\
\text { fertilizer) will } \\
\text { remain a key } \\
\text { constraint. } \\
\text { May not be as } \\
\text { profitable in more } \\
\text { remote areas due } \\
\text { to high input } \\
\text { costs. } \\
\text { Critical constraint } \\
\text { is uncertain } \\
\text { rainfall and high } \\
\text { cost of inputs (for } \\
\text { example, seed } \\
\text { and fertilizer). } \\
\text { Not crowding out } \\
\text { private-sector } \\
\text { input suppliers. }\end{array}$ & $\begin{array}{l}\text { Weighing costs and } \\
\text { benefits between more } \\
\text { intensive input packages, } \\
\text { for example, hybrids in } \\
\text { high-market-access areas, } \\
\text { versus low-input } \\
\text { packages, for example, } \\
\text { open-pollinated varieties } \\
\text { in low-market-access } \\
\text { areas. } \\
\text { Primary attention should } \\
\text { be on targeting the } \\
\text { majority of primary } \\
\text { smallholder producers in } \\
\text { low-income countries. } \\
\text { Significant capacity for } \\
\text { maize R\&D exists in the } \\
\text { region, with strong } \\
\text { programs in South Africa, } \\
\text { Zimbabwe (traditionally), } \\
\text { Zambia, Malawi, and } \\
\text { Tanzania. }\end{array}$ & $\begin{array}{l}\text { Need improved access to } \\
\text { input markets. } \\
\text { Complementary investments } \\
\text { needed in improving } \\
\text { fertilizer markets in the } \\
\text { region and reducing costs of } \\
\text { importing, marketing, and } \\
\text { distribution. } \\
\text { Lowering other production } \\
\text { costs and market } \\
\text { transaction costs. } \\
\text { Promoting regional input } \\
\text { markets, for example, } \\
\text { through harmonization of } \\
\text { seed laws and regulations } \\
\text { across countries. }\end{array}$ \\
\hline
\end{tabular}


Table C.1 Continued

\begin{tabular}{|c|c|c|c|c|c|c|}
\hline $\begin{array}{l}\text { Key } \\
\text { commodity } \\
\text { or sector }\end{array}$ & $\begin{array}{c}\text { Contribution to } \\
\text { total agricultural } \\
\text { growth }\end{array}$ & $\begin{array}{l}\text { Other welfare } \\
\text { considerations }^{a}\end{array}$ & $\begin{array}{c}\text { Research } \\
\text { benefits and } \\
\text { otential spillover } \\
\text { ranking }\end{array}$ & $\begin{array}{c}\text { Other } \\
\text { considerations } \\
\text {-key } \\
\text { constraints, } \\
\text { opportunities }\end{array}$ & $\begin{array}{l}\text { Implications for } \\
\text { regional } R \& D \text { policy } \\
\text { and investments }\end{array}$ & $\begin{array}{l}\text { Implications for other } \\
\text { policy considerations }\end{array}$ \\
\hline Cassava & $\begin{array}{l}\text { Ranks second in } \\
\text { its contribution to } \\
\text { overall } \\
\text { agricultural-sector } \\
\text { growth in the } \\
\text { SADC region- } \\
\text { about } 11 \text { percent } \\
\text { (even higher } \\
\text { among low- } \\
\text { income } \\
\text { countries-15 } \\
\text { percent). } \\
\text { Particularly } \\
\text { important in four } \\
\text { SADC countries } \\
\text { (Angola, DRC, } \\
\text { Malawi, and } \\
\text { Mozambique). } \\
\text { Contributes as } \\
\text { much as } 20 \text { to } 40 \\
\text { percent of AgGDP } \\
\text { and the most to } \\
\text { AgGDP growth } \\
\text { (ranking first } \\
\text { among three of } \\
\text { the countries). }\end{array}$ & $\begin{array}{l}\text { Important food staple } \\
\text { among all the major } \\
\text { producing countries. } \\
\text { Has known value for } \\
\text { being hardy during } \\
\text { drought years-hence } \\
\text { sometimes considered } \\
\text { an important food } \\
\text { security crop } \\
\text { (important implications } \\
\text { under climate change } \\
\text { uncertainty). } \\
\text { Price reductions are } \\
\text { modest relative to } \\
\text { those seen for coarse } \\
\text { grains, for example. } \\
\text { However, the } \\
\text { reductions are greater } \\
\text { than those for maize. } \\
\text { This will benefit } \\
\text { consumers, both } \\
\text { among subsistence } \\
\text { farmers and in urban } \\
\text { markets, where it is a } \\
\text { popular staple. }\end{array}$ & $\begin{array}{l}\text { Research } \\
\text { benefits are } \\
\text { likely to be quite } \\
\text { high, flowing } \\
\text { between } \\
\text { countries that } \\
\text { grow cassava. A } \\
\text { country that will } \\
\text { benefit the most } \\
\text { from potential } \\
\text { spillovers is } \\
\text { Mozambique, } \\
\text { given current } \\
\text { yield gaps. }\end{array}$ & $\begin{array}{l}\text { Has great market } \\
\text { potential (as a food } \\
\text { cash crop) in regions } \\
\text { where it is an } \\
\text { important staple (for } \\
\text { example, in Angola, } \\
\text { DRC, Northern } \\
\text { Zambia and Malawi, } \\
\text { Mozambique, and } \\
\text { parts of Tanzania). } \\
\text { Key constraints } \\
\text { include biotic and } \\
\text { abiotic constraints. } \\
\text { Traditional varieties } \\
\text { are prone to many } \\
\text { diseases and pests, } \\
\text { significantly reducing } \\
\text { yield. Hence lots of } \\
\text { potential for raising } \\
\text { yields through } \\
\text { improved varieties, } \\
\text { without required } \\
\text { purchased inputs } \\
\text { such as fertilizer. }\end{array}$ & $\begin{array}{l}\text { Disease- and pest- } \\
\text { resistant varieties, } \\
\text { postharvest technologies, } \\
\text { product development for } \\
\text { agro-industry (human } \\
\text { foods, livestock feed, } \\
\text { starch). }\end{array}$ & $\begin{array}{l}\text { Improvement in } \\
\text { processing technologies, } \\
\text { improving varieties for } \\
\text { human and agro- } \\
\text { industries (feed, } \\
\text { biofuels). } \\
\text { Targeting large regional } \\
\text { markets (DRC, Angola, } \\
\text { Northern Zambia and } \\
\text { Malawi, parts of } \\
\text { Tanzania, Mozambique, } \\
\text { and part of Zimbabwe) } \\
\text { for human consumption, } \\
\text { livestock feed markets in } \\
\text { middle-income countries } \\
\text { (great potential). }\end{array}$ \\
\hline
\end{tabular}


Table C.1 Continued

\begin{tabular}{|c|c|c|c|c|c|c|}
\hline $\begin{array}{l}\text { Key } \\
\text { commodity } \\
\text { or sector }\end{array}$ & $\begin{array}{l}\text { Contribution to } \\
\text { total agricultural } \\
\text { growth }\end{array}$ & $\begin{array}{l}\text { Other welfare } \\
\text { considerations }\end{array}$ & $\begin{array}{c}\text { Research } \\
\text { benefits and } \\
\text { otential spillover } \\
\text { ranking }\end{array}$ & $\begin{array}{c}\text { Other } \\
\text { considerations } \\
\text {-key } \\
\text { constraints, } \\
\text { opportunities }\end{array}$ & $\begin{array}{l}\text { Implications for } \\
\text { regional } R \& D \text { policy } \\
\text { and investments }\end{array}$ & $\begin{array}{l}\text { Implications for other } \\
\text { policy considerations }\end{array}$ \\
\hline Rice & $\begin{array}{l}\text { Ranks third on the } \\
\text { growth criteria } \\
\text { when we exclude } \\
\text { South Africa. } \\
\text { Considered a } \\
\text { higher-value staple, } \\
\text { it contributes up to } \\
8.7 \text { percent of the } \\
\text { additional growth } \\
\text { experienced due to } \\
\text { improved yield } \\
\text { gains by 2015. If } \\
\text { we include South } \\
\text { Africa, it falls to the } \\
\text { fifth rank (to be } \\
\text { replaced by } \\
\text { livestock, especially } \\
\text { cattle, and shared } \\
\text { with fisheries, } \\
\text { below). } \\
\text { Among the low- } \\
\text { income countries, } \\
\text { rice production is } \\
\text { especially } \\
\text { important in } \\
\text { Madagascar, which } \\
\text { has the most area } \\
\text { under irrigation. It } \\
\text { also has } \\
\text { importance in } \\
\text { Tanzania, } \\
\text { Mozambique, and } \\
\text { DRC. }\end{array}$ & $\begin{array}{l}\text { Demand is likely to } \\
\text { grow over time, } \\
\text { especially in urban } \\
\text { areas. Current } \\
\text { production is well } \\
\text { below demand-hence } \\
\text { no demand-side } \\
\text { problem. }\end{array}$ & & $\begin{array}{l}\text { Main constraint is } \\
\text { high cost of inputs. } \\
\text { Limited irrigation in } \\
\text { many of the low- } \\
\text { income countries (for } \\
\text { irrigated rice). } \\
\text { Ability to compete } \\
\text { with cheaper imports } \\
\text { from Asia. }\end{array}$ & $\begin{array}{l}\text { Lowering production costs } \\
\text { and practices, adaptation } \\
\text { of improved varieties from } \\
\text { the region or beyond. }\end{array}$ & $\begin{array}{l}\text { Improved access to } \\
\text { irrigation and other water } \\
\text { management } \\
\text { technologies. Improved } \\
\text { access to lower-cost } \\
\text { inputs. }\end{array}$ \\
\hline
\end{tabular}


Table C.1 Continued

\begin{tabular}{|c|c|c|c|c|c|c|}
\hline $\begin{array}{l}\text { Key } \\
\text { commodity } \\
\text { or sector }\end{array}$ & $\begin{array}{l}\text { Contribution to } \\
\text { total agricultural } \\
\text { growth }\end{array}$ & $\begin{array}{l}\text { Other welfare } \\
\text { considerations }\end{array}$ & $\begin{array}{c}\text { Research } \\
\text { benefits and } \\
\text { otential spillover } \\
\text { ranking }\end{array}$ & $\begin{array}{c}\text { Other } \\
\text { considerations } \\
\text {-key } \\
\text { constraints, } \\
\text { opportunities } \\
\end{array}$ & $\begin{array}{l}\text { Implications for } \\
\text { regional R\&D policy } \\
\text { and investments }\end{array}$ & $\begin{array}{l}\text { Implications for other } \\
\text { policy considerations }{ }^{c}\end{array}$ \\
\hline $\begin{array}{l}\text { Livestock } \\
\text { (cattle) }\end{array}$ & $\begin{array}{l}\text { Cattle ranks third } \\
\text { on the growth } \\
\text { criteria for all of } \\
\text { SADC. However, if } \\
\text { we exclude South } \\
\text { Africa it actually } \\
\text { falls to sixth place } \\
\text { (explaining } 4.6 \\
\text { percent of the } \\
\text { growth). } \\
\text { It is more important } \\
\text { among the middle- } \\
\text { income countries } \\
\text { (especially } \\
\text { Botswana, South } \\
\text { Africa, Namibia, } \\
\text { and Swaziland). } \\
\text { Ranks first among } \\
\text { these countries- } \\
\text { with cattle } \\
\text { contributing up to } \\
24 \text { percent of the } \\
\text { agriculture-sector } \\
\text { growth in this } \\
\text { region (second is } \\
\text { poultry). Livestock } \\
\text { total is } 45 \text { percent } \\
\text { (Table } 6.1 \text { ) } \\
\text { If we regard the } \\
\text { whole sector (that } \\
\text { is, all livestock as a } \\
\text { single group), it } \\
\text { then comes in third, } \\
\text { explaining up to } 19 \\
\text { percent of the } \\
\text { SADC growth } \\
\text { without South } \\
\text { Africa, and second } \\
\text { with South Africa. }\end{array}$ & $\begin{array}{l}\text { This is a sector that } \\
\text { will continue to face } \\
\text { increasing demand as } \\
\text { incomes rise (has a } \\
\text { high income elasticity) } \\
\text { and through urban } \\
\text { population growth. } \\
\text { This means even with } \\
\text { significant yield } \\
\text { growth, demand will } \\
\text { grow at rates that will } \\
\text { at least maintain } \\
\text { current import levels } \\
\text { for consumption. } \\
\text { Although prices are } \\
\text { still expected to rise } \\
\text { with increased } \\
\text { demand, improved } \\
\text { yields will help dampen } \\
\text { the effect and benefit } \\
\text { consumers (especially } \\
\text { in urban areas). } \\
\text { If much of the gain in } \\
\text { production comes from } \\
\text { producers in middle- } \\
\text { income countries, the } \\
\text { effect will be felt less } \\
\text { among rural producers } \\
\text { and consumers, and } \\
\text { thus have limited } \\
\text { impact on rural } \\
\text { incomes and food } \\
\text { security. }\end{array}$ & $\begin{array}{l}\text { Not included in } \\
\text { spillover } \\
\text { analysis. }\end{array}$ & $\begin{array}{l}\text { In poorer (low- } \\
\text { income) countries, it } \\
\text { is often the case that } \\
\text { livestock are } \\
\text { concentrated far from } \\
\text { major urban markets. } \\
\text { Yet great potential for } \\
\text { tapping growing } \\
\text { urban demand. }\end{array}$ & $\begin{array}{l}\text { Because of the } \\
\text { dominance of crop- } \\
\text { livestock systems among } \\
\text { smallholders, crops such } \\
\text { as sorghum and millet } \\
\text { may also need } \\
\text { consideration (especially } \\
\text { in semiarid agricultural } \\
\text { regions of Angola, } \\
\text { Botswana, Zambia, } \\
\text { Zimbabwe, and Namibia). }\end{array}$ & $\begin{array}{l}\text { Dealing with intraregional } \\
\text { trade issues, such as } \\
\text { transboundary animal } \\
\text { disease control. }\end{array}$ \\
\hline
\end{tabular}


Table C.1 Continued

\begin{tabular}{|c|c|c|c|c|c|c|}
\hline $\begin{array}{l}\text { Key } \\
\text { commodity } \\
\text { or sector }\end{array}$ & $\begin{array}{l}\text { Contribution to } \\
\text { total agricultural } \\
\text { growth }\end{array}$ & $\begin{array}{l}\text { Other welfare } \\
\text { considerations }\end{array}$ & $\begin{array}{c}\text { Research } \\
\text { benefits and } \\
\text { otential spillover } \\
\text { ranking }\end{array}$ & $\begin{array}{c}\text { Other } \\
\text { considerations } \\
\text {-key } \\
\text { constraints, } \\
\text { opportunities }\end{array}$ & $\begin{array}{l}\text { Implications for } \\
\text { regional } R \& D \text { policy } \\
\text { and investments }\end{array}$ & $\begin{array}{l}\text { Implications for other } \\
\text { policy considerations }\end{array}$ \\
\hline \multirow[t]{2}{*}{ Fruits } & $\begin{array}{l}\text { Fruits come in at } \\
\text { the fourth rank in } \\
\text { terms of } \\
\text { importance for } \\
\text { driving growth in } \\
\text { the agricultural } \\
\text { sector (contributing } \\
\text { up to } 7.2 \text { percent of } \\
\text { the total } \\
\text { agriculture-sector } \\
\text { growth in SADC). If } \\
\text { we remove South } \\
\text { Africa from the } \\
\text { equation, it } \\
\text { changes to fifth } \\
\text { rank, replaced by } \\
\text { fisheries. }\end{array}$ & $\begin{array}{l}\text { As in livestock, } \\
\text { demand is also more } \\
\text { elastic than for } \\
\text { traditional food staples. } \\
\text { Over time, demand is } \\
\text { likely to increase with } \\
\text { income growth in the } \\
\text { region. } \\
\text { Commercialized } \\
\text { entities are typically } \\
\text { large orchards that } \\
\text { grow for export or } \\
\text { industry, except for } \\
\text { traditional rural and } \\
\text { urban consumer } \\
\text { markets }\end{array}$ & Not included. & $\begin{array}{l}\text { Potential for links with } \\
\text { agroprocessing } \\
\text { industries. }\end{array}$ & & \\
\hline & $\begin{array}{l}\text { Much of the } \\
\text { commercial fruit } \\
\text { industry is } \\
\text { dominated by } \\
\text { South Africa, } \\
\text { contributing more } \\
\text { than } 10 \text { percent of } \\
\text { that country's } \\
\text { agriculture-sector } \\
\text { growth. }\end{array}$ & $\begin{array}{l}\text { Less likely to make a } \\
\text { big dent in rural } \\
\text { incomes and poverty } \\
\text { reduction. }\end{array}$ & & & & \\
\hline
\end{tabular}


Table C.1 Continued

\begin{tabular}{|c|c|c|c|c|c|}
\hline $\begin{array}{l}\text { Key } \\
\text { commodity } \\
\text { or sector }\end{array}$ & $\begin{array}{l}\text { Contribution to } \\
\text { total agricultural } \\
\text { growth }\end{array}$ & $\begin{array}{l}\text { Other welfare } \\
\text { considerations }\end{array}$ & $\begin{array}{c}\text { Research } \\
\text { benefits and } \\
\text { otential spillover } \\
\text { ranking }\end{array}$ & $\begin{array}{c}\text { Other } \\
\text { considerations } \\
\text {-key } \\
\text { constraints, } \\
\text { opportunities }\end{array}$ & $\begin{array}{l}\text { Implications for } \\
\text { regional R\&D policy } \\
\text { and investments }\end{array}$ \\
\hline \multirow[t]{5}{*}{ Fisheries } & $\begin{array}{l}\text { Ranks fifth in terms } \\
\text { of contribution to } \\
\text { SADC's (without } \\
\text { South Africa) } \\
\text { agriculture-sector } \\
\text { growth, explaining } \\
\text { up to } 6.9 \text { percent of } \\
\text { that growth. It } \\
\text { dominates the } \\
\text { sector growth in } \\
\text { Namibia (up to } 45 \\
\text { percent of overall } \\
\text { growth in the sector } \\
\text { comes from } \\
\text { fisheries). Likely to } \\
\text { be very high in the } \\
\text { Seychelles too, } \\
\text { although not } \\
\text { included in the } \\
\text { analysis. }\end{array}$ & $\begin{array}{l}\text { With a high income } \\
\text { elasticity, its demand is } \\
\text { likely to grow with } \\
\text { rising urban } \\
\text { populations, as in the } \\
\text { livestock sector. } \\
\text { A major source of } \\
\text { income in island } \\
\text { countries of } \\
\text { Madagascar and } \\
\text { coastal countries of } \\
\text { DRC, Angola, and } \\
\text { Tanzania, contributing } \\
\text { between } 8.2 \text { and } 9.8 \\
\text { percent to sector } \\
\text { growth. }\end{array}$ & Not included. & & $\begin{array}{l}\text { Emphasis should be given } \\
\text { to developing aquaculture. } \\
\text { Statistics on fisheries } \\
\text { need improvement-for } \\
\text { example, determining } \\
\text { freshwater stocks and } \\
\text { enhancing the } \\
\text { surveillance and } \\
\text { monitoring of fish health } \\
\text { for effective disease } \\
\text { control measures. }\end{array}$ \\
\hline & \multicolumn{5}{|c|}{ Cross-cutting \#1: Institutionalizing regional R\&D cooperation, resource and knowledge sharing } \\
\hline & Very important & Extremely important & & $\begin{array}{l}\text { Close collaboration, } \\
\text { consultation, and } \\
\text { coordination across } \\
\text { various efforts in the } \\
\text { region. }\end{array}$ & $\begin{array}{l}\text { In addition to commodity } \\
\text { research, analysis on how } \\
\text { to institutionalize the } \\
\text { research priorities is also } \\
\text { key. }\end{array}$ \\
\hline & \multicolumn{5}{|c|}{ Cross-cutting \#2: Building regional analytical capacity in research priority setting } \\
\hline & Important & Very important & & $\begin{array}{l}\text { Strong support from } \\
\text { universities, donors, } \\
\text { and IFPRI. }\end{array}$ & $\begin{array}{l}\text { Capacity in social } \\
\text { economic research needs } \\
\text { to be strengthened to } \\
\text { assess strategic options } \\
\text { on a constant basis. }\end{array}$ \\
\hline
\end{tabular}

Source: Authors based on spillover analysis results and economywide multimarket model results.

Notes: $\quad \mathrm{SADC}=$ Southern Africa Development Community. $\mathrm{R} \& \mathrm{D}=$ research and development. AgGDP $=$ agricultural value-added or agricultural gross domestic product.

DRC = Democratic Republic of the Congo. IFPRI = International Food Policy Research Institute.

${ }^{a}$ For example, effects on food security, rural incomes, and poverty. ${ }^{b}$ Technology considerations, extension capacities, and so on. ${ }^{c}$ For example, complementary investments, policy reforms. 


\section{APPENDIX D: THE SPATIAL ANALYSIS MODEL AND DETERMINATION OF DEVELOPMENT DOMAINS ${ }^{12}$}

To analyze the agricultural development domains used in this study - based on both agricultural potential and market potential — we used a combination of GIS and spatial analysis tools. Agricultural crop potential is determined by combining crop suitability, satellite imagery of the current cropland, and rural population density to identify the constraints and opportunities in agricultural production. Market potential uses market locations (size and potential affected by urbanization, globalization, and regional integration) and market access (affected by both physical barriers such as distance and institutional barriers) to identify market potential for agricultural products. The spatial analysis also uses a SPAM to make plausible allocations of crop production from large reporting units such as a country or state into smaller spatial units organized as cells of a regularly spaced grid. Such disaggregated results allow us to do analysis on diverse geographical scales at the levels of domains for agricultural potential and market potential.

\section{Agricultural Development Potential}

To determine agricultural development potential, we used three spatial datasets: crop suitability, cropland imagery, and rural population density. Different crops have different thermal, moisture, and soil requirements, particularly under rainfed conditions. The Food and Agriculture Organization of the United Nations (FAO), with the collaboration of the International Institute for Applied Systems Analysis (IIASA), has developed the agroecological zoning (AEZ) methodology that enables rational land-use planning on the basis of an inventory of land resources and evaluation of biophysical limitations and potentials. AEZ methodology provides a standardized framework for the characterization of climate, soil, and terrain conditions relevant to agricultural production. Crop modeling and environmental matching procedures are used to identify crop-specific limitations of prevailing climate, soil, and terrain resources, under assumed levels of inputs and management conditions (FAO/IIASA/ISRIC/ISSCAS/JRC, 2009).

We used a generic suitability, Plate 46 in the FAO-IIASA Global Agro-Ecological Zones (GAEZ) results, to indicate biophysical suitability for crop production in southern Africa. The crop suitability file contains records for each grid cell, including the suitable areas and their corresponding yields in the following six suitability classes: VS (very suitable), S (suitable), MS (moderately suitable), mS (marginally suitable), VmS (very marginally suitable), NS (not suitable). We defined our suitable area for each pixel as the sum of areas in the following three classes: VS, S, and NS.

Such crop suitability reflects the soil and climate conditions for crop production. However, the reality may be more complex. For example, many farmers still cultivate in nonsuitable areas. To closely reflect the ground reality, we bring in the satellite imagery of (current) cropland. The Global Land Cover 2000 (GLC2000) map was created using daily $1 \mathrm{~km}$ SPOT 4 VEGETATION data from November 1999 to December 2000. It followed a bottom-up approach in which more than 30 research teams around the world contributed to 19 regional windows, where local experts were responsible for the classification and mapping. The individual groups could freely choose their methodology, except that they followed the Land Cover Classification System developed by FAO (Di Gregorio and Jansen 2000; Fritz et al. 2003). The global product has 22 land cover classes, in which there are 3 explicit cropland classes: cultivated and managed areas (Class 15), cropland / tree cover / other natural vegetation (Class 16), and cropland / shrub or grass cover (Class 17). We corrected the suitability according to the following two rules: (1) if area (in sq $\mathrm{km}$ ) of cropland per pixel is greater than 0.31 , then that pixel is very suitable; (2) if area (in sq $\mathrm{km}$ ) of cropland per pixel is greater than zero and less than or equal to 0.31 , then that pixel is suitable. Since not all areas are croplands, there are many pixels with no data; these become areas with null data.

\footnotetext{
12 This section authored by Liang You, Michael Johnson, and Pius Chilonda.
} 
Finally, we added the rural population density, which is from the Global Rural-Urban Mapping Project (GRUMP). GRUMP, Alpha Version, consists of estimates of human population for the years 1990, 1995, and 2000 by 30 arc-second $(1 \mathrm{~km})$ grid cells and associated datasets dated circa 2000 . The data products include population count grids (raw counts), population density grids (per sq km), land area grids (actual area net of ice and water), mean geographic unit area grids, urban extents grids, centroids, a national identifier grid, national boundaries, coastlines, and settlement points. These products vary in GIS-compatible data formats and geographic extents (global, continent [Antarctica not included], and country levels). A proportional allocation gridding algorithm, utilizing more than 1 million national and subnational geographic units, is used to assign population values to grid cells. Additional global grids are created from the 30 arc-second grid at $1 / 4,1 / 2$, and 1 degree resolutions. The spatial reference metadata section information applies only to global-extent, 30 arc-second resolution. The GRUMP dataset is produced by the Columbia University Center for International Earth Science Information Network (CIESIN) in collaboration with IFPRI, the World Bank, and Centro Internacional de Agricultura Tropical (International Center for Tropical Agriculture, or CIAT). It is freely available from the CIESIN website. ${ }^{13}$

We divided pixels into three classes of suitability — high, medium, and low — and three classes of rural population density - high (> 150 persons per sq $\mathrm{km}$ ), medium (about 10-150 persons per sq $\mathrm{km}$ ), and low $(<10$ persons per sq km). Overlaying these two layers, and we obtained the Agricultural Development Zones (ADZ) as shown in Figure D.1. Table D.1 summarizes both relative share of total area of the ADZ classes. Two immediate features of SADC agriculture are obvious. One is that the population density is still quite low, with more than 60 percent of land having a low rural population density $(<10$ persons per sq $\mathrm{km}$ ). The other is that there is large agricultural potential in SADC, with almost 45 percent and 50 percent of land classified as having high and medium suitability, respectively, within this region.

\footnotetext{
13 http://www.ciesin.org/.
} 
Figure D.1 Agricultural development zones

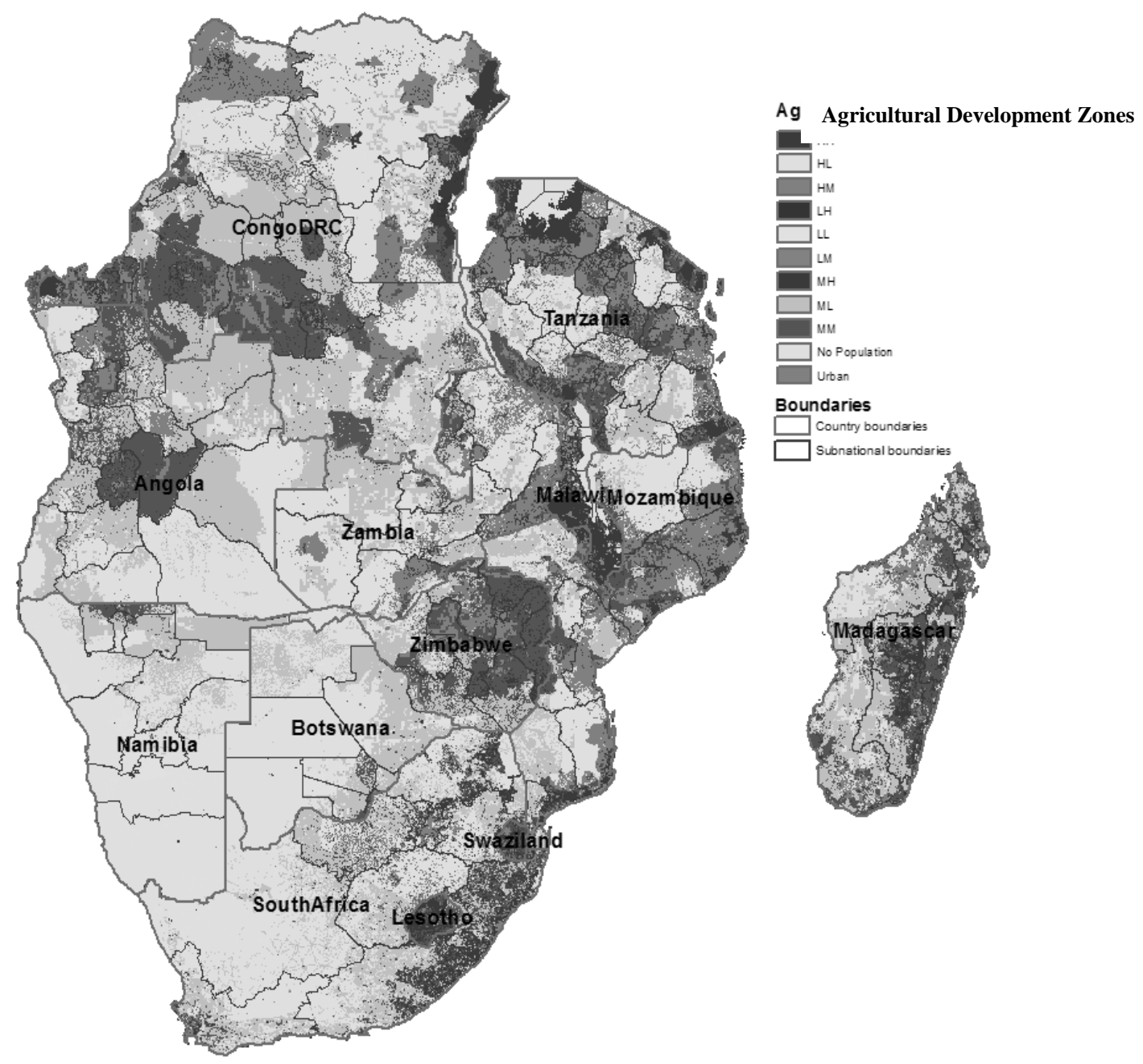

Source: Authors' creation based on GIS analysis.

Table D.1 Relative shares in total area of agricultural development zones

\begin{tabular}{|c|c|c|c|c|c|}
\hline \multirow[b]{2}{*}{$\begin{array}{l}\text { Agricultural } \\
\text { suitability }\end{array}$} & \multicolumn{4}{|c|}{ Rural Population Density (per square kilometer) } & \multirow[b]{2}{*}{ Total } \\
\hline & Urban & $\begin{array}{c}>150 \\
(H)\end{array}$ & $\begin{array}{c}>10-150 \\
(\mathrm{M})\end{array}$ & $\begin{array}{c}0 \text { and }<=10 \\
(L)\end{array}$ & \\
\hline $\begin{array}{ll}\text { Very suitable }(H) \\
\end{array}$ & $0.3 \%$ & $7.0 \%$ & $33.7 \%$ & $59.0 \%$ & $44.9 \%$ \\
\hline Suitable (M) & $0.4 \%$ & $6.4 \%$ & $32.5 \%$ & $60.7 \%$ & $51.8 \%$ \\
\hline Not Suitable (L) & $0.5 \%$ & $5.2 \%$ & $9.4 \%$ & $85.0 \%$ & $3.3 \%$ \\
\hline Total & $0.4 \%$ & $6.6 \%$ & $32.3 \%$ & $60.8 \%$ & $100.0 \%$ \\
\hline
\end{tabular}

Source: Authors from GIS analysis.

Note: $(\mathrm{H})=\operatorname{high} ;(\mathrm{M})=$ medium; $(\mathrm{L})=$ low.

\section{Livestock Consideration}

We did not undertake any spatial analysis of livestock production systems and yields as we were able to do for crops. Livestock would introduce complexities that the SPAM model is not yet able to integrate in its analysis. Nevertheless, there has been extensive work on identifying the livestock systems across Africa (for example, see Thornton et al. 2010 for East Africa, Otte and Chilonda 2002 for Africa south of the Sahara, and Kruska et al. 2003 for developing countries in general). Here we build primarily on the 
work of Otte and Chilonda (2002), and then mostly to illustrate the importance of this sector across a majority of countries in the SADC region.

Otte and Chilonda (2002) used an approach similar to the farming systems approach used by Dixon and Gibbon (2001) but focused entirely on classifying livestock production systems. The approach was intended to recognize the mixed crop-livestock farming system, whether or not livestock production is the sole activity in the system. The authors principally classified livestock production systems by farming system first before placing them in the context of an agroecological zone. This approach had the added advantage of providing information about resource endowments and constraints, such as livestock output-to-land and person-to-land ratios, the extent of tsetse infestation, and the biophysical characteristics of the agroecological zone. Ultimately, therefore, Otte and Chilonda (2002) assessed the characteristics of livestock production systems by the type of livestock and livestock products, by the function of the livestock, and by the management practices likely to be found in the system. More will need to be done to link such details with actual production levels and potential, but that is beyond the scope of this study.

\section{Market Potential Domains}

Production is one side of the story of productivity improvement. To make technology pay," farmers need markets for the increased production. To identify market potential domains, we used market locations (size and potential to be affected by urbanization, globalization, and regional integration) and market access (affected by both physical barriers such as distance and institutional barriers) to identify the market potential for agricultural products. We first mapped the major markets in SADC and used population sizes and income levels to distinguish the different market sizes. Then we used GIS tools to calculate travel time to those markets and used travel time as the indicator of market accessibility.

While market size, location, and travel time provide a good visual description of market potential, it is difficult to quantify such diverse parameters. We decided to combine travel time and market size to create one parameter: a market size-weighted travel time (weightedTT). Let $T T^{20 k}, T T^{50 k}, T T^{100 k}$, $T T^{250 k}$, and $T T^{500 k}$ represent the travel time to market centers with population sizes of around 20,000, $50,000,100,000,250,000$, and 500,000 people, respectively; then,

$$
\begin{gathered}
\text { weightedTT }=\frac{T T^{20 k}+\frac{T T^{50 k}}{2.5}+\frac{T T^{100 k}}{5}+\frac{T T^{250 k}}{12.5}+\frac{T T^{500 k}}{25}}{1.72} \\
\text { where: } \quad 1.72=1+\frac{1}{2.5}+\frac{1}{5}+\frac{1}{12.5}+\frac{1}{25}
\end{gathered}
$$

Such a syndicated travel time provided us with a simplified way to delineate market potential zones. We divided the weightedTT into the following five groups: less than 2 hours, between 2 and 4 hours, between 4 and 8 hours, between 8 and 12 hours, and more than 12 hours (a day).

\section{Spatial Production Allocation Model}

SPAM is a mathematical model that was developed to allocate crop production levels from a relatively aggregated level (for example, district level) to a highly spatially disaggregated level (pixel level). More specifically, the model generates the highly disaggregated, crop-specific production data by a triangulation of any and all relevant background and partial information. This information includes national or subnational crop production statistics, satellite data on land cover, maps of irrigated areas, biophysical crop suitability assessments, population density, secondary data on irrigation and rainfed production systems, cropping intensity, and crop prices (You and Wood 2006; You, Wood, and WoodSichra 2009). 
The model uses a maximum entropy approach that basically maximizes the unknown by constraining it to what is partially known. In our case the model is constrained by a series of the spatial agroecological and climate characteristics, known production and yield levels and distribution at the aggregate level, and performance under different farming technologies (for example, irrigated versus rainfed). In total, 20 crops (about 90 percent of SADC crop areas) are covered: cereals (6): wheat, rice, maize, barley, millet, sorghum; roots and tubers (3): potatoes, sweetpotatoes and yams, cassava; pulses (2): dry beans, other pulses; oil crops (3): soybeans, groundnuts, other oil crops; fiber crops (2): cotton, other fibers; sugar crops (2): sugarcane, sugar beets; beverage/stimulant crops (1): coffee (omitting tea, tobacco); and fruits (1): bananas and plantains. Figure D.2 illustrates how the analysis was carried out and the type of output generated. Further details of the approach have been documented by You and Wood (2006) and You, Wood, and Wood-Sichra (2009).

Basic data on yield potential, and therefore yield gap estimates, come from an FAO-IIASA GAEZ study and database. ${ }^{14}$ The GAEZ methodology uses spatial databases to map out climatic parameters, topography, soil and terrain, vegetation, and population distribution relevant to agricultural production. Crop modeling and environmental matching procedures are used to identify crop-specific limitations under assumed levels of input and management conditions. This procedure provides estimates of maximum potential and agronomically attainable crop yields for basic land resource units.

Figure D.2 Overview of spatial production allocation model (SPAM)

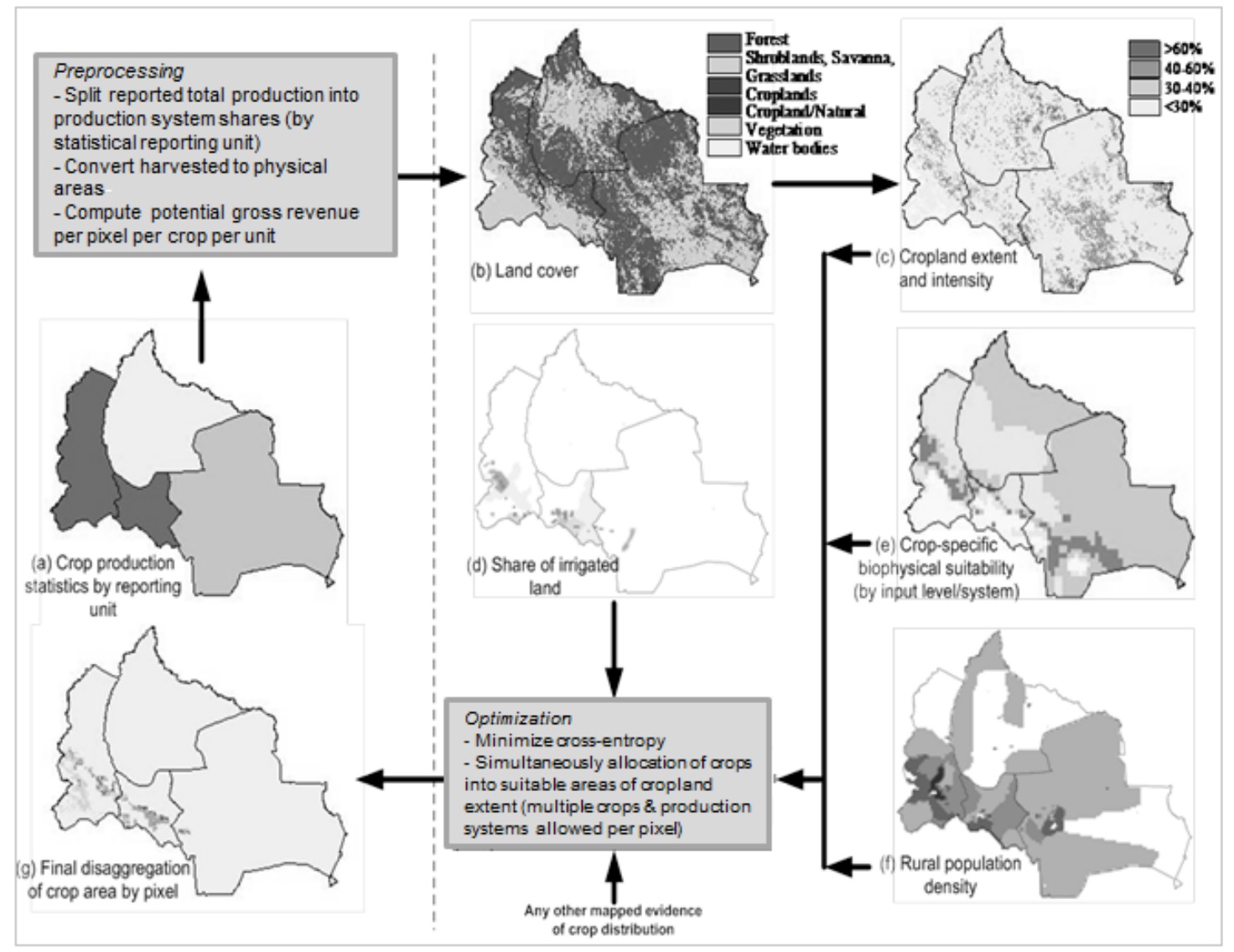

Sources: You and Wood (2006); You, Wood, and Wood-Sichra (2009).

\footnotetext{
${ }^{14}$ For more details of the GAEZ methodology, please see www.iiasa.ac.at/Research/LUC/GAEZ/index.htm.
} 


\section{APPENDIX E: ESTIMATING EX ANTE TECHNOLOGY SPILLOVERS ${ }^{15}$}

Despite the measurement challenge, empirical evidence of ex post technology spillovers has been shown for commonly grown commodities like maize and wheat (see Maredia and Byerlee 2000; Byerlee and Eicher 1997), and in Africa, improved germplasm for food staples like cassava has been shown to have spread beyond targeted regions and countries (Johnson, Masters, and Preckel 2006; Nweke, Spencer, and Lynam 2002). In international agriculture, early efforts to measure agricultural technology spillovers empirically can be found in the works of Evenson (1989) and White and Havlicek (1981). Evenson showed significant direct spillovers of crop and livestock technologies within similar agroecological regions in the United States. He also found that relatively small research systems benefited more from spillovers than larger ones.

Other studies in the literature have focused on the theory and empirical methods for assessing the economic benefits of technology spillovers, including studies by Oram, Davis, and Ryan (1987), and Alston, Norton, and Pardey (1995). The measurement of potential spillover coefficients is a key element in these studies, requiring estimates of how much a single technology derived through R\&D is adoptable in different parts of a country and across countries. Potential adaptability is therefore a function of agroecological and socioeconomic similarities. Other efforts to measure spillovers directly have examined the proximity of the research or the extent to which research in one institution overlaps that of another. For example, Pardey (1986) assessed the disciplinary mix of US agricultural experiment stations to derive an index for measuring proximity. Thorpe and Pardey (1990) used a citation index to estimate knowledge spillovers among Latin American countries. More recently, Maredia and Byerlee (2000) used the yield performance of improved varieties to directly estimate spill-in coefficients. They showed substantial spillover of wheat varieties from the International Maize and Wheat Improvement Center, implying that many developing countries - including some in Africa-would fare better by allocating their scarce resources to the adaptation of wheat technology spill-ins. More recently, Pardey et al.(2007) constructed a distance metric for technology spillovers across major regions of the world based on underlying production systems and agroecological zones. They found that some countries in Africa are actually closer in technology space to countries outside of the continent (for example, South Africa in relation to Mexico).

\section{Methodology for Constructing a Potential Spillover Matrix in the SADC Region}

To construct a spillover matrix in the SADC region, we use a measure that combines similarity of agricultural production from the spatial analysis described in Appendix D, probability of success in adaptive research (the pull or demand side), and probability for technology adoption and transfers (the push or supply side). Using these three different dimensions, we construct spillover matrixes to assess the potential spillover effects of agricultural R\&D investments in the SADC region for 11 key crops for which data were available (we did not have similar data for livestock, for example).

\section{Similarity of Agricultural Production Environment}

Following Jaffe's (1986, 1989) approach and the method popularized by Pardey et al. (2007), similarity of agricultural production environment or agroecological resources between countries $i$ and $j$ is calculated as

$$
\omega_{i j}=\frac{\sum_{m} f_{i m} f_{j m}}{\left(\sum_{m} f_{i m}^{2}\right)^{\frac{1}{2}}\left(\sum_{m} f_{j m}^{2}\right)^{\frac{1}{2}}},
$$

${ }^{15}$ This section was authored by Sam Benin and Michael Johnson. 
where $f_{i k}$, defined for each country $i$ within a vector $f_{i}=\left(f_{i l}, f_{i 2}, \ldots f_{i M}\right)$, is the share of attribute $k$ in country $i$. Following Pardey et al. (2007), we measure the similarity of agricultural production environment by defining $f_{i k}$ as the share of cultivated land in agricultural development zone (ADZ) ${ }^{16} k$ in country $i$. By definition, the shares sum to 1 over all attributes, and so $\omega_{i j}$ is like a correlation coefficient and varies between 0 (indicating no similarity in agricultural production environment and therefore research in either country has no potential spillover effect in the other) and 1 (indicating perfect similarity in agricultural production environment and therefore research in one country has perfect potential spillover effect [that is, a value of 1] in the other). Since there are numerous ADZs, within each of which different agricultural production activities take place, however, $\omega_{i j}$ is inherently more complex than a simple correlation coefficient that compares just one dimension against another.

Another feature of the measure as it is now is that it is symmetrical (that is, $\omega_{i j}=\omega_{j i}$ ), implying that spillover from one country to another is the same in the reverse direction. The data for this feature come from the spatial analysis on shares of cultivated land under different crops in each of 12 different ADZs. Table 4.1 in the main text shows an example for maize, which indicates that Malawi and Namibia are the least similar $\left(\omega_{i j}=0.03\right)$ while Botswana and Namibia are the most similar $\left(\omega_{i j}=0.46\right)$. There are 10 such matrixes, one each for the other 10 crops (beans, cassava, cotton, groundnuts, millet, potatoes/sweet potatoes, rice, sorghum, sugarcane, and wheat) considered in this analysis. Rather than present all the matrixes, we present in Table 4.3 in the main text a summary of the results for the least and most similar countries for each of the crops, reflecting smaller and larger potential for technology transfer and spillovers across the countries, respectively, based on this dimension alone. The results show that the extent of similarity between countries is different for different agricultural commodities.

\section{Probability of Success of Adaptive Research (Pull or Demand Side)}

As indicated earlier, research undertaken in one country is rarely directly usable in other countries without further adaptive research effort in the importing country. We measure the probability of success of adaptive research in country $i\left(R D_{i}\right)$ based on the study by Alene and Coulibaly (2009), in which they estimated the rates of return (RORs) on agricultural R\&D across several African countries, including 10 from the SADC region. The estimated RORs ranged from 5 percent in Lesotho, reflecting high agricultural $R \& D$ expenditures relative to agricultural productivity gains, to 62 percent in Tanzania, reflecting lower agricultural $R \& D$ expenditures relative to agricultural productivity gains (see Table 4.5 in the main text). In the context of this study, a high ROR (that is, our measure of $R D_{i}$ ) reflects high potential to adapt research outputs from other countries while a low ROR reflects the opposite. This dimension of the spillover index reflects the pull or demand-side effect in the technology generationconsumption continuum (the push or supply-side effect of the story is discussed in the next subsection). The study was based on data over the period 1980-2003 and controlled for the effect of several factors including agricultural R\&D expenditures and stocks, input and factor use, population density, total government expenditure, and the differential influence of NARS versus the CGIAR capacities. Because of this, using the RORs as a proxy here is neat. Using agricultural R\&D expenditures or stocks by itself as a proxy would seem a second-best alternative since one would still need to account for these other dimensions, complicating the measurement of such an index, for example what weights to attach to the other different factors.

Unfortunately, we do not have complete information on these indicators for all the relevant commodities for all the countries to use for commodity-specific analysis. The available information at this level is mostly on maize and few others in terms of the number of full-time equivalent researchers (Table E.1). And so we use the aggregate ROR (Table 4.5 in the main text) in the analysis, except that for maize we use the information in one scenario to estimate the spillover matrix.

\footnotetext{
${ }^{16} \mathrm{ADZ}$ is defined in Appendix D.
} 


\section{Technology Generation and Transfer (Push or Supply Side)}

The third dimension, capturing the push or supply-side effect in the technology generation-consumption continuum, is measured by the yield gap, $\tau_{i j}$, across countries using yield data from the spatial analysis. In particular, we measure the gap as a ratio, where $\tau_{i j}$ is the yield in country $j$ relative to the yield in country $i$, such that $\tau_{i j}=1 / \tau_{j i}$. As an example, Table 4.6 in the main text shows the yield gaps for maize, indicating that the gap is largest between Botswana and Malawi $\left(\tau_{i j}=10.33\right.$ or $\left.\tau_{j i}=0.10\right)$ and smallest between Madagascar and Swaziland ( $\tau_{i j}$ and $\tau_{j i}$ are both close to 1, implying very similar yield levels). It is logical that productivity-enhancing technologies, practices, and knowledge will flow from higher- to lowerproductivity areas, at least in net terms. Therefore, $\tau_{i j}>0$ implies net flow from country $j$ to $i$, while $\tau_{i j}<0$ implies net flow from country $i$ to $j$. As in the case with the production similarity index, there are 10 such additional matrixes, one each for the other 10 crops considered in this analysis. Again, rather than present all of them, we present in Table E.2 presents a summary of the results for country pairs with some of the smallest and largest yield gaps for each of the crops, reflecting larger and smaller potential for technology transfer and spillovers across the countries, respectively. Here too, the results show that the extent of the gaps between countries is different for different agricultural commodities, although South Africa tends to dominate in several of the crops, while Angola, Botswana, and Mozambique tend to lag.

Table E.2 Summary of yield gaps in crop production in SADC

\begin{tabular}{|c|c|c|c|}
\hline Crop & $\begin{array}{l}\text { Country with } \\
\text { highest yield }\end{array}$ & $\begin{array}{l}\text { Closest countries } \\
\text { (smaller yield gaps) }\end{array}$ & $\begin{array}{l}\text { Furthest countries } \\
\text { (largest yield gaps) }\end{array}$ \\
\hline Beans & South Africa & $\begin{array}{l}\text { Madagascar (1.1), Namibia (1.1), } \\
\text { Lesotho (1.3) }\end{array}$ & $\begin{array}{l}\text { Angola (4.2), Mozambique (2.5), } \\
\text { Zambia (2.5) }\end{array}$ \\
\hline Cassava & $\begin{array}{l}\text { Tanzania and } \\
\text { Malawi }\end{array}$ & Angola (1.1), DRC (1.1) & Zimbabwe (2.0), Zambia (1.5) \\
\hline Cotton & South Africa & $\begin{array}{l}\text { Namibia (1.1), Botswana (1.2), Zambia } \\
(1.3)\end{array}$ & Swaziland (4.6), DRC (3.8) \\
\hline Groundnut & South Africa & Madagascar (1.2), Botswana (1.4) & $\begin{array}{l}\text { Angola (3.7), Zambia (3.4), } \\
\text { Mozambique (3.1) }\end{array}$ \\
\hline Maize & South Africa & $\begin{array}{l}\text { Malawi (1.4), Zambia (1.8), Swaziland } \\
(1.8)\end{array}$ & $\begin{array}{l}\text { Botswana (14.8), Angola (4.5), DRC } \\
\text { (3.7) }\end{array}$ \\
\hline Millet & Tanzania & Malawi (1.2), Zambia (1.2), DRC (1.3) & $\begin{array}{l}\text { Botswana (3.5), Zimbabwe (2.9), } \\
\text { Namibia (2.8) }\end{array}$ \\
\hline Potato & Madagascar & South Africa (1.2), DRC (1.3) & Swaziland (3.0) \\
\hline Rice & Swaziland & $\begin{array}{l}\text { Zimbabwe (1.4), Madagascar (1.5), } \\
\text { South Africa (1.5) }\end{array}$ & $\begin{array}{l}\text { DRC (4.5), Angola (4.2), Mozambique } \\
\text { (3.5) }\end{array}$ \\
\hline Sorghum & South Africa & $\begin{array}{l}\text { Tanzania (3.3), Lesotho (3.8), } \\
\text { Madagascar (1.2) }\end{array}$ & $\begin{array}{l}\text { Angola (10.1), Namibia (8.1), Zimbabwe } \\
\text { (6.8) }\end{array}$ \\
\hline Sugarcane & South Africa & $\begin{array}{l}\text { Swaziland (1.1), Malawi (1.1), Tanzania } \\
(1.2)\end{array}$ & Mozambique (2.6) \\
\hline Wheat & Zimbabwe & $\begin{array}{l}\text { South Africa (1.1), Zambia (1.1), } \\
\text { Madagascar (1.3) }\end{array}$ & $\begin{array}{l}\text { Mozambique (2.2), DRC (2.2), Tanzania } \\
(2.2)\end{array}$ \\
\hline
\end{tabular}

Source: Spillover analysis results

Note: The figures in parentheses are the estimated $\tau_{i j}$, where $\mathrm{j}$ refers to the leading country. 
Table E.1 Number of full-time equivalent researchers by commodity in $\mathbf{2 0 0 8}$

\begin{tabular}{|c|c|c|c|c|c|c|c|c|}
\hline \multirow[b]{2}{*}{ Country } & \multirow[b]{2}{*}{ Total } & \multirow[b]{2}{*}{ Cassava } & \multirow[b]{2}{*}{ Groundnuts } & \multicolumn{3}{|c|}{ Percent in total } & \multirow[b]{2}{*}{ Sorghum } & \multirow[b]{2}{*}{ Wheat } \\
\hline & & & & Maize & Millet & Rice & & \\
\hline Angola & 189.0 & - & - & - & - & - & - & - \\
\hline Botswana & $107.3^{a}$ & - & - & 5.8 & 5.8 & - & 8.6 & - \\
\hline Congo, D. R. & 78.0 & - & - & 8.0 & - & - & - & - \\
\hline Lesotho & 30.7 & - & - & - & - & - & - & - \\
\hline Madagascar & 212.4 & - & - & 2.7 & - & 11.9 & - & - \\
\hline Malawi & $173.4^{\mathrm{a}}$ & 5.2 & - & 6.5 & - & - & - & - \\
\hline Mozambique & 263.3 & - & - & - & - & - & - & - \\
\hline Namibia & 70.2 & - & - & 0.5 & - & - & - & - \\
\hline South Africa & $1,156.0^{\mathrm{a}}$ & - & - & 3.8 & - & - & 4.8 & 4.8 \\
\hline Swaziland & $98.0^{\mathrm{a}}$ & - & - & - & - & - & - & - \\
\hline Tanzania & 637.5 & 3.3 & - & 4.2 & - & 4.2 & - & - \\
\hline Zambia & 212.0 & 5.6 & 2.9 & 10.7 & - & - & 7.4 & 2.8 \\
\hline Zimbabwe & $269.0^{\mathrm{a}}$ & - & - & - & - & - & - & - \\
\hline
\end{tabular}

Source: ASTI (2010).

Notes: 'A Authors' calculation applying a 1.12 percent annual average growth rate to 2001 data, where growth rate was estimated using 2001 and 2008 data for Madagascar, Namibia, Tanzania, and Zambia.

\section{Potential Spillovers in Agricultural Production}

We combined the above three dimensions to estimate the potential spillovers, ${ }_{i j j}$, for each of the 11 crops considered in this analysis according to $\delta_{i j}=R D_{i}=\omega_{i j}=\tau_{i j}$. This gives an $n \times n$ ( $n$ is number of countries in the SADC region studied) matrix of potential spillover effects, where each element of the matrix measures the effect of agricultural productivity growth in county $i$ due to agricultural R\&D outputs originating from country $j$. A critical assumption that has to be made relates to the use of $\tau_{i j}$ in terms of the direction of net flow. For a comparative analysis of the final results, we use 1.25 and 1.5 as the cutoff points, setting the value of $\tau_{i j}$ to zero when it is less than these cutoff points. This means that we assume net flows from one country to another in one direction only when the yield gap between the countries is 25 percent or 50 percent more, for the 1.25 and 1.5 cutoff points, respectively. Table 4.1 in the main text shows an example for maize using the 1.25 cutoff point. These are relative measures, so each cell or $\delta_{i j}$ measures the effect on agricultural productivity in country $i$ due to adoption of technologies originating from country $j$, relative to the productivity effect associated with adoption of country $i$ 's own technologies.

Results in the constructed matrixes suggest that the potential spillover effect on maize yield, for example, can be as high as 56 percent in the case of Angola. As an example, $\delta_{\text {ANG SAF }}=0.56$ means that the potential effect of technologies originating from South Africa on Angola's maize yield is about 56 percent compared with the effect of Angola's own technologies, other factors being the same. The column totals $^{17}$ reflect the average spillover effect on maize yield in the rest of the SADC region due to adoption of technologies originating from country $j$. The estimates suggest that maize research outputs originating from South Africa have the largest effect (average of 0.15) on yield in other countries in the region. The row totals, ${ }^{18}$ on the other hand, reflect the average spill-in effect on maize yield in the country due to adoption of maize technologies originating from other countries in the SADC region. The estimates suggest that Angola and Botswana benefit the most from technologies originating from the rest of SADC (average spill-in effect of 0.25 ), compared with the effect of their own technologies and research outputs.

\footnotetext{
${ }^{17}$ This is done by a weighted average, where the weights are the countries' shares of production in the total SADC production.

${ }^{18}$ This is done by a weighted average, where the weights are the countries' shares of researchers in the total for SADC.
} 


\section{APPENDIX F: DESCRIPTION OF THE ECONOMYWIDE MULTIMARKET MODEL FOR SADC ${ }^{19}$}

The economywide multimarket (EMM) model for the Southern Africa Development Community (SADC) is based on neoclassical microeconomic theory and includes 13 SADC member countries (excluded are the island economies of Mauritius and Seychelles due to data limitations). There are 47 agricultural and 2 nonagricultural products. Among the 47 agricultural products, ${ }^{20} 28$ are crops, including both annual crops and tree crops. Eighteen of the crops can be considered staple food crops, including cereals (6), roots and tubers (5), oilseeds and pulses (6), and plantains (1). The other 10 crops are considered high-value crops (for example, vegetables, fruits, and sugar) or export crops (such as cotton and nuts). The model also includes 11 livestock products. The livestock products are further grouped into live animals such as cattle, sheep/goats, pigs, and chickens, and processed products, such as beef, pork, milk, eggs, and skin. We also include 6 processed edible oils. Last, fishery products are included as 2 aggregated groups: freshwater fish and seawater fish. Due to data limitations, the model does not include forestry as an agricultural subsector.

The two nonagricultural sectors included in the model represent (1) a tradable industry and the services subsector and (2) a nontraded industry (for example, construction) and the domestic services subsector. This is done for each country in order to preserve an economywide perspective of cross-sector growth linkages.

\section{Supply Functions}

Consistent with most multimarket model setups, the supply function, instead of the production function, is used to capture producers' responses to market prices and growth in productivity. In the supply functions for crop production, there are two components: (1) yield functions that are used to capture supply response to own prices given farm area allocated to a particular crop and growth in yield, and (2) land allocation functions that are functions of all prices and hence are responsive to changing profitability across different crops given the total available land.

The yield function (for crops) is given by

$$
Y_{R, i, t}=\mathrm{YA} \underset{\mathrm{R}, \mathrm{i}, \mathrm{t}}{P_{R, i, t}^{\alpha_{R, i}}}
$$

where $Y_{R, i, t}$ is the yield for crop $i$ in country/region $R$ at time period $t$, and $P_{R, i, t}$ is the producer price for $i$ and can be different across countries. $\alpha_{R, i}$ is the supply elasticity of the own price. $Y A_{R, i, t}$ is the productivity shift parameter, which changes exogenously over time:

$$
\mathrm{YA}_{R, i, t+1}=\mathrm{YA}_{\mathrm{R}, \mathrm{i}, \mathrm{t}}\left(1+g_{Y_{R, i}}\right) \text {, }
$$

where $g_{Y_{R, i}}$ is the annual productivity growth rate in yield and is exogenous in the model.

The area function (for crops) is given by

$$
A_{R, i, t}=\mathrm{AA}_{\mathrm{R}, \mathrm{i}, \mathrm{t}} \prod_{j} P_{R, j, t}^{\beta_{R, j}} \text {, and } \sum_{j}^{J} \beta_{R, j}=0 \text {, }
$$

\footnotetext{
${ }^{19}$ This section was authored by Xinshen Diao.

${ }^{20}$ A full list is provided in Table B.9 in Appendix B and summarized in Table 5.1, Section 5.
} 
where $A_{R, i, t}$ is the area for crop $i$ and $P_{1}, P_{2}, \ldots P_{J}$ is the vector of producer prices for all commodities (including the two nonagricultural sectors). $\mathrm{AA}_{R, i, t}$ is the shift parameter, which captures the area expansion,

$$
\mathrm{AA}_{R, i, t+1}=\mathrm{AA}_{\mathrm{R}, \mathrm{i}, \mathrm{t}}\left(1+g_{A_{R, i}}\right)
$$

where $g_{A_{R, i}}$ is the annual area expansion rate for crop $i$, which is assumed exogenous in order to capture historical crop and country-specific trends. Given that many prices are endogenous in the model, area functions, similar to the supply functions for noncrop production, capture cross-sector linkages among crops, between crop and noncrop agriculture (such as livestock), and between agriculture and nonagriculture through the price elasticities, $\beta_{R, i}$, which are for the own- and cross-price elasticities.

Total supply of crops is given by

$$
S_{R, i, t}=\sum Y_{R, i, t} \cdot A_{R, i, t} .
$$

Supply function for noncrop sectors (livestock and nonagriculture) is given by

$$
S_{R, i, t}^{L V}=\mathrm{SA} \underset{\mathrm{R}, \mathrm{i}, \mathrm{t}}{\mathrm{LV}} \prod_{j} P_{R, j, t}^{\beta_{R, t}^{L V}} .
$$

Trends in the livestock and nonagricultural supply function are represented by

$$
\mathrm{SA}_{\mathrm{R}, \mathrm{i}, \mathrm{t}+1}^{\mathrm{LV}}=\mathrm{SA}_{\mathrm{R}, \mathrm{i}, \mathrm{t}}^{\mathrm{LV}}\left(1+g_{S_{R, i}}\right),
$$

where $g_{S_{R, i}}$ is the annual growth rate of livestock and nonagricultural productivity, and varies by country and commodity. As mentioned above, $g_{Y}, g_{A}$, and $g_{S}$ are all exogenous in the model. $\beta_{R, i}^{L V}$ is the output own- and cross-price elasticities.

\section{Own-Price and Cross-Price Supply Elasticities}

It is almost impossible to estimate supply elasticities for all agricultural commodities across 13 countries based on historical data. Thus, own-price elasticity in the supply functions is drawn from the literature and is assumed to be the same in the supply function of a similar commodity across countries. According to an intensive literature review, short-run supply response estimates reveal a diverse outcome, ranging from 0.1 to 0.4 for most commodities (cereals, root crops, pulses, and livestock). ${ }^{21}$ Based on these estimates, we chose to have a similar own-price elasticity in both yield and area functions across commodities and countries, about 0.2 for crops and 0.4 for livestock products. After that, the negative cross-price elasticities in the area (or supply) function are derived from the own-price elasticity multiplied by the value share of each commodity at the national level (with a negative sign). The condition of homogeneity of degree zero is imposed on the supply (or area) function such that, within each time period, there is no supply response if all prices change proportionally. The constraint on crop area function is also imposed to avoid a simultaneous expansion of all crop areas over a given time period due to price response. While there is similar own-price elasticity in supply functions for the same crop across

\footnotetext{
${ }^{21}$ See Appendix A in Diao et al. (2008) for more detail.
} 
countries, due to the difference in cropping patterns among the countries, the cross-price elasticities differ across countries, which results in country-different supply response to a similar change in a commodity price.

\section{Demand Functions}

The aggregate country-level demand function for each good is derived from maximizing a Stone-Geary type of utility function. The actual function used in the model is dependent on all prices and income. It is determined as follows:

$$
D C_{R, i, t}=\prod_{j} P C_{R, j, t}^{\varepsilon_{R, i, j}} G D P_{R, t}^{\varepsilon_{R, i}^{l}}
$$

where $D C_{R, I, t}$ is the demand for commodity $i$ in country $R$, and $P C_{R, j, t}$ is the consumer price for $j$ in country $R . j=1,2, \ldots, 17$ (including two aggregate nonagricultural goods). $G D P_{R, t}$ is total income (gross domestic product, or GDP) for country $R . \varepsilon_{R, i, j}$ is the price elasticity between demand for commodity $i$ and price

for commodity $j$, and $\varepsilon_{R, i}^{I}$ is income elasticity for commodity $i$.

The income elasticity is evaluated using household survey data at the sample means of all households for which such data existed in Africa, and the coefficients to calculate the elasticity are estimated from a semilog inverse function suggested by King and Byerlee (1978). The price elasticities are then derived from the linear expenditure of demand solved from maximizing the Stone-Geary utility function such that the budget constraint is satisfied for each demand function. That is,

$$
\sum_{j}^{J} \varepsilon_{R, Z, i, j}+\varepsilon_{R, Z, i}^{I}=0, \text { and } \sum_{j}^{J} s h_{R, Z, j} \cdot \varepsilon_{R, Z, j}^{I}=1,
$$

where $s h_{R, Z, i}$ is the expenditure share of commodity $i$. Income and price elasticities in the demand function are reported in Appendix A, Tables A.3 and A.4.

Due to lack of household survey data for many countries, we assume that the income elasticity for each commodity is the same across countries/regions, while price elasticities for any specific commodity vary across countries due to different consumption patterns at the country level. However, income elasticity is different for different commodities, and these variations across commodities affect the ratio of subsistence consumption over market demand for a specific commodity. Moreover, the variations in consumption patterns across countries affect the average budget share of each commodity in total expenditure. These two factors determine that for a similar change in prices or income, changes in the demand for a specific commodity are different across commodities and between countries. For a commodity with a large budget share (that is, a staple crop such as maize or cassava), both income and own-price elasticities in the demand function for this commodity are low relative to other commodities with smaller initial budget shares but higher income elasticities (such as poultry).

Additionally, for each country in SADC, we aggregate demand and household income separately into rural and urban sectors because growth rates of rural and urban populations differ in the process of urbanization. Moreover, the consumption structure and behavior also differs between the two household types. From this aggregation, future demand growth among each of the agricultural products is determined by these differences in demand structure as well as different population growth projections between the two.

\section{Exports, Imports, and Producer and Consumer Prices}

As the name of the model suggests, a multiple market structure is specified. There is perfect substitution between domestically and internationally produced commodities. Transportation and other market costs 
or barriers, however, distinguish prices for domestically traded products from those of imports and exports. Moreover, trade (either in imports or exports) is determined by the difference between national market prices and import/export parity prices (in which transportation and trade margins are taken into consideration). For example, while imported maize can perfectly substitute with domestically produced maize in consumers' demand functions, maize may still not be profitable to import if its domestic price is lower than the import parity price less transaction costs and other trade barriers. Maize imports can only occur when domestic demand for maize grows faster than domestic supply and the local market price rises significantly. A similar situation applies to exported commodities. Even though certain horticultural products are exportable, if domestic production is not competitive in international markets, due to either low productivity or high transaction costs, then exports will not be profitable. Only when domestic producer prices plus market costs are lower than the export parity price of the same product does it become profitable to export. Moreover, an initially imported commodity, for example rice, can become exportable if the domestic rice price falls to the level of the export parity price minus export margins after significantly rising rice productivity.

With all these assumptions, the producer and consumer prices in the domestic market are

$$
P C_{R, i, t}=\left(1+D m_{R, i}\right) \cdot P_{R, i, t},
$$

where $P C_{R, i, t}$ is consumer price and $P_{R, i, t}$ is the producer price in domestic market $R$ for commodity $i$; $D m_{R, i}$ is the domestic marketing margin between consumer and producer prices, and it can vary by country.

The relationship between import parity prices and consumer prices is defined as

$$
P C_{R, i, t} \leq\left(1+W m t_{R, i}\right) \cdot P W M_{R, i}, M_{i}>0 \text { if “="“, }
$$

where $W m t_{R, i}$ is the marketing margin between a country's cost/insurance/freight prices, $P W M_{R, i}$, and consumer prices, $P C_{R, i, t}$, in domestic markets for commodity $i$. When $P C_{R, i, t}$ is less than $\left(1+W m t_{R, i}\right) \cdot P W M_{R, i}, P C_{R, i, t}$ is an endogenous price determined by domestic supply and domestic demand. The equation holds only when the imports are positive. In this situation, the domestic price for commodity $i$ in country $R$ exogenously links with its border price. Thus, equation (10) is also a function for imports of $i$ in country $R$. The relationship between export parity and domestic producer prices is given by

$$
P_{R, i, t} \geq\left(1-W m t_{R, i}\right) \cdot P W E_{i}, E_{i}>0 \text { if " =", }
$$

where $P W E_{R, i}$ is export border prices. If $P_{R, i, t}$ is greater than $\left(1-W m t_{R, i}\right) \cdot P W E_{i}, P_{R, i, t}$ is an endogenous price determined by domestic supply and demand. The equation holds only when the exports are positive. Thus, equation (11) is also a function for exports of $i$ from country $R$. The combination of equations (10) and (11) indicates that for any commodity $i$ in country $R$ it is impossible to be both imported and exported during the same time period, though it is possible for an imported (exported) commodity to switch to an exported (imported) one when endogenous domestic price for $i$ in country $R$ changes significantly.

\section{Balance of Demand and Supply at the National Level}

At the national level, the balance of demand and supply is given by 


$$
S_{R, i, t}+M_{R, i, t}-E_{R, i, t}=D C_{R, i, t} .
$$

This equation in the first simulation (see below) solves for the price of commodity $i$ in country $R$ if both $M$ and $E$ are zero. Otherwise, it solves for the value of $M$ or $E$.

\section{Income (GDP) Function}

Income in the model is endogenous and determined by production revenues. Given that the model does not explicitly include inputs, producer prices are adjusted to represent value-added, and hence the aggregation of agricultural production equals agricultural GDP. For the two nonagricultural sectors, the sector-level GDP is used to represent production output with unit price. Thus, national GDP comprises agricultural GDP and nonagricultural GDP, which both are endogenous in the model

$$
G D P_{R, t}=\sum_{j} P_{R, j, t} \cdot S_{R, j, t}
$$

which represents income level in the demand function.

\section{Simulations of the EMM Model}

Two types of simulations are conducted using the EMM model for SADC. In the first scenario, we consider only baseline productivity growth based on past growth rates, together with modest land expansion. A second growth scenario considers increase in yields by crop and country calculated to results in achieving SADC targets, for example, 2 tons/ha for cereals. This is checked against and combined with current maximum achievable yields based on the spatial analysis in Appendix D and results in Figure 3.6 in the main text. The average annual growth rate, $g_{Y_{R, i}}$, is then calculated based on

achieving the targets for 2015 or maintaining current growth rates such that $\mathrm{YA}_{R, i, t+1}=\mathrm{YA}{ }_{\mathrm{R}, \mathrm{i}, \mathrm{t}}\left(1+g_{Y_{R, i}}\right)$, defined in equation (2), is augmented exogenously for the next five years, between 2009 and 2013. Land expansion is based on the historical trends of recent years, taking into account population growth, and varies across countries and crops. It is important to note that due to the price effect and supply responses to the changes in the endogenous prices, the actual growth rates in both yield and area expansion are endogenous model results and are therefore different from the initial exogenous "shocks" to output and land expansion $\left(g_{Y_{R, i}}\right.$ and $\left.g_{A_{R, i}}\right)$.

\section{Sensitivity Tests on the Supply and Demand Elasticities of the EMM Model}

In a computable general equilibrium model, due to full general equilibrium linkages, the inclusion of factor endowments, together with the assumption of imperfect substitution between domestically produced and consumed goods and between imported and exported goods, the simulation results of the model are usually not sensitive to the choice of elasticities in the production and demand equations. However, in an EMM model, as with any other simulation model with a reduced form of supply and demand functions, the simulation results are often sensitive to the choice of elasticities in the supply and demand functions. As discussed above, the supply elasticity is mainly drawn from the literature, while the income elasticity in demand is estimated using household-level data from available studies. This income elasticity, combined with expenditure shares by commodity across countries, is used to calculate price elasticities in the demand function such that the summation of these elasticities satisfies standard conditions imposed by economic theory. However, supply elasticities are often independently estimated in the literature for individual commodities and are often quite country specific. On the demand side, the income elasticity applied in our model is not estimated country by country due to data constraints. For 
these reasons, a series of sensitivity tests is conducted in order to justify the model results. The results of these sensitivity tests are available from the authors upon request.

The conclusion of the sensitivity tests is that, so long as the numbers of sectors and countries included in the model are sufficiently large, and because of the endogenous income variable, the model results are relatively less sensitive to the choice of elasticities. Moreover, the sensitivity depends critically on the switch between income elastic (income elasticity greater than 1) and income inelastic in the demand function. For example, if rice or poultry becomes an income-inelastic commodity (and both are income elastic in the current model), prices for rice and poultry can fall much more than what we reported in the paper as the model results. On the other hand, if they are still income-elastic commodities but the value of elasticities increases or decreases, the difference in terms of endogenous price changes in the model is very small. Given that demand for most agricultural products is income inelastic, we have less concern for these extreme cases (highly income elastic) that only apply to a very few commodities in Africa, such as rice, wheat, and livestock. 


\section{APPENDIX G: EVOLUTION OF REGIONAL RESEARCH AND DEVELOPMENT COOPERATION AND TECHNOLOGY TRANSFER IN SADC ${ }^{22}$}

The southern Africa region, and more specifically SADC, has a long history of regional R\&D cooperation and technology transfer beginning as far as back as the colonial era. We review this history briefly only to highlight some important lessons. ${ }^{23}$ However, much of this section will focus on a review of the experience with regional R\&D efforts after the establishment of SADC (beginning with the first Southern African Development Coordination Conference, or SADCC).

\section{The Early Years: A Brief Overview}

Beginning around the turn of the last century, some of world's foremost research on maize breeding came out of the SADC region, primarily Zimbabwe, Malawi, and Zambia, during the early 1930s and 1940s. In the first few decades of the 1900s, maize had quickly grown in importance as a food staple for millions of African miners and laborers across the region. Often it was used as an in-kind payment for labor. Consequently, between 60 and 80 percent of white settler farming areas grew maize to supply the growing African work force (Smale and Jayne 2003). Maize offered a number of advantages over the traditional cereals, millet and sorghum: It was well suited to several agroclimatic zones in the region and generated higher returns on land (for example, from bird resistance); it had a guaranteed export market in Britain, since the softer white dent varieties received a price premium; and the introduction of the hammer mill made maize milling much easier compared with sorghum and millet, which had to be dehulled (Smale and Jayne 2003).

The early maize breeding that began in earnest in the early 1930s eventually led to the first regionally developed hybrid, SR1 (south Rhodesia), in 1949. Although adopted widely in its first year (22 percent), its yields quickly became unstable with the recycling of seed (Byerlee and Eicher 1997). It was not until 1960 that Zimbabwe (then Rhodesia) released the successful SR52 variety, which improved yields by 46 percent. By 1968 this variety had spread widely to 65 percent of commercial farms in both Zimbabwe and Zambia, becoming one of the most widely adopted hybrids in the region. Aside from maize, there were also some early attempts at sorghum and millet breeding under colonialism. The interest in sorghum research began in eastern Africa, and between 1930 and 1950, some of the first regional collaboration was initiated between Uganda and Tanzania. The collaboration between the two colonies paid off in 1956/57 with the release of a bird-resistant variety by a breeding station in Tanzania. In the southern Africa region, similar advances occurred for varieties developed in South Africa and Botswana before World War II, including Striga- and drought-tolerant high-yield varieties. These would eventually spill over into Zimbabwe and Zambia (Bantilan et al. 2004).

As countries gained independence, however, agricultural R\&D priorities would shift away from mostly supporting "white" commercial or plantation agriculture to supporting smallholder African agriculture (Pardey, Roseboom, and Beintema 1997). For example, a second wave of innovation came from Zimbabwe in coming up with improved maize varieties that were more suitable for smallholder farmers. More specifically, short-duration varieties based on R200, 201, and 215 were developed to tolerate the lower rainfall levels and sandy soils of the marginal areas to which smallholder farmers had been relegated during colonial rule. The success of these varieties would quickly spread to neighboring countries. Similarly, maize production in Zambia was also supported by a number of locally developed hybrids, including double and three-way hybrids that benefited from international breeding materials crossed into local varieties (Smale and Jayne 2003).

\footnotetext{
22 This section was authored by Adam Kennedy, Michael Johnson, and Pius Chilonda.

${ }^{23}$ For interested readers, there is extensive literature on the history of agricultural R\&D systems in the SADC region. Some useful references include the work of Rukuni et al (2006) for Zimbabwe, Byerlee and Eicher (1997), Bantilan et al. (2004), Smale and Jayne (2003), and Blackie (1989).
} 
The inertia that began in the 1970s and 1980s with significant donor support would slow down dramatically with the onset of structural adjustment programs. With a significantly scaled-down public sector, few countries could afford expensive national research and extension targeted at the majoritysmallholder population, many in remote areas with poor infrastructure. With a limited financial base and an increasingly debt-laden government, overextended institutions were forced to scale down spending on R\&D. Donors also became uneasy with extension services, which had become ineffective after doubling or tripling in size in some countries (Eicher 1999, 2003). Eventually, the lack of confidence would steer donor support toward public-private R\&D partnerships while national governments shifted investments to universities.

It was within such an environment that the first SADCC would come into being in the early 1980s - at that time mostly representing the Frontline States opposing South Africa's apartheid regime. This was a time when member countries were either transitioning toward R\&D models that were more responsive to African smallholder farmers (for example, Zambia and Zimbabwe), having to build from scratch after years of dependence on neighboring countries (Botswana's dependence on South Africa $\mathrm{R} \& \mathrm{D}$ institutions), or engaged in conflict (Angola and Mozambique). In the climate of declining budgets for research, an SADCC regional strategy for improving R\&D was given strong donor support in order to address growing regional poverty and food security concerns. The strategy stressed crop improvement as a primary means of achieving this strategy, focusing on food staples that had a wide appeal across multiple AEZs. The strategy was also designed to draw on the strengths of NARS to help implement programs that had development implications for the region as a whole or to generate technologies that could be transferred (with little modification) to other parts of the region.

\section{The Establishment of SACCAR}

In order to help coordinate agricultural $R \& D$ and training activities across member countries, SADC established the Southern Africa Center for Cooperation in Agricultural Research and Training (SACCAR) in 1983. SACCAR was mandated to coordinate agricultural and natural resources research and training activities, and to promote cooperation between member states.

The primary focal point of its activities was the NARS, with which it tried to build the capacity to plan, manage, monitor, and evaluate research projects that could improve regional productivity (Spurling et al. 1992). SACCAR was not engaged in agricultural research per se but rather was a coordination body responsible for implementing a number of agricultural $R \& D$ projects throughout the region (Table G.1). Most of these programs were a collaboration of an outside executing partner organization such as a member of the CGIAR or a donor that held specific technical capacities (the German Agency for Technical Cooperation, the United Nations World Food Programme). Some of these programs had a tremendous amount of success that had wide impacts on the region (Maredia, Rohrbach, and Mgonja 2002). 
Table G.1 List of regional programs/projects/networks coordinated by SACCAR

\begin{tabular}{|c|c|c|c|c|}
\hline Item/network/program/project & $\begin{array}{l}\text { Executing } \\
\text { agency }\end{array}$ & $\begin{array}{l}\text { Inception } \\
\text { of project }\end{array}$ & $\begin{array}{l}\text { End of } \\
\text { project }\end{array}$ & Location \\
\hline $\begin{array}{l}\text { Land \& Water Management Research } \\
\text { Programme }\end{array}$ & SACCAR & 1988 & 2004 & SACCAR \\
\hline Sorghum \& Millet Improvement Program & ICRISAT & 1984 & 2003 & Zimbabwe \\
\hline $\begin{array}{l}\text { Grain Legume Improvement Program } \\
\text { (a) Bean }\end{array}$ & NARS, CIP & 1986 & 2002 & Malawi, Tanzania \\
\hline (b) Groundnut Improvement Program & ICRISAT & 1986 & 1999 & Malawi \\
\hline Training in Research Management & $\begin{array}{l}\text { SACCAR, } \\
\text { ISNAR, ESAMI }\end{array}$ & 1988 & 1996 & Tanzania \\
\hline Agroforestry Research Program & ICRAF & 1988 & 2001 & Malawi \\
\hline SADC Plant Genetic Resources Centre & $\begin{array}{l}\text { SACCAR, Nordic } \\
\text { Gene Bank }\end{array}$ & 1989 & 2008 & Zambia \\
\hline Maize \& Wheat Improvement Network & CIMMYT & 1994 & 1999 & Zimbabwe \\
\hline $\begin{array}{l}\text { Strengthening Faculties of Agriculture, } \\
\text { Forestry \& Veterinary Medicine }\end{array}$ & $\begin{array}{l}\text { Universities, } \\
\text { GTZ, } \\
\text { SACCAR }\end{array}$ & 1987 & 2002 & $\begin{array}{l}\text { Botswana, Malawi, } \\
\text { South Africa, } \\
\text { Tanzania, Zambia, } \\
\text { Zimbabwe }\end{array}$ \\
\hline $\begin{array}{l}\text { Regional Vegetable Research \& } \\
\text { Development Network }\end{array}$ & AVRDC & 1994 & 2001 & Tanzania \\
\hline $\begin{array}{l}\text { Southern African Root and Tuber Crops } \\
\text { Research Network }\end{array}$ & IITA & 1994 & 2004 & Malawi \\
\hline $\begin{array}{l}\text { Biosystematics Network for Southern } \\
\text { Africa (SAFRINET) }\end{array}$ & $\begin{array}{l}\text { SADC Bionet } \\
\text { International }\end{array}$ & 1996 & 1999 & South Africa \\
\hline SADC/USAID/UF Heart Water Project & $\begin{array}{l}\text { University of } \\
\text { Florida }\end{array}$ & 1997 & 1999 & Zimbabwe \\
\hline $\begin{array}{l}\text { SADC Animal Agriculture Research } \\
\text { Network }\end{array}$ & $\begin{array}{l}\text { ILRI } \\
\text { SACCAR }\end{array}$ & 1999 & & SACCAR \\
\hline
\end{tabular}

Source: Authors' compilation from the literature.

Note: $\quad$ SACCAR $=$ Southern Africa Center for Cooperation in Agricultural Research and Training; ICRISAT = International Crops Research Institute for the Semi-arid Tropics; NARS = national agricultural research systems; CIP = International Potato Center; ISNAR = International Service for National Agricultural Research; ESAMI = Eastern and Southern African Management Institute; ICRAF = World Agroforestry Centre; CIMMYT = International Maize and Wheat Improvement Center; GTZ = German Agency for Technical Cooperation; AVRDC $=$ World Vegetable Center; IITA $=$ International Institute of Tropical Agriculture; SADC = Southern Africa Development Community; USAID = United States Agency for International Development; UF = University of Florida; ILRI = International Livestock Research Institute.

The Sorghum and Millet Improvement Program, created to address the regional priority to support agriculture in the semiarid areas as part of the Lusaka Declaration, was one of the first and most successful of the SACCAR programs, emerging as the model for the region (Anandajayasekeram et al. 1995). Initially, the regional program took steps to identify a number of research stations that represented the different AEZs of each country. These stations were to be used as testing grounds for newly developed lines because varieties were not readily transferable between AEZs, which represented different disease environments that were not easily replicable elsewhere. Testing potential breeds for release is one of the most costly and time-consuming steps of the research cycle because genetic lines are produced in high numbers but the success rate of these varieties for mass production has been generally low. Initiating regional testing at a number of stations allowed the costs to be spread more widely and thereby reduced, while regional centers were able to identify problems and ecological situations that were unique to each area (Kiflewahid, George, and Lembuya 1989). 
Of the varieties of sorghum and millet released by national governments between 1985 and 2001 in southern Africa, nearly three-quarters were derived from germplasm developed by the International Crops Research Institute for the Semi-arid Tropics (ICRISAT) as a result of the Sorghum and Millet Improvement Program. Varieties generated by the program were released in several countries and have been estimated to cover nearly one-quarter of the total area sown with improved varieties of these crops in the region (Mgonja et al. 2004).

Work with Centro Internacional de Agricultura Tropical (International Center for Tropical Agriculture, or CIAT) through the Southern Africa Bean Research Network (SABRN) program operated in a similar manner, with SABRN maintaining stocks of germplasm for distribution to other research centers in the regional network (CIAT 2004). Many of the regional centers in the network lack the capacity or funding to undertake independent research but are able to screen varieties for release in that AEZ. While much of the germplasm has made its way into locally important varieties, the release of A286 has reached eight countries in eastern and southern Africa while A-197 and CAL-143 have each been released in three.

The Southern African Root and Tuber Crops Research Network (SARRNET) was one of the leaders of cassava research in the region. Under the coordination of SARRNET, cassava varieties released in the 1990s were able to double yields while reducing bulking times by 6-18 months. Likewise, other varieties improved resistance to pests such as cassava mosaic virus and cassava mealybug, which reduced the risk of planting cassava. With identical inputs of labor and land, farmers were able to double their production. For subsistence producers this outcome eliminated food security threats, while those producing for sale were essentially able to double their income (Nweke and Haggblade 2010).

By working at a regional level and utilizing the strengths of each of the national breeding institutions, the SACCAR portfolio of projects was able to make progress in improving productivity at a time of declining investment in national breeding programs. Spillovers between institutions were evident, with as many as eight countries in the region adopting a single variety of sorghum or beans (Mgonja et al. 2004).

In the mid-1990s, SACCAR also successfully completed an R\&D priority-setting exercise for the agriculture, forestry, and fisheries sectors of southern Africa by utilizing a scoring method based on agricultural-sector data and country-level consultations with key stakeholders (Munyinda et al. 1995). These analyses set priorities at two levels, first at the commodity level and then according to research themes within commodities. ${ }^{24}$ More recent work by Anandajayasekeram et al. (2007) analyzed the impact of 15 commodity programs coordinated by SACCAR and gave insights into their rates of return on investments (Table G.2). In the review, studies were chosen to represent a wide range of commodities as well as agroecological conditions. In all cases the assessment was of the successes and failures of the commodity program itself rather than a specific project or technology. Table G.2 presents the rates of return for these studies, which ranged from 11 to 59 percent. Although the research programs may not be randomly selected, the study includes a broad cross-section of the major types of R\&D programs, from those that were criticized to those considered highly successful. Based on these assessments it can therefore be seen that the returns on investments in $\mathrm{R} \& \mathrm{D}$ for southern Africa are similar to those found elsewhere, with the programs having a high payoff.

\footnotetext{
${ }^{24}$ We have not been able to obtain a copy of this report.
} 
Table G.2 Review of economic rates of return on research and development investments

\begin{tabular}{|c|c|c|c|c|}
\hline Country & Commodity & Time period & Rate of return (\%) & References \\
\hline \multirow[t]{2}{*}{ Namibia } & Millet & 1988-1999 & 11 & Anandajayasekeram et al. (1995) \\
\hline & Maize & $1965-1994$ & $19-23$ & Moshi et al. (1997) \\
\hline \multirow{2}{*}{ Tanzania } & Livestock research & $1966-1995$ & 29-37 & Kaliba (1995) \\
\hline & $\begin{array}{l}\text { Ag. research and } \\
\text { extension }\end{array}$ & $1971-1992$ & 33.2 & Isinika (1997) \\
\hline \multirow[t]{2}{*}{ Zambia } & Sorghum & 1983-2005 & $12-25$ & Chisi et al. (1997) \\
\hline & Cotton & $1970-1995$ & $45-50$ & Mudhara et al. (1995) \\
\hline \multirow{4}{*}{ Zimbabwe } & Groundnuts & $1966-2000$ & 59 & Mazhangara et al. (1997) \\
\hline & Sunflowers & $1976-2000$ & $20-23$ & Murata et al. (1997) \\
\hline & Sorghum & $1980-1999$ & 22 & Anandajayasekeram et al. (1995) \\
\hline & Livestock research & $1970-1996$ & $5-22$ & Mokoena (1998) \\
\hline South Africa & $\begin{array}{l}\text { Sorghum and Millet } \\
\text { Improvement } \\
\text { Program }\end{array}$ & $1983-1993$ & $5-14$ & Anandajayasekeram et al. (1995) \\
\hline
\end{tabular}

Source: Cited in Anandajayasekeram et al. (2007) and table adapted from the same.

The impacts of these programs also go beyond simple economic returns. There is ample evidence from these studies to suggest that $R \& D$ investments have contributed to institutional innovations in the form of methods and tools development, capacity strengthening, and the creation of institutional linkages. In many cases, therefore, these programs facilitated the development of human capital as well as physical infrastructure. In addition, the programs have had a substantial sociocultural impact, having generated additional income for smallholder farmers, which they in turn are able to use to purchase groceries or other basic needs. Oftentimes these benefits are accrued by women-headed households or other marginalized groups. Finally, the positive environmental impacts of these technologies cannot be neglected. In some cases technology transfer resulted in improved soil and erosion management, while others reduced the application rates of inputs such as fertilizers, pesticides, and labor.

In 1998, an SADC Council of Ministers decision transformed SACCAR from a commission of SADC to a sector coordinating unit, to be administered by the government of Botswana. Unfortunately, the transformation process resulted in no clear funding mechanisms to ensure the sustainability of SACCAR, leading to its demise by 2001. The Food, Agriculture and Natural Resources (FANR) Directorate of SADC had to assume SACCAR's role - effectively making the FANR Directorate the only subregional organization on regional $\mathrm{R} \& \mathrm{D}$ in Africa that has remained part of a political entity (that is, SADC).

The successes of past regional programs under SACCAR, nevertheless, clearly stress the value of scaling up regional investments in agriculture - especially those sectors and commodities that have a greater potential to meet the regional food security and poverty reduction goals of SADC. The move toward establishing the Centre for Agricultural Research and Development for Southern Africa (CARDESA) by SADC is generating renewed efforts to fill this critical gap. In the process, several reviews and consultations have sought to define more explicitly the key priorities needed in the context of the emerging multinational commitments and regional agreements. We review these next.

\section{Developing a Regional Agricultural Strategy}

In March 2001, SADC heads of state and government met in Windhoek, Namibia, and approved the restructuring of the SADC Secretariat. The key features of this reform included grouping the 21 development sectors into clusters under four directorates and establishing SADC national committees to coordinate their respective individual member-state interests relating to SADC. The reorganization aimed to implement a more cogent and coordinated strategy with a view to improving the efficiency and effectiveness of SADC policies and programs. 
This restructuring came at a critical time as leaders around the world solidified their commitment to ending chronic poverty and disadvantage by formulating the Millennium Development Goals (MDGs). The leaders of African states, through the African Union, likewise embraced this challenge and launched the African-led and -owned New Partnership for Africa's Development (NEPAD), which took a multidimensional approach to economic, political, social, and cultural development. Regional economic communities such as SADC are very much at the heart of implementing the African Agenda and advancing the broad-based growth strategies necessary to meet the MDGs.

The SADC Regional Indicative Strategic Development Plan (RISDP) was created in line with this thinking and was meant to complement the restructuring of SADC, deepen regional integration, and provide a clear direction for SADC policies and programs to achieve its long-term goals of meeting the MDG targets by 2015. This focus had important implications for agricultural R\&D and for the food security sector more broadly, both of which were now integrated and managed under the SADC FANR Development Unit. While the RISDP did include targets that focused exclusively on achieving food security and poverty reduction objectives, as a whole its purpose was to foster broad-based growth and to enhance regional integration.

Following the creation of RISDP, heads of state again met in Dar es Salaam, Tanzania, to further recognize agriculture as a key sector of the regional economy and to elaborate the priority areas of investment to improve this key subsector. Emerging from this meeting was what has become known as the Dar es Salaam Declaration, which recognizes agriculture's importance in the region, its contribution to national economies, and the implications that its accelerated development would have on poverty reduction and food security. The document further sets both short-term and long-term objectives in key subsectors such as agro-industrial development; agroprocessing; and crop, livestock, and fisheries production.

Both documents recognize the importance of agriculture in the development of the region and in achieving food security. The RISDP in particular picks out key subsectors that have the largest potential to increase production, productivity, and profitability of crops, livestock, and fisheries. Realizing the contribution of cereals to the diet of the region, the RISDP targets a yield increase from $1,392 \mathrm{~kg} / \mathrm{ha}$ to $2,000 \mathrm{~kg} / \mathrm{ha}$ by 2015 . In order to realize this goal, the RISDP provides regional targets for the increased use of key modern technologies:

- Increasing regional fertilizer usage from its present $44.6 \mathrm{~kg} / \mathrm{ha}$ to $65 \mathrm{~kg} / \mathrm{ha}$ by 2015

- Doubling the land under irrigation from 3.5 percent to 7 percent by 2015

- Doubling the adoption rates of improved seeds and sustainable farming technologies by 2015

With a high proportion of the region's population living in rural areas and dependent on agriculture for both income and sustenance, targeting productivity of cereals, the main staple of the region, is justified. The regions of southern Africa suffer a chronic food deficit, exacerbated by stagnant or even declining levels of agricultural productivity. This is despite the fact that all low-income southern African countries have relatively favorable agricultural potential and conditions. A recovery of maize productivity to even to its historical highs would thus provide these countries with more growth opportunities in agriculture (Nin Pratt and Diao 2006).

Likewise, the potential of the livestock sector to ensure food security and reduce poverty is also enormous, but improvements in the productivity of livestock and greater access to markets for livestock and livestock commodities are essential for exploiting this potential (FARA 2006). With the exception of Mauritius, Malawi, Mozambique, and South Africa, the region's livestock sector has contracted in recent years and many semiarid countries in particular have suffered large declines. Livestock production in the SADC region as a whole has experienced a growth rate of only 2 percent. In order to reverse this trend the RISDP places a high priority on the livestock sector and targets increasing livestock production by at least 4 percent annually. 
The implementation of the agricultural agenda of RISDP and the Dar es Salaam Declaration is manifested through a series of projects organized under the SADC FANR Development Unit. Two projects in particular are key to understanding $\mathrm{R} \& \mathrm{D}$ priorities for the region and raising agricultural productivity.

The SADC Multi-country Agricultural Productivity Programme (SADC MAPP) is intended to translate Pillar 4 of the Comprehensive African Agricultural Development Programme (CAADP) developed by NEPAD into a program of activities in agricultural research and technology generation, dissemination, and adoption. It is designed as a comprehensive 15-year program of change, arranged around three 5-year phases. The overall program goal is to bring about pluralistic agricultural technology generation and dissemination, together with strengthening the linkages among agricultural institutions in the SADC region in order to accelerate smallholder productivity to meet the RISDP targets. The program is expected to create accessible agricultural technologies that will spur growth, reduce poverty, and increase incomes, especially among the rural poor, in line with the goals of the RISDP and the Dar es Salaam Declaration.

The Implementation and Coordination of Agricultural Research and Training (ICART) program was a five-year regional project that ran from January 2006 to December 2010. This regional research program was targeted at enabling NARS in the 14 SADC countries to enhance their national efforts by identifying common regional researchable constraints and opportunities in agriculture. The program also targeted improvement of the capacity of the NARS to manage regional initiatives, thereby making a major contribution to the long-term sustainability of regional research.

In both the SADC MAPP and ICART projects, consultations with national stakeholders took place in order to develop priorities for regional action. The information collected by the ICART project provided a unique and complete picture of the status of national public and private R\&D institutions by identifying their research focus, the policies that govern research in the country, and the linkages that these institutions had nationally, regionally, and internationally. The SADC MAPP country reports offer a separate and distinct characterization of the NARS institutions by profiling them more widely to reveal their fundamental constraints to technology generation, dissemination, and adoption. In addition, the SADC MAPP country reports provide a unique summary of technologies developed in each country that are considered best bets, that is, successes that hold the most potential to be scaled up and replicated elsewhere in the region.

Between them, these documents provide useful profiles of R\&D systems at the national level by consolidating information about institutions' capacity and mandate, national agricultural policy frameworks, and successful innovations. Finally, to obtain more recent and additional information, local consultants hired for the current study prepared country reports summarizing the status of agriculture and agricultural research systems in their respective countries, including for example, institutional linkages at regional and international level, technology flows, and key constraints and challenges facing the systems. From the content of these documents we synthesized the relevant policy-related constraints to agricultural $\mathrm{R} \& \mathrm{D}$ and, from this, to generalize the primary policy-level actions necessary to kick-start a more effective regional R\&D system.

To accomplish this, we reviewed the key institutions and their primary functions within each country's national R\&D system, including any explicit linkages with others at the national, regional, or international level. We also examined the best bets summarized in the SADC MAPP country reports documents by organizing innovations into categories of breeding, agronomy, postharvest, and crosscutting projects. This provided us some idea of the strength of the research focus as well as of regional success stories. Constraints were also summarized and categorized as being institutional or related to dissemination or to adoption. By categorizing both best bets and constraints, we were more easily able to make comparisons across countries and generalizations about the region. Naturally, categories were not always distinct since often constraints such as funding were viewed as impinging on technology generation and extension (and thus dissemination), which in turn affected adoption. 
The following sections will summarize the salient points that emerged from the analysis of the various country reports. For countries such as Angola, DRC, and South Africa, English versions of either or both documents were not available. In such cases we referred to the ICART regional synthesis, Situation Analysis of Agricultural Research and Training in the SADC Region (ICART 2008), which provided a short summary of the R\&D institutions within each country.

\section{Institutional Capacity Challenges for Regional R\&D Cooperation}

The ICART project summary analysis of the capacity and priorities of the NARS shows that there is significant variation in the strength of the national institutions in terms of their capacity, mandate, and linkages (ICART 2008). Specifically, the review points out the following:

- Six of the 14 countries within the SADC lack well-defined agricultural research policies that highlight priorities for the NARS. In some cases, where they do exist, the policy documents are weak, lacking well-focused objectives and strategies.

- Inter-institutional coordination in all countries is very weak. Where linkages do exist, coordination is ineffective or poorly focused. In the cases of Malawi and South Africa, coordinating bodies focus on technology release and funding, respectively, but there remains a lack of harmonization in research polices.

- In only 2 of the countries (Lesotho and Tanzania) is there a concerted effort to match $R \& D$ priorities with the needs of the smallholder farmer. In the remaining 12 countries the priorities of the NARS are focused on other groups within the agriculture sector, often on those in the commercial agriculture sector.

- In only South Africa and Mauritius are there a sufficient number of qualified agricultural research scientists. In all other countries, the number of scientists serving the country is too low to provide the critical mass to initiate and maintain the research agenda.

Our review of the various country reports largely agrees with the ICART team's assessment. We find that inter-institutional coordination is largely lacking. Many countries have a number of institutions, be it universities, NARS, or the private sector, working on similar issues with little formal communication between the groups. This situation introduces inefficiencies and is a waste of resources. There are, however, some systems of governance within the NARS of Tanzania that have the potential to be models for the greater region.

As has been discussed earlier in this review, the spatial heterogeneity of southern Africa presents challenges to the NARS often by limiting their ability to harmonize research priorities as well as placing large demands on research budgets. Tanzania's NARS addresses this heterogeneity by operating eight different research institutions, one in each of the country's distinct AEZs. In order that research efforts be distinct and effective, the agricultural research institutes and livestock research institutes are coordinated first through the Zonal Research and Technical Committee (ZRTC). To better ensure that research is demand driven, stakeholder involvement is incorporated at the zonal level through participation of farmers, traders, policymakers, and researchers in ZRTC's research plan formulation.

Coordination of the NARS more broadly is loosely facilitated through the Tanzania Commission for Science and Technology $(\mathrm{COSTECH})$, a parastatal organization under the Ministry of Higher Education, Science and Technology. COSTECH has established a number of R\&D advisory committees, of which one is the R\&D Advisory Committee on Agriculture and Livestock (R\&D ACAL). The R\&D ACAL draws members from the Department of Research and Training; the Directorate of Research, Training and Extension; the private sector; nongovernmental organizations; and universities, and is guided by terms of reference that include providing recommendations on policy formation, interinstitutional cooperation, and priority setting. Although COSTECH's recommendations are not binding and the commission is unable to effectively coordinate all agricultural research in the NARS, the framework under which it operates provides a unique example in the region. 
Inter-institutional coordination is an effective way to build research linkages within national R\&D systems. However, for many countries in the southern African region, inter-institutional coordination is lacking and linkages in domestic research have usually been on an ad hoc basis and lacked formal recognition. For example, within Malawi the National Research Council, currently in the Ministry of Education, Science and Technology, is mandated to coordinate all research in the country. However, due to a number of constraints, including inadequate financial and human resources and weak linkages with other institutions, it is not effective in terms of management (ICART, 2008). Likewise, the Ministry of Agriculture, Water and Forestry of Namibia has the mandate to coordinate agricultural research and training. However, for purposes of specialization, the Directorate of Engineering and Extension Services, the Directorate of Veterinary Services, the Directorate of Planning, and the Directorate of Forestry all provide research and training activities, creating poor coordination. These two examples are representative of the region, where research institutions and ministries are made autonomous for purposes of specialization, yet their mandates overlap and research is not coordinated and thus duplicated. In other instances a coordination authority is present but its performance is poor. While Tanzania provides a good example of coordinated research that is demand driven and targeted at the country's various AEZs, it is still plagued by the same deficiencies that hamper coordination efforts in the other regions, making performance suboptimal and inefficient.

While inter-institutional linkages are not well formalized and coordination can be poor, regional and international linkages are often prominent and effective, as represented in the reports that we viewed. In nearly all of the reports, past linkages with the SADC regional R\&D coordination body SACCAR figured prominently. While SACCAR has since dissolved, some of the programs that existed in its lifetime have persisted. Both SADC's regional programs on sorghum and millet (the International Sorghum and Millet Collaborative Research Support Program, or INTSORMIL CRSP) and on roots and tubers (SARRNET) were frequently mentioned as being key partners with NARS and were important in the development and dissemination of new breeds. Likewise, regional networks have contributed to initiating spillovers to other member states, such as those with mosaic virus-resistant cassava varieties in the eastern states and participatory breeding practices throughout the whole of SADC.

Strong linkages with international organizations have emerged in part because of their active involvement with SADC's regional work but also independently through projects undertaken directly with member states. For instance, the International Maize and Wheat Improvement Center (CIMMYT) has a regional breeding center in Zimbabwe that works closely with the NARS of Tanzania, Mozambique, Malawi, Lesotho, and others. The International Rice Research Institute (IRRI), the CGIAR center for rice, works directly with the Institut National pour l'Etude et la Recherche Agronomiques (INERA), the primary NARS in the DRC, and the National Center for Applied Research on Rural Development (FOFIFA by its local acronym) in Madagascar. Other countries where rice is prominent have also sought to establish linkages with IRRI and the West Africa Rice Development Association. Other CGIAR centers such as CIP, CIAT, and the World Agroforestry Centre (ICRAF) are active in the region but to a lesser extent by concentrating their efforts on only a few national programs rather than working regionally. Through international partnerships, $R \& D$ of agricultural technologies has been enhanced and productive in terms of both technological innovation and knowledge sharing (methodologies, approaches, information systems, and practices).

\section{Identifying Best-Bet Technologies for Future Regional Cooperation}

In terms of breeding research, work on the prominent cereals in the region (maize, sorghum, and millet) has been very effective. Modern high-yielding varieties of maize have been developed that have Striga resistance, stem borer resistance, and drought tolerance. Tanzania, Mozambique, and Malawi have been particularly effective at developing varieties with these traits that are suitable to different AEZs and disease environments. Additionally, many are open-pollinated varieties, which are preferred by smallholders because the seeds can be recycled for multiple years. For countries with large areas that get little rainfall, such as Namibia, Botswana, and Zimbabwe, sorghum research on bird resistance, drought 
tolerance, and suitability for mechanization has been successfully undertaken. Within the legume best bets, most work has focused on soybean production, most likely for animal feed, but some research has been conducted on pigeon peas in Tanzania that improves the crop's ability to be intercropped with others. Angola has been particularly successful in breeding high-yielding vegetable crops that have high seed production for commercial markets.

Livestock work did not feature prominently in the successes named by the reports that we viewed. Namibia noted the successful breeding of four varieties of sheep and goats that were well suited for the country's dry climate and still had good mothering. Tanzania has also had some success in breeding dualpurpose (meat and milk) Mpwapwa cattle that produce high volumes of milk. Botswana's successful research on artificial insemination could be a model for the region and improve the success and rate at which improved livestock varieties spread. No technologies related to poultry breeding were mentioned, but work on maintaining animal health and controlling the spread of disease was.

Agronomic technologies to improve the sustainability and productivity of crops have been developed by nearly every country. Several types of low-input irrigation were mentioned throughout the region, varying from types of gray-water use to methods of subsurface micro-irrigation in Zimbabwe. The treadle pump, a simple manually operated suction and push pump designed to raise water from shallow depths, has been successfully used in small communities in Zimbabwe. By using the low-maintenance pump, recipients were able to increase household irrigated areas by 50 percent, leading to increased productivity and incomes.

Zimbabwe is also one of the primary proponents of reduced- and zero-tillage farming in the region, which holds a lot of promise. By minimizing tillage and directly seeding into the ground, farmers have been able to save money on fuel, reduce soil runoff and erosion, reduce planting times to improve crop timing to coincide with rains, and maintain overall soil health. While some of the technologies for zero-tillage farming may require a large up-front capital investment, Zambia appears to be leading the way with technologies catering to the smallholder farmer, such as jab planters, direct seeders, and permanent planting holes. As reported, these technologies have been adopted in Malawi, Namibia, and the DRC with some like-minded technology generation in Zimbabwe in the form of animal-drawn weed rippers and wipers.

Simple technologies to increase on-farm productivity through better planting procedures are also well documented throughout the region. Greater use of leguminous species, which replenish nitrogen in the soil, was mentioned by several countries through either improved fallows, improved systems of intercropping, or crop rotations. These low-cost production systems are simple to implement and require only training, with little investment on the part of the farmer.

Postharvest technologies have been developed for a number of different crops. Angola, Mozambique, and Malawi all indicated the development of a processor for cassava. Namibia, Malawi, and Zimbabwe have all contributed to the development of oil extractors and presses. Juice extractors have also been developed by Malawi and Namibia. There was little mention of improved storage facilities, with the exception of Lesotho and Zambia. This lack is of concern for the region, since postharvest losses can in some cases amount to up to 30 percent of an annual harvest.

\section{Addressing Constraints on R\&D, Technology Adoption, and Diffusion}

It is clear that the region has had a number of successes in agricultural innovation in the breeding of both crops and livestock and has developed a number of new agronomic approaches to preserving soil health and creating more sustainable farming systems. In most countries, research has become more demand driven through participatory breeding and extension, and the best practices of model (exemplary) farmers are being shared at a much larger scale.

But constraints remain that limit the effectiveness of national $R \& D$ systems, as is evidenced by the country reports that we have viewed. Human resource capacity was perceived to be a problem in the NARS by 11 out of 14 countries surveyed. Some postconflict nations such as DRC lost much of their senior staff to attrition during the war and now must rely on junior staff to develop and manage research 
programs. Other countries such as Lesotho struggle to retain staff and have high attrition rates because pay is uncompetitive, while countries such as Mauritius stated that they are forced to overburden staff with multiple tasks because staff numbers are insufficient. In nearly every country, the level of training and capacity of staff is insufficient to ensure that research is properly managed.

Infrastructure also constrains the proper functioning of the NARS in two ways. First, dilapidated labs and research facilities inhibit the ability of researchers to work effectively in several countries. Malawi, Tanzania, and Namibia reported the overall poor condition of agricultural research institutions, citing the need for resources such as technological equipment, laboratories, and greenhouses. Others, such as Botswana, Zimbabwe, and Zambia, as well as postconflict DRC, face major road and transportation challenges, which reduce the mobility of extension agents and thus limit their ability to interact with smallholder farmers.

The inability to work directly with farmers hampers the suitability and adoption of technologies. Six countries in the region reported that dialogue between farmers and extension agents was limited. In such cases the national research agenda becomes delinked to farmer needs and technologies become less suitable. Technology generation therefore can be said to be top-down rather than bottom-up in many countries. Much of the region has begun to reverse this trend by implementing farmer-centered research approaches that not only address the physical environment but are better targeted toward the socioeconomic environment of the farmer.

Funding, then, seems to be an underlying constraint in all countries. A lack of funding has limited countries' ability to maintain research facilities, train and retain senior staff, support extension agents, and scale up successful projects. Mozambique, a country that has struggled in the last decade to develop and implement a successful NARS, predicts that it will require a quadrupling of annual investments in agricultural R\&D in the coming years to meet the country's needs. Meeting the Maputo Declaration commitments of 10 percent of GDP to agricultural investments will go a long way toward overcoming these challenges.

\section{Looking Forward: The SADC MAPP}

The constraints outlined above limit the effectiveness of the NARS and further strengthen the case for a reappraisal of the way that $R \& D$ is currently implemented in the region. The SADC MAPP is being undertaken to do just that by taking into account the productivity targets set by regional leaders in the RISDP, the broad priorities for the agriculture sector outlined in the Dar es Salaam Declaration, and the potential synergies that can be achieved regionally by utilizing comparative advantages in agricultural $\mathrm{R} \& \mathrm{D}$. The work of SADC MAPP is organized around a set of priority thematic areas that form the basis for achieving progress on improving agricultural productivity and addressing the above-identified constraints of southern African NARS. They are as follows (FANR Directorate 2008):

- Enabling farmer empowerment and market access through capacity building, sharing best practices through regional exchange visits, and conducting studies to analyze the constraints and opportunities faced by farmers

- Improving research and technology generation by promoting partnerships and networks, and by funding regional research programs

- Supporting farmer-led advisory services and innovation systems by facilitating regional forums to encourage exchange of best practices and promoting and scaling up best-bet technologies

- Investing in education, training, and learning systems by supporting initiatives to identify good practices in curriculum development and through regional education initiatives that are supported with scholarship opportunities

- Fostering knowledge, information, and communication sharing by adapting private-sector experiences in information and communications technology usage, drawing on international expertise, and improving capacity in data recording and analysis 
- Fostering institutional development and capacity building by creating a subregional organization to coordinate regional activities

In selecting these priority areas, SADC MAPP intends to build on the strengths of SACCAR's successes in raising productivity while taking an updated (modern) approach to facilitating the exchange of knowledge and practices. However, since the phasing out of SACCAR as a sector coordinating unit in 2001, it has not been possible to mobilize adequate human and financial resources for R\&D functions to meet the current and growing needs of the SADC region. Consequently, regional productivity has continued to decline and development opportunities have been missed.

Under the SADC MAPP process, stakeholders in the SADC region have since chosen to establish a visible, dedicated, and effective subregional organization, (CCARDESA), which would be adequately staffed and funded to coordinate regional R\&D programs, as has been successfully done in East Africa by ASARECA and in West Africa by the West and Central African Council for Agricultural Research and Development. This entity, proposed as CARDESA, will strengthen the existing collaboration of diverse stakeholders within SADC member states and between SADC and other regional and international organizations. According to SADC MAPP documents, the entity will essentially serve as an institution focusing on coordination of a long-term $R \& D$ program of the region and as a vehicle for regional cooperation, working through regional and national agricultural R\&D institutions. 


\section{REFERENCES}

Alene, A. D., and O. Coulibaly. 2009. "The Impact of Agricultural Research on Productivity and Poverty in SubSaharan Africa." Food Policy 34:198-209.

Alston, J. M. 2002. "Spillovers." The Australian Journal of Agricultural and Resource Economics 46 (3): 315-346.

Alston, J. M., G. W. Norton, and P. Pardey. 1995. Science under Scarcity: Principles and Practice for Agricultural Research Evaluation and Priority Setting. Ithaca, NY, US: Cornell University Press.

Anandajayasekeram, P., D. Martella, J. Sanders, and B. Kupfuma. 1995. Report on the Impact Assessment of the SADC/ICRISAT Sorghum and Millet Improvement Program. Vol. 1. Gaborone, Botswana: Southern African Centre for Cooperation in Agricultural Research and Training.

Anandajayasekeram, P., M. Rukuni, S. Babu, F. Liebenberg, and C. Keswani. 2007. Impact of Science on African Agriculture and Food Security. Oxford, UK: CAB International.

ASTI (Agricultural Science and Technology Indicators). 2010. Global database on agricultural research and development in national agricultural research systems. Accessed November 10. http://www.asti.cgiar.org/

Bantilan, M., U. Deb, C. Gowda, B. Reddy, A. Obilana, and R. Evenson. 2004. Sorghum Genetic Enhancement: Research Process, Dissemination and Impacts. Andhra Pradesh, India: International Crops Research Institute for the Semi-arid Tropics.

Beintema, N., and G. J. Stads. 2006. Agricultural R\&D in Sub-Saharan Africa: An Era of Stagnation. Washington, DC: International Food Policy Research Institute.

Benin, S., S. Ehui, and J. Pender. 2003. "Policies for Livestock Development in the Ethiopian Highlands." Environment, Development and Sustainability 5 (3): 491-510.

Benin, S., J. Thurlow, X. Diao, C. Lungren, and F. Simtowe. 2008. Agricultural Growth and Investment Options for Poverty Reduction in Malawi. IFPRI Discussion Paper 794. Washington, DC: International Food Policy Research Institute.

Benson, T. 1997. The 1995/96 Fertilizer Verification Trial-Malawi: Economic Analysis of Results for Policy Discussion. Report by Action Group 1, Maize Productivity Task Force. Lilongwe, Malawi: Ministry of Agriculture and Livestock Development.

Blackie, M. 1989. "International Science and the Research Needs of Agriculturally Dependent Communities in Southern Africa." Agricultural Systems 31 (2): 169-183.

Block, S. A. 1995. "The Recovery of Agricultural Productivity in Sub-Saharan Africa." Food Policy 20 (5): $385-$ 405.

Boserup, E. 1965. The Conditions of Agricultural Growth: The Economics of Agrarian Change under Population Pressure. Chicago: Aldine.

Byerlee, D., and C. Eicher. 1997. Africa's Emerging Maize Revolution. Boulder, CO, US: Lynne Rienner Publishers.

Celis, R., J. Milimo, and S. Wanmali, Eds. 1991. Adopting improved farm technology: A study of smallholder farmers in Eastern Province, Zambia. Washington, DC: International Food Policy Research Institute.

Chisi, M., P. Anandajayasekeram, D. Martella, M. Ahmed, M. Mwape. 1997. Impact Assessment of Sorghum Research in Zambia. Deperatment of Research and Specialist Services, SACCAR, Lusaka, Zambia: Ministry of Agriculture, Food and Fisheries, Zambia

Christiaensen, L., L. Demery, and J. Kuhl. 2006. The Role of Agriculture in Poverty Reduction: An Empirical Perspective. Policy Research Working Paper 1043. Washington, DC: World Bank.

CIAT (International Center for Tropical Agriculture). 2004. Regional Bean Variety Testing in Southern Africa. Highlights: CIAT in Africa No. 20. Kampala, Uganda.

Delgado, C. L., J. Hopkins, and V. Kelly. 1998. Agricultural Growth Linkages in Sub-Saharan Africa. Research Report No.107. Washington, DC: International Food Policy Research Institute. 
Di Gregorio, A., and L. Jansen. 2000. Land Cover Classification System: LCCS: Classification Concepts and User Manual. Rome: Food and Agriculture Organization of the United Nations.

Diao, X., D. Headey, and M. Johnson. 2008. "Toward a Green Revolution in Africa: What Would It Achieve, and What Would It Require?” Agricultural Economics 39:539-550.

Diao, X., P. Hazell, D. Resnick, and J. Thurlow. 2007. The Role of Agriculture in Development: Implications for Sub-Saharan Africa. IFPRI Research Report 153. Washington, DC: International Food Policy Research Institute.

Diao, X., S. Fan, D. Headey, M. Johnson, A. Nin Pratt, and B. Yu. 2008. Accelerating Africa's Food Production in Response to Rising Food Prices: Impacts and Requisite Actions. IFPRI Discussion Paper 825. Washington, DC: International Food Policy Research Institute.

Dixon, J. A., and D. A. Gibbon. 2001. Farming Systems and Poverty: Improving Farmers' Livelihoods in a Changing World. Rome: Food and Agricultural Organization.

Eicher, C. 1999. Institutions and the African Farmer. CGIAR Issues in Agriculture No.14. Washington, DC: CGIAR.

Eicher, C. 2003. "Flashback: Fifty Years of Donor Aid to African Agriculture." Paper presented at the InWEnt, IFPRI, NEPAD, and CTA conference "Successes in African Agriculture," Pretoria, South Africa, December 1-3.

Evenson, R. E. 1989. "Spillover Benefits of Agricultural Research: Evidence from U.S. Experience.” American Journal of Agricultural Economics 71: 447-452.

FANR (Food, Agriculture and Natural Resources) Directorate. 2008. SADC Multi-country Agricultural Productivity Programme. Vol. 1. Gaborone, Botswana: Southern African Development Community.

FAO (Food and Agriculture Organization of the United Nations). 2010. FAOSTAT online database. Accessed November 15. www.faostat.fao.org.

FAO/IIASA/ISRIC/ISSCAS/JRC, 2009. Harmonized World Soil Database (version 1.1). FAO, Rome, Italy and IIASA, Laxenburg, Austria.

FARA (Forum for Agricultural Research in Africa). 2006. Framework for African Agricultural Productivity. Accra, Ghana.

Fischer, G., H. van Velthuizen, M. Shah, and F. Nachtergaele. 2002. Global Agro-ecological Assessment for Agriculture in the 21st Century: Methodology and Results. Rome: FAO.

Fritz, S., E. Bartholomé, A. Belward, A. Hartley, H. Stibig, H. Eva, P. Mayaux, S. Bartalev, R. Latifovic, S. Kolmert, P. Roy, S. Agrawal, W. Bingfang, X. Wenting, M. Ledwith, F. J. Pekel, C. Giri, S. Mücher, E. de Badts, R. Tateishi, J-L. Champeaux, and P. Defourny. 2003. Harmonisation, Mosaicing and Production of the Global Land Cover 2000 database (Beta Version). Ispra: European Commission, Joint Research Centre (JRC).

Geurts, P. 1997. Recomendações de Adubação Azotada e Fosfórica para as Culturas Annuais Alimentares e Algodão em Moçambique. Communication No. 88. Maputo, Mozambique: Land and Water Department, National Institute for Economic Research.

Government of Seychelles. 2010. "Seychelles Millennium Development Goals: Status Report 2010", Victoria, Seychelles: Ministry of Foreign Affairs, Government of the Republic of Seychelles.

Griliches, Z. 1991. The Search for R\&D Spillovers. NBER Working Paper No. 3768. Cambridge, MA, US: National Bureau of Economic Research.

Haggblade, S., and P. Hazell. 2010. Successes in African Agriculture: Lessons for the Future. Baltimore: Johns Hopkins University Press.

ICART (Implementation and Coordination of Agricultural Research and Training). 2008. Situation Analysis of Agricultural Research and Training in the SADC Region. Gaborone, Botswana: Southern African Development Community. 
Isinika, A.C. 1997. Evaluating Agricultural Research and Extension in Tanzania: the Production Function Approach. Department of Research and Specialist Services, Ministry of Agriculture, SACCAR, Gabarone, Botswana.

Jaffe, A. B. 1986. “Technological Opportunity and Spillovers of R\&D: Evidence from Firms' Patents, Profits and Market Value.“ American Economic Review 76 (5): 984-1001. . 1989. "Real Effects of Academic Research." American Economic Review 79 (5): 957-970.

Johnson, M., W. A. Masters, and P. V. Preckel. 2006. "Diffusion and Spillover of New Technology: A Heterogeneous-Agent Model for Cassava in West Africa." Agricultural Economics 35 (2): 119-129.

Johnson, M., R. Birner, J. Chamberlin, X. Diao, S. Fan, A. Nin-Pratt, D. Resnick, L. You, and B. Yu. 2008. Regional Strategic Alternatives for Agriculture-Led Growth and Poverty Reduction in West Africa. ReSAKSS Working Paper 22. Washington, DC: International Food Policy Research Institute.

Kaliba, R.M. 1995. "The Socio-economics of Improved Cattle Raising under Stall Feeding Management Systems in Semi-Arid Central Tanzania." MSc thesis, Department of Agricultural Economics, Kansas State University.

Keyser, J. C. 2002. The Costs and Profitability of Tobacco Compared to Other Crops in Zimbabwe. Economics of Tobacco Control Paper No.1, Health Poverty and Nutrition Discussion Papers. Washington, DC: The World Bank.

Kiflewahid, B., N. George, and I. Lembuya, eds. 1989. Integrated Agricultural Research: Proceedings of the SACCAR/WINROCK Workshop Held in Lilongwe, Malawi, November 26-December 1, 1989. Ottawa, Canada: International Development Research Centre.

King, R. P., and D. Byerlee. 1978. "Factor Intensities and Locational Linkages of Rural Consumption Patterns in Sierra Leone.” American Journal of Agricultural Economics 60 (2): 197-206.

Kruska, R. L., R. S. Reid, P. K. Thornton, N. Henninger, and P. M. Kristjanson. 2003. "Mapping livestock-oriented agricultural production systems for the developing world." Agricultural systems 77(1): 39-63.

Maredia, M. K., and D. Byerlee. 2000. "Efficiency of Research Investments in the Presence of International Spillovers: Wheat Research in Developing Countries.” Agricultural Economics 22 (1): 1-16.

Maredia, M. K., D. Rohrbach, and M. A. Mgonja. 2002. "Justification for Regionalized Plant Breeding and Variety Registration." In Seed Trade Liberalization in Sub-Saharan Africa, edited by D. Rohrbach and J. Howard, 81-100. Bulawayo, Zimbabwe: International Crops Research Institute for the Semi-arid Tropics.

Mazhangara, E.; P. Anandajayasekeram, M. Mudhara, D. Martella, M. Murata. 1997. Impact Assessment of Groundnut Research and the Enabling Environment of Zimbabwe: 1960-2000. Gaborone, Botswana: Southern African Centre for Cooperation in Agricultural Research.

Mgonja, M. A., E. Monyo, D. Rohrbach, and M. K. Maredia. 2004. "Regional Plant Breeding and Variety Registration: A Case of Southern Africa." In Seed Trade Liberalization in Sub-Saharan Africa, edited by D. Rohrbach and J. Howard, 65-80. Bulawayo, Zimbabwe: International Crops Research Institute for the Semi-arid Tropics.

Mokoena, R. 1988. Assessment of Livestock Research in South Africa. Faculty of Agriculture and Applied Biological Science, University of Pretoria, South Africa.

Moshi, A.; P. Anandajayasekeram, A. Kaliba, D. Martella, W. Mwangi, and F. Shao. 1997. Economic Impact of Maize research in Tanzania. Gaborone, Botswana: Southern African Centre for Cooperation in Agricultural Research.

Mudhara, M.; P. Anandajaysekeram, B. Kupfama, and E. Mazhangara. 1995. Impact Assessment of Cotton Research and the Enabling Environment of Zimbabwe: 1976-2000. Gaborone, Botswana: Southern African Centre for Cooperation in Agricultural Research.

Munyinda, K., C. Nkwanyana, E. Shumba, P. Anandajayasekeram, and P. Makhambara. 1995. Report on the LongTerm Strategy for Regional Research Priorities on Food, Agriculture and Natural Resources in Southern African Development Community $(S A D C)$. Vol. 1. Gaborone, Botswana: Southern African Centre for Cooperation in Agricultural Research. 
Murata, M.; P. Anandajayasekeram, M. Mudhara, D. Martella, E. Mazhangara. 1997. Impact Assessment of Sunflower Research and the Enabling Environment of Zimbabwe: 1976-2000. Gaborone, Botswana: Southern African Center for Cooperation in Agricultural and Natural Resources Research \& Training.

Nin Pratt, A., and X. Diao. 2006. Exploring Growth Linkages and Market Opportunities for Agriculture in Southern Africa. IFPRI Discussion Paper 42. Washington, DC: International Food Policy Research Institute.

Nin Pratt, A., and B. Yu. 2009. "An Updated Look at the Recovery of Agricultural Productivity in Sub-Saharan Africa." Paper presented at the International Association of Agricultural Economists conference, Beijing, China, August 16-22.

Nkonya, E., T. Schroeder, and D. Norman. 1997. "Factors Affecting Adoption of Improved Maize Seed and Fertilizer in Northern Tanzania." Journal of Agricultural Economics 48 (1): 1-12.

Nweke, F., and S. Haggblade. 2010. "The Cassava Transformation in West and Southern Africa." In Successes in African Agriculture: Lessons for the Future, edited by S. Haggblade and P. Hazell, 29-70. Baltimore: Johns Hopkins University Press.

Nweke, F., D. S. C. Spencer, and J. K. Lynam. 2002. The Cassava Transformation: Africa's Best-Kept Secret. East Lansing, MI, US: Michigan State University Press.

Omamo, S., X. Diao, S. Wood, J. Chamberlin, L. You, S. Benin, U. Wood-Sichra, A. Tatwangire. 2006. Strategic Priorities for Agricultural Development in Eastern and Central Africa. IFPRI Research Report 150. Washington, DC: International Food Policy Research Institute.

Oram, P. A., J. S. Davis, and J. G. Ryan. 1987. “Assessment of Agricultural Research Priorities: An International Perspective." ACIAR Monograph 4. Canberra, Australia; Washington, DC: Australian Centre for International Agricultural Research; International Food Policy Research Institute.

Otte, M. J., and P. Chilonda. 2002. Animal Health Economics: An Introduction. Rome: Animal Production and Health Division, Food and Agriculture Organization.

Pardey, P. 1986. "Public Sector Production of Agricultural Knowledge." PhD Dissertation, Department of Agricultural Economics, University of Minnesota, St. Paul, MN, US.

Pardey, P., J. Roseboom, and N. Beintema. 1997. "Investments in African Agricultural Research.” World Development 25 (3): 409-423.

Pardey, P., J. James, J. Alston, S. Wood, B. Koo, E. Binenbaum, T. Hurley, et al. 2007. Science, Technology and Skills. INSTEPP Center Working Paper. St. Paul, MN, US: International Science and Technology Practice and Policy Center, University of Minnesota.

Pender, J., P. Jagger, E. Nkonya, and D. Sserunkuuma. 2004. "Development Pathways and Land Management in Uganda." World Development 32 (5): 767-792.

Rukuni, M., P. Tawonezvi, C. Eicher, and M. Munyuki-Hungwe. 2006. Zimbabwe's Agricultural Revolution Revisited. Harare, Zimbabwe: University of Zimbabwe Publications.

Smale, M., and T. S. Jayne. 2003. Maize in Eastern and Southern Africa: "Seeds" of Success in Retrospect. EPTD Discussion Paper 97. Washington, DC: International Food Policy Research Institute.

Spurling, A., T. Pee, G. Mkamanga, and C. Nkwanyana. 1992. Agricultural Research in Southern Africa: A Framework for Action. Africa Technical Department Series 184. Washington, DC: The World Bank.

Stringfellow, R. 1997. Smallholder Outgrower Schemes in Zambia. Research Report for ODA Crops Post-harvest Programme. London: Overseas Development Administration and Natural Resources Institute.

Thorpe, P., and P. Pardey. 1990. "The Generation and Transfer of Agricultural Knowledge: A Bibliometric Study of a Research Network.” Journal of Information Science 16:183-194.

Thornton, P K, P. Jones, G. Alagarswamy, J. Andresen, and M. Herrero. 2010. "Adapting to Climate Change: Agricultural System and Household Impacts in East Africa." Agricultural Systems 103(2): 73-82

Thurlow, J. 2008. Agricultural Growth and Investment Options for Poverty Reduction in Mozambique. ReSAKSS Working Paper 20. Washington, DC: International Food Policy Research Institute. 
Thurlow, J., S. Benin, X. Diao, H. Kalinda, and T. Kalinda. 2008. Agricultural Growth and Investment Options for Poverty Reduction in Zambia. IFPRI Discussion Paper 791. Washington, DC: International Food Policy Research Institute.

Voortman, R., B. Sonneveld, and M. Keyzer. 2003. "African Land Ecology: Opportunities and Constraints for Agricultural Development.” Ambio 32 (5): 367-73.

White, K.J., and J. Havlicek, Jr. 1981. "Interregional Spillovers of Agricultural Research Results and Intergovernmental Finance: Some Preliminary Results." In Evaluation of Agricultural Research, Proceedings of a symposium held in Minneapolis,May 12-13, 1980. University of Minneapo.

Wood, S., and J. Chamberlin. 2003. "Enhancing the Role of Spatial Analysis in Strategic Impact Assessment: Improving Data Resolution for Regional Studies." Quarterly Journal of International Agriculture 42 (2): $167-187$.

World Bank. 2007. World Development Report 2008: Agriculture for Development. Washington, DC.

World Development Indicators. 2010. International Development Indicators Database. Accessed October 10, 2010 http://data.worldbank.org/data-catalog/world-development-indicators.

Yanggen, D., V. Kelly, T. Reardon, and A. Naseem. 1998. Incentives for Fertilizer Use in Sub-Saharan Africa: A Review of the Empirical Evidence on Fertilizer Response and Profitability. MSU International Development Working Paper No. 70. East Lansing, MI, US: Michigan State University.

You, L., and S. Wood. 2006. “An Entropy Approach to Spatial Disaggregation of Agricultural Production.” Agricultural Systems 90 (1-3): 329-347.

You, L., S. Wood, and U. Wood-Sichra. 2009. "Generating Plausible Crop Distribution Maps for Sub-Saharan Africa Using a Spatially Disaggregated Data Fusion and Optimization Approach." Agricultural Systems 99 (2-3): 126-140. 


\section{RECENT IFPRI DISCUSSION PAPERS}

\section{For earlier discussion papers, please go to www.ifpri.org/pubs/pubs.htm\#dp. All discussion papers can be downloaded free of charge.}

1317. How do intrahousehold dynamics change when assets are transferred to women?: Evidence from BRAC's Challenging the Frontiers of Poverty Reduction-Targeting the Ultra Poor Program in Bangladesh. Narayan Das, Rabeya Yasmin, Jinnat Ara, Md. Kamruzzaman, Peter Davis, Julia A. Behrman, Shalini Roy, and Agnes R. Quisumbing, 2013.

1316. Is there an app for that?: The impact of community knowledge workers in Uganda. Bjorn Van Campenhout, 2013.

1315. Can integrated agriculture-nutrition programs change gender norms on land and asset ownership: Evidence from Burkina Faso. Mara van den Bold, Abdoulaye Pedehombga, Marcellin Ouedraogo, Agnes R. Quisumbing, and Deanna Olney, 2013

1314. Moving in the right direction?:Maize productivity and fertilizer use and use intensity in Ghana. Antony Chapoto and Catherine Ragasa, 2013.

1313. Women's empowerment in agriculture, production diversity, and nutrition: Evidence from Nepal. Hazel Jean L. Malapit, Suneetha Kadiyala, Agnes R. Quisumbing, Kenda Cunningham, and Parul Tyagi, 2013.

1312. Don't tell on me: Experimental evidence of asymmetric information in transnational households. Kate Ambler, 2013.

1311. Can dairy value-chain projects change gender norms in rural Bangladesh?: Impacts on assets, gender norms, and time use. Agnes R. Quisumbing, Shalini D. Roy, Jemimah Njuki, Kakuly Tanvin, and Elizabeth Waithanji, 2013.

1310. Can government-allocated land contribute to food security?: Intrahousehold analysis of West Bengal's microplot allocation program. Florence Santos, Diana Fletschner, Vivien Savath, and Amber Peterman, 2013.

1309. The National Health Insurance Scheme in Ghana: Implementation challenges and proposed solutions. Gissele GajateGarrido and Rebecca Owusua, 2013.

1308. Gender inequalities in ownership and control of land in Africa: Myths versus reality. Cheryl Doss, Chiara Kovarik, Amber Peterman, Agnes R. Quisumbing, Mara van den Bold, 2013.

1307. Farmer preferences for drought tolerance in hybrid versus inbred rice: Evidence from Bihar, India. Patrick S. Ward, David L. Ortega, David J. Spielman, Vartika Singh, 2013.

1306. Borrowing from the insurer: An empirical analysis of demand and impact of insurance in China. Yanyan Liu, Kevin Chen, Ruth Hill, and Chengwei Xiao, 2013.

1305. Organizational partnerships for food policy research impact: A review of what works. Athur Mabiso, Teunis Van Rheenen, and Jenna Ferguson, 2013.

1304. Fertilizer in Ethiopia: An assessment of policies, value chain, and profitability. Shahidur Rashid, Nigussie Tefera, Nicholas Minot, and Gezahengn Ayele, 2013.

1303. The global landscape of poverty, food insecurity, and malnutrition and implications for agricultural development strategies. Derek Headey, 2013.

1302. Leveling with friends: Social networks and Indian farmers' demand for agricultural custom hire services. Nicolas Magnan, David J. Spielman, Travis J. Lybbert, and Kajal Gulati, 2013.

1301. Assessing the potential and policy alternatives for achieving rice competitiveness and growth in Nigeria. Michael Johnson, Hiroyuki Takeshima, and Kwabena Gyimah-Brempong, 2013.

1300. Revisiting agricultural input and farm support subsidies in Africa - The case of Ghana: lessons from four large government programs (mechanization, fertilizer, block farms, and marketing). Samuel Benin, Michael Johnson, Emmanuel Abokyi, Gerald Ahorbo, Kipo Jimah, Gamel Nasser, Victor Owusu, Joe Taabazuing, and Albert Tenga, 2013.

1299. The operational evidence base for delivering direct nutrition interventions in India: A desk review. Rasmi Avula, Suneetha Kadiyala, Kavita Singh, and Purnima Menon, 2013.

1298. Rethinking the measurement of undernutrition in a broader health context: Should we look at possible causes or actual effects? Alexander J. Stein, 2013.

1297. Women's empowerment in agriculture: What role for food security in Bangladesh?. Esha Sraboni, Hazel J. Malapit, Agnes R. Quisumbing, and Akhter U. Ahmed, 2013. 


\section{INTERNATIONAL FOOD POLICY RESEARCH INSTITUTE}

www.ifpri.org

IFPRI HEADQUARTERS

$2033 \mathrm{~K}$ Street, NW

Washington, DC 20006-1002 USA

Tel.: +1-202-862-5600

Fax: +1-202-467-4439

Email: ifpri@cgiar.org

IFPRI ADDIS ABABA

P. O. Box 5689

Addis Ababa, Ethiopia

Tel.: + 251 (0) 11-617-2500

Fax: + 251 (0) 11-646-2927

Email: ifpri-addisababa@cgiar.org

$\mathrm{t}$ 